\title{
Titanium Microalloyed steels
}

\author{
T.N. Baker \\ Metallurgy and Engineering Materials Research Group, \\ Department of Mechanical and Aerospace Engineering, University of Strathclyde, \\ Glasgow, G1 1XJ. \\ [ T. N. Baker (2018) Titanium microalloyed steels, Ironmaking \& \\ Steelmaking, DOI: 10.1080/03019233.2018.1446496]
}

\begin{abstract}
For many years titanium has been regarded as a relative minor element in microalloyed steels compared with niobium and vanadium. However, over the past decade or so, titanium compounds in microalloyed steels have been recognized as having a wider role than just involved in austenite grain refinement.This is considered in the present review.

The background and brief history are followed by sections dealing with the physical state of titanium and compounds of titanium, including borides, carbides, nitrides, oxides and sulphides characterized in MA steels. Many of the investigations on the solubility of these compounds in iron, and the precipitates they form, are considered, which leads to their functions in controlling the mechanical and toughness properties of MA steels.This now often involves the multiple alloying additions of titanium, niobium and vanadium with both carbon and nitrogen, and the morphologies of the various precipitates characterized in MA steels is presented. Titanium has become an important element in the development of line pipe steels, which for the higher grades have moved to bainite/acicular ferrite microstructures. The influence of Ti in the nucleation of acicular ferrite is an active research area, particularly with regard to the use made of titanium compounds in welding of MA steels. Finally, consideration is given to the influence of titanium on hot ductility and how titanium additions behave during continuious casting and thin slab direct charging processes.
\end{abstract}

Keywords: Titanium, Microalloyed steels, Niobium, Vanadium, Carbon, Nitrogen, Crystallography, Solubility, Processing, Microstructure, Properties 


\section{Introduction}

Microalloyed (MA) steels, also known as High Strength Low Alloy (HSLA) steels, have become an indispensable class for a range of applications such as in the construction of large ships, oil and gas transmission lines, offshore oil drilling platforms, pressure vessels, building construction, bridges, storage tanks and automomotives. In 1997, F.B. Pickering ${ }^{1}$ published what was probably the first review of titanium MA steels. In the intervening years, much has been written on the effect of titanium in low carbon steels, as additions of titanium, often with niobium and or vanadium have become more common practice, particularly in steels for linepipe applications. The present review attempts to fill the gap mentioned by Cochrane ${ }^{2}$ in a wide ranging review of 'phase transformations in microalloyed high strength low alloy (HSLA) steels' through the consolidation of many of the pertinent publications considering titanium in MA steels. It follows the format used by the author in previous reviews which dealt with the role of vanadium ${ }^{3}$ and with zirconium ${ }^{4}$ in MA steels. Parts of the present review were also discussed in an invited review on Microalloyed Steels. ${ }^{5}$

Titanium and its alloys have many applications in the aerospace, petrochemical energy producing industries and in prosthetic devices. Titanium, which weighs forty percent less than carbon steels, can be strengthened by alloying with elements such as aluminum and vanadium. ${ }^{6,7}$ The most widely used titanium alloy, Ti-6Al-4V, is present in forty-five percent of titanium alloy industrial applications. The unique combination of this alloy's physical and mechanical properties with workability, fabricability, production experience and commercial availability allows it to be economically useful..${ }^{8}$ However, only five percent of the titanium mined today is used in its metallic form. Some of the remainder is used to manufacture titanium dioxide $\left(\mathrm{TiO}_{2}\right)$, an ingredient in paper, paint, plastics and white food colouring, while a large percentage of the world annual tonnage is used in the steel industries as an alloying element. Titanium additions of 
$0.02 \%$ were known to reduce segregation of carbon, sulphur and phosphorus in rail steels as long ago as $1914,{ }^{10,11}$ and by 1921 it was being used as an alloying element in steel. ${ }^{12}$ Table 1 , taken from Baker ${ }^{4}$ and Morrison, ${ }^{12}$ lists data on the main microalloying additions, and it is noticeable that titanium was the earliest, and niobium the most recent. An examination of the literature shows that nearly all the elements now used as deliberate additions in MA steels were used in low alloy and stainless steels for what was described as precipitation strengthening, but was thought to be due to the precipitation of intermetallics such as $\mathrm{Ni}_{3} \mathrm{Ti}$ and $\mathrm{TiSi} .{ }^{11} \mathrm{To}$ achieve this, larger additions were made than in current MA steels. Initially, the role of titanium added to steel as ferro-titanium, was mainly to reduce grain size and as a deoxidizer. Small additions of titanium, $<0.05$ wt. \% can improve the strength of steel, and this was first exploited in Germany in 1921. Micro titanium and micro vanadium additions began to be used in China in the 1950s and 1960s. At this time, it is noticeable that whereas carbides and nitrides of some transition metals were known to form and considered to be responsible for grain refining, the idea that they could also precipitate in ferrite and induce significant dispersion strengthening does not appear to have been accepted until after the work of Morrison and Woodhead ${ }^{13,14}$ circa 1962 . This study on niobium steels showed that in the as-rolled state, if the strengthening due to the inherent lattice strengthening (the friction stress) together with the grain boundary strengthening was subtracted from the measured lower yield stress, a significant degree of strengthening remained still to be accounted for, which was shown to coincide with the formation of niobium carbide. A further very important aspect of this work, was that it was the first to apply the ideas proposed by Hall ${ }^{15}$ and Petch ${ }^{16}$ to account for the relationships found in mild steel between grain size and yield stress, and by Petch ${ }^{17,18}$ for that between grain size and the ductile-brittle impact transition temperature for an alpha iron.

Table 1 near here 
The term microalloying as applied to steels, is generally accepted as emanating from the additions of transition metals to commercial heats of a carbon steel. However the major event that initiated the HSLA Steel revolution did not occur until 1958 when the Great Lakes Steel Corporation of the USA began production of low C Mn steels microalloyed with niobium. ${ }^{19}$ This event created widespread interest among the world's steelmakers leading to the rapid development of HSLA Steels containing the additions of microalloying elements vanadium, niobium and titanium either singly or in combinations. In particular, titanium additions are known to give effective grain size control in HSLA steels at high temperatures in the austenite temperature range ${ }^{20}$, dispersion strengthening and sulphide shape control, all leading to improving the strength and toughness. Also, the properties of strip and plate steel products, such as cold formability and toughness anisotropy, are significantly improved by titanium additions, the latter also being important in welding metallurgy. ${ }^{21}$

Pickering ${ }^{1}$ noted 'that among the elements normally considered as those which constitute microalloying additions in HSLA steels, that is $\mathrm{Nb}, \mathrm{Ti}, \mathrm{V}, \mathrm{Zr}$ and possibly $\mathrm{Al}$, titanium is the most unique and versatile due to its strong affinity for C,N,S and O. This feature is not displayed by the other microalloying elements which often show strong affinities for one or more of the above elements, but not all of them'. However, because titanium is a strong deoxidizer, additions are only fully effective in fully killed, (aluminium deoxidized) steels, so that titanium is available for forming compounds other than titanium dioxide. ${ }^{22}$ The importance of titanium in microlloyed steels is summarized succinctly by Jönsson. ${ }^{23}$ 'Titanium has a very strong affinity for carbon and nitrogen, and it combines with these elements to form titanium carbonitride in the complete range from $\mathrm{TiC}$ to TiN. Due to the high thermal and chemical stability of the carbonitride, its solubility limit in iron is very low, and as a result, particles of titanium carbonitride are precipitated in steels at very low concentrations of titanium, even at very high temperatures. These precipitates retard recrystallization and grain growth during thermomechanical treatments, which improve the 
transformation characteristics of the steel and lead to the superior mechanical properties of microalloyed steels.'

\section{Background}

Titanium, (Ti), atomic number 22 , atomic weight 47 , density $4.506 \mathrm{~g} . \mathrm{cm}^{-3}$, is a lustrous transition metal with a silver, greyshire colour, low density and high strength. It is as strong as steel but 45 percent lighter, and it is twice as strong as aluminium but only 60 percent heavier. It is highly resistant to corrosion in sea water, aqua regia and chlorine. ${ }^{24}$

Titanium was discovered in Cornwall, UK, by the British clergyman and amateur geologist William Gregor in 1791, who produced a white metallic oxide from black magnetic sands. Titanium dioxide $\left(\mathrm{TiO}_{2}\right)$ has a very high refractive index, which means that it has high lightscattering ability. As a result, $\mathrm{TiO}_{2}$ imparts whiteness, opacity, and brightness to many products. In 1795, the German chemist Martin Heinrich Klaproth named the oxide "titanium” after the Greek Titans, a mythical race of immortal giants with incredible strength and stamina.

Titanium has not been found in the free state in nature and always bonded to other elements. It is the ninth-most abundant element in the Earth's crust $(0.63 \%$ by mass $)$ and the seventh-most abundant metal. It is present in most igneous rocks and in sediments derived from them (as well as in living things and natural bodies of water). Of the 801 types of igneous rocks analyzed by the United States Geological Survey, 784 contained titanium. Its proportion in soils is approximately 0.5 to $1.5 \%$. It is a metal resembling tin in its chemical properties, and like tin, is capable of forming oxides, $\mathrm{TiO}$ and $\mathrm{TiO}_{2}$. Only the latter occurs in nature; it supplies an example of trimorphism, constituting the three minerals, rutile, anatase and brookite. Titanium oxide also enters into the composition of ilmenite, the oxide of titanium and iron, $\mathrm{FeO}^{\mathrm{TiO}} \mathrm{Ti}_{2}$. Many samples of magnetite contain varying amounts of titanium, giving the titaniferous magnetites. At the present 
time, ilmenite and rutile are the chief sources of the titanium required in industry. Titanium also occurs in a number of rock forming silicates, the chief of which is sphene or titanite, $\mathrm{CaTiSiO}_{5}$. Most of the exploited minerals, however, are of detrital character, such as beach-sands. The annual world production of titanium minerals has increased from 50,000 tons in 1947 to 6.8 million tons in 2013. Currently, the chief producers of ilmenite and rutile are Australia (19.4\%), South Africa(17.3\%), Canada (10.4\%) India 8.6\%), Mozambique (7.7\%), China (7.5\%) Vietnam(7.3\%) and Ukraine $(5.3 \%){ }^{25}$

Pure titanium metal was first isolated in 1910 by chemist Matthew Hunter. Hunter's difficult isolation process made titanium metal mainly a laboratory curiosity until 1938 when William Kroll developed a method (known as the Kroll method) to produce titanium metal in commercial quantities. ${ }^{6,26,27}$

A more recently developed method, the FFC Cambridge process, may eventually replace the Kroll process. ${ }^{28}$ If mixed oxide powders are used, the product is an alloy manufactured at a much lower cost than the conventional multi-step melting Kroll process. The FFC Cambridge process may render titanium a less rare and expensive material for the aerospace industry and the luxury goods market, and could be seen in many products currently manufactured using aluminum and specialist grades of steel.

Narita ${ }^{29}$ has assembled data on the recovery of the elements in Groups IVA and VA, which are reproduced in Table 2.

Table 2 near here

Titanium bearing steelmaking additions range from titanium metal to Ti alloys containing 83-99\% Ti to ferrotitanium containing $70 \%$ Ti with some $4.5 \% \mathrm{Al}$ and $3 \% \mathrm{~V} .{ }^{1}$

\section{Titanium: the physical state}

Titanium is an element of the second subgroup, Group IVA, of the periodic table, the outermost surface layer electron structure of which is $3 d^{2} 4 s^{2}$. Titanium has two allotropic forms, alpha, which 
is hexagonal close packed and stable up to $882^{\circ} \mathrm{C}$, while beta, which is body centred cubic, is stable between $882^{\circ} \mathrm{C}$ and the melting point, $1668 \pm 2{ }^{\circ} \mathrm{C}$. The specific heat of the alpha form increases dramatically as it is heated to this transition temperature, but then falls and remains fairly constant for the beta form, regardless of temperature. ${ }^{6,30}$ The relationship between titanium and other elements, which are in Groups IVA, VA and VIA, is given in Table $3 .{ }^{31}$

\section{Table 3 near here}

The properties of titanium, zirconium and iron have been compared by Schwope. ${ }^{32}$ These metals all possess allotropic transformations and they form solid solutions with each other if the size factors of the metallic elements are favourable, and the formation of continuous solid solutions has been observed in most of these systems. ${ }^{33}$

\section{Table 4 near here}

Table 4 shows the atomic radii of many of the transitions elements and their difference from iron. ${ }^{31}$ Here it can be seen that while the vanadium atom radius has the smallest difference compared to the iron atom, zirconium and hafnium have the largest difference, with titanium midway.

A summary of their allotropic transformation and the influence on the number of outer electrons on the stability of carbides and nitrides was given by Baker. ${ }^{4}$ Andrews and Hughes ${ }^{34}$ have pointed out that an unusual feature of the carbides and nitrides of the transition metals is that the metal atom partial structures in the interstitial phase is different from that of the crystal structure found in the pure metal. These phases show little solubility for iron, and are readily formed at quite low percentages of carbon. This is not the case with $\mathrm{VC}$, since vanadium has an additional $d$-electron which forms a $\mathrm{V}-\mathrm{V}$ bond. The electrons in the two kinds of bonds, $\mathrm{V}-\mathrm{C}$ and $\mathrm{V}-\mathrm{V}$ mutually repel, leading to a reduction in the stability of $\mathrm{VC}$ when compared with TiC. This problem becomes greater along the row of the periodic table until MC carbide formation becomes impossible or unlikely. 


\section{Compounds characterized and reported based on titanium additions to MA}

steels.

\section{Borides}

Boron additions to titanium MA steels forming $\mathrm{TiB}_{2}$ have been shown to have beneficial effects on the weld metal toughness. ${ }^{35}$ Munroe ${ }^{36}$ has collected and critically reviewed the material properties of titanium diboride. The crystallographic data are similar to that given in Table 5 . $\mathrm{TiB}_{2}$ is not normally found in MA steels, but has been characterized in high speed steels. ${ }^{37}$ It has also been used for cladding of low carbon steels using laser surface engineering. The high surface hardness was attributed to a composite of $\mathrm{TiB}_{2} 10-20 \mu \mathrm{m}$ long needles within an equiaxed dendritic matrix of iron. ${ }^{38}$

Ohtani et al. ${ }^{39}$ have calculated the Fe-Ti-B ternary system which has also been investigated in part by Tanaka and Saito. ${ }^{40}$ The Fe-rich portion of an isothermal section of the Fe-Ti-B ternary phase diagram at $1273 \mathrm{~K}$ is shown in Figs. $1 \mathrm{a}$ and $1 \mathrm{~b}$

Figs.1ab. near here

Here $\mathrm{TiB}_{2}$ is in equilibrium with Fe containing between 0 and 5.5 at $\%$ Ti which is applicable to MA steels The system has been up-dated by Raghavan ${ }^{41}$ and recently by Antoni-Zdziobek et al. ${ }^{42}$ Much of the current interest in the Fe-Ti-B system is due to the development of high strength, high modulus MMC steels containing 10-20 vol.\% of $\mathrm{TiB}_{2}$, These are of particular interest to the automotive industry, ${ }^{42,43}$ but out-with the scope of MA steels. Little is available on more complex systems containing $\mathrm{C}$ and $\mathrm{N}$, except to note that in the Fe-Ti-B-C system, increasing $\mathrm{C}$ leads to the formation of $\mathrm{TiC}$ in addition to $\mathrm{FeB}_{2}{ }^{41}$

\section{Carbides and nitrides}


Titanium, zirconium and hafnium $[\mathrm{M}]$, which in the periodic table are elements near the beginning of the long periods, form very stable MC carbides, but the affinity for carbon diminishes further along the rows of the periodic table. With $\mathrm{M}$ carbides, the metal has to sacrifice four electrons to form the bonds with carbon. Titanium has exactly the right number, so that on forming TiC, its $d$-orbitals are left empty.

\section{Table 5 near here}

Titanium carbide, TiC, and titanium nitride TiN, both fcc compounds, Table 5, are the most commonly noted titanium precipitates in MA steels. Since the 1970's, TiC, TiN and their complexes with $\mathrm{Nb}$ and $\mathrm{V}$, have been the subject of more thermodynamic modelling than other transition metal carbonitrides. ${ }^{23}$ In the size rage $1-100 \mathrm{~nm}$, they are known to provide Orowan dispersion strengthening. ${ }^{44,45}$ The complex compounds based on TiC-TiN in the presence of $\mathrm{Nb}$ and $\mathrm{V}$ are considered in the following section.

While titanium carbonitrides have been characterized on several occasions, the presence of an iron borocarbide, $\mathrm{Fe}_{23}(\mathrm{~B}, \mathrm{C})_{6}$, was identified in a Ti-B weld by $\mathrm{Oh}$ et al. ${ }^{46}$

\section{Oxides}

The study of the oxides of titanium is a subject in its own right. Titanium exists in several oxidation states, $\mathrm{Ti}^{2+}, \mathrm{Ti}^{3+}$ and $\mathrm{Ti}^{4+}$, and the oxides, $\mathrm{Ti}_{\mathrm{n}} \mathrm{O}_{2 \mathrm{n}-1}(\mathrm{n}=4-10)$, known as the Magnéli phases, appear in the following order, going from the surface to the bulk of TiO being oxidized: $\mathrm{TiO}_{2}-\mathrm{Ti}_{10} \mathrm{O}_{19}-\mathrm{Ti}_{9} \mathrm{O}_{17}-\mathrm{Ti}_{8} \mathrm{O}_{15}-\mathrm{Ti}_{7} \mathrm{O}_{13}-\mathrm{Ti}_{6} \mathrm{O}_{11}-\mathrm{Ti}_{5} \mathrm{O}_{9}-\mathrm{Ti}_{4} \mathrm{O}_{7}-\mathrm{Ti}_{3} \mathrm{O}_{5}-\mathrm{Ti}_{2} \mathrm{O}_{3}-\mathrm{TiO}$. These are shown in Fig. 2, an O-Ti equilibrium diagram based on Murray and Wreidt. ${ }^{47}$

\section{Fig.2 Near here}

Many titanium oxides have important applications arising from their magnetic and electronic properties, and also as catalysts and in pharmaceutics and paints. Furthermore, they are important compounds in steels because titanium is a strong deoxidizer in liquid steel, but less so 
than aluminum, magnesium or calcium,as seen in Fig.3, which shows a plot of the free energy ,$\Delta \mathrm{G}$ vs temperature $\mathrm{T}, \mathrm{K}$, of oxides including titanium,present in steels.

\section{Figure 3 Near here}

Much of the research on titanium oxides in steel has been concerned with their behavior in the region of $1600^{\circ} \mathrm{C}$ as slags, before quenching to ambient for identification. ${ }^{48,49}$ Mutale et al. ${ }^{50}$ using TEM/ SAED, have identified six forms of titanium oxide from individual inclusions in liquid steel at $1600^{\circ} \mathrm{C}$. Because of structural similarities, it is established that a series of solid solutions based on $\mathrm{TiC}$, $\mathrm{TiN}$ and $\mathrm{TiO}$, with a general formula of $\mathrm{TiC}_{\mathrm{x}} \mathrm{N}_{\mathrm{y}} \mathrm{O}_{\mathrm{z}} \cdot(0 \leq \mathrm{x}, \mathrm{y}, \mathrm{z} \leq$ $1,+\mathrm{x}+\mathrm{z}=1$ ), can form. ${ }^{49}$ However, these complex compounds, as far as is known, have not been identified in steel. Titanium-iron oxides have been identified in steel by Cha et al ${ }^{49}$, and as seen in Fig. 4, forms several complex compounds.

Figure $4 \quad$ Near here

\section{Sulphides}

The Ti-S phase diagram has been studied extensively through empirical techniques ${ }^{51,52}$ and modelling. ${ }^{53}$ In Fig. 5, the equilibrium diagrams published prior to 1986, collated by Murray, ${ }^{52}$ show a number of phases between $\mathrm{Ti}_{6} \mathrm{~S}$ and $\mathrm{TiS}_{2}$.

Figure $5 \quad$ Near here

Raghaven ${ }^{54}$ and Bochvar and Rokhlin ${ }^{55}$ have collected information on the ternary systems based on Fe-S, including Fe-S-Ti. The titanium sulphide phases identified in steels are shown in Table 5.The most common titanium sulphide constituent of microalloyed, maraging and interstitial free (IF) titanium bearing steels is $\mathrm{Ti}_{4} \mathrm{C}_{2} \mathrm{~S}_{2}$.It has been suggested that this compound has a deleterious influence on fracture. ${ }^{56}$ 
Oikawa et al. ${ }^{57}$ have established a thermodynamic database for the Fe-Cr-Mn-Ni-Ti-S-C-N system, with the specific aim of predicting the precipitation behaviour of sulphides and carbosulphides in titanium containing IF steels. In particular, they have examined critically, data on $\mathrm{Ti}_{4} \mathrm{C}_{2} \mathrm{~S}_{2}$ and TiS phases which they consider have significant influence on both texture and mechanical properties of IF steels. Kudielka and Rohde ${ }^{58}$ were the first to identify $\mathrm{Ti}_{4} \mathrm{C}_{2} \mathrm{~S}_{2}$ and it has been characterized by many since 1960 , mainly in IF steels.

Hua et al. ${ }^{59,60}$ made a distinction between IF steels, $\mathrm{C} \approx 0.003$, and dilute MA steels, $\mathrm{C} 0.04 \%$ $0.08 \%$, but considered that titanium sulphides did not normally precipitate in MA steels. However, this distinction did not follow in the steels containing $0.05 \%-0.075 \% \mathrm{C}$ with $0.05 \%$ to $0.25 \% \mathrm{Ti}$ and $0.01 \% \mathrm{~S}$,investigated by Liu et al. ${ }^{61}$ Their extensive research collected data and micrographs using analytical TEM and SEM, and showed in Fig.6, that while the \%C influenced the $\% \mathrm{Ti}_{4} \mathrm{C}_{2} \mathrm{~S}_{2}$, this compound should form in Ti-MA steels.

In several instances, $\mathrm{Ti}_{4} \mathrm{C}_{2} \mathrm{~S}_{2}$ particles were observed by Hua et al. ${ }^{59,60}$ to be surrounded by MnS. MnS stringer inclusions rich in $\mathrm{Mn}, \mathrm{S}$ and $\mathrm{Ti}$ were found in the $005 \%-0.18 \% \mathrm{Ti}$ steels, while in the $0.25 \%$ Ti steel, globular sulphides, with no detectable Mn, were observed. ${ }^{59}$ Iron was not identified in any of the inclusions. Liu et al. ${ }^{61}$ concluded that the optimum level of titanium required to form a globular sulphide inclusion in a $1.5 \% \mathrm{Mn}$ steel,was around five to six times that necessary to tie up the $\mathrm{N}$ as TiN.

\section{Figure 6 Near}

Earlier work by Bandi and Krapf, ${ }^{62}$ studying $0.13 \mathrm{C}$ steels containing $0.053-0.13 \mathrm{Ti}$, found $\mathrm{Ti}_{4} \mathrm{C}_{2} \mathrm{~S}_{2}$ in all their steels.. However, they were unable to distinguish between $\mathrm{Ti}_{4} \mathrm{C}_{2} \mathrm{~S}_{2}$ and $\tau \mathrm{Ti}_{2} \mathrm{~S}$ by $\mathrm{x}$-ray diffraction, but using differential thermal analysis-evolved gas analysis procedures, they considered there was some evidence for the presence of $\tau \mathrm{Ti}_{2} \mathrm{~S}$ in one of their steels. 
$\mathrm{Ti}_{4} \mathrm{C}_{2} \mathrm{~S}_{2}$ was also identified in IF ultra- low carbon Ti-stabilized and semi-stabilized cold -rolled sheet steels, widely used for automotive bodies. ${ }^{61,63}$ Mizui et al. ${ }^{63}$ found that the solubilities of both $\mathrm{Ti}_{4} \mathrm{C}_{2} \mathrm{~S}_{2}$ and TiS in IF steels increased with Mn content, equations (13) and (13a), and that $\mathrm{Ti}_{4} \mathrm{C}_{2} \mathrm{~S}_{2}$ was more stable than TiS between 950 and $1250^{\circ} \mathrm{C}$. The crystal structure of titanium sulphides was re- examined by Ball. ${ }^{64} \mathrm{He}$ critically compared the data of $\tau \mathrm{Ti}_{2} \mathrm{~S}$, JCPDS data file (11-664), and suggested that this compound may have been confused with $\mathrm{Ti}_{4} \mathrm{C}_{2} \mathrm{~S}_{2}$. Ball ${ }^{64}$ concluded that $\tau \mathrm{Ti}_{2} \mathrm{~S}$ did not exist in steels and had it been confused due to additional lines appearing in some X-ray diffraction patterns.

It has been pointed out by Wilson and Chen, ${ }^{65}$ that ten intermediate phases the Ti-S system have been identified, ${ }^{63,64}$ making it particularly complicated. One method considered as a means of lowering the volume fraction of $\mathrm{MnS}$ in steels, and hence improving toughness, was by reducing the $\mathrm{Mn}$ content to $<0.3 \%$. This approach was investigated by Wilson and Chen ${ }^{65}$ who made a comparison of the effect of a Ti-free steel with one containing an $0.01 \%$ Ti addition, (lower than any addition studied by Liu et al., ${ }^{61}$ on the sulphides identified in $0.06 \mathrm{C}-0.3 \mathrm{Mn}-0.017 \mathrm{Nb}$ 0.011S- $-0.003 \mathrm{~N}$ steels. Their specimens were heated to $1350^{\circ} \mathrm{C}$, held for $1 \mathrm{~min}$, cooled at $200^{\circ} \mathrm{C}$ $\min ^{-1}$ to the testing temperature of 800 or $900^{\circ} \mathrm{C}$, where they were strained to fracture at $1 \times 10^{-3} \mathrm{~s}^{-1}$, then water quenched to room temperature, all using a Gleeble simulator.Analytical TEM /SAED showed that the most numerous sulphide identified in both steels was manganese -ironsulphide, either as $50-400 \mathrm{~nm}$ globules or as rods, $\leq 7 \mu \mathrm{m}$ long by $0.2 \mu \mathrm{m}$ wide. In the Ti containing steel, smaller iron titanium sulphides were found, Figs. 7(a) and 7(b). The large rod precipitates were considered to remain undissolved at $1350^{\circ} \mathrm{C}$, ${ }^{65}$ while iron titanium sulphides were likely to be a mixture of TiS, $\mathrm{Fe}_{1-\mathrm{x}} \mathrm{S}$ and $\mathrm{NbS}$, which could be written as $(\mathrm{Fe}, \mathrm{Ti}, \mathrm{Nb}) \mathrm{S}$. Figures 7(a) and 7(b) near here

The SAED patterns collected by Wilson and Chen ${ }^{65}$ indexed as an hexagonal structure with lattice parameters $\mathrm{a}=0.34 \mathrm{~nm}$ and $\mathrm{c}=0.57 \mathrm{~nm}$, which fits with a composition of $\mathrm{Fe}_{1.2} \mathrm{Ti}_{0.8} \mathrm{~S}_{2}$ in 
Table 5. Hexagonal structures of TiS were not found in this study. ${ }^{65}$

Some of the main orientation relationships (OR) found between phases in MA steel are collected in Table 6.

Table 6. near here

\section{Solubility of titanium compounds in iron}

Prior to the roughing rolling sequence, the soaking temperature of the steel must be sufficient to take into solution the microalloying compounds. In MA steels, the most important particles are carbides and nitrides, often present as carbonitrides of the transition metals, niobium, titanium, vanadium, and to a considerably lesser extent, zirconium. In certain cases, oxides of titanium and sulphides are of importance, as are aluminium nitride precipitates. During processing, the lowest temperature for taking into solution the particles precipitated on casting, which are later to control grain size and dispersion strengthening, is determined by their solubility in iron as a function of temperature and time. Matlock and Speer ${ }^{66}$ considered that the main precipitates were likely to be based on $\mathrm{NbC}, \mathrm{V}(\mathrm{C}, \mathrm{N})$ or TiN. In particular, solute niobium, remaining in solution in austenite, may also contribute to subsequent formation of nano- precipitates or clusters ${ }^{67-74}$ and finer dispersion strengthening precipitates in ferrite. Recently, Kapoor et al. ${ }^{75}$ using atom probe tomography (APT), have characterised GP -zone like clusters corresponding to $(\mathrm{Ti}, \mathrm{Nb}) \mathrm{C}$, along with $(\mathrm{Ti}, \mathrm{Nb})(\mathrm{C}, \mathrm{N})$ nano-precipitate in $\mathrm{Nb}$-Ti steels.

TiN is very stable and usually precipitates at high temperatures in the austenite phase and may resist subsequent austenite grain coarsening, when added as a small addition. The basis for most of the conclusions made by Matlock and Speer ${ }^{66}$ lay with the solubility equations associated with iron phases appropriate for carbides and nitrides of niobium, titanium and vanadium in austenite. These equations developed for binary compounds, are also the source for the more complex alloys, such as $(\mathrm{Nb}, \mathrm{Ti}, \mathrm{V})\left(\mathrm{C}, \mathrm{N}, \mathrm{V}_{\mathrm{a}}\right)$, where $\mathrm{V}_{\mathrm{a}}$ is the vacancy concentration in non-equilibrium situations. 
Solubility equations allowing the temperature of compounds in a solvent to be estimated, for example, titanium carbide in austenite, ${ }^{76}$ are normally described in the form of an Arrhenius equation. This gives the dependence of the rate constant $K$ of chemical reactions on the temperature $T$ (in absolute temperature, kelvins) and activation energy $E_{a}$, as shown below

$$
K=A^{-E a} / R T
$$

where $A$ is the pre-exponential factor and $R$ is the Universal gas constant.

In microalloyed steels, the microalloying element, $M$ is often combined with an interstitial $X$, to give a compound, $M X$, some or all of which, dissolves in austenite as the temperature is raised.

$$
[M]+[X]=M X]
$$

The rate constant $K$ in equation (1) is now described as an equilibrium constant for the reaction given by equation (2). In practice, the concentrations of $M$ and $X$ are normally low, being less than $1 \%$ and therefore may be considered as having an ideal solution behaviour. $M$ and $X$ are expressed in terms of the weight percentage of the alloying element present in the steel chemical composition. This allows equation (1) to be expressed as

$$
\begin{aligned}
& \log _{10}[M][X]=K_{x}=-Q_{1} / R T+C \quad \mathrm{~J} \text { mole }^{=1} \\
& \text { and putting } Q_{1} / R=Q \text {, gives: } \\
& \log _{10} \mathrm{k}_{\mathrm{x}}=\mathrm{C}-Q / T
\end{aligned}
$$

Here $\mathrm{x}$ can be written as $1, \delta, \gamma$, or $\alpha$, for the four phases of iron, liquid-1, delta ferrite- $\delta$, austenite- $\gamma$, ferrite- $\alpha$. 
Empirical Arrhenius equations have been determined for many of the important refractory carbides and nitrides known to form in steels, but similar equations for sulphides are less common. Table (7), summarizes selected $Q$ and $C$ values, collated from the literature, for the relevant grain boundary pinning and dispersion hardening compounds found in steels containing titanium additions.

The solubility equations of the binary compounds in iron of the transition metals combined with carbon and nitrogen, form the basis for investigating the phase relations in higher order systems such as Fe-Nb-V-Ti-C-N. Improvements in this data have been continually sought and been attained since the 1970's.

The solubility of titanium carbide and titanium nitride in iron has been the subject of many investigations, based on both experimental data and thermodynamic modelling. Much of what was published prior to the year 2000 has been considered by Jonsson ${ }^{23}$ and by Dumitrescu and Hillert. ${ }^{77}$ The latter based parts of their own thermodynamic analysis on that undertaken by Jonsson. ${ }^{23}$ They collated data for C and Q of equation (4), which is reproduced in Table (7). Lines of best fit are shown in Figure 8.

\section{Figure 8 and Table 7 near here}

The solubility constants for TiC in $\gamma$ considered by Dumitrescu and Hillert ${ }^{77}$ include those determined by Balasubramanian et al. ${ }^{78}$ at $1273 \mathrm{~K}$ and $1473 \mathrm{~K}$, and by Ohtani et al. ${ }^{79}$ at 1273,1373 and $1473 \mathrm{~K}$. They do not include data by used by Gladman, ${ }^{80}$ taken from Mori et al., ${ }^{81}$ whose values of C, 5.12 and Q, 10300, are in also good agreement with those of Ohtani et al. ${ }^{79}$ 
There have been many investigations into the solubility of TiN in iron, the main studies being associated primarily with the liquid phase, with the precipitation of TiN during melting, casting and rolling, and then in austenite, usually concerning grain refining. ${ }^{82,83}$

Kunze et al. ${ }^{84}$ provided critical summaries of the iron phase, through considering the importance firstly of dissolution and secondly the experimental methods employed, including their short comings. This provides what they regarded as the best solubility equations for TiN in the four phases of iron, liquid-1, delta ferrite- $\delta$, austenite- $\gamma$, ferrite$\alpha$.These are included below, along with results from other work.

\section{Liquid iron:}

Turkdogan ${ }^{85}$ considered the work of Frage et al ${ }^{86}$, Morita and Kunisada ${ }^{87}$ and Evans and Pehlke, ${ }^{88}$ in arriving at :

$$
\log _{l 0}([\% T i][\% N])=-17040 / T+6.4
$$

This equation gave an almost identical solubility product at $1873 \mathrm{~K}$ to that obtained by a thermodynamic analysis conducted by Ohtani and Hillert. ${ }^{89}$ Kim et al.${ }^{90}$ considered that errors were introduced by selecting interaction parameters obtained by different experimental techniques and taken from several sources. ${ }^{88,91}$ They investigated this system using metalnitride- gas equilibration under different nitrogen partial pressures. The results of Kim et al. ${ }^{90}$ were consolidated into the most recent theoretical work on the solubility of TiN in liquid iron, carried out by Jang et al., ${ }^{92}$ over the temperature range 1823 to $1973 \mathrm{~K}$, resulting in equation (7),

$$
\log _{l 0}([\% T i][\% N])=-12740 / T+4.06
$$

The data of Jang et al. ${ }^{92}$ is presented in Fig.9 where it is compared with earlier work. ${ }^{91-94}$ At $1823 \mathrm{~K}$ and $1873 \mathrm{~K}$, with the exception of the higher curve from Evans and Pehlke, ${ }^{88}$ where $k_{l}$ 
was determined by the Sieverts' method, excellent agreement is obtained. However, at 1923K and $1973 \mathrm{~K}$, the curves predicted in the work of Morita and Kunisada ${ }^{87}$ are higher than those of Kim et al. ${ }^{90}$ and Jang et al. ${ }^{92}$ This was considered by the latter ${ }^{92}$ to result from the location of the thermocouple used to measure the melt temperature: at the bottom of the crucible, ${ }^{87}$ compared with immersion. ${ }^{92}$ Figure $9 \mathrm{~d}$ shows the $k_{l}$ data at $1903 \mathrm{~K}$ and $1953 \mathrm{~K}$ measured by Ishii and Fuwa, ${ }^{94}$ which are in excellent agreement with the curve calculated by Jang et al. ${ }^{92}$ Furthermore, equations (6) and (7) agree well at the lower two temperatures, but deviate at $1923 \mathrm{~K}$. At $1973 \mathrm{~K}$, considering a melt containing $0.3 \% \mathrm{Ti}$ and $0.016 \% \mathrm{~N}$, gives $k_{J l}$ of $4.8 \times 10^{-3}$, while equation (6) gives $k_{T l}$ of $5.8 \times 10^{-3}$. This latter value lies much closer to the full line in Fig 9d, representing the solubility products given by the calculations of Jang et al., ${ }^{92}$ than any of the curves above it, suggesting that there is little to choose between the equations (6) and (7) for the temperature range considered here.

Fig 9 near here

\section{Delta ferrite:}

The solubility equation of titanium nitride in delta ferrite was revised by Kunze et al. ${ }^{84}$ from the earlier measured version by Kunze ${ }^{95}$ of $\log k_{\delta}=-15490 / \mathrm{T}+5.19$ to equation(8):

$$
\left[\log _{\delta}([\% T i][\% N])=-17205 / T+5.56\right.
$$

derived from experimental measurements within the temperature range 1693-1783K.

Kunze et al. ${ }^{84}$ noted that the equation obtained by Ohtani and Hillert, ${ }^{89}$ based on a thermodynamic analysis, gave solubilities which were lower by a factor of 2 than their own experimentally determined solubilities.

\section{Austenite:}

A large number equations have been published to describe the solubility TiN in austenite. They have been compared in some detail by both Kunze et al., ${ }^{84}$ who concentrated on errors 
which may arise from the choice of experimental method, and Dumitrescu and Hillert, ${ }^{77}$ who discussed the choice of data available in the literature necessary for a thermodynamic analytical approach. A reassessment undertaken by Dumitrescu and Hillert ${ }^{77}$ on the solubility of TiN in iron was based on the $\mathrm{C}$ and Q data collated in Table 8 which compare quite well with their calculated estimates. Dumitrescu and Hillert ${ }^{77}$ do not mention the detailed correlations made by Kunze et al., ${ }^{84}$ who included some different sources.

\section{Table 8 near here}

Fig 10 near here

The solid line in Fig. 10 is from calculations made by Dumitrescu and Hillert, ${ }^{77}$ while the dashed and dotted lines are from the survey made by Jönsson. ${ }^{23}$ The calculated line ${ }^{77}$ in Fig. 10 falls well below the experimentally determined data of Kunze for TiN in $\gamma \cdot{ }^{96}$

The dashed line in Fig. 11 is the same as the solid line in Fig. 10 from Dumitrescu and Hillert. ${ }^{77}$ This lies reasonably close to that determined from the experimental approach taken by Kunze et al., ${ }^{84}$ showing a particularly good correlation for the solubility of TiN in $\gamma$ over a wide temperature range. The assessment by Kunze et al. ${ }^{84}$ which considered much of the earlier data, concluded that, 'owing to the large scattering, only an order of magnitude of TiN solubility in austenite can be recognized. However, a temperature dependence described by the term -15000/T is highly probable.' Further experiments reported by Kunze et al. ${ }^{84}$ involved zone melting in a carburizing atmosphere, to obtain a distribution coefficient of a component, here titanium, which is the relation between its concentrations in solidus and in the liquidus.

Fig 11 near here

This enabled Kunze et al. ${ }^{84}$ to derive equation $(9$,

$$
\log _{\gamma}([\% T i][\% N])=k \gamma=-15000 / T+4.06
$$

which supersedes the earlier equation: ${ }^{92}$ 


$$
\log _{\gamma}([\% \mathrm{Ti}][\% \mathrm{~N}])=-15490 / T+5.19
$$

Alpha ferrite

Equation (8) is considered by Kunze et al. ${ }^{84}$ to hold for TiN solubility in both $\alpha$ and $\delta$ ferrite.

More complex systems have been considered in an attempt to predict the effect of the interaction of multi- elements in MA steels on the solubility of compounds characterised experimentally, and to allow quantitative determination of their concentrations.

Gorbachev and Popov ${ }^{97}$ have considered the Fe-Ti-C, Fe-Ti-N, and Fe-Ti-C-N systems. Their main conclusion was that 'the thermodynamic calculations show that under equilibrium conditions in the austenite region of steels alloyed with titanium, only cubic carbonitrides can form. If the amount of titanium in the steel is greater than that of nitrogen, the influence of carbon becomes more noticeable.' They also mention the possible formation of an intermetallic hexagonal Laves phase based on $\mathrm{Fe}_{2} \mathrm{Ti}$, which, in the case of the Fe-Ti-C system, can precipitate from bcc $\alpha$ solid solution. It would appear that this phase is very unlikely to be present in MA steels. This is due to the amount of titanium required to form the Laves phase, which depends linearly on the content of the carbon in the steel. The solubility of titanium carbide in ferrite is considerably less than the solubility of the Laves phase. Titanium therefore combines preferentially with carbon, and only the remainder not capable of being dissolved in ferrite, is left to form the Laves phase. This explanation applies equally to the Fe-Ti-N system.

As mentioned above, a mutual solubility of intermetallic carbides and nitrides often occurs. However, there are more exceptions than those based on $(\mathrm{Ti}, \mathrm{Zr})(\mathrm{C}, \mathrm{N})$ system documented by Goldschmidt. ${ }^{33}$ Kieffer et al ${ }^{98}$, showed that there was two-phase separation in some NaCl-type complex carbonitrides. They determined experimentally the miscibility gap within the systems: TiC- $(\mathrm{ZrC}, \mathrm{HfC})$ and $\mathrm{VC}-(\mathrm{NbC}, \mathrm{TaC})$, in the region from $1200^{\circ} \mathrm{C}$ up to the temperature of the 
critical point. Non-uniform compositions within precipitate particles of MA steels, considered to be due to phase separation within the particles, were found experimentally by Zhou and Kirkaldy. ${ }^{99,100 .}$ As noted by Rudy ${ }^{101}$ and by Inoue et al., ${ }^{102}$ 'phase separation occurs in precipitates depending on the difference of thermodynamics of terminal components in the $\left(\mathrm{M}_{1}, \mathrm{M}_{2}\right)\left(\mathrm{X}_{1}, \mathrm{X}_{2}\right)$ double pseudo-binary system'. Here $\mathrm{M}_{1}$ and $\mathrm{M}_{2}$ are transition metals while $\mathrm{X}_{1}$ and $\mathrm{X}_{2}$, carbon and nitrogen.

For detailed information on the thermodynamic modelling of complex carbonitride formation of the system Fe-Nb-Ti-C-N, the work of both Lee ${ }^{103}$ and of Gorbachev et al. ${ }^{104}$ should be consulted, and for Fe-V-Ti-C-N, that of Gorbachev et al. ${ }^{105}$ Their critical examination of the available data for both of these systems provides a good source for the earlier work in this field. Inoue et al. ${ }^{102}$ was perhaps the first to attempt a thermodynamic description of the system Fe-V-Nb-Ti-C-N. This was a calculation of the phase equilibria between austenite and $(\mathrm{Nb}, \mathrm{Ti}, \mathrm{V})(\mathrm{C}, \mathrm{N})$ in MA steels, based on the Gibbs free energy of each phase being described by two sub-lattices. These required evaluations of the solubility products, $\mathrm{K}$, formation energies and interaction parameters, L, of each carbide and nitride. For fcc compounds, a linear relationship has been shown to hold between the lattice constant and the mole fraction. ${ }^{98,101}$ Inoue et al. ${ }^{102}$ equated $\mathrm{L}^{\mathrm{fcc}}$ to the compositional average of the lattice constants of the two terminal components, $\overline{\mathrm{a}}$, and the difference from the average, $\Delta \mathrm{a}$, through the equation:

$$
L^{f c c}=6.03 \times 10^{6}(\Delta a / \bar{a})^{2} \quad\left(\text { Jmole }^{=1}\right)
$$

and listed the $\mathrm{L}^{\mathrm{fcc}}$ and $\mathrm{K}$ data used for each carbide and nitride. However, more recent data for $\mathrm{K}$ is considered in detail below. Inoue et al. ${ }^{102}$ concluded that the carbonitride separates into TiN and $\mathrm{NbC}$, whereas $\mathrm{V}$ tends to dissolve into the nitride.

One of the difficulties in comparing experimental data with computer predictions, is that of obtaining good experimental data, as phase equilibria is rarely obtained, due to the low diffusivity in carbonitrides. 
An examination undertaken by Liu ${ }^{106}$ involved a detail comparison of calculated compositions of the carbonitrides expected in the $(\mathrm{Ti}, \mathrm{Nb})(\mathrm{C}, \mathrm{N})$ system with experimental data published by Craven et al. ${ }^{107}$ In their work on multicomponent Ti Nb MA steels, ${ }^{107}$ with the compositions given in Table 9, some $\left(\mathrm{Ti}_{\mathrm{x}} \mathrm{Nb}_{1-\mathrm{x}}\right) \mathrm{N}_{\mathrm{y}} \mathrm{C}_{\mathrm{z}}$ carbonitride particles consisted of multiple caps in the form of epitaxial overgrowths on a core as seen in Fig.12.

Fig.12 near here

Using parallel electron energy loss spectroscopy (PEELS), Craven et al. ${ }^{107}$ obtained the amount of both metallic elements and carbon and nitrogen, showing that the $\mathrm{N} /(\mathrm{Ti}+\mathrm{Nb})$ atomic ratio in the core was similar to the average value in the steel, whereas the $\mathrm{Nb} / \mathrm{Ti}$ ratio was much smaller than that in steel. The composition in the cap changed from $\mathrm{Nb}(\mathrm{C}, \mathrm{N})$ to $(\mathrm{Nb}, \mathrm{Ti}) \mathrm{C}$ as the N/Ti ratio in steels decreased.

\section{Table 9 near here}

Using the steel compositions given in Table 9, the thermodynamic calculations of Liu, ${ }^{106}$,based on a three miscibility gap formulation, indicated that the precipitates formed above $1400^{\circ} \mathrm{C}$ are $\mathrm{Ti}$ and $\mathrm{N}$ rich, whereas those nucleated around $1100^{\circ} \mathrm{C}$, are $\mathrm{Nb}$ and $\mathrm{C}$ rich. The calculated particle compositions ${ }^{106}$ are given in Tables 10 and 11, together with calculated values of Frisk, ${ }^{108}$ which were also considered to be in reasonable agreement with the experimental data of Craven et al. ${ }^{107}$ An excellent summary of previous thermodynamic modelling for iron multicomponent $\mathrm{Nb}, \mathrm{Ti}$, and $\mathrm{V}$ carbides and carbonitrides, is given by Frisk, ${ }^{108}$ extending that of Jonsson. ${ }^{23}$ Frisk $^{108}$ calculated data based on the application of a CALPHAD approach to consider the thermodynamics of cubic Nb, Ti and V carbonitrides in iron. Gorbachev et al. ${ }^{104}$ described the approach used by Frisk ${ }^{108}$ as 'fairly qualitative', due to the revisions made by taking some of the parameters from earlier work, including that of Inoue et al. ${ }^{102}$ However, the calculated compositions of cap and core for the $(\mathrm{Ti}, \mathrm{Nb})(\mathrm{C}, \mathrm{N})$ precipitates made by Frisk ${ }^{108}$ and given in 
Tables 10 and11,show a reasonable comparison with the experimental data of Craven et al., ${ }^{107}$ many somewhat closer than the calculations made by Liu. ${ }^{106}$

Tables 10 and 11 near here

Frisk and Borggren ${ }^{109}$ have recently extended the earlier model to consider the Fe-Cr$\mathrm{Nb}-\mathrm{V}-\mathrm{Mo}-\mathrm{C}-\mathrm{N}$ system. Experimental data was obtained to study the phase separation into Vrich and $\mathrm{Nb}$ - rich carbides/carbonitrides, and allow comparison with the calculated data. They concluded that 'the types of precipitates were correctly predicted by the calculations in all cases, and the compositions well reproduced. $\mathrm{Xu}$, Thomas and $\mathrm{O}^{\prime} \mathrm{Malley}{ }^{110}$ have presented a computational model of equilibrium precipitation of 18 different oxides, sulphides, nitrides and carbides and 13 different elements in MA steels. The model is based on satisfying solubility limits including Wagner interaction between elements, mutual solubility between precipitates, and mass conservation of alloying elements. It predicts the compositions and amounts of stable precipitates for multicomponent microalloyed steels in liquid, ferrite and austenite phases at any temperature. These calculations were validated by those of commercial packages, and predicted the evolution of precipitates in two commercial steels containing $\mathrm{Nb}-\mathrm{Ti}-\mathrm{V}$ additions, which also agree with the experimental data of Craven et al. ${ }^{107}$

More recently, Xu, Tang and Song ${ }^{111}$ proposed a simpler theoretical model to predict complex equilibrium precipitation in $\mathrm{Nb}-\mathrm{Ti}-\mathrm{V}$ bearing microalloyed steels. It is assumed that the complex precipitate with B1 type consists of six kinds of binary compound, namely, $\mathrm{NbC}$, $\mathrm{NbN}, \mathrm{TiC}, \mathrm{TiN}, \mathrm{VC}$, and VN. The authors note that their predictions agree well with other recent research.

Roy et al. ${ }^{112}$ modelled the effect of segregation on the stability of microalloy precipitates and on the size distributions at different regions (solute rich and solute depleted), an area which is not well understood. They compared of two as-cast slabs:

(A) $0.09 \mathrm{C}-1.42 \mathrm{Mn}-0.035 \mathrm{Al}-0.050 \mathrm{Nb}-0.019 \mathrm{Ti}-0.05 \mathrm{~V}$ and 
(B) 0.07C-1.20Mn-0.-034Al-0.041 Ti. The nitrogen level was not given.

In slab (A), cuboidal TiN, cruciform and cuboidal $(\mathrm{Nb}, \mathrm{Ti})(\mathrm{C}, \mathrm{N})$, and spherical $\mathrm{NbC}$ and $\mathrm{VC}$ precipitates which had the greatest volume fraction, were characterised, and varied with position in the slab. TiN precipitates, with various morphologies and sizes, were found in slab (B). The model ${ }^{112}$ proposed for micro-segregation, which was a feature of the slab microstructure, gave a satisfactory agreement between experimental observations and predictions for precipitate size distribution and the amount of precipitates in the interdendritic and dendrite centre regions of segregated slabs. It was concluded that this type of model may help,

(i) to avoid hot cracking,

(ii) in the selection of soaking time and temperature and predicting austenite grain size during soaking and

(iii) in designing the rolling schedule for achieving maximum benefit from the microalloying precipitates. ${ }^{113}$

It is of interest to note that by using data from many of the papers referred to above, Raghavan ${ }^{114}$ has up-dated the phase diagrams of the C-Fe-N-Nb-Ti system.

Sulphur in low carbon steels is normally present as $\mathrm{MnS}$, and over the years, the effects of the various morphologies have been the subject of much research. ${ }^{115,116}$ In steels with additions of titanium, titanium sulphide, sometimes containing iron, and / or titanium carbosulphide, are both frequently reported. ${ }^{58-65}$ The solubility of TiS in $\gamma$-iron was probably first investigated by Swisher ${ }^{117}$ who determined the solubility product as:

$$
\log _{\gamma}[\mathrm{Ti} \%][S \%]=-17,640 / T+8.20
$$

More recently, Mizui et al. ${ }^{63}$ assessed the solubility products of $\mathrm{TiS}$ and $\mathrm{Ti}_{4} \mathrm{C}_{2} \mathrm{~S}_{2}$ in $\gamma$ iron,through a consideration of ten previous publications, and then undertook experimental determinations of these two compounds, in particular for the case of IF steels. They considered 
that the presence of MnS has an influence on the solubility of TiS, and included a manganese term in equation (13):

$$
\log _{\gamma}[T i \%]^{2 / 3}[S \%]=-0.021-5847 / T-(3.360-5195 / T \cdot[M n \%]
$$

where they describe TiS as $\mathrm{Ti}_{2} \mathrm{~S}_{3}$, to account for the presence of iron in this compound, which showed an atomic ratio, $\mathrm{Ti} / \mathrm{S}$ of $2 / 3$ in their steels.

Equation 13a was deduced for $\mathrm{Ti}_{4} \mathrm{C}_{2} \mathrm{~S}_{2}$ in $\gamma$-iron. ${ }^{63}$

$$
\log _{\gamma}[\mathrm{Ti}][C]^{1 / 2}[S]^{1 / 2}=0.392-7004 / T-(4.783-7401 / T) .[M n]
$$

Among the beneficial effects in strip and plate steel products resulting from additions of titanium, are improvements in cold formability and toughness anisotropy. This has been attributed to the formation of titanium carbosulphide $\left(\mathrm{Ti}_{4} \mathrm{C}_{2} \mathrm{~S}_{2}\right.$, sometimes written as $\left.\mathrm{Ti}_{2} \mathrm{C}_{2} \mathrm{~S}\right)$, which remains undeformed during hot rolling, due to its high hardness at elevated temperatures. ${ }^{116}$

The solubility product of $\mathrm{Ti}_{4} \mathrm{C}_{2} \mathrm{~S}_{2}$ in $\gamma$ was determined by Liu et al. ${ }^{61}$ and described by equation (14):

$$
K_{\gamma}=\log _{\gamma}[T i \%][C \%]^{0.5}[S \%]^{0.5}=-15,600 / T+6.5
$$

$\mathrm{Ti}_{4} \mathrm{C}_{2} \mathrm{~S}_{2}$ has often been reported as the main sulphide in IF $(0.005 \% \mathrm{C})$ steels compared with MA $(0.05 \% \mathrm{C})$ steels. Using equation (14) to calculate $K_{\gamma}$, it is evident in Fig.6, that the solubility of $\mathrm{Ti}_{4} \mathrm{C}_{2} \mathrm{~S}_{2}$ in $\gamma$ is significantly greater in IF steels, resulting in more solute Ti and $\mathrm{S}$ available to form TiS.

The solubility product for manganese sulphide in $\gamma$-iron is given by Turkdogan et al. ${ }^{118}$ as;

$$
\begin{gathered}
\mathrm{k}_{\mathrm{s}}=[\mathrm{Mn} \%][\mathrm{S} \%] f_{s}^{M n} \\
\log k_{s}=-9020 / T+2.93 \\
\log f_{s}^{M n}[(-215 / T+0.097][\% M n] \text { in } \gamma)
\end{gathered}
$$

Here $f_{s}^{M n}$ expresses the effect of manganese on the activity coefficient of sulphur in austenite $(\gamma)$. Fig 13 near here

Figure 13 shows the influence of sulphur and manganese on the solution temperature of $\mathrm{MnS}$ in $\gamma$. Even with low S levels of $\sim 20 \mathrm{ppm}, 1.0 \% \mathrm{Mn}$ steels have solution temperature close to $1300^{\circ} \mathrm{C}$, so 
that for many titanium-free MA steels, containing $\geq 1 \% \mathrm{Mn}$, most of the sulphur is combined as MnS. Liu et al. ${ }^{61}$ compared in Fig. 14, the temperature dependence of $\mathrm{K}_{\gamma}$ in $\gamma$ of $\mathrm{Ti}_{4} \mathrm{C}_{2} \mathrm{~S}_{2}$ with the other most likely compounds to precipitate in titanium steels. It can be seen clearly that $\mathrm{K}_{\gamma}$ of $\mathrm{MnS}$, TiS and $\mathrm{Ti}_{4} \mathrm{C}_{2} \mathrm{~S}_{2}$ lie between the values of $\mathrm{TiC}$ and $\mathrm{TiN}$.

Fig 14 near here

\section{Precipitation of titanium compounds in microalloyed steels}

The precipitation of carbides, nitrides and carbonitrides, regarded as the main class of particles influencing mechanical properties and toughness in MA steels, is described by Lui and Jonas ${ }^{119}$ as occurring at three different stages during the thermomechanical processing (TMP) routes. Type 1 precipitates are formed in the liquid phase and during or after solidification for the duration of casting, on the liquid/solid interface or in delta ferrite. These precipitates, or inclusions as they are often described, are very stable, and while they are normally too large to influence recrystallization of austenite, the smallest may effectively retard coarsening of austenite grains during reheating or during a welding cycle. Type 11 precipitates nucleate in austenite after solution treatment and during hot deformation, such as controlled rolling, as the temperature is decreasing. A pre-precipitation grouping of atoms, known as Guinier-Preston(GP) zones in non-ferrous alloys and also described as 'clusters', has received increased attention over the past decade due to the development of atom probe tomography (APT). These clusters grow to what is sometimes described as nano-precipitates. Following TMP, the precipitates are usually strain induced, (SIP); that is nucleated on dislocations and can retard the recovery and recrystallization of austenite. Grain refinement of MA steels associated with TMP is mainly due to this group of particles, which have been shown to coarsen during cooling through the austenite phase.

Finally, type 111 particles are formed during or after the austenite to ferrite phase transformation, nucleating on the austenite/ferrite interface and in ferrite. Through these changes, a fine precipitate dispersion, which may include interface precipitation, is usually observed, normally 
resulting in dispersion strengthening in ferrite, also known as precipitation hardening. Ardell ${ }^{120}$ makes a distinction between these two forms of strengthening.

Several of these precipitate nucleation processes have been recognised in MA steels. These include homogeneous precipitation, resulting in coherent precipitates with strain fields, leading to semi-coherent and incoherent precipitates, interphase precipitation, heterogeneous precipitation on grain boundaries and dislocations.

Titanium oxides ${ }^{49}$ and titanium nitride ${ }^{92,121,122}$ have been characterised as type 1 particles, in both MA welded and in as cast steels. Type 11 particles observed after solidification, can take the form of dendrites, Fig.15, or in the case of TiN, a cube shape, Fig.16. Particles in this category also nucleate on prior grain boundaries and fall into a smaller size group than those in Figs. 17 and 18.

\section{Figs 15 and 16 near here}

Figs 17 and 18 near here

In controlled rolled MA steels, much attention has been paid to the combination of additions of titanium and vanadium, titanium and niobium or titanium and niobium with vanadium, the expectation being that the potential of each element will be fully exploited. Most of the work discussed below emphasises that titanium additions are normally made as hypostoichiometric relative to nitrogen, i.e. $<1: 3.4$. This ratio is discussed by Crowther and Morrison, ${ }^{124}$ who explained the influence that titanium additions were observed to have in Al$\mathrm{V}$ and $\mathrm{Al}-\mathrm{Nb}$ MA steels, particularly with regard to loss of strength. This was purported to be due to changes in the dispersion strengthening associated with modifications to niobium precipitates. However, the individual levels of $\mathrm{Ti}$ and $\mathrm{N}$ are perhaps the main factors which result in TiN precipitating in the liquid phase as type 1 particles.

Chen et al. ${ }^{125}$ studied $\mathrm{Nb}-\mathrm{Ti}$ and $\mathrm{Nb}-\mathrm{V}$-Ti steels, with the aim of assessing the thermal stability of large precipitates formed during continuous casting. Their two experimental steels had the following compositions: 
- $\quad \mathrm{Nb}-\mathrm{V}-\mathrm{Ti}$ steel $\quad 0.082 \mathrm{C}-1.32 \mathrm{Mn}-0.030 \mathrm{Al}-0.0076 \mathrm{~N}-0.039 \mathrm{Nb}-0.019 \mathrm{Ti}-0.057 \mathrm{~V} \quad \mathrm{Ti} / \mathrm{N}=2.53$

Three particle morphologies were noted in the as cast samples. In the Nb-V-Ti steel, cuboidal TiN particles, with the same morphology as in Fig. 16 , but these $>0.5 \mu \mathrm{m}$, type 1 particles, were considered to nucleate in the liquid phase, due to the concentrations of titanium and nitrogen in the steel. The authors believed that type 1 precipitates should be avoided, as they have no advantageous effect on the steels properties, removing both $\mathrm{Ti}$ and $\mathrm{Nb}$, which would otherwise form smaller precipitates capable of grain refining or dispersion strengthening, as later confirmed by He and Baker. ${ }^{126}$

Secondly, type 11 , TiN- rich $(\mathrm{Ti}, \mathrm{Nb})(\mathrm{C}, \mathrm{N})$ dendritic precipitates up to $10 \mu \mathrm{m}$ long, were recorded in the $\mathrm{Nb}-\mathrm{V}-\mathrm{Ti}$ steel and $\mathrm{NbC}-$ rich in $(\mathrm{Ti}, \mathrm{Nb})(\mathrm{C}, \mathrm{N})$ dendritic precipitates in the $\mathrm{Nb}-\mathrm{Ti}$ steel. Thirdly, dendritic precipitates nucleating on $(\mathrm{Ti}, \mathrm{Nb}) \mathrm{N}$ during the final stage of solidification of the interdendritic liquid or on $\delta$-phase boundaries and growing in the solid state. EELS spectra indicated that they were nitrides with a $\mathrm{Ti}$ core and a $\mathrm{Nb}$-rich skin. This sequence of precipitate chemistry and morphology was, in the main, found to hold by Li et al ${ }^{127}$ who compared experimental observations made by TEM/EDX/PEELS techniques on MA steels having two carbon levels and two nitrogen levels, shown in Table 12, with a thermodynamic model for processing thin slab direct rolled (TSDR). The Ti/ $\mathrm{N}$ ratios for each cast were $2.5,2.18,0.43$ and 5.10 .

Table 12 near here

After solidification, the casts were quenched from $1400^{\circ} \mathrm{C}$ to investigate eutectic carbonitrides, which were found to form as $\mathrm{Nb}(\mathrm{C}, \mathrm{N})$, only in the high $\mathrm{C}$ steels casts 1 and 3 . This was explained as being due to the strong segregation of $\mathrm{Nb}$ and weak segregation of $\mathrm{Ti}$ to the liquid during freezing. Good agreement with the thermodynamic model was found, if it was assumed that the eutectic carbonitride was in equilibrium with austenite. During reheating 
experiments, new precipitates, $\mathrm{Nb}$ rich at low and intermediate temperatures $\left(1300^{\circ} \mathrm{C}\right)$ and $\mathrm{V}$ rich at low temperatures $\left(800^{\circ} \mathrm{C}\right)$, were observed. The particles became more cuboidal at high reheating temperatures. After holding for $24 \mathrm{hrs}$ at $1200^{\circ} \mathrm{C}$, TiN particles in cast 4 , Table 12 , were found to be pure nitrides, but above this temperature, TiMnO tended to supplant TiN. In low N cast3 steel, co-precipitation of oxide and nitride, sometimes with MnS, was observed. However, the flower/cruciform precipitates or the coatings of $\mathrm{Nb}(\mathrm{C}, \mathrm{N})$ observed by Baker et al ${ }^{128}$, were not reported by Li et al ${ }^{127}$ or by Yuan and Laing ${ }^{129}$. Unfortunately, the latter did not provide the composition of their forged $\mathrm{Ti} / \mathrm{Nb}$ MA steels, which were isothermally held at $1300^{\circ} \mathrm{C}$ for up to 48hrs, before water quenching. After forging, they observed two kinds of type11 (Ti,Nb)(C,N) precipitates,

- cuboidal $50-100 \mathrm{~nm}$ Ti rich, with $\mathrm{Ti} / \mathrm{Nb}$ ratios initially of $6: 1$,increasing to $15: 1$ after $48 \mathrm{hrs}$, and

- $\quad 10-<5 \mathrm{~nm}$ spherical, Nb-rich carbonitrides.

The former were considered to precipitate on solidification, while the later were SIP in austenite during the forging process. From their analytical TEM/SAED/EDX data, they argued that the original large precipitates were nucleated with complex monophase TiNb compositions, rather than TiN particles, which then acted as nucleation sites for $\mathrm{Nb}(\mathrm{C}, \mathrm{N})$, as found in previous work. The first stages of precipitation in ferrite of type 111 carbonitride particles in TMP MA steels involves SIP with some interphase precipitation, or in heat-treated steels, interphase precipitation followed by homogeneous precipitation.

A detailed review of precipitation in iron alloys was undertaken by Edmonds and Honeycombe ${ }^{130}$, citing 260 references. This provides a valuable source of earlier work in this area. It includes information pertinent to this review, and deals in particular, with the mechanisms of precipitation of titanium carbide and titanium nitride. 
The initial stages of nucleation of particles in steels has intrigued scientists for decades, particularly when nitrogen was involved. K. H. Jack ${ }^{131}$ proposed that homogenous precipitation of carbides, nitrides and carbonitrides in ferrite in heat treated steels followed a sequence analogous to that occurring during the ageing of $\mathrm{Al}-4 \% \mathrm{Cu}$ alloy, commencing with $\mathrm{GP}$ zones. That is: homogeneous solid solution, GP zones- mixed substitutional - interstitial solute clusters, coherent, semi-coherent, and finally incoherent precipitates. He pointed out that GP zones are metastable and have a higher solubility than the equilibrium precipitate. The high supersaturation was regarded as the driving force for clustering. Early evidence, by Kirkwood et al ${ }^{132}$, for this sequence was detected following nitriding of Fe-3\% Ti alloys, which developed a microstructure with tetragonal distortion of the ferrite lattice by nitrogen, and coherency between the matrix and thin plates on $\{100\}_{\alpha}$ planes. Initially this was identified as clustering or zone formation, through streaking in $200 \alpha$ reflections of the matrix diffraction patterns, being replaced by streaking through $110 \mathrm{MCN}$ precipitate reflections, which occurred after annealing at $850^{\circ} \mathrm{C}$, when softening was noted. The microstructure was described as having a 'tweed' appearance. TiN plates were identified lying on $\left\{100_{\alpha}\right.$ planes with a Bain orientation relationship with the matrix, Table 6. The streaking disappeared when the precipitates lost coherency. This precipitation sequence for the Fe-Ti-N system was fully described by D.H.Jack. ${ }^{133}$ He also estimated the thickness of the zones from streaking in SAED patterns. The zones comprised two planes of iron atoms together with a Ti-N plane, giving a three layer stack, with two $0.194 \mathrm{~nm}$ interplanar spacings. No evidence of dislocation formation accompanying the development of the coherent plates was reported.

Cuddy et al, ${ }^{134}$ studying the elevated temperature strengthening of iron alloys, found anomalies in the case of titanium additions, which showed unusual strength when heated between $300^{\circ} \mathrm{C}$ and $600^{\circ} \mathrm{C}$.Neither dispersion hardening by $\mathrm{Ti}(\mathrm{C}, \mathrm{N})$ particles or solid solution hardening by titanium atoms, produced the hardening peaks observed at elevated temperatures. They 
suggested that 'this effect was due to the presence in the lattice of stable clusters of titanium and carbon or nitrogen atoms, which reorient in the stress field of mobile dislocations, thereby impeding their motion.' At this time, the authors were unable to characterize the particles in their specimens, to provide support for their ideas.

The atom probe, (AP), was used by Dunlop and Turner ${ }^{135}$ to determine the chemical composition of carbides precipitated in a low alloy steel containing two strong carbide forming elements, $\mathrm{V}$ and Ti, which, as mentioned above ${ }^{33}$, develop isostructural carbides with an NaCl- type crystal structure. A vacuum melted model steel, Fe-0.08C-0.18V-0.13Ti, was solution treated at $1300^{\circ} \mathrm{C}$, water quenched, followed by isothermal transformation at $725^{\circ} \mathrm{C}$ or $800^{\circ} \mathrm{C}$. Characterisation of the precipitates, present predominantly as interphase precipitation, was undertaken by TEM and AP analysis in a field ion microscope ( FIM). Typically, 25-30 atoms were analysed for each particle, and Table 13 shows data for three particles, $\sim 6 \mathrm{~nm}$ in size. The data show a mixed transition metal composition, including iron as part of the precipitate. The iron disappeared on subsequent ageing. However, clustering of atoms prior to nucleation of precipitates, was not dealt with.

\section{Table 13 near here}

Dunlop and Honeycombe ${ }^{136}$ extended this work, ${ }^{135}$ through the study of Fe-0.08C-0.40V and Fe-0.09C-0.33Ti model steels. Using dark field TEM, they compared the high- temperature coarsening behaviour of interphase precipitates of $\mathrm{VC}, \mathrm{TiC}$ and $(\mathrm{V}, \mathrm{Ti}) \mathrm{C}$ particles in ferrite, It was found that $\mathrm{TiC}$ interphase dispersions initially coarsened most rapidly, while $(\mathrm{V}, \mathrm{Ti}) \mathrm{C}$ coarsened the least rapidly. The identification of clusters through the presence of streaking in SAED patterns is fully discussed by Chechenin et al, ${ }^{137}$ who used a variety of techniques to examine precipitate formation in nitride FeNiTi films, which supported many of the ideas mentioned above, concerning the formation of mixed Fe-Ti-N GP zones. Clusters of C-Cr together with TiC particles of $\sim 3 \mathrm{~nm}$, identified by APT were reported by Timokhina et al. ${ }^{138}$ More recently, 
Kostryzhev et al. ${ }^{71}$ studied the strengthening sources following TMP, in a commercial steel containing $0.08 \mathrm{C}-0.064 \mathrm{Nb}-0.021 \mathrm{Ti}$ and $0.0047 \mathrm{~N}$. Analytical SEM and AP was used to characterize and size atom clusters and precipitates. Two size groups of particles were identified, $<70 \mathrm{~nm}$ and $>70 \mathrm{~nm}$.All particles in the $<70 \mathrm{~nm}$ range, for all the TMP schedules used, were Tifree, and were mainly $\mathrm{NbC}$. The APT study revealed $\mathrm{Nb}$ - containing solute atom clusters and very fine precipitates, with diameters in the range $3-13 \mathrm{~nm}$. No clusters containing Ti atoms were recorded. The particles $>70 \mathrm{~nm}$ had various morphologies and compositions, being cuboidal $(\mathrm{Ti}, \mathrm{Nb})(\mathrm{C}, \mathrm{N})$, ellipsoidal $\mathrm{Nb}(\mathrm{C}, \mathrm{N})$ or ellipsoidal $\mathrm{NbC}$.

Problems associated with the quantitative analysis of $\operatorname{Ti}(\mathrm{C}, \mathrm{N})$ using APT, based on a model Ti $\left(\mathrm{C}_{0.7} \mathrm{~N}_{0.3}\right)$ material,were considered in detail by Angseryd et al. ${ }^{139}$ The method they proposed to deal with the inaccuracies associated with carbon data was shown to provide a similar analysis to PEELS, but without the problems due to surface oxidation. Their method was applied by Kapoor et al., ${ }^{75}$ who followed the precipitation sequence from the core to the surface of particles in two steels, whose base composition is given in Table 14. Alloy 1, a high-Ti 750MPa steel, containing Ti-rich $(\mathrm{Ti}, \mathrm{Nb})(\mathrm{C}, \mathrm{N})$ and Ti-rich $(\mathrm{Ti}, \mathrm{Nb}) \mathrm{C}$ precipitates, was compared with Alloy 2,a high-Nb, $580 \mathrm{MPa}$ steel containing Ti-rich $(\mathrm{Ti}, \mathrm{Nb})(\mathrm{C}, \mathrm{N})$ precipitates and $(\mathrm{Ti}, \mathrm{Nb}) \mathrm{C}$ clusters. These embryonic precipitates were smaller than the (Ti, $\mathrm{Nb}) \mathrm{C}$ precipitates in Alloyl, being only a few atomic layers thick, with a chemical analysis of $33.8 \pm 8 \mathrm{C}-38.4 \pm 10 \mathrm{Ti}-27.8 \pm 6.8 \mathrm{Nb}$ (at.pct).The absence of clusters in Alloy 1 was considered to be due to the Ti addition being twice that of Alloy 2.

\section{Table 14 near here}

There are several reports of clusters of $\mathrm{Nb}$ atoms in $\mathrm{Nb}$ containing steels, ${ }^{68-75}$ while clusters of $\mathrm{TiO},{ }^{140} \mathrm{TiOC}^{141}$ and $(\mathrm{Ti}, \mathrm{Mo}) \mathrm{C}^{142}$ in steels have been noted. APT was used to generate analyses of solute clusters and precipitates in an $0.04 \mathrm{C}-1.52 \mathrm{Mn}-0.21 \mathrm{Si}-0.08 \mathrm{Ti}-0.22 \mathrm{Mo}$ steel processed by Mukherjee et al., ${ }^{142}$ under simulated strip-rolling conditions, up to HT in Fig.19, 
Fig 19 near here

The AP data revealed the coexistence of nanoclusters and precipitate particles, even after isothermal holding for $3600 \mathrm{~s}$. The size of the nanoclusters and the precipitates was expressed as a Guinier radius, associated with the small angle scattering technique, which lay between 0.5 and $8 \mathrm{~nm}$, with the average size $\sim 1.8 \mathrm{~nm}$, for two strain conditions, $\varepsilon=0$ or 1 . The composition of the nanoclusters and precipitates varied over a wide range, comprising a mixture of $\mathrm{Ti}$ and Mo, mostly rich in $\mathrm{C}$. The average precipitate composition was close to that of MC carbide stoichiometry, where $\mathrm{M}$ represents a mixture of Ti and Mo. In most cases, the Ti/Mo ratio in the MC carbides was $>1$. As the Guinier radius exceeded $2.5 \mathrm{~nm}$, the composition range became narrower towards the MC carbide stoichiometry, including a small amount of Fe ( 3-12 at.\%). These microstructural features occurred both within 3-D interphase precipitate sheets, considered more fully in the next section, and in randomly selected fields of view. It was observed that the interphase row spacing of precipitates was reduced with the application of a pre-strain. A bimodal distribution of larger precipitates $(\sim 8-10 \mathrm{~nm})$ coexisted with smaller nanoclusters $(\sim 3 \mathrm{~nm})$ within the interphase sheets/rows. Both the nanoclusters and the precipitates had a disc morphology, although nanoclusters with less than $\sim 30$ atoms were found to be more irregular in shape. Recently Mukherjee et al. ${ }^{143}$ have extended their earlier work to obtain a fundamental understanding of interphase precipitation during an isothermal hold at $650^{\circ} \mathrm{C}$, up to $100 \mathrm{hrs}$. A steel of lower Ti, containing $0.04 \mathrm{C}-1.52 \mathrm{Mn}-0.21 \mathrm{Si}-0.06 \mathrm{Ti}-$ 0.13Mo,which was given an additional heat treatment beyond HT in Fig.19 was studied.They reported that the size of clusters and nano-precipitates increased from $\sim 2 \mathrm{~nm}$ after $300 \mathrm{~s}$ to $\sim 15$ $\mathrm{nm}$ after $100 \mathrm{~h} .{ }^{139}$ To understand how the precipitation sequence, including the volume fraction of precipitates, and their composition were influenced by the combined addition of $\mathrm{Nb}$ and $\mathrm{Ti}$, Kapoor et al. ${ }^{75}$ conducted thermodynamic calculations based on Thermo-Cal, for temperatures between $600^{\circ} \mathrm{C}$ and $1500^{\circ} \mathrm{C}$. Considering the precipitation sequence for Alloy 1, Table 14, based on the experimental results and the thermodynamic calculations, it was concluded that 
carbonitride precipitates nucleated at a high temperature, were rich in $\mathrm{Ti}$ and $\mathrm{N}$, but lean in $\mathrm{C}$. As the temperature decreased, successive $\mathrm{Ti}(\mathrm{C}, \mathrm{N})$ precipitate layers nucleated on the TiN rich cores, followed by layers richer in $\mathrm{C}$ and leaner in $\mathrm{N}$. $\mathrm{Nb}$ then started to precipitate, to give $(\mathrm{Ti}, \mathrm{Nb})(\mathrm{C}, \mathrm{N})$ in the outer particle layers. Eventually, when $\mathrm{N}$ was exhausted from the matrix, a second set of precipitates, $(\mathrm{Ti}, \mathrm{Nb}) \mathrm{C}$ rich in $\mathrm{Nb}$, nucleated homogeneously, on lattice defects or on existing carbonitrides. These sequences are illustrated in Fig.20, taken from Kapoor et al., ${ }^{75}$ and agree in part with similar experimental precipitate compositional data collected by Baker et al. ${ }^{128}$ using PEELS with EDX, and Shanmugam et al. ${ }^{144}$ Similar observations were recorded by Li et al. ${ }^{145}$ investigating the precipitate evolution in a TMP microalloyed steel containing $0.09 \mathrm{C}-0.025 \mathrm{Nb}-0.03 \mathrm{~V}-0.011 \mathrm{Ti}-0.0037 \mathrm{~N}$. SEM, TEM and SAED was used to characterise precipitates. The first to form were cuboidal TiN, 200-500nm and $(\mathrm{Ti}, \mathrm{Nb}) \mathrm{CN}$, both considered to remain undissolved in austenite, following heating to $1200^{\circ} \mathrm{C}$. These were followed by carbides of $\mathrm{Nb}$ and /or $\mathrm{V}$, which decreased to a size range of $2-15 \mathrm{~nm}$, as the FRT decreased from $660^{\circ} \mathrm{C}$ to $540^{\circ} \mathrm{C}$.

Fig 20 near here

Kapoor et al. ${ }^{75}$ analysed moiré fringes associated with some of their precipitates, which implied they were mixed $(\mathrm{NbV}) \mathrm{C}$, with a $\mathrm{V}$ to $\mathrm{Nb}$ ratio of 0.534 and a lattice parameter of $0.433 \mathrm{~nm}$, someway between $\mathrm{VC}, \mathrm{a}=0.421 \mathrm{~nm}$ and $\mathrm{NbC}, \mathrm{a}=0.447 \mathrm{~nm}$. The carbides did not obey BakerNutting or Nishiyama-Wassermann orientation relationships with ferrite. Also, no Ti was found in the smaller precipitates which nucleated at lower FRT.

\section{Interphase precipitation}

Microstructural studies on MA steels have shown that banded precipitate dispersions arise during the $\gamma \rightarrow \alpha$ transformation when the alloy carbides, nitrides and carbonitrides are repeatedly nucleated at the $\gamma / \alpha$ interfaces as they move through the austenite 
grains. This is known as interphase precipitation, and previous research ${ }^{135,136}$ showed that two major types occur,

- discrete, Fig 21 a, and

- fibrous precipitation, Fig.21b,

the latter first reported by McCann and Ridal. ${ }^{146}$

Discrete precipitation was summarized by Jang et al. ${ }^{147}$ who stated that ' the characterisitic feature is the fine dispersion of precipitate particles observed as regular rows in thin foils examined using TEM,Fig. 21a, all of which usually have the same crystallographic BNOR (Baker -Nutting orientation relationship), Table 6, in any given ferrite grain. The process is for the most part associated with a mechanism in which the $\alpha / \gamma$ interface is translated by the propagation of steps, with the particles precipitating on the stationary, immobile component of the interface, because the steps themselves move too rapidly to allow successful nuclei to develop.'

\section{Figs 21a and 21b near here}

The same precipitate row interphase formation as that reported for MA steels containing niobium ${ }^{13,14,148,149}$ or vanadium, ${ }^{146,150}$ was found in the titanium containing steels, first studied by Freeman and Honeycombe. ${ }^{151,152}$ Table 15 gives the compositions of the three laboratory steels studied. Nitrogen content was between 10 and 45ppm.

\section{Table 15 near here}

Direct transformation of austenite to ferrite by subcritical isothermal transformation occurred in the range $600-800^{\circ} \mathrm{C}$. Electron microscopy showed that titanium carbide occurred in a fine banded form during the $\gamma \rightarrow \alpha$ transformation, the dispersion parameters being very dependent on 
the transformation temperature. The particles measured by field ion microscopy were found to be $2-5 \mathrm{~nm}$ in size.

Yen et al. ${ }^{153}$ investigated the crystallography and morphology of TiC particles in an experimental steel containing $0.10 \mathrm{C}-0.10 \mathrm{Si}-1.43 \mathrm{Mn}-0.185 \mathrm{Ti}-41 \mathrm{ppmS}$, (N was not given), cast and rolled to $30 \mathrm{~mm}$ thick plate. Using a deformation dilatometer the specimens were austenitsed at $1200^{\circ} \mathrm{C}$, and isothermal heat treatments (IHT) were conducted at $755^{\circ} \mathrm{C}$ for various times followed by quenching. A detailed study was carried on specimens using SAED and HRTEM, based on moiré patterns,(i) after short IHT, $\leq 60 \mathrm{~min}$, and (ii) long IHT,3 days. This showed that after short times, the fine plate-like TiC precipitate/ $\alpha$ - matrix OR was close to the BNOR, but after long times, the coarser plate- like TiC possessed an OR near a NWOR with respect to the ferrite matrix. This was an identical result to that found by Chechenin et al. ${ }^{137}$ for TiN precipitated in ferrite.

Dunne ${ }^{154}$ pointed out that the many studies by Honeycombe and co-workers, summarized by Edmonds and Honeycombe, ${ }^{130}$ usually involved highly alloyed ternary or quaternary laboratory steels, which were often studied in the isothermally treated condition, producing high volume fractions of precipitates. This research was undertaken to elucidate the fundamental mechanisms of interphase precipitation, but also sought processing conditions giving the highest strength. At the time, this work was derided by many in the steelmaking industry as having no practical use and just another example of how out of touch academics were with the real world. The recent advances in sheet steel for automotives, which is based on Ti-Mo MA steels in which interphase precipitation is an important microstructural feature, vindicates the approach taken by Honeycombe.

\section{Random precipitation from supersaturated ferrite}


At temperatures below those giving rise to interphase precipitation, random precipitation,Fig.22, occurs from supersaturated ferrite. ${ }^{157}$ This is particularly the case in as-cooled or as-rolled steels, as distinct from isothermally-treated MA steels.

\section{FIG.22 near here}

Random precipitation may be nucleated within the matrix and is often associated with dislocations, described as strain-induced precipitation (SIP), following controlled rolling at lower temperatures. It is well established that the onset of precipitation is greatly enhanced by deformation. The effect of a titanium addition on SIP of $\mathrm{NbC}$ in simulated deformed $0.047 \% \mathrm{Nb}$ and $0.043 \% \mathrm{Nb}-0.016 \% \mathrm{Ti}$ steels was explored by Hong et al. ${ }^{155}$ using two-stage interrupted compression tests. They found that the size of $\mathrm{NbC}$ formed in $\mathrm{Nb}$-Ti steel was smaller than in the

$\mathrm{Nb}$ steel, and that the precipitation start time in the $\mathrm{Nb}$-Ti steel was delayed, compared to that of the $\mathrm{Nb}$ steel,Fig.23. After reheating the $\mathrm{Nb}$-Ti steel at $1250^{\circ} \mathrm{C}$, undissolved Ti-rich $(\mathrm{Ti}, \mathrm{Nb})(\mathrm{C}, \mathrm{N})$ particles were located at prior austenite grain boundaries, resulting in a finer austenite grain size of $130 \mu \mathrm{m}$, compared to $180 \mu \mathrm{m}$ of the $\mathrm{Nb}$ steel. This topic is expanded when thin slab direct charged Ti steels are discussed later in this review.

\section{Fig 23 near here}

An absence of SIP of $\mathrm{NbC}$ was observed by Ma et al. ${ }^{156}$ in a conventional hot rolled Nb-Ti microalloyed X90 strip. Quantitative analysis using TEM and 3D APT indicated that epitaxial growth of $\mathrm{NbC}$ on pre-existing TiN particles, with a small inter-particle spacing of $300 \pm 65 \mathrm{~nm}$, suppressed SIP of $\mathrm{NbC}$ on dislocations. The model for predicting kinetics of SIP of $\mathrm{NbC}$ on dislocations was incorporated into a criterion for the end of nucleation of SIP, allowing an estimate of the effects of processing parameters on the suppression of strain-induced precipitation of $\mathrm{NbC}$. Control of TiN particle inter-spacing was identified as the key parameter influencing the precipitation behaviour of $\mathrm{NbC}$ during thermomechanical controlled processing. 
The authors ${ }^{156}$ concluded that TiN-NbC composite precipitates offered an alternative approach to $\mathrm{SIP}$ of $\mathrm{NbC}$ for high temperature processing of $\mathrm{Nb}$ microalloyed steels requiring a high toughness.

\section{Control of strength and toughness through microstructure}

Several well-established microstructural characteristics, which are known to control both the strength and toughness properties in polycrystals, including steels, are grain size, precipitates/inclusions and dislocations. ${ }^{1,5,13,44,45}$ The first in-depth understanding of these interrelated features, was based on a series of publications, which included those of Hall, ${ }^{15}$ Petch ${ }^{16-18}$ and Cottrell. ${ }^{158}$ The Hall -Petch equation, (18), concerned initially only with ferrite-pearlite steels, conveniently allows $\sigma_{y}$, the lower yield stress, (or often in practice, the $0.2 \%$ proof stress) to be related to the grain size, $d$ :

$$
\sigma_{y}=\sigma_{o}+k_{y} d^{-1 / 2}
$$

where $\sigma_{o}$ and $k_{y}$ are experimental constants.

$\sigma_{o}$ is usually referred to as the friction stress, ${ }^{16}$ and includes features which arrested the motion of dislocations across the grains. Problems associated with the determination of $\sigma_{o}$ have been discussed in detail by Baker. ${ }^{159}$ These included strain fields from misfitting solute atoms in solid solution $\left(\sigma_{s s}\right)$ incoherent precipitates $\left(\sigma_{p}\right)$ and other 'forest' dislocations $\left(\sigma_{d}\right)$. Other features which may play a role are sub-grain sizes $\left(\sigma_{s g}\right)$ and texture $\left(\sigma_{t}\right)$ plus the basic lattice PeierlsNabarro component, $\left(\sigma_{i}\right)$. The $\left(\sigma_{p}\right)$ contribution to yield strength in MA steels has usually been considered to be due to the by- passing of incoherent hard precipitates by dislocations, as proposed by Orowan, which here is described as dispersion strengthening. Particles which are coherent with the matrix can be cut by dislocations, and this strengthening mechanism will be described as precipitation hardening, after the distinction made amongst others, by Ardell. ${ }^{120}$ There has always been controversy surrounding the Hall-Petch equation. A recent paper by Li et al. ${ }^{160}$ concludes that 'it is clear that there is neither experimental nor theoretical evidence for the 
60 year old Hall-Petch (equation,which) is a valid empirical relation and as such, is useful for prediction -for interpolation and extrapolation-whether or not it is theorectically correct.' This is how it will be considered in this paper.

With the recent developments in the characterisation of precipitates in the size range of 1$10 \mathrm{~nm}$, the importance in many applications including the recent surge of interest in automotive steels, discussed below, of not just mean size, $2 \bar{r}$, also described as the average particle diameter, but also the volume fraction, f. Fig. 24, taken from Gladman, ${ }^{80}$ shows the general effect on dispersion strengthening through changes in incoherent precipitate size and volume fraction, including the overestimate using the original Orowan equation, and the closer estimate given by the modifications made by Ashby. ${ }^{45}$ This equation predicts $\sigma_{\mathrm{p}}$ values $>250 \mathrm{MPa}$ when precipitates are $\sim 5 \mathrm{~nm}$ diameter. However, as discussed below, the combined effect of small $2 \overline{\mathrm{r}}$ and large $\mathrm{f}$, have a profound influence on $\sigma_{p}$.

\section{Fig 24 near here}

The Ashby-Orowan equation, as modified for iron alloys,

$$
\sigma_{p}(M P a)=5.9 f / 2 \bar{r}\left(\ln (2 \bar{r}) / 2.5 \times 10^{-4}\right)
$$

is applied to TiC precipitates in Fig. 25, taken from Seto et al. ${ }^{161}$

\section{Fig 25 near here}

A recalculation in Fig.25, based on the Ashby-Orowan equation, shows the significance of volume fraction together with particle size, on the estimated increases in dispersion strengthening. A reduction in TiC particle size from $10 \mathrm{~nm}$ to $1 \mathrm{~nm}$, together with an increase in the amount of carbon precipitated, predicted a maximum $\sigma_{\mathrm{p}}$ for $10 \mathrm{~nm}$ particles at $0.02 \% \mathrm{C}$ as $\mathrm{TiC}$, but the graph for $1 \mathrm{~nm}$ particles continues to climb as $\% \mathrm{TiC}$ increases.

The linear summation of these components leads to the relationship:

$$
\sigma_{o}=\sigma_{i}+\sigma_{s s}+\sigma_{p}+\sigma_{d}+\sigma_{s b}+\sigma_{t}
$$




$$
\text { giving } \quad \sigma_{y}=\sigma_{i}+\sigma_{s s}+\sigma_{p}+\sigma_{d}+\sigma_{s b}+\sigma_{t}+k_{y} d^{-1 / 2}
$$

For microstructures with large dislocation densities and copious precipitation, alternative means of summation have been recommended. ${ }^{157,159,162,163 .}$

Petch $^{17,18}$ was the first to attempt to relate impact toughness to microstructure in terms of grain size. Equation 21 takes the same form as the well-established Hall-Petch relationship, equation (18), only here the impact transition temperature $T_{c}$ in ${ }^{\circ} \mathrm{C}$ is related to $d$ through

$$
T_{c}=T_{o}-K_{y} d^{-1 / 2}
$$

where $T_{o}$ and $K_{y}$ are constants. This classic work ${ }^{18}$ did not include the influence of carbide films usually present at the ferrite grain boundaries in steels. In a later paper, Petch ${ }^{164}$ refined his ideas to include the effects of both grain size and carbide thickness. However, he pointed out that over a $d^{-1 / 2}$ range of 3-10 $\mathrm{mm}^{-1 / 2}($ i.e. $100-10 \mu \mathrm{m})$ and with some carbide refinement concurrent with grain refinement, equation (21) can be used. With a finer grain size, as in microalloyed steels, where $\mathrm{d}$ is in the range 10 to $3 \mu \mathrm{m}\left(d^{-1 / 2}\right.$ range of $\left.10-18 \mathrm{~mm}^{-1 / 2}\right)$, then equation (22) gives a more accurate assessment of $T_{c}$.

$$
5.5 T_{c}=770-46 d^{-1 / 2}-\sigma_{c}
$$

where $\sigma_{c}$ is the cleavage strength. The derivation of equation (22) is discussed in detail by Petch. ${ }^{164}$

It has long been recognized that dispersed, hard, incoherent particles can either retard or accelerate recrystallization of a metallic matrix ${ }^{165}$, affirmed by the work of Doherty and Martin. ${ }^{166}$ Zener was the first to devise a relationship involving a dispersion of particles and the retarding force which they exerted on a grain boundary. The effect, after his original analysis, is known as the Zener drag and was first published as an appendix to a paper by Smith. ${ }^{167}$ Zener proposed that the driving pressure for grain growth due the curvature of the grain boundary would be counteracted by a pinning (drag) pressure exerted by the particles on the boundary. Consequently, 
normal grain growth would be completely inhibited when the average grain size reached a critical maximum grain radius, also known as the Zener limit, $\left(R_{c}\right)$ given by:

$$
R_{c}=4 \bar{r} / 3 f
$$

Here $f$ is the volume fraction of the particles and $r$ their average radius. Zener considered that both grains and particles could be approximated to spheres. In its general form the Zener Equation is given as :

$$
R_{c}=K_{g} r / f^{m}
$$

where $K_{g}$ is a dimensionless constant and $m$ an index for $f$.

However, the model has been shown to overestimate $R_{c}$ when compared with experimental data. ${ }^{168}$ Several other models have been produced, collated and critically reviewed. ${ }^{169,170}$ The most extensive consideration of the many modifications proposed to the Zener equation has been undertaken by Manohar et al., ${ }^{171}$ who examined in detail some 32 models published up

\section{Fig 26 near here}

to 1987. Their conclusions are summarized in Figs. 26 and 27. Data taken from these models is plotted in Fig.26, which shows that $R_{c} / r$ as a function of $f$ results in the data falling into three bands for the exponents $\mathrm{m}=0.33,0.5$ and 1.0.In addition, for the range of particle volume fractions commonly found in engineering materials $\left(f=10^{-4}\right.$ to $\left.10^{-2}\right)$, values of $R_{c}$ for $m=0.33$, also fall within the band $m=0.5$, and all the bands in this range of $f$ overlap. The dashed line in Fig.26 shows the limiting grain radius for $K_{\mathrm{g}}=0.17$ and $m=1$, values which are close to those given by a number of equations in the 32 models considered. Furthermore, Manohar et al. ${ }^{171}$ collated experimental grain growth data from a variety of materials which were then used to examine the models. These are plotted in Fig. 27 and show that a number of the data closely follow the line for $K_{g}=0.17$ and $m=1.0$, particularly at lower volume fractions. The authors conclude that for systems where $\mathrm{f}$ is less than $0.05, K_{g}=0.17$ and $m=1$ are a reasonable choice.

\section{Fig 27 near here}


In general, the pinning of sub-grain and high-angle grain boundaries ${ }^{168,172}$ have been shown to occur when the particle radius, $r$, is in the size range $30-800 \mathrm{~nm}$, and particle volume fraction (f) less than 0.01

There also exists a body of experimental evidence to show that in steels, particles, particularly carbides, nitrides and oxides $>0.5 \mu \mathrm{m}$ with interparticle spacings also $>0.5 \mu \mathrm{m}$, can lead to acceleration of recrystallization due to nucleation of new grains at carbide particles ${ }^{173}$ and at oxide slag inclusions. ${ }^{174}$ These particles are assumed to create lattice curvature at particle matrix interfaces in the deformed matrix, which enhances recrystallization and gives rise to accelerated recrystallization.

Depending on the composition of the steel, titanium additions have been shown to precipitate compounds which have a strong pinning effect on austenite grain boundaries. Vega et al. ${ }^{175}$ studied the role of TiN precipitates in influencing the recrystallization in austenite during rolling of four steels with composition in the range $0.13 \mathrm{C}-1.2 \mathrm{Mn}-0.32 \mathrm{Si}-0.018-0.047 \mathrm{Ti}$ $0.0043-0.0083 \mathrm{~N}$. They used torsion testing to simulate rolling, and determined and compared the pinning forces exerted by TiN particles based on Gladman's ${ }^{169}$ approach, with the driving forces for recrystallization determined for each of 20 rolling passes. TiN particles were in two ranges; fine 14-65nm and coarse 1.3-2.6 $\mu \mathrm{m}$. The driving forces were found to be approximately two orders of magnitude higher than the pinning forces. This explained why little hardening of austenite occured in their steels and why the accumulated stress prior to the $\gamma \rightarrow \alpha$ transformation was insufficient to refine the ferrite grains.

In certain conditions, titanium may be considered as a replacement for niobium for this purpose ${ }^{173}$ However, in industrial processes, the aim is to take most of the carbide, nitride and carbonitride particles precipitated on cooling from the casting stage into solution during the soaking treatment, prior to hot rolling. This should be attained without allowing excessive austenite grain growth, which would give problems with later processing to achive a fine ferrite 
grain size.As shown in Fig.14,TiN requires the highest solution temperature of the titanium compounds normally found in steels, just below ZrN,Fig.28.

This is highlighted in the work of Gomez et al. ${ }^{176}$ who also used torsion testing to study the effects of $\mathrm{Nb}, \mathrm{V}, \mathrm{Ti}$ and $\mathrm{Al}$ on recrystallisation/precipitation interactions in MA steels. They found that for a steel containing $0.094 \mathrm{C}-1.48 \mathrm{Mn}-0.3 \mathrm{Si}-0.018 \mathrm{Ti}-0.008 \mathrm{~N}$, soaking at $1300^{\circ} \mathrm{C}$ was too low a temperature to take the TiN precipitates present in the parent steel into solution. This resulted in a refined austenite grain size of $38 \mu \mathrm{m}$ compared with $150 \mu \mathrm{m}$ for an $0.09 \mathrm{~V}$ steel, $110 \mu \mathrm{m}$ for an $0.034 \mathrm{Nb}$ steel and $550 \mu \mathrm{m}$ for an $\mathrm{Al}$ steel of corresponding compositions. However, due to the large difference in average precipitate size, VN $10.5 \mathrm{~nm}, \mathrm{NbCN} 22 \mathrm{~nm}, \mathrm{AlN}$ $87 \mathrm{~nm}$ and TiN $1250 \mathrm{~nm}$, inhibition of austenite recrystallization (plateau) was longer for $\mathrm{V} / \mathrm{Nb}$-microalloyed steels than for Al-steels, mainly due to their different precipitate sizes. This inhibition was not displayed in Ti-steel phases.

\section{Fig 28 near here}

\section{Grain refining of austenite through additions of titanium}

The grain refining of austenite through additions of aluminium, niobium, titanium, vanadium and zirconium was established by the 1960 's. ${ }^{177-181}$ As pointed out by George and Irani, ${ }^{181}$ most of the early research concerned with precipitation in titanium steels, was concentrated on the carbide.Halley ${ }^{182}$ compared the effects on the grain coarsening temperature of aluminum, titanium and zirconium additions in a carbon steel, in probably the first study on grain growth inhibition due to particles, or inclusions.

\section{Fig 29 near here}

Figure 29 is redrawn from his paper, and shows a clear influence of the analyzed percentage of titanium on the mean of the grain coarsening temperature. This paper was published in 1946, several years before viewing of these particles was possible, and several decades before 
analytical TEM could both resolve and analyze the 'inhibitors'. The discussion of the paper considered the possibility of oxide or sulphide particles controlling the grain size. However, Halley was firmly of the opinion that titanium carbides were the inhibitors. It should be noted that the steels studied contained $\sim 0.3 \% \mathrm{C}$. At this time, it was not normal to analyze the nitrogen level.

Probably the first to consider the influence of titanium nitride particles on austenite grain refinement were George and Irani ${ }^{181}$ in 1968. They studied a series of 21 laboratory steels, produced as 9 or $22 \mathrm{Kg}$ vacuum melted casts, which included Ti steels $(0.027-0.040$ or $0.013-$ $0.018 \mathrm{Ti})$ ), and Ti-Nb steels ( $\sim 0.015$ or $\sim 0.033 \mathrm{Ti}: \sim 0.028$ or $\sim 0.034 \mathrm{Nb})$ with $\sim 0.017 \mathrm{~N} . \mathrm{C}$ varied between 0.03 and 0.10 .Ferrite grain sizes between $10.5 \mu \mathrm{m}$ and $15 \mu \mathrm{m}$ were determined following grain coarsening temperature, $\mathrm{T}_{\mathrm{GC}}$, experiments, by holding steels for $30 \mathrm{mins}$ between $1050{ }^{\circ} \mathrm{C}$ and $1250^{\circ} \mathrm{C}$, before air cooling to ambient. The highest $\mathrm{T}_{\mathrm{GC}}, \sim 1200{ }^{\circ} \mathrm{C}$, was obtained in Ti steels with low Ti/ $\mathrm{N}$ ratios, 1.3 to 2.4 , and also in Ti-Nb steels, 0.65 to 1.64. Xray diffraction and chemical analysis was undertaken on residues after heating between $1000{ }^{\circ} \mathrm{C}$ and $1250^{\circ} \mathrm{C}$, followed by quenching to ambient. Only TiN precipitates $(\mathrm{a}=0.4234 \mathrm{~nm})$ were detected in the low $\mathrm{Ti} / \mathrm{N}$ ratio steels. However, in steels of high $\mathrm{Ti} / \mathrm{N}$ ratios, both $\mathrm{TiN}$ and $\mathrm{TiC}$ phases $(a=0.418 \mathrm{~nm})$ were identified, in line with thermodynamic predictions. George and Irani $^{181}$ also found that 'in steels with the highest $\mathrm{T}_{\mathrm{GC}}$, almost all the titanium was combined as TiN precipitates, and none was available for subsequent precipitation as TiC.' Coarse particle sizes, 0.6 to $7.5 \mu \mathrm{m}$, were measured using optical microscopy, while fine particle size distributions, 5-80nm, were determined by TEM. However, when both TiN and TiC precipitates were present, lower $\mathrm{T}_{\mathrm{GC}}$ data were recorded than for $\mathrm{TiN}$ precipitates alone. A summary of the distribution of fine particles is presented in Fig.30. In samples heated below $\mathrm{T}_{\mathrm{GC}}$, the particle size distribution curve shows a pronounced peak, seen in each case in Fig.30. The authors point out that many of their particle sizes of up to $0.5 \mu \mathrm{m}$, are significantly smaller than those reported 
by Gladman, ${ }^{172}$ for steels containing niobium or aluminium, with $\mathrm{T}_{\mathrm{GC}}$ of $\sim 1050^{\circ} \mathrm{C}$. The higher $\mathrm{T}_{\mathrm{GC}}$ temperatures seen in Fig30 occurred with low Ti-high $\mathrm{N}$ steels having a dense dispersion of TiN precipitates.

\section{Fig 30 near here}

Cuddy and Raley ${ }^{170}$ extended Halley's work, measuring the austenite grain size and recording the $\mathrm{T}_{\mathrm{GC}}$ of 28 vacuum melted steels containing $0.053-0.079 \mathrm{C}, 0.001-0.009 \mathrm{~N}$, with additions of aluminium, niobium, titanium or vanadium. Six steels contained additions of titanium, two with 0.059 or $0.22 \mathrm{Ti}$ were designed to precipitate $\mathrm{TiC}$ particles, and four with $0.016-0.020 \mathrm{Ti}$ to nucleate TiN particles. Figure 31 is a graph of $\mathrm{T}_{\mathrm{GC}}$ versus microalloy concentration, showing that the most effective additions were those of titanium, combined as TiN and the least effective, VN. It was found that austenite grains, with a mean size of $20 \mu \mathrm{m}$ after holding for $15 \mathrm{~min}$ in the range $1200-1250^{\circ} \mathrm{C}$, were pinned by $\mathrm{TiN}$ particles averaging $10 \mathrm{~nm}$, measured by TEM,after extraction by carbon replicas. ${ }^{170}$ The two readings for TiC particles were close to the $\mathrm{NbCN}$ data.

\section{Fig 31 near here}

It is interesting to note that the titanium steel studied by Phillips and Chapman ${ }^{180}$ contained $0.02 \mathrm{Ti}$ and $0.16 \mathrm{C}$, and it also contained $0.007 \mathrm{~N}$. At $1227 \mathrm{~K}, \Delta \mathrm{G}$ of $\mathrm{TiN}$ is $196 \mathrm{~kJ}$ and of TiC is $167 \mathrm{~kJ}$, which means that titanium would first combine with nitrogen. Also, it is likely that titanium carbonitride would form in austenite. Furthermore, based on binary compounds, there should be $\sim 0.0094 \% \mathrm{TiN}$ and $0.022 \mathrm{TiC}$ i.e. $2 / 1: \mathrm{TiC} / \mathrm{TiN}$, but more probably combined as lowN and high $\mathrm{C}$, Ti (C,N). This could also apply to the steels studied by Cuddy and Raley. ${ }^{170}$

While many of the early studies assessing the effects of titanium additions in MA steels tended to concentrate on the role of titanium carbides and nitrides on austenite grain refinement, quenched and tempered (Q\&T) treatments were also explored as a means of increasing strength 
through what is described as secondary hardening. This was reported as early as 1935 in a paper by Houdremont et al. ${ }^{183}$ which however, concentrated mainly on vanadium steels.

Haynes and Baker ${ }^{184}$ compared two groups of steel compositions based on:

- $\quad 0.14 \mathrm{C}-1.4 \mathrm{Mn}-0.04 \mathrm{Ti}-0.005 \mathrm{~N}$ and

- $0.11 \mathrm{C}-1.26 \mathrm{Mn}-0.53 \mathrm{Ti}-0.002 \mathrm{~N}$.

The steels were vacuum melted, heated to $1200^{\circ} \mathrm{C}$, forged and then rolled to $16 \mathrm{~mm}$ dia. bar. Slices were solution treated at $1300^{\circ} \mathrm{C}$, quenched in brine, tempered in evacuated quartz capsules in the range $500-700^{\circ} \mathrm{C}$ for between 0.1 and $100 \mathrm{~h}$,before water quenching. Using an equation taken from Irvine at al., ${ }^{76}$ solution temperatures for $\mathrm{TiC}$ were calculated to be $968^{\circ} \mathrm{C}$ and $1484^{\circ} \mathrm{C}$ for the two steel compositions, with corresponding precipitate volume fractions of $0.08 \%$ and $0.87 \%$, representing $100 \%$ and $64 \%$ of $\mathrm{TiC}$ dissolved at $1300^{\circ} \mathrm{C}$. The maximium secondary hardness of $470 \mathrm{Hv}$ was similar to that obtained by Kuo ${ }^{185}$ as a result of what was described as 'alloy carbides precipitated during the 4th stage of tempering.' This developed during tempering for $3.5 \mathrm{~h}$ at $550^{\circ} \mathrm{C}$ or $0.6 \mathrm{~h}$ at $600^{\circ} \mathrm{C}$ due to fine particles of both $\mathrm{TiC}$ and $\mathrm{Fe}_{3} \mathrm{C}$. As part of the study on interphase precipitation in titanium steels described earlier by Freeman and Honeycombe, ${ }^{152}$ these authors compared the proof stress(PS) of isothermally transformed steels, whose composition is given in Table 15,with those quenched and tempered over the same temperature range of $600^{\circ} \mathrm{C}-850^{\circ} \mathrm{C}$, following solution treatment at $1250^{\circ} \mathrm{C}$. The graphs in Fig.32, show that the $\mathrm{Q}+\mathrm{T}$ steel $\mathrm{B}$, tempered at $650^{\circ} \mathrm{C}$, had a maximum $0.2 \% \mathrm{PS}$ of $\sim 1100 \mathrm{MPa}$, which converts to a hardness ${ }^{186}$ of $520 \mathrm{Hv}$, slightly higher than that obtained by Haynes and Baker. ${ }^{184}$

\section{Fig 32 near here}

Predicting possible future strength levels of MA steels, Freeman and Honeycombe ${ }^{152}$ concluded by writing that 'bearing in mind that these Ti steels are high-purity laboratory melts, it seems clear that yield stresses of $600-750 \mathrm{MPa}$ can easily be achieved in commercial Ti steels by 
controlled rolling and subsequent fast cooling to give both a fine grain size and a fine dispersion of TiC.'These figures were significantly higher than those determined for controlled rolled MA steels at this time.

More recently, Wei et al. ${ }^{187}$ used high resolution TEM to study the crystallography and morphology of TiC particles precipitated in Q\&T 0.05C-0.20Ti -2.0Ni steel.Plate-like precipitates with thicknesses up to $20 \mathrm{~nm}$ were observed after tempering between $550^{\circ} \mathrm{C}$ and $800^{\circ} \mathrm{C}$, always obeying the BNOR (Table 6) to within $\sim 5^{\circ}$. Similar OR were previously deduced by Freeman ${ }^{151}$ and Yen et al. ${ }^{153}$ The presence of interfacial misfit dislocations was revealed by examining the excess lattice fringes terminating at the interfaces between the $\mathrm{TiC}$ platelet and the ferrite matrix. The location and number of the excess lattice fringes terminating at the broad plane and the lateral interface were consistent with the mismatch in the atomic arrangement between the BNOR between TiC and ferrite.

\section{Multiple alloying additions in MA steels}

The design of MA steels containing multiple alloying additions, capable of forming complex precipitates with different roles such as austenite grain refinement, dispersion strengthening,modifying particle morphology to a less deleterious shape and reducing particle coarsening, has become more common over the past twenty years. From the above consideration of the microstructural aspects, which in general, control strength and toughness of polycrystalline alloys, it is apparent that if the aim is to produce a ferrite matrix, then two separate groups of particles with different sizes and volume fractions are required to achieve the maximum benefit from microalloying in carbon steels. Manohar et al. ${ }^{171}$ confirmed that the pinning of sub-grain and high-angle grain boundaries, considered above, occurred when the particle radius, $r$, is in the size range $30-800 \mathrm{~nm}$, and particle volume fraction $f<0.01$. On the other hand, Seto et al. ${ }^{161}$ in a recalculation of the dispersion strengthening contribution to the yield strength, showed in Fig.25, the significance of a large volume fraction of small particles. 
A reduction in $\mathrm{TiC}$ particle size from $10 \mathrm{~nm}$ to $1 \mathrm{~nm}$, together with an increase in the amount of carbon precipitated as $\mathrm{TiC}$, gave rise to a substantial increase in $\sigma_{\mathrm{p}}$. In MA steels, the alloying additions provide an opportunity for the steelmaker to control the final ferrite grain size through refinement of the austenite grain size during controlled rolling, sometimes including an accelerated cooling process. On the other hand,dispersion strengthening normally depends on precipitation in ferrite, either (a) as strain induced precipitation (SIP) through particles nucleating on dislocations which are then prevented from being involved in a recovery process by particle pinning, or (b) by interphase precipitation, discussed above. Using either routes (a) and (b) to achieve a small particle dispersion, depends on restricting the coarsening of particles, also known as Ostwald ripening, as any process which reduces the spacing between two particles regarded as obstacles to dislocation movement, will affect the strength. The particle stability at high temperatures is an important factor. For example, Roy et al. ${ }^{188}$ have studied recently a complex HSLA steel containing 0.09C-1.42Mn-0.003S-0.035Al-0.050Nb-0.019Ti$0.05 \mathrm{~V}-0.008 \mathrm{~N}$, which was continuously cast and controlled rolled. They found abnormal grain growth, AGG, occurred at different soaking temperatures for as-cast $\left(\sim 1200^{\circ} \mathrm{C}\right)$ and as rolled plates $\left(\sim 1000^{\circ} \mathrm{C}\right)$, a variation not reported previously. This difference was explained by the presence of coarse complex precipitates, such as $(\mathrm{Nb}, \mathrm{Ti}, \mathrm{V})(\mathrm{C}, \mathrm{N})$ and $(\mathrm{Nb}, \mathrm{Ti})(\mathrm{C}, \mathrm{N})$, which remained stable up to $\sim 1150^{\circ} \mathrm{C}$,restricting $\mathrm{AGG}$ in the as-cast state. $\mathrm{NbC}$ and $\mathrm{VC}$ were the main precipitates, $<200 \mathrm{~nm}$ size, present in the as-rolled steel, and the dissolution of $\mathrm{VC}$ at the soaking temperature, $\sim 1000^{\circ} \mathrm{C}$, was believed to be responsible for AGG in the rolled plate. The average measured grain size agreed well with that predict from the formulation devised by Gladman ${ }^{169}$ using TEM measured particle size, and predicted particle volume fractions obtained by Thermo-Calc. ${ }^{188}$

Lifshitz, Wagner and Slyozov (LWS) are considered to be the first to undertake mathematical investigations involving the factors influencing particle coarsening. They related 
the initial particle radius $r_{o}$ to that the particle radius $r_{t}$ after time $t$, and initially stated how a single particle grows in a solution where diffusion of material is the slowest process. Equation (25) describes the situation where the boundary is between small shrinking particles and large growing particles. They finally concluded that the average radius of the particles $\langle\mathrm{r}\rangle$, grows according to an equation similar to equation (25):

$$
\left(\bar{r}_{t}\right)^{3}-\left(\bar{r}_{o}\right)^{3}=k_{m} \frac{8 D \rho V_{m} C_{\alpha}}{9 R T}(\theta)
$$

where $\rho$, is the particle surface tension or surface energy, $\mathrm{C}_{\alpha}$, solubility of the particle material, $\mathrm{V} \mathrm{m}$, molar volume of the particle material, $\mathrm{D}$, diffusion coefficient of the particle material, $\mathrm{R}$, ideal gas constant, T, absolute temperature. The term $k_{m}$ was introduced by Ardell ${ }^{189}$ to take account of the effect of particle volume fraction on particle radius. When $k_{m}$ is unity, for a zero volume fraction of precipitate, the original LWS version of equation (25) holds.However, $k_{m}$ increases to 2 at a volume fraction of $1 \%$, to 5 at $7 \%$ and 10 for $\mathrm{V}$ m equivalent to $25 \%$. While coarsening of particles has been of particular importance in aluminum ${ }^{189,190}$ and nickel based alloys $^{191}$, it has been considered to be less relevant to MA steels.However, for particle volume fractions which might occur in some modern MA steels, $\geq 1 \%$, a significant increase in the rate of particle coarsening may occur.A concise account of Ostwald ripening of precipitates can be found in the book by Martin and Doherty, ${ }^{190}$ while a more recent review ${ }^{191}$ highlights some of the short comings of LWS theory and more recent theories, while still leaving some questions unanswered .

The coarsening behaviour of TiC interphase precipitates in the ferrite of MA steels, has been modelled by Jang et al., ${ }^{192}$ who found 'that coarsening was very sensitive to the $\mathrm{Ti} / \mathrm{C}$ atomic ratio in the steel composition. A slight excess of carbon to that required for the stoichiometric ratio had a dramatic effect on reducing particle coarsening in a ferrite matrix for the Fe-Ti-C system.The concentration of titanium in ferrite at the interface becomes so small that diffusion gradients which drive coarsening become extremely shallow'. 
Among the first to discover the effect of muti-alloying on restraining particle coarsening in an MA steel were Dunlop and Honeycombe. ${ }^{136}$ They investigated three experimental steels, Table 16, prepared from high purity materials, solution-treated at $1300^{\circ} \mathrm{C}$, followed by isothermal transformation in molten tin at $725^{\circ} \mathrm{C}$ for times between $5 \mathrm{~min}$ and $150 \mathrm{~h}$.Interphase precipitation (primary)was present in all three alloys,

\section{Table 16 near here}

Fig 33 near here

Figure 33 shows typical primary disc-shaped particle dispersions, where the finest dispersion, 2nm, in (b) Alloy 2 (V-Ti), has considerably more particles present than the coarsest in (c) Alloy 3 (Ti). The primary particles had a BNOR with ferrite, Table 6, which was also the case for secondary lenticular particles, present after ageing for 50h, Fig. 33d.These are similar to the shapes in Fig.21b. Using convergent beam microdiffraction, the secondary particles, which were found only in Alloys 1 and 2, were shown to be a long range ordered compound, $\mathrm{M}_{6} \mathrm{C}_{5}$, here $(\mathrm{Ti}, \mathrm{V})_{6} \mathrm{C}_{5}$. This led the authors to the conclusion that Alloy 3 may potentially have the best long term stability. The particle size distributions of the three alloys were determined. Fig.34c, and Fig.33 (c) supports this view. However, the 15min. ageing of Alloy2, Fig.34(b), indicates that a significantly smaller mean particle size, $(2.1 \mathrm{~nm})$ was retained in $(\mathrm{Ti}-\mathrm{V})$, which recorded a maximum hardness of $\sim 320 \mathrm{Hv}$. This equates through $\mathrm{Hv} / 0.3=\sigma_{\mathrm{y}}$, to a yield strength of $\sim 1000 \mathrm{MPa}$. Fig 34 is a good illustration of the distortion to an average, one or two high contributions can make, comparing the particle size distributions in alloys 1 and 2 with 3, in Fig 34.

\section{Fig 34 near here}

The reduced particle coarsening kinetics observed in the laboratory scale Ti-V microalloyed steels, reported by Dunlop and Honeycombe, ${ }^{136}$ has been shown to be repeated in some Ti-Mo 
steels with industrial applications. Heavy gauge MA hot rolled steels, with a tensile strength of 440-590MPa, are frequently used to meet weight reduction requirements for suspension and chassis parts in automobiles. In addition to the strength and rigidity requirements, the MA steels need sufficient elongation and hole expansionability to allow these units to be produced by complex stretch-forming operations. Following investigations on laboratory steels using a thermomechanical treatment based on that shown in Fig.35, Funakawa et al. ${ }^{193}$ achieved a $\sigma_{\mathrm{y}}$ of $730 \mathrm{MPa}$ in a mill trial steel containing $0.047 \mathrm{C}-1.59 \mathrm{Mn}-0.2 \mathrm{Mo}$ and $0.082 \mathrm{Ti}$. Mn was added to lower the $\mathrm{Ar}_{3}, \gamma \rightarrow \alpha$ transformation temperature, reducing the growth rate of titanium carbides, while Mo was included to retard the deposition of both pearlite and large cementite particles at grain boundaries. With processing schedules similar to that in Fig.35, a dispersion of $\sim 3 \mathrm{~nm}$ (Ti, Mo)C particles, with a Ti/Mo atomic ratio of 1.16, was reported. Using an equation comparable to equation 19 , this dispersion was calculated to provide a contribution $\sigma_{\mathrm{p}}$ of $\sim 300 \mathrm{MPa}$.

Fig 35 near here

The reduced MC (metal/carbide) precipitation coarsening kinetics in austenite, due to the addition of Mo to Ti MA steels, has been the subject of several studies since the initial work of Funakawa et al. ${ }^{193}$ In a series of well executed investigations, Wang et al. ${ }^{194}$ have considered in detail the evolution of precipitation of $(\mathrm{Ti}, \mathrm{Mo}) \mathrm{C}$ particles. They have summarized the mechanisms considered responsible for this phenomenon of type II precipitates, described by Lui and Jonas, ${ }^{119}$ including

- weakened diffusivity of Ti atoms in the matrix due to Mo atoms, ${ }^{195}$

- decelerated diffusion of Ti atoms into particles due to solute drag effect of Mo atoms at the particle/ matrix interface ${ }^{196}$,

- reduced concentration of Ti due to partial substitution by Mo ${ }^{197}$, and

- decreased misfit strain at the particle /matrix interface due to Mo incorporation. ${ }^{198}$ 
Mo enrichment is reduced after reheating and soaking at $1100^{\circ} \mathrm{C}$. In similar work on $\mathrm{Nb}-$ Mo steels, Enloe et al. ${ }^{199}$ using APT, found their experimental results in general agreement with thermodynamic predictions based on an ideal solution model, with a substantial Mo level incorporated into Nb-rich carbonitrides in ferrite, but very little Mo incorporation into Nb-rich precipitates in austenite, although Mo was detected in Nb-rich precipitates in austenite held at $900^{\circ} \mathrm{C}$.Here, Mo was only detected in particles $<40 \mathrm{~nm}$, and unlike the (Ti,Mo)C particles, no measurable segregation of Mo occurred to the carbonitride-matrix interface. Wang et al. ${ }^{200}$ found clear evidence that Mo was incorporated into the TiC lattice in austenite, and even at high temperatures, the coarsening of particles was less than that in ferrite. They suggested that coarsening kinetics may be affected by the solute drag effect of Mo atoms which, during the initial stage of coarsening, enriched the surface layers of the complex $(\mathrm{Ti}, \mathrm{Mo}) \mathrm{C}$ particles. This restrained the $\mathrm{MC}$ precipitation due to the higher Gibbs free energy of ( $\mathrm{Ti}, \mathrm{Mo}) \mathrm{C}$ relative to $\mathrm{TiC}$, and in a more pronounced effect, promoted MC precipitation by decreasing the interfacial energy of the MC/austenite system. They argued that compared with TiC particles, the stronger coarsening resistance of ( $\mathrm{Ti}, \mathrm{Mo}) \mathrm{C}$ particles supressed austenite recovery and recrystallization more effectively, maintaining the deformed microstructures at high temperatures. Their two vacuum cast laboratory steels had a composition of $0.04 \mathrm{C}-0.20 \mathrm{Si}-1.5 \mathrm{Mn}-0.10 \mathrm{Ti}-0.002 \mathrm{~N}$, with one containing $0.21 \mathrm{Mo}$. The evolution of $(\mathrm{Ti}, \mathrm{Mo}) \mathrm{C}$ particles formed in austenite after hot deformation at $925^{\circ} \mathrm{C}$ followed by isothermal holding of between 1 and 3000s , as envisaged by Wang et al., ${ }^{200}$ is depicted schematically in Fig. 36.High angle annular dark field scanning transmission microscopy showed that the particles changed morphology during isothermal holding from spherical to octagonal to tetra-kai-decahedral, and finally to an irregular shape, Fig.36. The EDX analysis shows that more Mo counts were detected during the growth stage, mainly from the surface of the particles.

Fig 36 near here 
Fig. 37 shows the variation in particle size as a function of holding time. ${ }^{194}$ The steel without Mo exhibited well- established two stage TiC particle growth characteristics; the growth stage followed by a coarsening stage. The steel containing ( $\mathrm{Ti}, \mathrm{Mo}) \mathrm{C}$ particles displayed three stage growth characteristics, those of $\mathrm{TiC}$, followed by a fast coarsening stage.

\section{Fig 37 near here}

The results discussed above have unleashed a great deal of activity exploring the evolution of precipitation in Ti-Mo steels. One such study involved a comparison of the dispersion strengthening ( precipitation hardening ) in Ti,Ti-Nb and Ti-Mo laboratory vacuum melted steels, investigated under various conditions of continuous and interrupted cooling using dilatometery, by Chen et al. ${ }^{201}$ Their levels of $\mathrm{C}$ at $0.1 \%$ and $\mathrm{Ti}$ at $0.2 \%$ were higher than most other studies, whereas $\mathrm{Nb} 0.04 \% \mathrm{Mo} 0.2 \%$ and $40 \mathrm{ppm} \mathrm{N}$ are similar.For cooling rates below $0.5 \mathrm{Ks}^{-1}$ from $650^{\circ} \mathrm{C}$ to $\mathrm{RT}$, interphase carbide precipitation in ferrite was obtained. The average carbide size decreased from $16 \mathrm{~nm}$, to $13 \mathrm{~nm}$ to $5 \mathrm{~nm}$ for Ti, TiNb and Ti-Mo steels respectively, with corresponding microhardness values of $184 \mathrm{Hv}, 202 \mathrm{Hv}$ and $210 \mathrm{Hv}$. These results are similar to others,reporting the effect on properties by limiting particle coarsening of (Ti, Mo)C precipitates in Ti-Mo steels, which can strongly maintain nanometer-scaled sizes and give the largest contribution to the hardness when compared to $\mathrm{TiC}$, and $(\mathrm{Ti}, \mathrm{Nb}) \mathrm{C}$ precipitates. This conculsion also recognizes that steels strengthened by $(\mathrm{Ti}, \mathrm{Mo}) \mathrm{C}$ precipitates possess excellent thermal stability.

In controlled rolled MA steels, attention has been paid to the combination of additions of titanium and vanadium, titanium and niobium or titanium and niobium and vanadium, with the expectation that the potential of each element will be fully exploited. Most of the work discussed below emphasise that titanium additions are normally made as hypostoichiometric relative to nitrogen, i.e. $<3.4$. This ratio is discussed by Crowther and Morrison, ${ }^{124}$ who explained the effect that titanium additions were observed to have with $\mathrm{Al}-\mathrm{V}$ and $\mathrm{Al}-\mathrm{Nb} \mathrm{MA}$ 
steels, particularly with regard to loss of strength. This was purported to be due to changes in the dispersion strengthening associated with modifications to niobium precipitates. Strid and Easterling ${ }^{202}$ used STEM-EDX microanalysis to investigate the influence on microstructure of precipitate compositions, morphologies and sizes in hot rolled MA steels containing $\mathrm{Ti}, \mathrm{Ti}-\mathrm{V}$ and $\mathrm{Ti}-\mathrm{Nb}$, with different levels of nitrogen. They found that the median ferrite grain sizes in the Ti-Nb steels, 29 and $32.5 \mu \mathrm{m}$, was greater than in the $\mathrm{Ti}(\sim 16 \mu \mathrm{m})$ and $\mathrm{Ti}-\mathrm{V}(13 \mu \mathrm{m})$ steels. In addition, the median particle size, $19 \mathrm{~nm}$, of an $\mathrm{Ti}-\mathrm{Nb}-0.010 \mathrm{~N}$ steel containing predominantly nitrides, showed a coarser size distribution than in a $\mathrm{Ti}-\mathrm{Nb}-0.006 \mathrm{~N}$ steel, where the median particle size of predominantly carbides, decreased to $10 \mathrm{~nm}$. Increasing the aluminium content of their Ti and Ti-V steels from 0.022 to $0.072 \%$ resulted in an increase in the particle size from $\sim 8$ to $\sim 12 \mathrm{~nm}$. These changes had only a minor influence on the yield strength, which reached $377 \mathrm{MPa}$ for the steels with Ti and Ti-V additions, but was not given for those with $\mathrm{Ti}-\mathrm{Nb}$. Strid and Easterling ${ }^{202}$ were unable to quantify the $\mathrm{C}$ or $\mathrm{N}$ levels in this work, and therefore, details of the chemical compositions of the particles were restricted to the transition metals. This problem was overcome to some extent by He and Baker, ${ }^{126}$ who were perhaps the first to use both TEM-EDX, in an EM400, and electron energy loss spectroscopy (EELS) in an HB5 instrument, to characterise their carbonitride precipitates present in an MA steel. They attempted to elucidate the problems associated with additions of titanium in MA steels, which had been reported to have differing effects when used with additions of niobium compared to vanadium. ${ }^{124}$ Following controlled rolling, three steels containing nominally $0.10 \mathrm{C}-1.4 \mathrm{Mn}-0.005 \mathrm{~N}-0.017 \mathrm{Nb}$, with respectively $<0.005,0.010$ or $0.022 \mathrm{Ti}$, were examined. For the different titanium additions, giving different $\mathrm{Ti} / \mathrm{N}$ ratios, a distinct size variation of the $\mathrm{Ti}-\mathrm{Nb}$ carbides and nitrides was observed, especially for the coarser particles. Figure $38 \mathrm{a}$ includes large $\mathrm{Ti}-\mathrm{Nb}$ particles in an $0.01 \% \mathrm{Ti}-\mathrm{Nb}$ steel, with many smaller $\mathrm{Nb}$-rich spheroids, 
while an EELS spectrum, Fig. 38b collected from the centre of a $\sim 20 \mathrm{~nm} \mathrm{Nb}$ rich spheroid, shows the niobium, carbon, nitrogen and titanium edges. ${ }^{126}$

\section{Fig 38 near here}

Using a similar range of techniques to He and Baker, ${ }^{126}$ Subramanian and Weatherly ${ }^{203}$ investigated the precipitation behaviour in $\mathrm{Ti}-\mathrm{V}$ and $\mathrm{Ti}-\mathrm{Nb}$ steels, containing a higher carbon level of $\sim 0.43$. The presence of complex precipitates in as-cast blooms was confirmed; in the $\mathrm{Ti}-\mathrm{V}$ steel, nitrides $\left(\mathrm{Ti}_{\mathrm{x}} \mathrm{V}_{1-\mathrm{x}}\right) \mathrm{N}$ were observed followed at lower temperatures by carbides $\left(\mathrm{V}_{4} \mathrm{C}_{3}\right)$; in the $\mathrm{Ti}-\mathrm{Nb}$ linepipe steel processed from slabs, dense, well dispersed mixed nitrides $\left(\mathrm{Ti}_{\mathrm{x}} \mathrm{Nb}_{1-\mathrm{x}}\right)$, on which epitaxial growth of $\mathrm{Nb}$ rich mixed carbides, were observed. The authors considered that epitaxial growth obviated the need for SIP of mixed carbides. Here, the increase in the volume fraction of precipitates raised the Zener drag force on boundary mobility, thereby retarding recrystallization.

Similar results were found by Baker et al. ${ }^{128}$, and He and Baker ${ }^{126},{ }^{204-206}$ studying controlled rolled $\sim 0.10 \mathrm{C}$ steels containing additions of $\mathrm{Nb}-\mathrm{Ti}-\mathrm{N}$ or $\mathrm{Nb}-\mathrm{Ti}-\mathrm{Zr}-\mathrm{N}$. They observed $\mathrm{NbC}$ or $\mathrm{Nb}(\mathrm{C}, \mathrm{N})$ caps or coatings to nucleate on $(\mathrm{Ti}, \mathrm{Nb}) \mathrm{N}$ core particles (Fig. 12a and $12 \mathrm{~b}$ ), which reduced the niobium available for both grain refinement and dispersion strengthening. An $0.016 \mathrm{Zr}$ addition resulted in complex nitrides, $>100 \mathrm{~nm}$ size, of $\mathrm{Ti}-\mathrm{Zr}$ and $\mathrm{Ti}-\mathrm{Nb}-\mathrm{Zr}$ particles, which appeared to have no effect on $<100 \mathrm{~nm} \mathrm{Ti}-\mathrm{Nb}$ carbonitrides, also present. All the steels had $\sigma_{\mathrm{y}}$ values $\sim 400 \mathrm{MPa}$ with $50 \mathrm{~J}$ IIT of 280 to $100^{\circ} \mathrm{C}$, data similar to that of Carretero Olalla et al. ${ }^{207}$ The presence of caps nucleating on more stable core precipitates has been reported recently. Caps of $\mathrm{Nb}$ rich $(\mathrm{Nb}, \mathrm{Ti}) \mathrm{C}$ were observed to nucleate heterogeneously on undissolved $(\mathrm{Ti}, \mathrm{Nb})(\mathrm{C}, \mathrm{N})$ core particles by Hong et al. ${ }^{155}$ and by Grajcar. ${ }^{208}$ In another work, Beres et al. ${ }^{209}$ found that a $0.03 \mathrm{C}-0.08 \mathrm{Nb}-0.01 \mathrm{Ti} 20 \mathrm{~mm}$ thick plate steel 'produced complex agglomerates with a cubic TiN seed crystal overgrown by a 
cubic $\mathrm{NbC}$ particle'. In some of the studies where core/caps particles were observed, the choice of reheating temperature before processing has been too low to take all of the core precipitate, normally titanium or zirconium based, into solution. While the resultant conglomerate may affect the rate of grain growth, in general, these particles should be avoided through relating the steel composition to higher reheating temperatures.

The above sections have highlighted the renewed interest in MA steels which have transformed by an interphase precipitation route.Many years ago, Baker ${ }^{210}$ among others, reported that ferrite grains in controlled rolled MA steels frequently showed a mixture of interphase and randomly nucleated precipitates, as in Fig.21a. Recently, this dual precipitation mode has been re-examined by Chen et al. ${ }^{211}$ in a hot rolled, accelerated cooled $0.02 \mathrm{C}$ 1.5Mn-0.1Si-0.2Ti-0.2Mo-0.004N-0.002O steel.Samples were sealed in quartz tubes under argon, homogenized for two days at $1250^{\circ} \mathrm{C}$, directly cooled to isothermal ageing temperatures of $625^{\circ} \mathrm{C}$ or $725^{\circ} \mathrm{C}$ and held for $5 \mathrm{~min}$ and $60 \mathrm{~min}$ respectively, before water quenching. Wide ranges of microhardness within ferrite grains were recorded for all conditions:for example,5min at $625^{\circ} \mathrm{C}$ gave $240-420 \mathrm{Hv}$. This scatter was attributed to the varying mixture of interphase ( low Hv) and random (high Hv) precipitates, contributing to each hardness indent. It was recommended that as random precipitation was considered to produce a higher hardness, low isothermal holding temperatures should be used to achieve this distribution. However, the contribution to $\sigma_{\mathrm{p}}$ is based on the interaction of dislocations with incoherent precipitates, and to date the literature does not provide any reason why a dislocation interacts with interphase precipitates in a different manner from random precipitates.

Also, it is apparent that the calculated $\sigma_{y}$ has, at best, $\sim 90 \%$ accuracy compared with total obtained from the measured microstructural parameters $\sigma_{\mathrm{M}}$. The $\pm 10 \%$ error is often due to the inhomogeneous microstructure, problems in obtaining the volume fraction of particles $<10 \mathrm{~nm}$ in size and the high magnifications required to image small particles. The calculated 
values from measurements and those predicted from equations in the literature given by Chen et al. ${ }^{211}$, match exactly.Errors were not considered in this work.

A different aspect to strengthening was considered by Fu et al., ${ }^{212}$ who pointed out that nano-size cementite precipitates can make a significant contribution to strengthening in steels at a relatively small cost.In a wide ranging paper, one of the areas investigated involved the addition of titanium in high-strength weathering steels.Figure 39, from Mao, ${ }^{213}$ provided the basis for the selection of the level of titanium additions for strip production,made by Fu et al. ${ }^{212}$ and shows that as the $\mathrm{Ti}$ content of the steel increases from 0.04 to $0.10 \%, \sigma_{\mathrm{y}}$ increases by $>300 \mathrm{MPa}$.

\section{Fig.39 near here}

Electrolytically extracted particles were comprehensively characterized; their size fell in the range 1 and 36nm. As predicted in Fig.24, when the average particle size was $>40 \mathrm{~nm}$, the value of $\sigma_{\mathrm{p}}$ is small.However, for smaller particles, Fu et al. ${ }^{212}$ found that the $\sigma_{\mathrm{y}}$ and $\sigma_{\mathrm{M}}$ data did not match.With $0.09 \% \mathrm{Ti}, \sigma_{\mathrm{d}}$ was calculated to be $130 \mathrm{MPa}, 200 \mathrm{MPa}$ lower than the actual contribution. This discrepancy was attributed the omission of a contribution to $\sigma_{y}$ from nano $\mathrm{Fe}_{3} \mathrm{C}$ precipitates, which was shown to be 4.4 times greater than that provided from $\mathrm{TiC}$ precipitates in the same size range. The paper emphasises the importance of the significant volume fraction of nanosized cementite precipitates present in MA steels, which contributes to the increase in the yield strength. The authors discuss how this might be achieved commercially.

A TEM study conducted by Tirumalesetty et al. ${ }^{214}$ on nanoprecipitates formed in Ti microalloyed transformation-induced-plasticity-assisted (TRIP) steels, revealed the presence of $\mathrm{Ti}(\mathrm{N}), \mathrm{Ti}_{2} \mathrm{CS}$ and a novel type of ultra-fine $\mathrm{Fe}(\mathrm{C})$ precipitate. The matrix/precipitate orientation relationships, sizes and shapes were investigated in detail. The ultrafine, disc-shaped $\mathrm{Fe}(\mathrm{C})$ 
precipitates were observed with sizes of $2-5 \mathrm{~nm}$, possessed a hcp crystal structure with lattice parameters $a=5.73 \pm 0.05 \AA, c=12.06 \pm 0.05 \AA$. They are in a well-defined Pitsch-Schrader OR, Table 6, with the basal plane of the precipitate parallel to the $\left\{\begin{array}{lll}1 & 1 & 0\end{array}\right\}$ habit plane of the surrounding bec ferritic matrix. Detailed analysis of precipitate distribution, orientation relationship, lattice mismatch and inter-particle spacing suggests that these ultrafine precipitates contribute considerably to the strengthening of these steels.

A similar conclusion was reached by Deng et al. ${ }^{215}$ who used a combination of deformation and controlled cooling through the $\gamma / \alpha$ phase fields, to investigate the possibility of developing high strength in a simple $\mathrm{Ti}-\mathrm{Nb} \mathrm{MA}$ steel suitable for linepipe applications. The composition of the vacuum melted $150 \mathrm{Kg}$ ingots was: $0.02 \mathrm{C}-0.23 \mathrm{Si}-0.98 \mathrm{Mn}-0.014 \mathrm{P}-$ 0.002S- $0.096 \mathrm{Ti}-0.02 \mathrm{Nb}-0.022 \mathrm{Al}-0.0036 \mathrm{~N}$. The ingots were rolled and forged to $100 \mathrm{~mm} \times$ $100 \mathrm{~mm} \times 120 \mathrm{~mm}$ plates, the starting size for the processing shown in Fig.40. Three types of cooling processes were adopted during the transformation of $\gamma \rightarrow \alpha$, to control the precipitates and thereby the mechanical properties:

- (I) slow cooling to room temperature at the rate of $\sim 0.5^{\circ} \mathrm{Cs}^{-1}$.

- (II) ultrafast cooling to $650-700^{\circ} \mathrm{C}$ and then slow cooling to room temperature, the cooling rate of the ultra-fast cooling and slow cooling was $\sim 80{ }^{\circ} \mathrm{Cs}^{-1}$ and $\sim 0.5{ }^{\circ} \mathrm{Cs}^{-1}$ respectively,

- (III) ultra-fast cooling to $650-700^{\circ} \mathrm{C}$ and subsequent small deformation (reduction of $\sim 10 \%$ ), followed by slow cooling to room temperature at the rate of $\sim 0.5^{\circ} \mathrm{Cs}^{-1}$.

The ultra-fast cooling (III) processing during the $\gamma \rightarrow \alpha$ transformation after hot rolling, resulted in long thin strips and spherical $\mathrm{Fe}_{\mathrm{x}} \mathrm{C}$ precipitates. A high density of nano-sized precipitates with an average size $\sim 4 \mathrm{~nm}$ was obtained; the EDX spectra of finest carbides showed that they contained $\mathrm{Ti}, \mathrm{Nb}, \mathrm{Fe}$ and $\mathrm{C}$, which was considered to be combined as ( $\mathrm{Ti}$, $\mathrm{Nb})_{\mathrm{x}} \mathrm{C}$. Process (III) refined both ferrite and pearlite and restricted the formation of pearlite. 
The respective yield strength, tensile strength and elongation data were $605 \mathrm{MPa}, 670 \mathrm{MPa}$, and $24 \%$.

The above discussions have involved multiple precipitation of Ti based compounds in austenite (A) and ferrite (F). A different approach to produced strong tough steels has been to study precipitation in bainitic (B) and martensitic matrices. ${ }^{216}$ Bainitic microstructures have been explored, driven by the development of linepipe steels requiring higher strength combined with superior toughness, and yet still weldable, compared to ferrite-pearlite ( F-P) steels. Some of the advantages of a bainitic microstructure on toughness have been discussed by Edmonds and Cochrane. ${ }^{217}$ The formation of bainite has been recognized as a diffusion assisted, shear type (displacive) transformation, with excess carbon partitioned by diffusion to highly concentrated islands of austenite, A, in the B-F microstructure either within the ferrite grains or between the grains. ${ }^{216}$ The early work at BISRA, Sheffield, circa 1970, reported the advantages of superior strength, while maintaining good impact resistance, of microalloyed steels that were rapidly cooled immediately after hot deformation, compared with the same steels which had been air cooled after rolling. ${ }^{218-220}$ This change in processing route produced a different microstructure from the F-P associated with conventional controlled rolling. ${ }^{221,222}$ These non-F-P steels were originally developed as laboratory experimental steels, at a time when both nitrogen additions $\geq 0.005$ and the development of bainitic microstructures were generally regarded as deleterious to toughness. Tither et al. ${ }^{220}$ concluded that by utilizing the direct-quenching process, the near maximum secondary hardening potential of steels could be achieved.

Among the first to consider moving from ferrite-pearlite to acicular ferrite microstructures for applications which included linepipes, were Smith et al., ${ }^{223}$ who investigated the microstructure and properties of thirty six laboratory steels. Among the most successful were steels based on a composition of $0.04 \mathrm{C}-1.6 \mathrm{Mn}-0.09 \mathrm{Nb}-0.2 \mathrm{Mo}, \mathrm{FR}$ at $870{ }^{\circ} \mathrm{C}$, 
spray cooled at $\sim 22{ }^{\circ} \mathrm{Cs}^{-1}$ to a simulated- coiling temperature of $635^{\circ} \mathrm{C}$, the approximate temperature for acicular ferrite formation in this steel. The schedule resulted in a yield strength of $\sim 550 \mathrm{MPa}$ and $1 / 2$ size Charpy transition temperature of $-60^{\circ} \mathrm{C}$. This was a typical compostion and schedule in the 1970's for achieving the X65 and X70 (480 to 550MPa yield strength) linepipe steels based on acicular microstructures.

Of the 19 papers presented in the session on linepipe steels at Microalloying '75 conference, only two mention titanium additions, both in a marginal context. ${ }^{224,225}$ Most compositions for the following three decades were based on Nb-Mo additions, and are still the subject of investigation. ${ }^{226}$ In recent times, the advantages of more complex steel compostions for linepipe steels, including titanium, which was often combined with niobium and or vanadium as carbonitrides, as discussed above, have been investigated.

For example, the application of ultra-fast cooling of laboratory vacuum melted $0.15 \mathrm{C}$ 0.08Ti-27ppmN steels, to obtain a mixture of $\mathrm{TiC}$ and $\mathrm{Fe}_{3} \mathrm{C}$ in a bainitic microstructure was studied by Li et al. ${ }^{227}$ with the same aim as Fu et al. ${ }^{.212}$ After roughing,one sequence consisted of rolling in the recrystallization temperature zone, $1150-1096^{\circ} \mathrm{C}$,further rolling in the non- recrystallization temperature zone, finishing at $864^{\circ} \mathrm{C}$, then water cooling at $64^{\circ} \mathrm{Cs}^{-1}$ through the $\gamma \rightarrow \alpha$ transformation region to $580^{\circ} \mathrm{C}$, followed by an isothermal holding for 20 min, prior to air cooling to RT. A fully bainitic microstructure was observed in the $12 \mathrm{~mm}$ thick plate. Besides nanoscale TiC particles,a high volume fraction of cementite, $\leq 35 \mathrm{~nm}$ was observed,which, it was claimed made a greater contribution to $\sigma_{\mathrm{y}}$ of $\sim 690 \mathrm{MPa}$, than the $\mathrm{TiC}$ particles. This is a similar conclusion to that of Mao. ${ }^{213}$

Tirumalesetty et al. ${ }^{228}$ characterized the nanosized precipitates of $\mathrm{NbC}$ and $(\mathrm{Nb}, \mathrm{Ti}) \mathrm{N}$ in a multiphase transformation induced plasticity (TRIP) steel containing fractions of bainite, martensite and retained austenite in a predominantly ferritic matrix. The material was produced on an industrial hot dip galvanising line using a conventional intercritical annealing 
cycle, which is standard practice for dual phase $\alpha / \gamma$ (DP) and TRIP steels. Precipitates were observed in ferrite, martensite and bainite, but not in austenite. Two kinds of precipitates were found in this steel, $(\mathrm{Nb}, \mathrm{Ti}) \mathrm{N}$ and $\mathrm{NbC}$. $(\mathrm{Nb}, \mathrm{Ti}) \mathrm{N}$ precipitates of sizes ranging from 10 to $150 \mathrm{~nm}$, with the larger precipitates having a Ti/ $\mathrm{Nb}$ ratio of approximately $2.8 \pm 0.8$ and faceted in shape.Smaller $\mathrm{NbC}$ precipitates were found in the size range 5-20 $\mathrm{nm}$. The $(\mathrm{Nb}, \mathrm{Ti}) \mathrm{N}$ precipitates had a well-defined $\mathrm{N}-\mathrm{W}$ orientation relationship with the ferrite matrix, Table 6, while the $\mathrm{NbC}$ precipitates were in random orientations. A comparison of the calculated and experimental lattice parameters indicated that both precipitates were deficient in carbon and nitrogen contents,but they are still expected to strengthen these steels.

A series of papers by Misra et al. ${ }^{144,145,227,229-232}$ included investigations into titanium containing steels, and have made significant contributions to understanding the development of microstructures essential to attaining yield strengths eventually exceeding $1000 \mathrm{MPa}$. This strength level permits reduced strip thickness in automotive weight reduction applications and in pipeline. Laboratory processed MA steels ${ }^{229}$ in the composition range: 0.05C-1.5Mn-(0.1-0.2) Mo-(0.07-0.09) Nb-(0.065-0.085)Ti-(0.0005-0.0010)B were reheated at $\sim 1325^{\circ} \mathrm{C}$, finished rolled at $\sim 900{ }^{\circ} \mathrm{C}$ and coiled at $\sim 600{ }^{\circ} \mathrm{C}$ to give a $\mathrm{F}$-B microstructure. The precipitates in the final state were characterised from foils and replicas included 120-400nm $(\mathrm{Ti}, \mathrm{Nb}) \mathrm{N}, 10-120 \mathrm{~nm}$ spherical or plates of $(\mathrm{Nb}, \mathrm{Ti}) \mathrm{C}$ and $3-5 \mathrm{~nm}$ needle-like $(\mathrm{Nb}, \mathrm{Ti}) \mathrm{C}$ precipitates. It is quite possible that the precipitates were carbonitrides, as PEELS analysis was not available to analyse carbon and nitrogen in the particles. The high yield strengths of $\sim 770 \mathrm{MPa}$ were attributed to the presence of a fine grain size in a mixed $\mathrm{F} \sim 10 \% \mathrm{~B}$ microstructure containing an estimated $10^{14} \mathrm{~m}^{-2}$ dislocation density, retained by a fine dispersion of $(\mathrm{Nb}, \mathrm{Ti}) \mathrm{C}$ precipitates. The observed good toughness of $50 \mathrm{~J}$ at $-40{ }^{\circ} \mathrm{C}$, was believed to be a consequence of fine grain size of $3-5 \mu \mathrm{m}$ and a bainitic low temperaturetransformation product. 
Another study of steels for pipelines, with similar carbon and niobium levels, but having a slightly lower titanium and with $0.3-0.4 \mathrm{Cr}$ replacing $\mathrm{Mo}$, included an examination of the welded steel. ${ }^{230}$ The type and size range of precipitates was comparable to those characterised by Charleux et al. ${ }^{233}$ and found in the parent plate, HAZ and weld metal, together with small areas of degenerate pearlite/upper bainite, martensite and M-A, all as microphases, which contributed to the yield strength of $\sim 700 \mathrm{MPa}$.

Achieving even higher yield strengths, $\sim 1000 \mathrm{MPa}$, is possible, but at an increased cost in both alloying and processing. ${ }^{232} \mathrm{~A}$ steel with a nominal composition of 0.12C-0.5Si-1.4Mn-0.45(Mo+Nb+Ti+V) -0.00015B, was hot rolled to $6 \mathrm{~mm}$ thick strip and coiled at $600^{\circ} \mathrm{C}$.It was then subjected to high frequency induction tempering at $600{ }^{\circ} \mathrm{C}$ following quenching at $\sim 40^{\circ} \mathrm{Cs}^{-1}$ from $900{ }^{\circ} \mathrm{C}$. This produced a duplex microstructure of lath $\mathrm{M}$ and conventional bainite (CB) laths. Particles, $<10 \mathrm{~nm}(\mathrm{Nb}$, V) $\mathrm{C}$ and $\sim 5 \mathrm{nmVC}$ were identified by FEG-TEM-EDX, the latter considered to precipitate in ferrite, obeying the BNOR, Table 6.

Recently, a novel low carbon $\mathrm{Nb}-\mathrm{V}-\mathrm{Ti}-\mathrm{Cr}$ microalloyed bainitic steel with yield strength of $1000 \mathrm{MPa}$ and excellent low temperature toughness was successfully processed. The experimental results obtained by Xie et al. ${ }^{232}$ indicated that the steel which was subjected to a cooling rate of $65^{\circ} \mathrm{C} \mathrm{s}^{-1}$ and a coiling temperature of $380-400^{\circ} \mathrm{C}$ (above $\mathrm{M}_{\mathrm{s}}$ of $372{ }^{\circ} \mathrm{C}$ ), finally furnace cooling to RT, resulted in the superior mechanical properties. The ultra-high yield strength of $1058 \mathrm{MPa}$ was attributed to the transformation strengthening due to $\mathrm{CB}$ and precipitation hardening from nano-scale $(\mathrm{Nb}, \mathrm{Ti}) \mathrm{C}$ precipitates. A Charpy impact absorbed energy of $24 \mathrm{~J}$ at $-20^{\circ} \mathrm{C}$, was associated with $\mathrm{CB}$ and acicular ferrite (AF), together with a high fraction of large misorientation grain boundaries, obtained by controlling the coiling temperature. 
Similar laboratory steels to those of Shanmugam et al., ${ }^{230}$ were investigated by Yi et al., ${ }^{234-237}$ who achieved $\sigma_{\mathrm{y}}$ of $700 \mathrm{MPa}$ through conventional rolling ${ }^{234}$ a bainitic high strength steel containing $0.08 \mathrm{C}$, and 0.06 to 0.08 of $\mathrm{Nb}, \mathrm{V}$ and Ti.The steel was rolled to $4 \mathrm{~mm}$ strip, FRT at $800^{\circ} \mathrm{C}$ and cooled at $40{ }^{\circ} \mathrm{Cs}^{-1}$ to a coiling temperature between $560{ }^{\circ} \mathrm{C}$ and $350^{\circ} \mathrm{C}$. The authors claimed that coherent precipitation occurred during coiling, which, along with a ferrite grain size of $2-6 \mu \mathrm{m}$ contributed to the strength. $\mathrm{Nb}$-Ti precipitates were identified by EDX. ${ }^{235}$ A yield strength of $730 \mathrm{MPa}$ in ferrite was accredited to the combined addition of $\mathrm{Nb}$ and Ti. In later work by Yi et al., ${ }^{237}$ this yield strength was raised to $\sim 800 \mathrm{MPa}$, in a steel of composition $0.04 \mathrm{C}-0.09 \mathrm{Ti}-0.2 \mathrm{Mo}$, through dispersion strengthening by nanometre carbides. A slightly lower yield strength was achived by Ning et al. ${ }^{238}$ who rolled an experimental steel of composition $0.12 \mathrm{C}-0.48 \mathrm{Si}-1.53 \mathrm{Mn}-0.16 \mathrm{Ti}-0.23 \mathrm{Mo}-0.01 \mathrm{~N}$, in the deformation-induced-ferrite transformation (DIFT) region, shown in Fig.41.

\section{Fig 41 near here}

They concluded that rolling in the DIFT region increased the dislocation density and the nucleation rate of ferrite and then refined the ferrite grain size. Additionally, the amount of precipitation in austenite was decreased by rolling in the DIFT region. This increased the degree of supersaturation in ferrite which increased the equilibrium volume fraction of $\left(\mathrm{Ti}_{y} \mathrm{Mo}_{1-y}\right) \mathrm{C}$ precipitation in ferrite to a calculated value of $0.17 \%$. The fine grain strengthening was increased by $34 \mathrm{MPa}$ and the precipitation strengthening by $64 \mathrm{MPa}$, to give a maximum yield strength of 592MPa.

\section{Multialloying in the development of linepipe steels}

Much of the above research has been concerned with the development of linepipe steels 239-241, in which titanium additions have played an important part in the improvement of the 
mechanical properties. The X series is collected in Table 17, where X65 means a $\sigma_{\mathrm{y}}$ of (65ksi)i.e. $65,000 \mathrm{psi}$, using a conversion of $145 \mathrm{ksi}=1000 \mathrm{MPa}$.

\section{Table 17 near here}

The development of linepipe steels over the past 40 years can be followed in Fig.42.The increase in $\sigma_{\mathrm{y}}$ is mirrored by the change in microstructure from F-P through to B-M with more complex steel compositions.It can be seen in Fig.42 that the strongest steels have titanium additions. Figure 42 does not include acicular ferrite matrix titanium line pipe steels, which are considered below. In practice, higher strength steels allow higher operating pressures through the production of thinner walled pipe which provides weight savings, and hence lower costs for transport-to-site and field welding,culminating in lower gas transportation costs. This is well illustrated in Fig.43, which shows that replacing X70 in the construction of the first Ruhrgas pipeline by X80 steel led to a materal saving of about $20,000 \mathrm{t}$ through a reduction in wall thickness from $20.8 \mathrm{~mm}$ to $18.3 \mathrm{~mm}$. Significantly greater savings are possible with X120 grade.

\section{Figs 42 and 43 near here}

As discussed above, the B-M microstructures in line pipe steels are obtained by accelerated cooling processes following rolling. State of the art accelerated cooling plant is expensive to install, and therefore limited.

While linepipe steels with X65 to X100 properties are readily available, steels meeting X120 are a more limited recent commercial option ${ }^{242,243}$ and both X120 and X140 are still under development. X120 steel is $\geq 50$ percent stronger than the strongest linepipe steel commonly used for gas transmission pipelines today (X70 and X80) and is expected to reduce substantially pipeline project costs. ${ }^{242-244}$ Some of the many attempts to increase the strength to meet X120 requirements, while at the same time retaining acceptable toughness and ductility levels in weldable steels, have been considered above. The commercial 
development of X100 is well covered in the literature, ${ }^{239,240,}$ but the scaling up of the processing of X120 from laboratory to plant has presented challenges. It should be emphasised that much of this work was conducted on experimental steels processed on a laboratory scale. However, over 12 years ago a one mile pilot pipeline, meeting X120 specification, was added as a loop to an existing pipeline installed in Alberta, ${ }^{243}$ and by 2011 , this MA steel, containing Ti, ${ }^{244}$ was available commercially. ${ }^{245}$ Titanium is frequently added to incease the weldability of API 5L grade steels through its ability to the inhibit austenite grain growth. Moon et al. ${ }^{246}$ have pointed out that the use of linepipe steel and pressure vessels for transporting sour media gas $\left(\mathrm{H}_{2} \mathrm{~S}\right)$ has increased due to exhaustion of natural sweet gas.Steels exposed to aqueous $\mathrm{H}_{2} \mathrm{~S}$ absorb hydrogen ions, which may result in the formation of blisters in tri-axial stress zones such as matrix/inclusion interfaces. ${ }^{247}$ These can give rise to hydrogen gas induced penetration, leading to hydrogen induced cracking (HIC).Hydrogen pick-up can also occur during welding. The work of Moon et al. ${ }^{246}$ suggests that caution should be exercised when considering the composition of the steel.They compared X70 steels with and without titanium additions, having the compositions shown in Table 18.

\section{Table 18 near here}

They concluded that:

- after HIC testing, cracking occurred along coarse $(\mathrm{Nb}, \mathrm{Ti}, \mathrm{V})(\mathrm{C}, \mathrm{N})$ complex particles present at the mid-thickness line of the tested sample; this is related to segregation of solute atoms at mid-thickness and the final solidification zone during continuous casting.

- solute atom segregation resulted in a high local concentration of Ti atoms in the centerline leading to the formation of coarse $(\mathrm{Nb}, \mathrm{Ti}, \mathrm{V})$ complex particles. 
- $\quad$ HIC test results clearly proved that coarse $(\mathrm{Nb}, \mathrm{Ti}, \mathrm{V})(\mathrm{C}, \mathrm{N})$ particles above $7.5 \mu \mathrm{m}$ can act as hydrogen trapping sites in the ferrite matrix/particle interface and thus cause hydrogen blistering.

Calcium can restrict the formation of $\mathrm{MnS}$, which, in an elongated morphology, is known to increase susceptibility to HIC. ${ }^{248}$ The microstructure contained ferrite and upper bainite.After HIC testing for $96 \mathrm{~h}$ to the procedure of NACE TM0284:2003, cracks associated with interface between coarse $(\mathrm{Nb}, \mathrm{Ti})(\mathrm{C}, \mathrm{N})$ cubic particles with caps and ferrite were observed. ${ }^{246}$ These particles were considered to be related to centreline segregation, occurring during the final solidification in continuous casting. Not only are the mechanical and toughness properties specified, but also those of the welding process to mitigate HIC in joining the sections. This will be consider later when dealing with welding.It of interest to note that the systems $\mathrm{Ca}-\mathrm{Ti}-\mathrm{O}{ }^{249}$ and $\mathrm{CaO}$-iron oxide and $\mathrm{TiO}_{2}{ }^{250}$ have been explored, but at much higher titanium contents than are likely to be present in the oxides produced during melting of MA steels, and more frequently in mineralogical and lunar oxides.

Beidokhti et al. ${ }^{251}$ studied fine $\operatorname{Ti}(\mathrm{C}, \mathrm{N})$ inclusions in high strength low alloy (API X70) welds, with Ti additions ranging from 0.004 to $0.16 \mathrm{wt} . \%$. The trapping sites were investigated by electron microscopy and thermal desorption spectroscopy. MnS particles were the main initiation sites for HIC. The sulphide stress cracking (SSC) resistance of the welds was increased by the addition of titanium up to $0.02 \%$, due to the distribution of AF and $\operatorname{Ti}(\mathrm{C}, \mathrm{N})$ particles in the microstructure. $\operatorname{Ti}(\mathrm{C}, \mathrm{N})$ acted as strong hydrogen trapping sites. In the $\mathrm{AF}$ matrix, dislocations were pinned by the dispersed fine $\operatorname{Ti}(\mathrm{C}, \mathrm{N})$ particles and consequently these dislocations were considered to act as beneficial hydrogen traps. 


\section{Acicular Ferrite in MA Steels with particular reference to titanium}

\section{additions}

Due to the important role acicular ferrite $(\mathrm{AF})$ microstructures are now recognized to hold in the development of ultra high strength MA steels,they are given critical attention here. Smith et al., ${ }^{223}$ who investigated Mn-Mo-Nb steels, were among the first to develop AF microstructures in line pipe steels.More recently, AF microstructures formed in titanium steels have been studied extensively. ${ }^{252-258}$

Acicular ferrite, also referred to as intragranular ferrite (IGF), has been recognized as a separate phase in steels for over 40 years, initially in arc welded deposits of low alloy steels, to be discussed later,where it was most commonly present due the transformation of austenite, during cooling at intermediate transformation temperatures of 650 to $500^{\circ} \mathrm{C} .{ }^{216} \mathrm{AF}$ has been found to improve HAZ toughness ${ }^{259,260}$ and is also observed in wrought steels which have been deliberately inoculated with non-metallic inclusions. ${ }^{216}$ As summarized by Koseki and Thewlis, ${ }^{261}$ 'with a high density of inclusions,a fine interlocking microstructure can be produced. Ultra fine $(2-3 \mu \mathrm{m})$ AF microstructures have resulted in tensile strength levels around $750 \mathrm{MPa}$ with $80 \mathrm{~J}$ impact energy at $-100^{\circ} \mathrm{C}$.' More recently, AF microstructures have been developed as the preferred matrix for MA line pipe steels, with high yield strengths of 800-1000MPa, as discussed above. ${ }^{226}$ In their review, Sarma et al. ${ }^{262}$ make the point that historically, inclusions present in steel were regarded as deleterious to ductility,toughness, fatigue strength and corrosion resistance. 'However, due to prolonged and detailed studies to improve toughness of the fusion zone of welds, considerable knowledge has been acquired on the role of inclusions in controlling the grain size of steels. $^{257}$

It is important to appreciate that the microstructure of steels based on AF also contains other phases such as significant fractions of bainite and also Widmanstatten ferrite 
${ }^{252}$, as seen in Fig.44.Much research has been undertaken to maximize the quantity of AF in the microstructure. For example ${ }^{263}$, in Fig.44 (a) the influence of manganese and titanium on the amount of AF in a weld metal is shown to be $\sim 35 \%$ with $0.65 \% \mathrm{Mn}$ and $75 \mathrm{ppm} \mathrm{Ti}$, while in Fig.45(b) with $1.8 \% \mathrm{Mn}$ and $>36 \mathrm{ppm} \mathrm{Ti,} \mathrm{AF} \mathrm{is} \mathrm{significantly} \mathrm{more} \mathrm{at} \geq 60 \%$.

\section{Figs 44,45 and 46 near here}

Figure 46 shows the main features of acicular ferrite: fine interlocking non-equiaxed ferrite laths of various sizes with multiple impingements, which are distributed in a random or a "chaotic arrangement", nucleating intergranularly within austenite grains. The prior austenite grain boundary network is completely eliminated and some fine M-A (martensite/austenite) island constituents are scattered throughout the matrix. A high density of dislocations within AF is common. ${ }^{265}$ Inclusions such as those at $\mathrm{S}$ and $\mathrm{C}$ in Fig. 45, and $\mathrm{Ti}_{2} \mathrm{O}_{3}$ in Fig.46 are recognized as favoured sites for nucleating acicular ferrite, particularly in weld metal.

Mechanisms responsible for the formation of AF have been extensively and critically discussed. ${ }^{216,260-262,265-268}$ There are differences in the development of AF in terms of the competitive nucleation and growth reactions at austenite grain boundary and intragranular inclusion nucleation sites. In early research involving weld metals, control of AF formation was considered to be due to:

- austenite grain size,

- alloy content and

- inclusion characteristics. ${ }^{261,266 \text {, }}$

Simultaneously with, or immediately after the formation of ferrite side-plates at the austenite grain boundaries, AF may start to nucleate intragranularly at inclusions. ${ }^{266}$ The role of nonmetallic-inclusions in the nucleation of AF was first shown by Abson et al. ${ }^{269}$ and Cochrane and Kirkwood, ${ }^{270}$ and has been reviewed by many others. ${ }^{271-277}$ 


\section{Fig.47 near here}

These reviews consider the body of research undertaken to understand how the fine interlocking ferrite, seen in Fig. 47, is nucleated in the body of austenite grains, containing a dispersion of non-metallic inclusions, $\leq 1 \mu \mathrm{m}$ in dia., which might act as heterogeneous nucleation sites. $^{216,260,291-298}$ Sarma et al. ${ }^{262}$ list the main factors they consider to influence the formation of AF which can improve the strength and toughness of weld metal and /or the HAZ.These also apply to wrought MA steels and are:

- chemical composition of the steel,

- cooling rate in the temperature range $800^{\circ} \mathrm{C}$ to $500^{\circ} \mathrm{C}$,

- $\quad$ size of austenite grains, and

- the composition of the nucleants, their size range and volume fraction.

The role of different elements on the formation of AF in steel are summarized below: ${ }^{262}$

(i) changing the $\gamma \rightarrow \alpha$ transformation temperature, thereby increasing ( $\mathrm{Mn}, \mathrm{Ni}, \mathrm{C}$ ) or decreasing (Al,Si,V,Cr,Mo,Ti) the austenite zone,

(ii) a reduction of grain boundary energy, due to segregation of solute elements such as boron, and

(iii)precipitation of inclusion particles favourable for nucleation of ferrite at the inclusion surface during the $\gamma \rightarrow \alpha$ transformation.

This latter effect has received the most attention in the literature.

Four aspects of AF nucleation associated with inclusions have been considered: ${ }^{261,262}$

- a reduction in interfacial energy for heterogeneous nucleation on the surface of inclusions, ${ }^{271,278}$

- epitaxial nucleation on inclusions, which have a good coherency with ferrite, ${ }^{261,279}$ favours $\mathrm{Al}_{2} \mathrm{O}_{3}, \mathrm{MnO}, \mathrm{TiO}, \mathrm{TiN}$ 
- differential coefficients of thermal expansion of steel and inclusion inducing tessellated stresses in material near inclusions, ${ }^{266}$ favours Mn-Al or Al-silicates. ${ }^{262}$

- nucleation arising from solute depletion of elements in the matrix near to the inclusions. ${ }^{260,275,280,281}$

It has been suggested that an austenite stabilizing element such as manganese could be absorbed into the inclusion, giving rise to a manganese depleted zone (MDZ) around an inclusion, such as $\mathrm{Ti}_{2} \mathrm{O}_{3}$, which has a relatively poor coherency with ferrite. This is shown diagrammatically in Fig.48.

\section{Fig.48 near here}

Experiments undertaken by Yamamoto et al. ${ }^{282}$ found that HAZ toughness, especially after large heat input welding, was improved by a boron addition to Ti $0.015 \%$ MA steels containing fine dispersed $\mathrm{Ti}_{2} \mathrm{O}_{3}$. Using analytical TEM to study carbon extraction replicas, they observed that an MDZ formed around $\mathrm{Ti}_{2} \mathrm{O}_{3}$ inclusions , $0.2-2.0 \mu \mathrm{m}$ dia.following the precipitation of $\mathrm{MnS}$, schematic illustrated in Fig. 48. The $\mathrm{Ti}_{2} \mathrm{O}_{3}$ particles with $\mathrm{TiN}$ and the MDZ act as preferential nucleation sites for AF, which covered up to $90 \%$ of the surface studied. It was considered that segregation of boron at austenite grain boundaries suppressed the nucleation of grain boundary ferrite.

W hile it is generally agreed that steels containing a titanium addition are involved in AF nucleation, there is no agreement on which of the aspects mentioned above produce the greatest volume of AF in the microstructure.

Differences are found in the Ti content required to nucleate AF: Bonnet and Charpentier ${ }^{283}$ $>40$ - 50 ppm, Seo et al. ${ }^{280} 410$ or 580 ppm, while Kim et al. ${ }^{281}$ found that 9 ppm produced a sudden increase to an AF of $\sim 70 \%$. Both Seo et al. ${ }^{280}$ and Byun et al. ${ }^{276}$ found that increasing titanium content changed the microstructure from bainite to AF. 
Figure 49, from the work of Ilman et al. ${ }^{252}$, shows clearly the importance of inclusion size as a function of nucleation probability, with the steel containing the highest $\mathrm{Ti}$

addition,580ppm, having the greatest number of inclusions in size $>0.6 \mu \mathrm{m}$, which was associated with the highest \% AF. This data supported the view of Zhang and Farrar ${ }^{278}$ that the number and size of nucleants is the dominant factor in determining the volume of AF in the microstructure.

\section{Fig.49 near here}

Summarizing data from various studies, Loder et al. ${ }^{265}$ collated the lower critical inclusion size to be $0.3-0.5 \mu \mathrm{m}^{259,277}$ and the upper critical value as $1 \mu \mathrm{m} .{ }^{265,277}$ Lee et al. ${ }^{284}$ noted that in their weld metal experimenta, a large inclusion size $>1 \mu \mathrm{m}$ had a large probability of AF nucleation, but most AF nucleants in steel have diameters in the range 0.5-0.8 $\mu \mathrm{m}$, as found by Ilman et al., ${ }^{252}$ Fig 49 . They also found that only $36 \%$ of inclusions were 'active' AF nucleants, but these provided a microstructure comprising $80 \% \mathrm{AF}$. Chemical composition of the inclusions was considered to be an important factor in developing 'active' nucleants. Shama et al. ${ }^{262}$ noted that inclusions with a complex composition were more likely to be active, as listed in their paper, with titanium-compounds predominated, as was the case in the review by Loder et al. ${ }^{277}$

As mentioned earlier, the beneficial role of inclusions in nucleating AF microstructures in as -deposited weld metal, initiated in the 1970's, was transferred in the 1990 's to grain refining the microstructure of wrought steel. In particular, MA steels have been subject to so called 'inclusion engineering' through inoculation by inclusions to promote grain refinement of austenite, ferrite and AF microstructures. ${ }^{285-288}$ Gregg and Bhadeshia ${ }^{273}$ added powdered mineral phases to steel to promote AF microstructures and found titanium oxides to be effective. The effect of boron, ${ }^{282} \mathrm{C}$ and $\mathrm{Mn},{ }^{277} \mathrm{~S},{ }^{289}$ and Ti and $\mathrm{Al}^{290}$ in inclusions of Ti complexes,normally considered as being deleterious to 
toughness, ductility or fatigue properties, has been studied as a means of mitigating these effects through control of the AF microstructure by steel composition.

Gröng et al. ${ }^{291}$ used the term 'dispersiods', to distinguish inclusions 'active' in grain refining from those known to be deleterious to toughness, which are larger. They considered that there were two main solutions to the grain refining problem, i.e. either to create the nucleating dispersoids within the system during steelmaking by modifying the deoxidation and desulphurisation practice, or following Gregg and Bhadeshia, ${ }^{273}$ to add them directly to the liquid steel via a grain refining masteralloy. However, in both cases, as discussed above for weld deposits, a very fine and narrow size distribution of the dispersoids, $\leq 1 \mu \mathrm{m}$, was aimed for, to utilise fully the latent grain refining potential without compromising toughness. This has been a very active research area since the 1990's, when alternatives to F-P microstructures for MA steels were reviewed, ${ }^{292}$ and remains so today.

\section{Welding of Titanium MA steels}

The weldability of microalloyed steels containing titanium has been addressed in numerous publications, including several reviews..$^{1,4,5,260,266,267,293}$ It is important that the properties of a weld should be similar or superior to those of the parent alloy. To influence the properties, further to being an alloy addition to the parent metal, titanium has also been added through the filler wire or the flux coating of weld consumables. While titanium was usually added to carbon steels for austenite grain refinement through precipitation of TiN, Figs. 29 and 31. Hart and Ferguson, ${ }^{21}$ pointed out that this approach is also useful for improving HAZ toughness, being particularly beneficial during high heat input welding, which allows a reduction in the number of welding passes, with concomitant financial savings. All these topics will be considered below. 
Many of the aspects of Ti MA steel welds involve the influence of process parameters on the microstructural evolution related to toughness. These embrace, for example,

- Ti oxides in the nucleation of AF, Figs 44,46 and $47,,^{260-263}$

- $\quad \mathrm{TiN}$ and complexes with $\mathrm{Nb}$ and $\mathrm{C}$, pinning grain boundaries, and

- SIP associated with dislocations, ${ }^{155}$ which have been addressed earlier in this paper.

Several reviews $260,266,267$ have considered the effect on properties of the most important elements present in carbon steel welds. The factors influencing the strength and toughness of as- deposited weld metal in C-Mn steel welds, including composition, were reviewed to 1986 by Abson and Pargeter. ${ }^{267}$ Carbon is recognized as the most important element in steel in controlling the volume of carbides formed and influencing the solidification microstructure; oxygen also has a major influence in welded steels. ${ }^{258}$ Farrar and Harrison ${ }^{260}$ commented on the complex interaction between Ti-A1 and oxygen, mentioned by Bailey, ${ }^{294}$ which suggested that aluminium could reduce titanium from either the flux or the coating formulation, and thus limit the extent of titanium oxide formation, which in turn would affect the volume of AF.

The opinion expressed by Hunt et al. ${ }^{295}$ implied that there 'seems to be general agreement that microstructures consisting primarily of AF, as in Fig.46, provide optimal weld metal mechanical properties, both from the point of view of strength and toughness,' confirms a widely held view. ${ }^{266,269,270,296}$ The formation of large proportions of upper bainite, ferrite side plates, or grain boundary ferrite, on the other hand, was considered detrimental to toughness, since these structures provided preferential crack propagation paths, especially when continuous films of carbides were present between the ferrite laths or plates. The detrimental effect of continuous films of carbides mentioned above is in agreement with the views of Hart ${ }^{297}$ who considered 'the opportunities that microalloying 
gives for improving weldability by reducing carbon content was fairly quickly recognised and became another major driving force for their development and understanding.' As discussed above, many modern steels have low sulphur $<0.003 \%$ and generally low nitrogen $<4 \mathrm{ppm}$.However, rapid cooling of regions adjacent to the weld, the heat affected zones (HAZ), frequently produced martensitic hard zones leading to local increases in hardness, which can result in lower toughness. It is common practice to specify a maximum hardness that can be tolerated in the HAZ. As the hardness of martensite is related to the carbon content of the steel, this has a profound influence on hardenability. Other elements affecting hardenability are considered in the carbon equivalent (CE) equations deduced from multiple regression analysis, such as the original devised by Dearden and O’Neill, 298

$$
C E=C+M n / 6+(C r+M o+V) / 5+(N i+C u) / 15
$$

However, equation (26) does not include Ti, as it was devised before Ti additions became more commonplace in alloy steels. Recently more complex relationships have been formulated such as: 299

$$
C E=C+A(C) x(S i / 24+M n / 6+C u / 15+N i / 60+C r+M o+N b+V / 5+5 B
$$

where $A(C)=0.75=+0.25 \tanh (20 x(C-0.12))$

also do not contain a term for Ti.

Lagneborg et al. ${ }^{300}$ have pointed out that, 'nitrogen levels in plain C-Mn steels display a strong correlation with coarse-grained HAZ toughness, where higher N-levels are clearly deleterious, showing a marked increase in Charpy $\mathrm{T}_{\mathrm{c}}$, which is reflected in maximum permitted contents in various steels specifications. However, the presence of the nitride forming elements $\mathrm{Al}, \mathrm{Ti}, \mathrm{Zr}, \mathrm{Nb}, \mathrm{V}$, can mitigate considerably the negative effect of nitrogen, indicated in the relaxation of the limit of nitrogen allowed in MA steels in the presence of these elements.' In general, much attention has been paid to steels containing 
titanium and nitrogen and how these elements interact in combination with $\mathrm{V}$ and $\mathrm{Nb}$. In Ti microalloyed steels, the effects of Ti and $\mathrm{N}$ contents on improving the HAZ toughness through the pinning of austenite grains by TiN particles is well established, ${ }^{183,294,301,302}$ and both TiN particle size and volume fraction influence the toughness. ${ }^{303,304}$

With hyperstoichiometric titanium additions, coarse TiN particles (side length $>0.5 \mu \mathrm{m}$ ), forming in the liquid state and above a critical number density, can act as fracture initiation sites when ferrite grain sizes are $>9 \mu \mathrm{m} .{ }^{304}$ It is recommended that the contents of Ti and $\mathrm{N}$ should be kept as close to the stoichiometric ratio $\mathrm{Ti} / \mathrm{N}=3.42$. Another view is that soluble nitrogen should be minimized. Mixed additions of $\mathrm{Nb}-\mathrm{Ti}-\mathrm{V}$ in microalloyed steels were considered by Adrian and Pickering ${ }^{305}$ and by Hamada et al., ${ }^{306}$ as a function of nitrogen content. Both concluded that high nitrogen, $0.018 \%$ and $0.0084 \%$ respectively, was advantageous, resulting in the substantial refinement of austenite grains ${ }^{305,306}$ and in the case of HAZ simulation, an austenite grain size of $\sim 30 \mu \mathrm{m}$ was produced by $\sim 10 \mathrm{~nm}(\mathrm{Nb}$, Ti)N precipitates. The effects of zirconium with those of titanium and vanadium on submerged arc deposits were compared by Koukabi et al., ${ }^{307}$ who concluded that vanadium had a greater effect on the increasing toughness in both the as-welded and stress relieved welds than titanium or zirconium. It is well established that both $\mathrm{TiN}$ and $\mathrm{ZrN}$ particles have little solubility in austenite, as seen in Fig 28. Zirconium additions were expected to behave similarly to titanium, but Koukabi et al. ${ }^{307}$ found that $\mathrm{ZrN}$ particles did not promote AF and the weld toughness was only slightly improved, due they considered, to the removal of the soluble nitrogen. Chai et al. ${ }^{308}$ explained the observations of Koukabi et al., ${ }^{307}$ suggesting that the equilibrium number and composition of the inclusion phases changed with the zirconium addition from $\mathrm{Ti}_{2} \mathrm{O}_{3}$ to $\mathrm{ZrO}_{2}$. When the zirconium content was lower than $0.0085 \%$, the inclusions were mainly $\mathrm{Ti}_{2} \mathrm{O}_{3}$ and $\mathrm{ZrO}_{2}$, and the oxides shared the same proportion of $\sim 0.0045 \% \mathrm{Zr}$ content. 
During welding processes which use a high heat input, as in pipe forming and construction procedures, the HAZ experiences a severe thermal cycle with fast heating rate, high peak temperatures and developes thermal stresses. Close to the fusion boundary, HAZ temperatures will approach and maybe exceed $1400^{\circ} \mathrm{C}$, and with the slow cooling rate of high heat input welding, austenite grains can grow to several hundred micrometers in size. Improvements in HAZ toughness shown by Charpy and Crack Tip Opening Displacement (CTOD) testing following high heat input studies were consider by Tomita et al. ${ }^{309}$ to benefit from a TiN-MnS addition:TiN pinning austenite grain boundaries while the complex TiN-MnS complex precipitate nucleated AF. The effect of heat input and Ti/N on austenite grain size of Ti-Nb MA steels was reported by Hart and Ferguson. ${ }^{21}$ They investigated five steels containing 0.06 to $0.10 \mathrm{C}-1.27$ to $1.47 \mathrm{Mn}-0.006$ to $0.022 \mathrm{Nb}-0.005$ to $0.017 \mathrm{Ti}-5$ 50ppm O-27 to 50ppnN.Figure 50 shows clearly a resistance to austenite grain size coarsening following welding trials using different heat inputs. The data disagree with the maxim that the best properties occur with the stoichiometric ratio of $\mathrm{Ti} / \mathrm{N}=3.42$. Here austenite grain size decreases with increasing $\mathrm{Ti} / \mathrm{N}$ ratio from 1.85 to 3.6. The authors suggested that particle size and volume fraction may have an over riding influence in this case.

\section{Fig.50 near here}

Both particle size and volume fraction were considered by Zhang et al. ${ }^{310}$ who undertook an HAZ simulation using a Gleeble 3800 machine, heating to $1673 \mathrm{~K}$ and studying the influence of cooling rate. They examined 0.014 Ti MA steels at two $\mathrm{N}$ levels: (A) $0.0031, \mathrm{Ti} / \mathrm{N}=4.84$ and ( B) $0.0083, \mathrm{Ti} / \mathrm{N}=1.57$. Figure 51 from their work, follows the influence of holding time at $1400^{\circ} \mathrm{C}$ on the austenite grain size. TEM results showed that the number density of TiN precipitates increased from (A) $4 \times 10^{3} \mathrm{~mm}^{-2}$ to (B) 
$3 \times 10^{5} \mathrm{~mm}^{-2}$, which after soaking for $2000 \mathrm{~s}$, was accompanied by a reduction in the prior austenite grain size from 850 to $350 \mu \mathrm{m}$.

Charpy impact absorption energies at $253 \mathrm{~K}\left(-20^{\circ} \mathrm{C}\right)$ for

- $\quad$ steel (A) were $\geq 234 \mathrm{~J}$ with $\mathrm{t}_{8 / 5}$ between 40 and $300 \mathrm{~s}$ and $\leq 44 \mathrm{~J}$ with $\mathrm{t}_{8 / 5} \geq 550 \mathrm{~s}$

- $\quad$ those for steel (B) were $\geq 285 \mathrm{~J}$ with $\mathrm{t}_{8 / 5}$ between 40 and $1000 \mathrm{~s}$ and $\leq 47 \mathrm{~J}$ with $\mathrm{t}_{8 / 5} \geq$ 1400 s.

Here, the higher nitrogen with an $0.0014 \mathrm{Ti}$ addition, giving a Ti/ $\mathrm{N}$ ratio close to the stoichiometric ratio $\mathrm{Ti} / \mathrm{N}$ of 3.42 , was seen to be beneficial for the simulated HAZ toughness.

\section{Fig.51 near here}

This view is in agreement with the work of Hamada et al. ${ }^{306}$ In a study of HAZ toughness, they found that on following simulating welding cycles for an $0.06 \mathrm{C}, 1.6 \mathrm{Mn}, 0.042 \mathrm{~V}, 0.050 \mathrm{Nb}, 0.012 \mathrm{Ti}$ with $\mathrm{N}$ between 12 and $84 \mathrm{ppm}$, increasing the total $\mathrm{N}$ content to $\sim 80 \mathrm{ppm}$, produced the lowest $100 \mathrm{~J}$ transition temperature. ${ }^{306}$ Also, as the total $\mathrm{N}$ increased, the microstructure changed from a coarse bainite to fine polygonal ferrite. In the 16ppm and $84 \mathrm{ppm} \mathrm{N}$ steels, particles $\sim 10 \mathrm{~nm}$ size containing both $\mathrm{Nb}$ and $\mathrm{Ti}$, but no $\mathrm{V}$, were identified by EDX and chemical analysis of extracted residues. The improved HAZ was considered to be due to the influence of total $\mathrm{N}$ residing in the $(\mathrm{Ti}, \mathrm{Nb}) \mathrm{N}$ precipitates, refining the austenite grain size, as shown in Fig52.

\section{Fig.52 near here}

In contrast to Zang et al., ${ }^{310}$ Lagneborg et al. ${ }^{300}$ in assessing the importance of nitrogen on HAZ toughness of MA steels, noted that low nitrogen levels, $\sim 0.003 \%$ were preferable.More recently the role of both $\mathrm{Ti}$ and $\mathrm{N}$ in line pipe steels has been reviewed by Zhu et al., ${ }^{311}$ with the aim of advising on the optimum levels of both elements associated with the greatest HAZ toughness. They discussed the varying views reported on the 
recommended levels of $\mathrm{Ti}$ and $\mathrm{N}$ in the steel to avoid coarse $>0.5 \mu \mathrm{mTiN}$ precipitates nucleating and growing in the liquid phase, when the TiN solubility limit is exceeded.They concluded that as they found the results in the literature contradictory, no clear recommendation could be made.

The influence of different $\mathrm{Ti} / \mathrm{N}$ ratios, $1.88,3.22$ and 4.88 , on the Geeble simulated coarse grained heat affected zone (CGHAZ) of three MA steels was explored by Zhu et al. ${ }^{312}$ All three steels were found to have a similar bainitic microstructure with small amounts

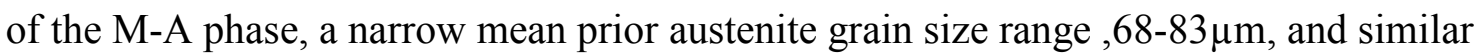
hardness, $\sim 210 \mathrm{Hv}$. In an extension of this work ${ }^{313}$ showed that while the $\mathrm{Ti} / \mathrm{N}$ ratio had little influence on the mean precipitate sizes $(52-57 \mathrm{~nm})$, which were obtained through TEM, the steel with a $\mathrm{T} / \mathrm{N}$ ratio of 3.22 , which was closest to the stoichiometric ratio,contained the highest precipitate density and the smallest prior austenite grain size. This steel showed the best toughness properties. The same group ${ }^{314}$ found that the beneficial effect of nearstoichiometric $\mathrm{Ti} / \mathrm{N}$ ratio observed in CGHAZ did not translate to the intercritical coarse grained heat affected zone (ICCGHAZ). This was because of the negative effect of the blocky M-A constituent formed on prior austenite grain boundaries. Similar observations were reported by Huda et al. ${ }^{315}$ on $\mathrm{Nb}-\mathrm{Ti}-\mathrm{V}, \mathrm{X} 80$ line pipe steels, based on earlier work. ${ }^{316-318}$

HAZ toughness is well recognized as being influenced by

- undissolved TiN particles at the peak welding temperatures and

- amount of free nitrogen present in the steel during the weld thermal cycle. ${ }^{319}$ TiN particles $>0.3 \mu \mathrm{m}$ have been reported to initiate cracking in $\mathrm{HAZ} .{ }^{320}$ As considered above, the $\mathrm{Ti} / \mathrm{N}$ ratio is often used as a guide to avoid coarse TiN particles in the steel. In MA steels alloyed only with $\mathrm{Ti}$, when the $\mathrm{Ti} / \mathrm{N}$ stoichiometric ratio $>3.42$, the GCHAZ toughness can be adversely affected. However, with an hypostoichiometric Ti 
addition $(\mathrm{Ti} / \mathrm{N}=2), \mathrm{He}$ and Baker ${ }^{205}$ found that with a low finishing rolling temperature, $800^{\circ} \mathrm{C}$, excellent toughness and mechanical properties were obtained due to grain refinement and strain induced precipitation. Using the $\mathrm{Ti} / \mathrm{N}$ ratio as a guide to avoiding poor toughness was also supported by the work of Okastu et al., ${ }^{321}$ who investigated X65 steels with Ti/ $\mathrm{N}$ ratios from 2 to 4 . Although most investigations have considered the $\mathrm{Ti} / \mathrm{N}$ ratio as a reasonable guide for obtaining MA steels with acceptable toughness levels, Shen and Hansen ${ }^{322}$ concluded from their work, that any effects related to coarse TiN particles should be analysed using $[\mathrm{Ti}][\mathrm{N}]$ product rather than $\mathrm{Ti} / \mathrm{N}$ ratio.

Bang and Jeong ${ }^{319}$ undertook multiple regression analysis to relate the impact absorption of the $\mathrm{HAZ}$ at $-20^{\circ} \mathrm{C}$ for MA steels containing boron, $\mathrm{Ti}$ and $\mathrm{N}$ additions, and a peak temperature of $1350^{\circ} \mathrm{C}$ to provide the following equation:

$$
\mathrm{vE}_{-20}=152+1620(\%<\mathrm{TiN}>)-6520(\%[\mathrm{~N}])
$$

where $\mathrm{vE}_{-20}$ is the impact absorption energy at $-20^{\circ} \mathrm{C}$ and $<\mathrm{TiN}>$ and $[\mathrm{N}]$ are the calculated amounts of TiN and free $\mathrm{N}$ present after the formation of boron nitride. This showed that the detrimental effect of free $\mathrm{N}$ was much greater than the beneficial effect of TiN on HAZ toughness. The optimum content of $\mathrm{N}$ was found to be $60 \mathrm{ppm}$ for the $0.02 \% \mathrm{Ti}$ steel, which is close to the stoichiometric composition. ${ }^{310}$

The HAZ toughness of low carbon steels with different $\mathrm{N}$ contents was also investigated by Mukae et al., ${ }^{320}$ who found that HAZ toughness was closely related to the existing form of $\mathrm{Ti}$ and $\mathrm{N}$. Their equation related impact transition temperature $(\mathrm{K}), \mathrm{T}_{\mathrm{c}}$, to Sol. Ti Sol. N and Insol.Ti.

$$
\left.\mathrm{T}_{\mathrm{c}}=0: 229 \text { Sol:Ti +0:991Sol:N+0:047Insol.Ti-75:1( } \mathrm{R}=0.84\right)
$$

Sol. Ti and Sol. $\mathrm{N}$ are the Ti and $\mathrm{N}$ contents in solution respectively, Insol.Ti is the Ti content present in precipitates and $\mathrm{R}$ is the linear correlation coefficient. Equation 29 
suggests that Sol.N has about a four times stronger influence on $\mathrm{T}_{\mathrm{c}}$ than Sol.Ti, while Insol.Ti has only a minor effect. They proposed that a decrease in $\mathrm{N}$ content in solution can significantly improve HAZ toughness. ${ }^{320}$

As has been considered earlier, the presence of TiN precipitates in the correct size range $(<0.1 \mu \mathrm{m})$ can enhance grain size control through

- refinement of prior austenite grains by pinning and

- by heterogeneous nucleation of ferrite on precipitates of TiN within austenite grains.

To enhance properties, many MA steels contain two or all three of the elements niobium, titanium and vanadium, resulting in complex precipitate compositions, the formation sequence of which is important for mechanical properties, particularly the weld HAZ.Differing results have been reported for Ti-Nb steels. ${ }^{323}$. Crowther and Morrison ${ }^{124}$ observed a decrease in yield strength in C-Mn-Nb-0.01\%Ti hot rolled steels, while the work of Craven et al. ${ }^{107}$ on similar steels showed an enhanced strengthening effect of $\mathrm{Nb}$ when Ti combined with all the N. A similar conclusion was reached with Mo-Nb-Ti steels, when the formation of TiN resulted in dispersion strengthening through $\mathrm{NbC}$ or $\mathrm{Nb}(\mathrm{C}$, N). ${ }^{322}$ Also Li et al. ${ }^{324}$ found that the addition of $\mathrm{Ti}$ to $(\mathrm{Nb}, \mathrm{V})$ steels increased the dissolution temperature of carbonitrides, which can therefore withstand higher temperatures. The differing opinions on the merits of multialloying on HAZ toughness led Zhu et al. ${ }^{311}$ in their review, to conclude that the reports in the public domain were contradictory: more research therefore is required to form a firm conclusion.

In the above discussions, the influence of titanium oxides in the nucleation of $\mathrm{AF}$ has been covered in some detail, particularly in relation to the microstructures of MA steels $^{273,276,282,285}$ and weld metal. ${ }^{271,278,281,283}$ Work by Mu et al., ${ }^{325}$ with the aim of improving control of steel quality during casting and in the HAZ of weldments, includes a 
review of the concept of oxide metallurgy. The idea of deliberately nucleating oxides in the steel prior to welding, which would be present in the HAZ, restricting austenite grain growth and also nucleating AF to improve HAZ toughness, has been explored since the 1990 's. ${ }^{273,282,326}$

In the HAZ, the distribution of oxides after solidification during steelmaking may be greatly affected by the interaction between oxides and the advancing solid/ liquid interface during solidification. Using computer aided X-ray microanalysis, Sawai et al. ${ }^{327}$ compared the distribution of oxides in unidirectional solidified and controlled cooled steels containing $0.08 \mathrm{wt}-\% \mathrm{C}$ steels deoxidized with either $0.004 \mathrm{wt}-\% \mathrm{Ti}$ or an addition of $0.04 \mathrm{wt}-\% \mathrm{Zr}$. The steels were quenched from $1480^{\circ} \mathrm{C}$, which was considered to correspond to the temperature just after the completion of solidification. Using SEM and EDX, oxides were identified as complexities of manganese silicate and $\mathrm{Ti}_{2} \mathrm{O}_{3}$ or $\mathrm{ZrO}_{2}$, distributed in the dendrites. It was concluded that in the zirconium deoxidized steel, $\mathrm{ZrO}_{2}$ distributed more uniformly than $\mathrm{Ti}_{2} \mathrm{O}_{3}$ in the titanium deoxidized steel. In both steels, oxides tended to be in the range 3 to $15 \mu \mathrm{m}$ in diameter, and the number of oxides whose diameter was above $10 \mu \mathrm{m}$ increased with greater fractions of solid. Liquid oxides that form as complex oxides in the titanium deoxidized steel are rejected by the solid/ liquid interface more easily than the solid oxides that are produced by zirconium deoxidization, because the interfacial energy between liquid oxides and liquid metal is smaller than that between solid oxides and liquid metal. ${ }^{326}$ More recently, the AF formation potency of Ti-Rare earth metal (REM)-Zr (TRZ) complex oxides have been investigated in the simulated HAZ of low carbon steel by Nako et al. ${ }^{328}$ The TRZ complex oxide shows a higher AF formation potency than either titanium or aluminium oxides. AF crystals nucleate on the interface between austenite and the Zr-rich oxide phase. Good lattice coherency through the orientation relationship between AF-TRZ, promotes AF nucleation on TRZ complex oxides. The AF-austenite 
orientation relationship is that of Kurdjumov-Sachs (K-S), and the AF-TRZ and K-S 'three phase' orientation relationships is caused by variant selection of AF, in addition to the formation of a rational orientation relationship between Zr-rich oxide phase and the austenite matrix during the HAZ thermal cycle. This result is quite different from that discussed above by Koukabi et al., ${ }^{307}$ who found that while TiN particles promoted AF, $\mathrm{ZrN}$ particles did not.

\section{Titanium additions to modify sulphide inclusions}

The role of titanium additions associated with manganese and sulphur levels in MA steels on hot ductility,centre-line cracking of continuously cast slabs and lamellar tearing during hot rolling has received much attention, for example Refs.64,67,329-332. This role was linked with a drive, which commenced over sixty years ago, to improve the toughness of steels. It was realised that a small ferrite grain size had a beneficial effect on toughness ${ }^{18}$, as did the development of so- called cleaner steels, emanating from the knowledge that in ductile fracture, voids can nucleate at inclusion surfaces, while in brittle fracture, cracks associated with inclusions can propagate, resulting in fracture of a component. The length of the inclusions in the direction of crack propagation has been shown to be related closely to the fracture toughness of the steel, ${ }^{333,334}$ and thus the deformation characteristics of the inclusions are of paramount importance in determining the material properties. Hence, the subject of inclusion shape control was launched. ${ }^{335}$ The main inclusions of concern in steels are based on oxides, silicates and sulphides. Manganese plays several important roles in carbon steels, including solid solution strengthening, $\sigma_{\mathrm{s}}$, and in combination with sulphur as MnS, thereby avoiding the formation of FeS, which is linked to hot shortness. However, MnS inclusions can themselves cause problems. Sims ${ }^{336}$, in a series of publications which he summarized in 1959, explored in detail the $\mathrm{MnS}$ sulphides in cast steel and classified them into three groups. Changing the sulphide 
morphology from stringers, type II to small spheres, type III, together with reducing their volume fraction, proved to be beneficial. Detailed work by Maunder and Charles ${ }^{337}$ observed that manganese sulphides deformed little above $1200^{\circ} \mathrm{C}$, but became more plastic with decreasing temperature until they approached the deformability of the matrix at $900^{\circ} \mathrm{C}$.Also, the size of inclusions was shown to be important, and Segal and Charles ${ }^{338}$ found that $\mathrm{MnS}$ inclusions $<1 \mu \mathrm{m}$ did not deform to long stringers. It is well established that manganese, even at levels of $1.0 \%$, tends to segregate along the centre-line of cast slabs, where it combines with sulphur to form coarse MnS inclusions. Reducing the presence of manganese sulphides in steels by lowering the sulphur content from $\sim 0.05 \%$ to $0.003 \%$, has been employed, but desulphurization adds to the cost of production. An alternative approach ${ }^{339-341}$ is to lower the manganese content of the steel from $1.0-1.5 \%$ to $\sim 0.3 \%$, on the grounds that only a small amount of the manganese is needed to combine with sulphur, the balance providing SSS. This was addressed by Wilson and Chen ${ }^{64}$ and discussed above. In MA steels, the loss of SSS is compensated through dispersion strengthening, $\sigma_{\mathrm{p}}$, provided by carbides, nitrides and carbonitrides of niobium, titanium and vanadium singly, or in combination. ${ }^{342}$ These transition metals also form sulphides, which are harder, and therefore less deformable into the long stringer shap es which are associated with poor toughness. ${ }^{335} \mathrm{~A}$ summary of these effects is given by Baker. ${ }^{4}$ The crystallography and morphology of titanium sulphides which have been identified in MA steels was presented earlier, Table 5.Titanium additions bring about a marked decrease in the size of $\mathrm{MnS}$ inclusions which are otherwise large and globular in Ti-free specimens. The effect on MnS inclusions of additions of titanium in $0.1 \mathrm{C}-1 \mathrm{Mn}-0.02 \mathrm{~S}-0.028 \mathrm{O}-$ $0.0014 \mathrm{~N}$ steels, was studied by Oikawa et $a 1 .{ }^{343}$ who found a marked decrease in the size of $\mathrm{MnS}$ as Ti was increased from 0 to $0.09 \%$. Figure 53 shows that for a steel containing $0.04 \mathrm{Ti}$, the mean radius of $\mathrm{MnS}$ inclusions is about $1 / 3$ the size of those in the titanium-free 
steel, while the number density is about 30 times that seen in the titanium-free steel. The authors ${ }^{343}$ proposed that 'the reduction in size is due to the formation of liquid nuclei of (Ti, $\mathrm{Mn}) \mathrm{O}$ at the solid/liquid interface of iron, which acts as heterogeneous nucleation sites for the formation of liquid droplets of $\mathrm{MnS}$. These droplets become anchored to the interface, subsequently trapped into iron, and solidify as small inclusions.'

\section{Figure 53 near here}

A detailed TEM analysis of precipitates influenced by low manganese contents in a titanium steel was undertaken by Aminorroaya and Dippenaar. ${ }^{344}$ They simulated sulphide precipitation at the centreline during continuous casting by a concentric solidification technique in a steel containing $0.095 \mathrm{C}-0.293 \mathrm{Mn}-0.01 \mathrm{~S}-0.03 \mathrm{Al}-0.025 \mathrm{Ti}$ $0.005 \mathrm{Si}-0.0036 \mathrm{~N}-0.018 \mathrm{P}$. Two main classes of precipitates forming on austenite grain boundaries were observed; $\mathrm{MnS}$ with some iron, and $\mathrm{FeTiS}_{2}$, a $\mathrm{CdI}_{2}$-type structure with a $\mathrm{P} \overline{3} \mathrm{~m} 1$ space group, $\mathrm{a}=0.341 \mathrm{~nm}$ and $\mathrm{c}=0.569 \mathrm{~nm}$. The paper also discussed previous identifications of titanium iron sulphides, Table 5.The variety of crystal structures is tentatively suggested to arise from different ratios of iron to titanium. A second paper ${ }^{67}$ compared the above steel with one with an $0.008 \mathrm{Ti}$ addition. It was concluded that the irontitanium-sulphides in the steel containing $0.024 \mathrm{Ti}$ had a higher titanium and a lower iron content in the $(\mathrm{Mn}, \mathrm{Fe}) \mathrm{S}$ inclusions. The authors considered that the sulphides formed in the higher titanium steel were less deformable. These included cubic MnS, FCC, $\mathrm{a}=0.52 \mathrm{~nm}$, and not $\mathrm{P} 6{ }_{3} \mathrm{mc}$, hex. $\mathrm{a}=0.399, \mathrm{c}=0.644 \mathrm{~nm}$, as identified in their earlier paper ${ }^{67}$

MA steels often contain $\sim 0.2 \% \mathrm{Cu}$, which can provide resistance to atmospheric corrosion. However, in controlled rolled titanium and niobium bearing MA steels, complex copper bearing sulphide phases have been observed, first reported by He and Baker. ${ }^{345}$ Their analytical TEM studies of titanium MA steels showed that in many cases these particles had duplex sizes and were multiphase. Smaller particles, $0 \cdot 2$ to $0-7 \mu \mathrm{m}$ 
dia. had a round or ellipsoidal disc-like morphology. They were present close to and/or within the pearlite banding where segregation of the alloying elements is severe, and tended to be associated with other precipitates such as manganese sulphide and titanium carbonitrides. Occasional larger particles, $>1 \mu \mathrm{m}$ occurred, often associated with spinel $\mathrm{MgO} \cdot \mathrm{AI}_{2} \mathrm{O}_{3}$ and/or $\mathrm{Al}_{2} \mathrm{O}_{3}, \mathrm{Ti}(\mathrm{C}, \mathrm{N}), \mathrm{MnS}$, or silica. These larger particles had complex chemical compositions with a ratio of $(\mathrm{Cu}+\mathrm{Mn}) / \mathrm{S}$ ranging from $0-77$ to 1.42 ; their electron diffraction patterns lead to lattice parameters which are very close to either that of covellite $(\mathrm{CuS})$ or digenite $\left(\mathrm{Cu}_{1.65} \mathrm{~S}\right.$ to $\left.\mathrm{Cu}_{179} \mathrm{~S}\right)$. With segregation of copper and sulphur in the as-cast state, and in the presence of more strongly sulphide forming elements such as manganese, the formation of copper bearing sulphide complexes can occur on cooling during or after processing.

The problems of linepipe steel and pressure vessels for transporting sour media gas $\left(\mathrm{H}_{2} \mathrm{~S}\right)$,trapping of hydrogen by Ti/S containing precipitates, leading to hydrogen embrittlement (HE) and to unpredictable failure has been mentioned earlier. ${ }^{247,248}$ It is known that resistance to $\mathrm{HE}$ is improved by decreasing the diffusible hydrogen by nanocarbides such as $\mathrm{VC}, \mathrm{NbC}$ and $\mathrm{TiC}$. However, while sulphides such as $\mathrm{TiS}$ and $\mathrm{Ti}_{4} \mathrm{C}_{2} \mathrm{~S}_{2}$ are known to form in MA steels ${ }^{61,346,347}$ the effectiveness of sulphides as hydrogen traps does not appear to have been investigated. Escobar et al. ${ }^{348}$ invstigated the hydrogen takeup in low carbon , 0.01Ti-0.0008N steels. TEM EDX analysis did not identify the expected precipitates of TiS and $\mathrm{Ti}_{4} \mathrm{C}_{2} \mathrm{~S}_{2}$, but found the average precipitate composition to be close to $\mathrm{Fe}_{1.2} \mathrm{Ti}_{0.8} \mathrm{~S}_{2}$. It was this precipitate composition they considered to be responsible for hydrogen trapping.

\section{Hot Ductility of Titanium Microalloyed Steels}


In continuous casting, cracks can initiate in the mould due to low hot ductility, and then propagate by thermal cycling when the solid strand, which is cast in a curve, is straightened.

The evaluation of hot ductility was originally undertaken by torsion testing, as this method was considered to provide a good simulation of hot rolling. ${ }^{349,350}$ For investigating continuous casting failures and predicting the likelihood of transverse cracking during the casting process, hot tensile testing using a Gleeble machine is often the preferred method. ${ }^{329,330,351-355}$ The sample is cooled at the rate experienced by the surface of the strand during the continuous casting operation, $\sim 60 \mathrm{~K} \mathrm{~min}^{-1}$, and is strained at rates between $10^{-3}$ and $10^{-4} \mathrm{~s}^{-1}$, which are chosen to simulate those associated with straightening. ${ }^{329}$ The variation in hot ductility with temperature is obtained by plotting reduction in area, RA\%, versus test temperature, as in Fig. 54. For both the cast and wrought states, a decrease in hot ductility, described as a ductility trough, occurs between 700 and $1200^{\circ} \mathrm{C}$; intergranular fracture is observed. The ductility trough has implications, both for conventional continuous cast and for thin slab cast steels. ${ }^{329,330,351,353}$ Several explanations have been suggested for the ductility trough, including failure within a thin film of ferrite at the austenite grain boundaries, or SIP of carbonitrides, which pin austenite grain boundaries and therefore reduce boundary mobility. Fig. 54, taken from the work of Crowther and Mintz, ${ }^{356}$ shows that refining the austenite grain size is general beneficial to hot ductility, as it reduces the width of the trough and increases the minimum RA\%. This is also shown in Fig.55, which compares data for Ti containing and $\mathrm{Ti}$ free steel that decreasing the austenite grain size from 350 to $70 \mathrm{~mm}$ increased the RA by $20 \%$, with Ti steels being particulary effective. The hot ductility of as-cast $\mathrm{Nb}, \mathrm{Ti}$ and $\mathrm{Nb}$-Ti bearing low-carbon steels was also investigated by Luo et al. ${ }^{354}$ From hot tensile testing of in-situ melted specimens, they found that the addition of $0.014-0.04 \% \mathrm{Ti}$ to an $0.1 \% \mathrm{C}-0.03 \% \mathrm{Nb}-005 \% \mathrm{~S}-0.005 \% \mathrm{~N}$ steel 
lead to a large volume fraction of fine SIP at temperatures up to $1000^{\circ} \mathrm{C}$, with serious deterioration of the hot ductility in spite of the type of prior thermal history. Generally three types of precipitates were recorded in the $\mathrm{Ti}-\mathrm{Nb}$ microalloyed steels, having different sizes and compositions: coarse boundary precipitate, coarse frond-like and fine SIP. In their steels it was found and explained by thermodynamic modelling, that the beneficial effect of Ti can only be achieved in some instances with high nitrogen ( $80-100 \mathrm{ppm})$ and low titanium contents $(0.02 \%)$, i.e. a low $\mathrm{Ti} / \mathrm{N}$ ratio, which greatly encouraged coarse $\mathrm{Ti}-\mathrm{Nb}$ precipitation at high temperatures and leaving less $\mathrm{Nb}$ in solution to provide fine SIP. ${ }^{354}$ This is in line with previous descriptions provided by Mintz. ${ }^{357}$ Luo et al. ${ }^{354}$ concluded that a small addition of Ti might be considered to be advantageous to the hot ductility,but only for the case of electric arc steels, which typically have a high nitrogen level.

\section{Figs 54 and 55 near here}

Over many years, Mintz and co-workers ${ }^{330,355-360,363,364}$ have conducted extensive investigations on hot ductility of steels to understand the role of titanium, often combined with other transition metals, $\mathrm{Nb}$ and $\mathrm{V}$, together with $\mathrm{Al}, \mathrm{N}$ and $\mathrm{C}$. They stress that care must be taken with titanium additions, particularly where the $S$ level is $\geq 0.015$. Steels detailed in Table 19, were heated to $1330^{\circ} \mathrm{C}$ and cooled at $60^{\circ} \mathrm{C} \mathrm{min}^{-1}$ to the test temperature, then strained to failure at a strain rate of $3 \times 10^{-3} \mathrm{~s}^{-1}$. It can be seen in Fig. 56 that adding Ti $(0.02-0.03 \%)$ to the $\mathrm{C}-\mathrm{Mn}$ steels, can have a beneficial effect on hot ductility by reducing both the depth and width of the trough. ${ }^{329}$ This is due to the restrained effect on austenite grain growth by coarse TiN particles still remaining out of solution after soaking at $1330^{\circ} \mathrm{C}$. For steels 4-8 in Table 19, it was considered that the suppression of AlN precipitation, due to removal of nitrogen to form the more stable TiN, resulted in improved hot ductility shown in Fig. 56. It should be noted that in the steels considered in Table 19 the $\mathrm{S}$ levels at $\geq 0.015 \%$ are higher than many produced today at $\sim 0.005 \%$ S.However, as discussed by Luo et al., ${ }^{354}$ 
precipitation of TiN does appear to be beneficial for hot ductility of MA steels containing lower levels of sulphur.

\section{Table 19 and Fig.56 near here}

However, if due to increased cooling rates during the simulation, fine TiN particles precipitate restricting particle growth, the beneficial influence of the titanium addition is lost. Therefore, variation in cooling rates during hot tensile testing, to simulate as close as possible the conditions pertaining to the continuous casting operation, have been an important objective in this research. ${ }^{329,361}$ A major concern in simulating the continuous casting process with a Gleeble machine is in deciding the thermal programme that will ensure that the appropriate RA\% is recorded. ${ }^{360,361,362}$ Introducing a cooling regime similar to that undergone by the strand during commercial continuous casting has been shown for low $\mathrm{C}$ low $\mathrm{Ti}$ containing $\mathrm{C}-\mathrm{Mn}-\mathrm{Nb}$ steels, always to result in an improvement in hot ductility below $900^{\circ} \mathrm{C}$. When the test $\mathrm{RA} \%$ is $>40 \%$, the steel should not be susceptible to this cracking problem. ${ }^{355}$ Mintz and Crowther ${ }^{363}$ have discussed in detail the reasons noted for the different results obtained between laboratory tests and work trial involving the hot ductility of TiMA steels. Generally, Ti additions have been found to benefit surface quality and reduce the propensity to cracking on straightening during continuous casting. In contrast to industrial experience, the simple laboratory tensile test, in which an average cooling rate to the test temperature after melting has been used, often shows Ti additions to give very poor ductility or at best no improvement. ${ }^{354,358-361}$ This may be because the laboratory casting conditions do not simulate sufficiently the commercial casting conditions. It is likely that for commercial casting, the segregation of Ti to the interdendritic boundaries is greater than occurs in the small tensile specimens so that precipitation is coarser but as will be referred to later in this section, temperature cycling of the tensile specimens to simulate the conditions during the cooling of the strand has an overriding influence in controlling the ductility in these steels. ${ }^{362,363}$ 
Many MA steels now have additions of Nb, V and Ti. Banks et al. ${ }^{364}$ studied the hot ductility of in situ melted tensile specimens of $\mathrm{Ti}-\mathrm{Nb}$ containing steels having $\mathrm{C}$ contents in the range $0 \cdot 12-0 \cdot 17 \%$ with and without $\mathrm{V}$, examined over the temperature range $700-1000^{\circ} \mathrm{C}$. In the temperature range $750-850^{\circ} \mathrm{C}$, the $\mathrm{Nb}$ containing steels showed an improvement in the ductility as the Ti/ $\mathrm{N}$ ratio increased. However, ductility at $800^{\circ} \mathrm{C}$ was still below the $35-40 \%$ reduction in area values required to avoid transverse cracking. This was attributed to the copious precipitation of $\mathrm{NbTi}(\mathrm{CN}),<40 \mathrm{~nm}$ in size, along the grain boundaries, with finer precipitates within the grains. Adding $\mathrm{V}$ to the $\mathrm{Ti}-\mathrm{Nb}$ containing steels resulted in significantly improved ductility with reduction in area values at $800^{\circ} \mathrm{C}$ in excess of $45 \%$. The improvement was considered to be due to a decrease in the fraction of fine particles. In view of this improved ductility, the authors' claim that the addition of $\mathrm{V}$ eliminated the problem of transverse cracking of industrial $\mathrm{Ti}-\mathrm{Nb}$ containing steel slabs. They also noted that the $\mathrm{N}$ content of these steels seems to be very important probably because it controls the volume fraction of both $\mathrm{Ti}$ rich and $\mathrm{Nb}$ rich precipitates, and should be as low as possible.

\section{Conventional and Direct Charged Thin Slab Casting}

The importance of the compositional, size and volume control of oxide, nitride and sulphide based inclusions to avoid defects in the final product, which lead to a deterioration in mechanical and toughness properties of Ti-containing MA steels, has been discussed above.These problems often originate with the steelmaking process.For example, shrouding, argon protection and sealing procedures to reduce reoxidation and nitrogen pickup during liquid transfer operations are well documented, and have been discussed by McPherson and McLean ${ }^{365}$ and by Zhang and Thomas. ${ }^{366}$ By shrouding between the ladle and the tundish, the main effects are a reduction of total oxygen and nitrogen in the slab.As reported by DeMasi and Hartman, ${ }^{367}$ with additional argon sealing, oxygen was lowered from 48 ppm to $29 \mathrm{ppm}$ and to $23 \mathrm{ppm}$. Also, improving the bayonet system between the ladle nozzle and 
ladle shroud lowered the nitrogen pick-up from 8 to $<1 \mathrm{ppm} .{ }^{368}$ However, neither of the above noted reviews ${ }^{365,366}$ includes details on the effect of Ti additions.

Pickering ${ }^{1}$ in his 'Overview of Titanium Microalloyed Steels' of 1994 pointed out that 'because of its affinity for $\mathrm{O}$ and $\mathrm{S}$, if the Ti is required to be dissolved in the steel, the melt must be heavily deoxidised and desulphurised prior to the Ti addition. Deoxidation is by $\mathrm{Al}$ and desulphurisation by $\mathrm{Ca}$ is very effective. To prevent reaction between $\mathrm{Ti}$ and air, liquid metal streams must be shrouded. The Ti oxides produced in unshrouded metal streams can also lead to ladle or tundish nozzle blockage particularly in the small metering nozzles of continuous casting billet machines. This usually occurs with more than $0.02 \% \mathrm{Ti}$ and can lead to surface problems due to the occurrence of scums in the continuous casting mould and nonmetallic inclusions in the final product.' A more recent example ${ }^{369}$ is for continuous casting of a Ti interstitial free steel, with a tundish average chemistry of:

C-0.0013, Si-0.004, S-0.009, P-0.009, Mn-0.089, N-0.0029, totalAl-0.04, Ti-0.053, Ca0.0003 .

To control castability, clogging and product quality, the practice outlined below is followed:

- a controlled level of oxygen on arrival at degassing,

- limiting chemical reheating, an interval, ideally to be $5 \mathrm{~min}$, between the final Al addition and the Ti addition,

- for exposed auto parts, avoiding further Al, scrap or alloy trim additions after deoxidation, $15 \mathrm{~min}$. minimum end of treatment to ladle open floatation time.

In continuous casting, mould powders constitute an area of importance, which is summarized by Kromhout: ${ }^{370}$ 'during casting, mould powder melts on the steel surface, forming a layer of liquid mould slag. Subsequently, the mould slag infiltrates between the steel shell and the oscillating mould, creating a thin slag film which solidifies into glassy 
and crystalline phases. The properties of the slag film dictate the main mould powder functions of strand lubrication and mould heat transfer.' Mills et al. ${ }^{371}$ consider that 'the role of the slag in continuous casting is to provide the following functions:

- protect the meniscus of the steel from oxidation

- $\quad$ provide thermal insulation to protect the steel surface from freezing

- provide liquid slag to lubricate the strand

- $\quad$ provide the optimum level of horizontal heat transfer for the steel grade being cast and

- $\quad$ absorb inclusions from the steel.'

It has been observed that powder consumption, $Q_{\mathrm{s}}$, is frequently lower than predicted when casting steel grades containing titanium. This is thought to be due to the formation of $\operatorname{TiN}$ or $\operatorname{Ti}(\mathrm{C}, \mathrm{N})$ which has a low solubility in the slag pool and thus, tends to exist as solid particles. ${ }^{372 .}$ These particles agglomerate through turbulent collisions and the agglomerates restrict the slag flow when they are sited in the mouth of slag/mould channel, shown schematically in Fig. $57 .{ }^{373}$ The solid particles also increase the slag viscosity and thus, decrease $Q_{\text {s. }}$ Alternatively, $\mathrm{TiO}_{2}$ particles can form perovskite $\left(\mathrm{CaO} . \mathrm{TiO}_{2}\right)$ which has a high-melting temperature and thus reduces both the thickness of the liquid slag film and $Q_{\mathrm{s}}$. It is necessary to keep the basicity, $\left(\mathrm{CaO} / \mathrm{SiO}_{2}\right)<1.0$ to avoid perovskite formation. ${ }^{373}$ Others suggest that in some situations there is an advantage in forming perovskite: a fruitful research topic!

\section{Fig.57 near here}

McPherson and McIntosh ${ }^{374}$ noted that crusts can form in the mould, which may lead to beak-outs when continuously casting low carbon titanium steels. Crust formation leading to severe skin lamination on cold-reduced coil, was normally associated with 
titanium enriched mould powder. The move in many recent MA steels of reducing the titanium addition to $\leq 0.015 \%$, should go some way to avoiding some of the problems associated with mould powders during continuous casting.

The background to the DSTC processes, known also as thin slab direct rolling (TSDR) and compact strip production, which originated in 1989 in Crawfordsville, IN, USA, has been very well described by Glodowski. ${ }^{375}$ Compared to conventional slab casting, the thin slabs solidify much quicker, show less segregation, smaller inclusion sizes and a more homogeneous microstructure. In addition, when scrap based electric arc furnace routes are used, the refining process takes place in separate ladle-furnace operations. Thin slabs will have a very coarse as- cast grain size before hot rolling, experience a smaller total reduction during rolling and record higher nitrogen and residual element concentrations. Some of these aspects can result in a loss of microalloying efficiency as a consequence of premature precipitation before rolling.

The TSDC process involves higher casting speeds and rapid cooling at $3.5-6.0 \mathrm{~m} \mathrm{~min}^{-1}$ necessary for high-volume slabs from 50 to $100 \mathrm{~mm}$ in thickness, compared with $0.75-1.25$ $\mathrm{m} \mathrm{min}^{-1}$, for conventional rolling. Without undergoing a $\gamma \rightarrow \alpha$ phase transformation, the slab is directly charged into a tunnel holding furnace at a temperature between $1100^{\circ} \mathrm{C}$ and a maximum of $1150^{\circ} \mathrm{C}$, compared to conventional rolling with soaking at $1200-1250^{\circ} \mathrm{C}$ for up to $8 \mathrm{hr}$ before rolling. Finally, the $50 \mathrm{~mm}$ slab will enter directly into a 5 - or 6 -stand finishing mill, normally without undergoing a roughing mill reduction. When processing thicker $80-$ $100 \mathrm{~mm}$ slabs by the TSDC process, casters will have one or two roughing mills prior to a 5stand finishing mill. Retaining part of the heat of casting in the slabs through to the rolling process, and casting to a "'near net shape,' reduces the amount of hot working necessary to roll to the final gauge.

Fig 58a/b near here 
A comparison between conventional continuous casting and TSDC is shown schematically in Fig.58, taken from Sha et al. ${ }^{376}$ and from Glodowski. ${ }^{375}$ Fig. $58 \mathrm{~b}$ indicates the metallurgical processes which are taking place at each stage of the TSDC process. It is noted that mini-mill processes which make thin slabs, use lower reheat temperatures and

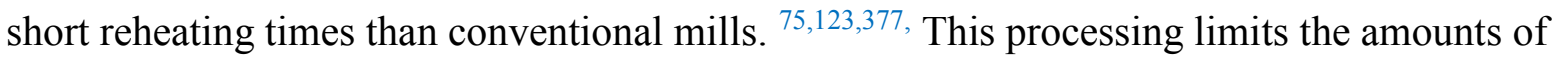
elements that can be added and held in solution to be precipitated later for microstructural control. So, multiple strengthening mechanisms, using various elements, need to be employed to achieve strength levels comparable to those attained with conventional rolling mills using single-element microalloying combined with long high-temperature slab soaking times. A particular theme running through an excellent review of 52 papers published up to 2005 , which are considered in some depth by Rodriguez-Ibabe, ${ }^{378}$ is the dependence on microstructure of the production parameters of TSDR technology route. He considered this route particularly attractive to MA steels, because the microstructural development during TSDR, and the mechanical properties of the final coil, differ from equivalent steels conventionally controlled rolled.

The growing use of industrial facilities based on near net-shape casting routes may introduce new opportunities in Ti microalloying. Bruns and Kasper, ${ }^{379}$ who together with Priestner and Zhou, ${ }^{380}$ published some of the earliest studies describing the laboratory simulation of TSDR, considered the microstructural evolution of $\mathrm{Nb}-\mathrm{Ti} \mathrm{MA}$ steels. The former ${ }^{379}$ found that direct charging resulted in a greater dissolution of niobium and titanium compared with cold charging, leading to more precipitation of $(\mathrm{Nb}, \mathrm{Ti})(\mathrm{C}, \mathrm{N})$, with a consequential greater strength in the final product. ${ }^{377}$

A series of papers involving with $\mathrm{Li}^{123,128,317,381,382}$ also used laboratory simulation to study several MA steels, which were vacuum melted, cast into moulds and controlled cooled at $3.5^{\circ}$ $\mathrm{C} \mathrm{s}^{-1}$, transferred to an equalisation furnace and held at either 1050,1100 or $1200^{\circ} \mathrm{C}$ for 
between 30 and 65 min prior to rolling to $7 \mathrm{~mm}$ strip in 5 passes. After rolling, the strip was cooled under water sprays to simulate run-out table cooling, with a cooling rate of $18^{\circ} \mathrm{C} \mathrm{s}^{-1}$, and the aim end temperature was $600^{\circ} \mathrm{C}$. Following cooling, the strip was immediately transferred to a furnace set at $600{ }^{\circ} \mathrm{C}$ and slow cooled to simulate coiling. Samples were quenched after casting, after equalisation, after the fourth rolling pass and after coiling, to follow the evolution of both precipitation and mechanical and impact properties. Using this TSDR simulation in an investigation comparing the effect of an $0.008 \mathrm{Ti}$ addition to a $0.10 \mathrm{Vsteel}$, Li et al. ${ }^{123}$ reported that for both $\mathrm{V}$ and $\mathrm{V}$-Ti steels, the average austenite grain size in the one-fourth thickness position of the as cast ingot was $1 \mathrm{~mm}$. This was reduced to a ferrite grain size of $4.8-7.2 \mu \mathrm{m}$ in the final strip. After equalisation at $1050^{\circ} \mathrm{C}$, precipitation of $\mathrm{VN}$ in austenite in the $\mathrm{V}$ steel was replaced by $(\mathrm{V}, \mathrm{Ti}) \mathrm{N}$ in the $\mathrm{V}-\mathrm{Ti}$ steel. Both types of precipitates, which were in the range of $2-10 \mathrm{~nm}$, made a contribution of $\sim 90 \mathrm{MPa}$ to dispersion strengthening. However, the yield strength of the V-Ti steel was lowered by the removal of a significant fraction of vanadium and nitrogen to form $(\mathrm{V}, \mathrm{Ti}) \mathrm{N}$ in austenite, thereby reducing the volume fraction of $\mathrm{V}(\mathrm{C}, \mathrm{N})$ particles precipitated in ferrite. Similar observations have been reported for conventionally rolled V-Ti ${ }^{124,383}$ and Ti steels. ${ }^{384}$ In the $\mathrm{V}-\mathrm{Nb}-\mathrm{Ti}$ steels, after equalisation at $1200^{\circ} \mathrm{C}$, Ti- rich precipitates included large $\leq 1 \mu \mathrm{m}$ cubic TiN and dendritic particles, also present after casting, plus spherical (20-50nm), cuboidal $(10-70 \mathrm{~nm}$, ave. $35 \mathrm{~nm})$ and cruciform particles, Fig. $12(30-60 \mathrm{~nm}$, ave. $42 \mathrm{~nm}) .{ }^{317}$ These smaller particles were frequently observed to outline prior austenite grain boundaries, Fig.17, and their density increased with decreasing equalisation temperatures, $1100^{\circ} \mathrm{C}$ and $1050^{\circ} \mathrm{C}$. The addition of $\mathrm{Ti}$ to $\mathrm{V}-\mathrm{Nb}$ steels, resulted in a reduction of the yield strength due to precipitation in austenite of nanosized particles of $(\mathrm{V}, \mathrm{Nb}, \mathrm{Ti}) \mathrm{N}$, characterised by both EDX and PEELS. 381,382 However, these transition metal nitrides did not coarsen during the final stages of processing, retaining a size of $\sim 7 \mathrm{~nm}$. Others have reported previously the retention of fine 
TiN based precipitates after casting and equalisation processing. Earlier work by Sage et al. ${ }^{385}$ considered the relevance of solidification and post-solidification cooling rates to particle size, supported the observations of Li et al. ${ }^{317}$ Both Sage et al. ${ }^{385}$ and Arribas et al. ${ }^{386}$ showed that fine TiN particles could precipitate when rapid cooling rates were achieved. The faster cooling rates taking place during the continuous casting of thin slabs and beam blanks, compared to conventional sections, for hypostoichiometric Ti/N (>3.4) compositions, result in smaller TiN precipitates. ${ }^{372}$ After casting $50 \mathrm{~mm}$ thin slabs, Nagata et al. ${ }^{387}$ reported TiN mean particle sizes between $20 \mathrm{~nm}$ and $27 \mathrm{~nm}$, while Arribas et al. ${ }^{386}$ obtained TiN mean particle size, $2 \mathrm{r}$, of between $12 \mathrm{~nm}$ and $41 \mathrm{~nm}$ following reheating Ti steels for 10mins at $1220^{\circ} \mathrm{C}$,produced by'beam blank' casting. The effect of cooling rate on the mean particle size of TiN, collated by López and Rodriguez-Ibabe ${ }^{388}$ is shown in Fig.59: for $1000^{\circ} \mathrm{C} \mathrm{min}^{=1}$, a $2 \mathrm{r}$ of $<10 \mathrm{~nm}$, is predicted by extrapolation, which compares well with $\sim 7 \mathrm{~nm}$ measured by Li et al. ${ }^{381,382}$

\section{Fig.59 near here}

Liu and Jonas ${ }^{389}$ developed a technique for determining precipitation-time-temperature relations particularly applicable to MA steels, such as Ti steels. ${ }^{390}$ Their stress relaxation technique can investigate precipitation phenomena during cooling, allowing a parallel to be made with controlled rolling and fast cooling rates, such as occur during TSDC operations. The measured fractional softening, normally expressed as the softening ratio $\mathrm{X}$, which occurs between deformation passes during rolling when the load is absent, is a combination of recovery and static recrystallization processes. Fernández et al. ${ }^{391}$ have considered the approaches made to distinguish the parts of softening due only to recovery or only to recrystallization. Experimentally, the softening kinetics have been investigated by interrupted torsion $^{391}$, plain strain compression ${ }^{392}$ or compression tests ${ }^{389}$, the latter often using a

Gleeble simulator. ${ }^{155,393-396}$ In MA steels, with the exception of the study of Leduc and 
Sellars, ${ }^{392}$ the precipitation of nitrides, carbonitrides and carbides on dislocations introduced by the deformation (SIP) have been shown to result in a delay in the softening processes.Fig.60, shows an example of an interrupted compression test and the method of obtaining $\mathrm{X} .{ }^{396}$ Here is the $\sigma_{\mathrm{m}}$ maximum flow stress and $\sigma_{0.2 \%}$ the flow stress at a plastic strain of $2 \%$, both of the first curve, while $\sigma_{\mathrm{r}, 2 \%}$ is the flow stress in the second curve at the same plastic strain.

From the extent of the delay, usually recorded in seconds for a given temperature, the precipitation-time-temperature curves ${ }^{155,389}$, such as that in Fig.22, are compiled.

\section{Fig 60 near here}

Investigations on stress relaxtion related to SIP include those made on $\mathrm{Ti}(\mathrm{C}, \mathrm{N}),{ }^{388,393} \mathrm{TiN}$, $385,392 \mathrm{TiC},{ }^{293}(\mathrm{Nb}, \mathrm{Ti}) \mathrm{C}{ }^{155},(\mathrm{Ti}, \mathrm{Mo}) \mathrm{C}^{394}$ and $\mathrm{Ti}_{4} \mathrm{C}_{2} \mathrm{~S}_{2}{ }^{395}$. Arribas et al. ${ }^{386}$ found that the fine TiN particles present in the steel prior to rolling, in addition to decreasing grain growth by pinning the austenite grains, produced a beneficial delay in both static and dynamic recrystallization kinetics of austenite,Fig.61. The result is additional austenite grain refinement compared with conventional rolling.

\section{Fig 61 near here}

This view is in agreement with earlier work by Roberts et al. ${ }^{397}$ who coined the phrase 'recrystallisation hot rolling', to introduce a process for Ti-0.015, V $-<0.08, \mathrm{~N}-0.011$ steels which produced a fine recrystallized austenite grain size by finish rolling at $1000-900^{\circ} \mathrm{C}$.They showed that this was due to a dispersion of small stable TiN precipitates formed during continuous casting, and attributed the delay in recrystallization to the Zener drag effect exerted by the TiN particles on the recrystallizing boundaries.

In the case of Ti-Nb-N steels, the results in Fig.61 from Sage et al. ${ }^{385}$ and the RodriguezIbabe group, ${ }^{388,399}$ show experimental data from several hypostoichiometric Ti-MA steels, having a range of fine $\mathrm{TiN}$ particle sizes, for the time to obtain $50 \%$ static recrystallization 
plotted as a function of deformation temperature, prior to hot deformation.Data corresponding to TiN particle sizes of 12 and $41 \mathrm{~nm}$ is corrected for comparison with an initial austenite grain size of $700 \mu \mathrm{m}$. The solid lines represent the behaviour associated with conventional C-Mn grades or solute drag effect, while dashed lines correspond to the delay exerted by fine particles.With a mean particle size of $99 \mathrm{~nm}$, the Ti steel behaves in a similar manner to a C-Mn steel, showing no additional delay. After deformation at $1050^{\circ} \mathrm{C}$, when some SIP can occur, there is a delay in recrystallization. As the TiN particle size decreases to $41 \mathrm{~nm}$ and then to $12 \mathrm{~nm}$, the delay becomes significant. The authors concluded that the fine TiN particles introduced a delay which should be added to that produced by the solute drag effect of $\mathrm{Nb}$ in solution. ${ }^{388}$

An investigation was undertaken by Nagata et al. ${ }^{387}$ to assess the potential of obtaining and utilising titanium nitride refinement, primarily for austenite grain size control, through the greater post-solidification cooling rates associated with the TSDC process. They compared eight commercially TSDC cast steels with a conventionally cast (CC) steel. The $0.05 \mathrm{C}, 1.2 \mathrm{Mn}$ steels had titanium contents in the range of $0.009-0.048 \%$ and $\mathrm{Ti} / \mathrm{N}$ ratios between 0.6 and 6 . Slabs were reduced from an initial thickness of $\sim 50 \mathrm{~mm}$ to a sheet thickness between 4.32 and $8.69 \mathrm{~mm}$. The precipitation behaviour was explored with extensive TiN particle size distributions evaluated by TEM. Nagata et al. ${ }^{387}$ used the form of solubility curves designed by Wadsworth et al. ${ }^{400}$ shown in Fig. 62 for Ti vs N. Here the average particle sizes from the end product of six of the steels are included, with the solubility curves for four temperatures: $1509^{\circ} \mathrm{C}$ representing the liquid phase, while $1500^{\circ} \mathrm{C}, 1250^{\circ} \mathrm{C}$ and $1000^{\circ} \mathrm{C}$ are typical of the solid phase. Despite designing the steels to prevent precipitation in the liquid state, TiN cubic particles of $\sim 1 \mu \mathrm{m}$ were found in some steels after casting.Fig. 63 collates the mean particle for the end product for the six steels, the $\mathrm{Ti}$ and $\mathrm{N}$ contents being provided in this figure. The hyperstoichiometric steels (excess 
titanium) exhibited cubic TiN particles of mean size $<40 \mathrm{~nm}$ after casting and soaking, but showing dramatic coarsening to $>90 \mathrm{~nm}$ after hot rolling. Hypostoichiometric steels, which contain excess carbon and/or nitrogen, exhibited no coarsening in the end product.

Furthermore, comparison of the particle sizes of the TSDR and CC steels showed a shift to larger sizes and greater relative frequency for the particles in the CC steel. This work concentrated on obtaining good particle size data at various stages in the TSDC process and assumed that the precipitates were TiN.However, later work using TEM/PEELS analysis by Craven et al, ${ }^{107}$ as described earlier,produced evidence that particles in Ti steels which have additions of carbon and nitrogen, precipitated initially as high nitrogen $\mathrm{Ti}(\mathrm{C}, \mathrm{N})$ particles, and on cooling, $\operatorname{Ti}(\mathrm{C}, \mathrm{N})$ with increasingly higher $\mathrm{C}$ contents.As far as is known, research combining data on particle size distribution of titanium carbonitrides as a function of $\mathrm{C} / \mathrm{N}$ at different stages during thermomechanical treatment is not available in the open literature.

Several other papers have been based on commercial TSDC production of titanium containing MA steels. The synergistic effect of Mn and Ti inTi-MA strip produced on a TSRC plant was considered by Mao et al. ${ }^{401}$ It was found that increasing Mn from $0.5 \%$ to $1.1 \%$ in a MA steel containing $\mathrm{Ti}>0.08 \%$ raised $\sigma_{\mathrm{y}}$ from $580 \mathrm{MPa}$ to $730 \mathrm{MPa}$ due to changes in the $\gamma \rightarrow \alpha$ transformation temperature. Thermocalc calculations for the $0.5 \% \mathrm{Mn}$ steel showed that ferrite containing $0.012 \% \mathrm{C}$ was associated with an $\mathrm{Ar}_{3}$ of $800^{\circ} \mathrm{C}$ and an $\mathrm{Ar}_{1}$ of $600^{\circ} \mathrm{C}$; for the $1.5 \mathrm{Mn}$ steel these temperatures were reduced to $\mathrm{Ar}_{3}$ of $650^{\circ} \mathrm{C}$ and $\mathrm{Ar}_{1}$ of $580{ }^{\circ} \mathrm{C}$. With a $\mathrm{C}$ content of $0.025 \%$, TiC precipitation in ferrite was enhanced, resulting in an increase in $\sigma_{\mathrm{y}}$. Precipitation of TiN was calculated to occur in austenite and limit the grain size. Based on microhardness determination, the estimated $\sigma_{\mathrm{y}}$ values were $542 \mathrm{MPa}$ for the $0.5 \% \mathrm{Mn}-0.079 \% \mathrm{Ti}$ steel and $761 \mathrm{MPa}$ for the $1.5 \% \mathrm{Mn}-0.11 \% \mathrm{Ti}$ steel.

In a second paper, Wang et al. ${ }^{402}$ used electron backscatter diffraction (EBSD) technology and high resolution TEM, extending the microstructural characterisation to understand the 
synergistic effects of Mn and Ti in TSDC processed MA steel. The compositions of the hyperstoichiometric Ti/N ratio MA steels which they investigated are given in Table 20.

\section{Table 20 near here}

However, based on equations 6 and 10, calculation of the solution temperature of TiN in steel 2 predicts that TiN precipitates start to nucleate in liquid steel. The paper reports that large TiN particles are present. This therefore makes little use of the $0.012 \% \mathrm{~N}$.

Steel 2 showed a higher frequency of low angle grain boundaries associated with a greater weight fraction of TiC particles, $26 \%$, compared with $7.6 \%$ in steel 1 . The particle size distribution of steel 2 was $24 \%$ for TiC particles with $<5 \mu$ minimum size compared with $6 \%$ for steel 1 .The authors calculated that this difference was responsible for the higher $\sigma_{\mathrm{p}}$ of steel 2, due to a greater contribution to $\sigma_{0.2}$, as seen in Table 20. The same group ${ }^{393}$ studied SIP in steel 2 using an interrupted deformation technique based on a Gleeble simulator mentioned earlier. ${ }^{155,156}$ The precipitation-time-temperature curves of the microalloyed steel, showing the start and finish times of SIP were very similar to those shown in Fig.22 obtained for $\mathrm{Nb}$ and $\mathrm{Nb}-\mathrm{Ti}$ steels, $\mathrm{P}_{\mathrm{s}}$ being between 1-10s and $\mathrm{P}_{\mathrm{f}} 500-2000 \mathrm{~s}$, depending on temperature. The finest particles, around 5nm, extracted on to carbon replicas, were considered to be too small for characterising by EDX.They were judged to be TiC,while larger spherical particles were confirmed to be $\mathrm{Ti}_{4} \mathrm{Si}_{2} \mathrm{C}_{2}$ present after casting, having a volume fraction remaining largely unchanged during the experimental cycle.

Detailed data about a TSCR process used at TATA Jamshedpur were given by Bhattacharaya and Misra. ${ }^{403}$ The steels in this study had a composition of $0.03 \% \rightarrow 0.07 \% \mathrm{C}$ $0.7 \% \mathrm{Mn}-0.01 \% \rightarrow 0.04 \% \mathrm{Nb}, 0.02 \% \operatorname{maxTi}, 0.0004 \% \mathrm{Nmin}$. The slab thickness was reduced from $57 \mathrm{~mm}$ to a coil thickness of $2.5 \mathrm{~mm}$. After the TSCR processing, a $\sigma_{\mathrm{y}}$ of $\sim 450 \mathrm{MPa}$ was achieved with a predominantly ferrite grain structure of $10-12 \mu \mathrm{m}$ and pearlite content of 2 $5 \%$ obtained through optical microscopy which was used to study microstructure The 
authors concluded that a $\mathrm{Ti}$ addition up to $0.02 \%$ gave no significant increase to the $\sigma_{\mathrm{y}}$ levels.

A TSDR process, similar to that described by Glodowski, ${ }^{375}$ called the Angang strip production process, ${ }^{404}$ has been used with medium thin slab of $170 \mathrm{~mm}$, by installing a roughing mill after the reheating furnace and before the finishing mill. Sha and Sun $376,404,405$ studied commercial sized slabs of an $0.04 \mathrm{C}-0.06 \mathrm{Nb}-0.30 \mathrm{~V}-0.014 \mathrm{Ti}-0.23 \mathrm{Mo}-0.0032 \mathrm{~N} \mathrm{MA}$ steel in the as cast condition. The slower cooling rate of the $170 \mathrm{~mm}$ slab influenced the secondary dendrite arm spacing and the austenite grain sizes $(320-2200 \mu \mathrm{m})$, which were slightly larger compared to the microstructure of specimens taken from a corresponding TSDC route processing of $53 \mathrm{~mm}$ thick slab $(150-2000 \mathrm{~mm})$. Dendritic precipitates were mainly niobium rich carbonitrides, while large cubic $(150-600 \mathrm{~nm})$ and fine cubic (10-40 $\mathrm{nm}$ ) particles were characterised as titanium rich carbonitrides. The refinement of the coarse grained austenite in the same steel during roughing rolling after simulated equalisation, and more recently, after preliminary rolling in a roughing mill installed between the reheating furnace and the finishing mill, was also examined by Sha and Sun. ${ }^{403}$ The microstructural homogeneity using the Angang strip production route was found to be better than the TDSR route without additional rolling, due to a higher reheating and entry temperatures and a larger reduction with the thicker slab. The coarse grained austenite $(\sim 1 \mathrm{~mm})$ that developed during equalisation (compared with $\sim 250 \mathrm{~mm}$ in as-reheated) in the $\mathrm{Nb}-\mathrm{V}-\mathrm{Ti}$ steels was modelled by Sha and Sun. ${ }^{403}$ following an approach used by Uranga et al. ${ }^{400}$ These authors ${ }^{403-406}$ concluded that their models highlighted production pit-falls which should be avoided, supporting the view that strict control of grain size at each stage of the TDSR process is essential.

The application of the TDSR process for thin slab production for pipeline MA steels, reducing $60 \mathrm{~mm}$ slab to $6-12.5 \mathrm{~mm}$ thick strip, was reported by Reip et al. ${ }^{407}$ Two 
steels containing nominally $0.06 \mathrm{C}-1.35 \mathrm{Mn}-0.074 \mathrm{~V}-0.04 \mathrm{Nb}-0.0065 \mathrm{~N}$ with (a) $0.01 \mathrm{Ti}$ steel and (b) $0.002 \mathrm{Ti}$ were processed in a commercial caster. After processing, both steels exhibited very good notch toughness of $200-400 \mathrm{~J} \mathrm{~cm}^{-2}$ at $240^{\circ} \mathrm{C}$, and steel (a) had $\sigma_{\mathrm{y}}$ of 680 MPa, which was $100 \mathrm{MPa}$ higher than steel (b) The excellent toughness of both steels was attributed to the fine grain sizes of $2.6 \mu \mathrm{m}$ and $6 \mu \mathrm{m}$ respectively.The multi-microalloying approaches of $\mathrm{CMn}(\mathrm{VNbTi})$ resulted in the formation of triplex carbonitrides. ${ }^{399}$ It has been shown by Lee et al. ${ }^{408}$ that increasing the dislocation density opposed the formation of AF and bainite through a mechanical stabilisation effect. The results of Reip et al. ${ }^{407}$ suggest that the exclusion of titanium in steel (b) favours the formation of AF and bainite. It is suggested that this is possibly due to the higher percentage of dissolved niobium, which supports the formation of $\mathrm{AF}$ and bainite, because titanium precipitated as TiN, may provide nucleation sites for precipitation of $\mathrm{Nb}(\mathrm{C}, \mathrm{N})$ during the final phase of rolling, reducing the nucleation of AF. However, this is at odds with the earlier discussion which highlighted the importance of titanium compounds in the nucleation of AF. Further work was devoted to comparing fine scale precipitates in high strength industrially processed trial steels containing $\mathrm{Ti}-\mathrm{Nb}$ and $\mathrm{Ti}-\mathrm{Nb}-\mathrm{Mo}-\mathrm{V}$ additions. This focused on the precipitate characterisation based on crystallography through some careful analysis of electron diffraction patterns gained from thin foils. The cuboidal-type precipitates were earlier identified as titanium/niobium nitrides, $[(\mathrm{Ti}, \mathrm{Nb}) \mathrm{N}]$, spherical/irregular precipitates as titanium/niobium carbides [(Ti, $\mathrm{Nb}) \mathrm{C}]$, and fine precipitates as carbides, $[(\mathrm{Ti}, \mathrm{Nb}, \mathrm{V}) \mathrm{C}]$. This result is broadly in agreement with previous work.

\section{Summary.}

- Over 20 years ago F.B. Pickering ${ }^{1}$ complied, what was probably the first review of the influence of titanium in microalloyed steels. Since then there has been a growing awareness that, particularly when present in $\mathrm{a} \leq \mathrm{Ti} / \mathrm{N}$ hypostoichiometric ratio, 
titanium has more roles than just as an austenite grain refining nitride, carbonitride or carbide.

- The economic and environmental advantages of producing higher strength MA steels with good toughness and acceptable weldability has been one of the major driving forces in alloying with titanium. This to a large extent has be obtained by multi alloying additions of Ti in particular with $\mathrm{Nb}, \mathrm{V}, \mathrm{C}$ and $\mathrm{N}$. As is well illustrated in Fig.43, for line pipe steels, moving from X70 to X120 allows a significant reduction in wall thickness, while meeting property requirements. This is achieved by replacing microstructures based on ferrite-pearlite with those of bainite/acicular ferrite.

- The nucleation of acicular ferrite has been shown in many research articles to be associated with titanium nitride particles and/or titanium oxide complexes, their critical size range and volume fraction still being unresolved. The advantages of titanium oxide inclusions mentioned by Pickering, ${ }^{1}$ was first recognized in welds and later deliberately nucleated in HAZ as a means of improving toughness. A similar role for titanium additions was adopted when used as a sulphide shape controller.

- More recently, with the extension of continuous casting to TSDC processing and associated accelerated cooling with conventional rolling, fine TiN and TiC precipitates, both probably $\operatorname{Ti}(\mathrm{C}, \mathrm{N})$ with varying $\mathrm{C} / \mathrm{N}$ ratios, have been found to precipitate in austenite on dislocations (SIP) introduced during the rolling, and retain their size due to the fast cooling rates.

- Avoiding particle coarsening through small additions of Mo has resulted in fine Ti based precipitates maintaining a small size in the final product, developing higher strengths.

- Titanium containing precipitates have roles in both grain refining and matrix strengthening and can be more complex when niobium and vanadium are present. 
- However, the search for the optimum additions of titanium, dependent on their perceived roles, along $\mathrm{Nb}$ and $\mathrm{V}$, together with those elements normally present in MA steels, is still on going research.

\section{Acknowledgement}

Thanks are due to Dr N.A. McPherson for stimulating discussions and suggestions, and for reading and commenting on the manuscript.

\section{References}

1. F.B. Pickering: in 'Titanium technology in microalloyed steels', (ed. T. N. Baker), 12- 43, 1997, London, The Institute of Materials.

2. R. C. Cochrane: 'Phase transformations in microalloyed high strength low alloy (HSLA) steels', in 'Phase transformations in steels', vol.2,(ed E. Pereloma and D. V. Edmonds), 153-212; 2012, Woodhead Publishing, Oxford

3. T.N. Baker: 'Processes, Microstructure and Properties of Vanadium Microalloyed Steels', Mater. Sci. Technol., 2009, 25, 1083-1107.

4. T.N. Baker: 'Role of zirconium in microalloyed steels: review', Mater. Sci.Technol.,2015,31,265-294.

5. T.N. Baker: 'Microalloyed steels', Ironmaking Steelmaking,2016,43,264-307.

6. A.D. McQuillan and M.K. McQuillan:'Titanium',1956,London,Butterworths Scientific Publications.

7. E.W. Collings: 'The physical metallurgy of titanium alloys', 1984, Metals Park, $\mathrm{OH}$, American Society for Metals.

8. www.csa.com/discoveryguides/titanium/overview.php

9. www.chemguide.co.uk/inorganic/extraction/titanium.htm

10. G F Comstock: 'Titanium and effects on steel', J. Ind. Eng. Chem., 1915, 7, 87-94.

11. G F Comstock: 'Titanium in iron and steel', 1955, New York, John Wiley.

12. W.B. Morrison:'The Use of Vanadium in Steel' - Proc. Vanitec Sympos., Guilin, China, 2000, 25-35.

13. W. B. Morrison and J.H. Woodhead: 'Influence of small niobium additions on mechanical properties of commercial mild steels', J. Iron Steel Inst., 1963, 201, 43-46.

14. W. B. Morrison: 'Influence of small niobium additions on properties of carbon-manganese steels', J. Iron Steel Inst., 1963, 201, 317-325.

15. E.O. Hall: 'The deformation and ageing of mild steel.3 Discussion of results', Proc. Phys.Soc, 1951, 64B,747-753.

16. N.J. Petch: 'The cleavage strength of polycrystals', J. Iron Steel Inst., 1953, 174, 25-28.

17. N.J. Petch: 'The fracture of metals', Prog.Met.Phys., 1954, 5,1-52.

18. N.J. Petch: 'The ductile-cleavage transition in alpha iron',Proc. Swampscott Conf. on 'Fracture',(ed. B.L Averback et al),54-64,1959,New York, John Wiley.

19. C. A. Beiser: 'The effect of small columbium additions to semi killed, medium carbon steels', ASM preprint no138, 1959, Metals Park, OH, Am. Soc. Met.

20. W. B. Morrison: 'Microalloy steels - the beginning', 
Mater. Sci. Technol., 2009, 25, 1066-1073.

21. P.H.M. Hart and G. Ferguson: 'The role of titanium on the weldability of microalloyed structural steels', in‘Titanium Technology in Microalloyed Steels', (ed. T.N. Baker), 169-179, 1997, London, Institute of Materials.

22. 'High -strength structural and high -strength low alloy steels', in 'Properties and selection: irons ,steels and high performance alloys', ASM Metals Handbook, $10^{\text {th }}$ edition, vol.1,403-423.

23. S. Jönsson: 'Assessment of the Fe-Ti-C system, calculation of the Fe-TiN system, and prediction of the solubility limit of Ti(C,N) in liquid Fe',Metall.Mater.Trans.B,1998,29B,371-384.

24. http://education.jlab.org/itselemental/ele022.html

25. http://metalpedia.asianmetal.com/metal/titanium/resources\&production.shtml

26. http://titanium.com/technical-data/history-of-titanium/

27. Rutley's Elements of Mineralogy $25^{\text {th }}$ edition, (ed. H. H. Read), 1953,London, Thomas Murby $\&$ Co.

28. G. Z. Chen, D. I. Fray and T .W. Farthing: 'Direct electrochemical reduction of titanium dioxide to titanium in molten calcium chloride', Nature, 2000,407, 361-364.

29. K. Narita: 'Physical chemistry of group-IVA (Ti, Zr ), Group-VA(V, Nb, Ta) and rare earths in steel', Trans. Iron Steel Inst. Japan, 1975,15,145-152.

30. http://en.wikipedia.org/wiki/Titanium\#Chemical_properties

31. W. Hume-Rothery,R.E.Smallman and C.W.Howarth: ' The structure of metals and alloys', $5^{\text {th }}$ edition,262,1969, London ,The Institute of Metals.

32. A. D. Schwope: 'A general comparison of the metallurgy of zirconium with that of better known commercial metals', in Symposium 'Zirconium and zirconium Alloys' 111, 1953, Cleveland, Ohio. Amer.Soc.Metals.

33. H. J. Goldschmidt: ' Interstitial Alloys',1957, London, Butterworths.

34. K. W. Andrews and H. Hughes: 'Hexagonal carbide and nitride phases and their occurrence in some alloy steels', J Iron Steel Inst.,1959, 193, 304-311.

35. Z. Si, Z. Wang, P. Liu, D. Yu and L. Liu: 'Effects of B and Ti on the toughness of HSLA steel weld',Chin.J.Met.Sci. Technol.,1992, 8,294-298.

36. R.G. Monroe: 'Material properties of titanium diboride', J.Res.Nat.Inst.Stand.Technol.,2000,105,709-720.

37. A.S. Chaus and M. Dománková: 'Precipitation of secondary carbides in M2 high speed steel modified with titanium diboride', J.Mater.Eng.Perfom.,2013,22,412-420.

38. A. Agarwal and N. B. Dahotre : 'Synthesis of Boride Coating on Steel using High Energy Density Processes: Comparative Study of Evolution of Microstructure',Mater.Char.,1999,42,31-44.

39. H. Ohtani, M.Hasebe,K.Ishida and T.Nishizawa: 'Calculation of Fe-C-B Ternary Phase Diagram', Trans. ISIJ, 1988, 28, 1043-1050.

40. K. Tanaka and T.Saito: 'Phase equilibria in $\mathrm{TiB}_{2}$-reinforced high modulus steel', J. Phase Equil.1999,20,207-214.

41. V. Raghavan 'B-Fe-Ti (Boron-Iron-Titanium)', J. Phase Equilib., 2003,24, 451-454.

42. A. Antoni-Zdziobek, M. Gospodinova , F. Bonnet and F. Hodaj: 'Solidification paths in the iron-rich part of the Fe-Ti-B ternary system', J. Alloy Compds,2016,657,302-312.

43. S. Chen, P. Seda, M. Krugla and A. Rijkenberg: ' High-modulus steels reinforced with ceramic particles through ingot casting process', Mater. Sci. Technol., 2016, 32, 992-1003.

44. E. Orowan: 'Internal stresses in metals and alloys', Inst. Met., London, 1948, 451-457.

45. M. F. Ashby: 'The hardening of metals by non-deforming particles', Z. Metallkd, 1964, 55, 5-17

46. D.W. Oh, D.L.Olson and R.H.Frost: 'The influence of boron and titanium on low carbon steel weld metal',Weld.J.1990, 69,(4),S151-158. 
47. J.L. Murray and H.A. Wreidt 'ASM handbook', 'Alloy phase diagrams', 2-324, 3; 1992, Materials Park, OH, ASM International.

48. A.M. Smellie and H.B.Bell: 'Titanium deoxidation reactions in liquid iron',Canad.Metall.Quart.,1972,11,351-361.

49. W. Y Cha, T.Miki, Y.Sasaki and M.Hino: 'Identification of titanium oxide phases equilibrated with liquid Fe-Ti alloy based on EBSD analysis', ISIJ Internl.,2006,46,987-995.

50. C.T Mutale, A.S Tuling, and S.M.C Verryn:'TEM study of solid titanium oxides inclusions in steel melt at $1600^{\circ} \mathrm{C}$, VII International Conference on Molten Slags Fluxes and Salts, The South African Institute of Mining and Metallurgy, 2004,pp293-297.

51. J. Xiao, B. Jiag,K.Huang,S.Jiao and H.Zhu: 'Structural and Thermodynamic Properties of TiCxNyOz Solid Solution: Experimental Study and First-Principles Approaches', Metall.Mater.Trans.A.,2016,47A,4721-4731.

52. J. L. Murray: 'Ti-S phase diagram', Bull. Alloy Phase Dia., 1986, 7, (2), 156.

53. P. Walder and A. D. Pelton: ' Thermodynamic modeling of the Fe-S system', J Phys. Equil. Diff.,2005,26,23-38.

54. V. Raghaven: 'Ternary Systems containing iron and sulphur', Phase diagrams of ternary iron alloys Part2, 1988,Calcutta,The Indian Institute of Metals.

55. N. Bochvar and L. Rokhlin: 'Iron systems: phase diagrams, crystallographic and thermodynamic data, iron- sulphur -titanium', Volume 11 'Subvolume D ,Ternary Alloy Systems, Landolt-Börnstein - Group IV 'Physical Chemistry'. Volume 11D5 of the series Landolt-Börnstein - Group IV Physical Chemistry.Ternary Alloy Systems,2009, 534-554.

56. T. J. Baker: 'Nonmetallic inclusions in maraging steels', J. Iron Steel Inst., 1972, 210,793-795.

57. K. Oikawa, H. Mitsui and K.Ishida: 'A thermodynamic database for Fe-Cr-Mn-Ni-Ti-S-C-N system', Mater. Sci. Forum 2005, 500-501, 711-718.

58. H. Kudielka and K Rohde: 'Strukturuntersuchungen an Carbosulfiden von Titan und Zirkon', Z.Krist., 1960, 114, 447-456.

59. M.I.Hua, C.I.Garcia and A.J.DeArdo: 'Multiphase precipitates in interstitial-free steels', Scripta Metall Mater., 1993, 28,973-978.

60. M. Hua, C.I.Garcia and A.J.DeArdo: ' Precipitation behavior in ultra-low -carbon steels containing titanium and niobium', Metall.Mater.Trans.A,1997,28A,1769-1780.

61. W. J. Liu, S. Yue and J. J. Jonas: Characterization of Ti carbosulphide precipitation in Ti microalloyed steels,' Metall. Trans. A, 1989, 20, 1907-1925.

62. W.R. Bandi and G.Krapf: 'Identification and determination of titanium sulphide and carbosulphide compounds in steel', Analyst.1979,104,812-821.

63. N. Mizui, T. Takayama and K. Sekine: 'Effect of Mn on solubility of Ti-sulfide and Ticarbosulfide in ultra-low C Steels', ISIJ Internal, 2008, 48, 845-850.

64. C.J. Ball: 'X-ray powder diffraction patterns of titanium carbosulphide and $\tau$ titanium sulphide', Metal Sci.1984, 18, 577-579.

65. P.R. Wilson and Z. Chen: 'TEM characterisation of iron titanium sulphide in titanium- and niobium-containing low manganese steel', Scripta Mater.,2007, 56,753-756.

66. D.K. Matlock and J.G. Speer: 'Microalloying concepts and applications in long products', Mater. Sci.Technol. 2009, 25, 1118-1125.

67. S. Aminorroaya and R. Dippenaar: 'TEM characterization of precipitates in the segregated regions of a low-carbon, low manganese, titanium-added steel', J.Micro.,2007, 227,92-97.

68. E.V. Pereloma, I. B. Timokhina, K. F. Russell and M.K. Miller: ' Characterization of clusters and ultrafine precipitates in Nb-containing C-Mn-Si steels', Scripta Mater. 2006, 54, 471476.

69. A. Deschamps, F. Danoix, F. De Geuser, T. Epicier, H. Leitner and M. Perez: 'Low temperature precipitation kinetics of niobium nitride platelets in iron', Mater.Lett.,2011,65,2265-2268. 
70. F. Danoix, T. Epicier, F. Vurpillot and D. Blavette: 'Atomic scale imaging and analysis of single layer GP zones in a model steel'. J. Mater. Sci., 2012, 47, 1567-1571.

71. G. Kostryzhev, A. Al Shahrani, C. Zhu. J.M. Cairney, S.P. Ringer, C.R. Killmore and E.V.Pereloma: 'Effect of niobium clustering and precipitation on strength of an NbTimicroalloyed ferritic steel',Mater.Sci.Eng.A,2014,A607,226-235.

72. A. J. Breen, K. Y. Xie, M. P. Moody, B. Gault, H-W. Yen, C. C. Wong, J. M. Cairney, and S. P. Ringer: 'Resolving the Morphology of Niobium Carbonitride Nano-Precipitates in Steel Using Atom Probe Tomography', Microsc. Microanal., 2014, 20, 1100-1110.

73. E.V. Pereloma, A.G. Kostryzhev, A. AlShahrani, C. Zhu, J.M. Cairney, C.R. Killmore and S.P. Ringer: 'Effect of austenite deformation temperature on $\mathrm{Nb}$ clustering and precipitation in microalloyed steel', Scripta Mater., 2014,75, 74-77.

74. K. Y. Xie, T. Zheng, J. M. Cairney, H. Kaul,J. G. Williams, F. J. Barbaro, C. R. Killmore and S. P. Ringer: 'Strengthening from Nb-rich clusters in a Nb-microalloyed steel', Scripta Mater., 2012, 66,710-713.

75. M. Kapoor, R. O’Malley and G.B. Thompson: 'Atom Probe Tomography Study of Multimicroalloyed Carbide and Carbo-Nitride Precipitates and the Precipitation Sequence in $\mathrm{Nb}-\mathrm{Ti}$ HSLA Steels', Metall. Mater. Trans. A., 2016, 47A, 1984-1995.

76. K.J. Irvine, F.B. Pickering and T. Gladman: 'Grain-refined C-Mn steels ', J Iron Steel Inst, 1967, 205, 161-182.

77. L.F.S. Dumitrescu and M.Hillert: 'Reassessment of the Solubility of TiC and TiN in Fe', ISIJ Int., 1999, 39, 84-90.

78. K. Balasubramanian, A. Kroupa and J. S. Kirkaldy: 'Experimental Investigation of the Thermodynamics of the Fe-Ti-C Austenite and the Solubility of Titanium Carbide', Metall.6

79. H. Ohtani, T. Tanaka, M. Hasebe and T. Nishizawa: 'Calculation of the Fe-C-Ti Ternary Phase Diagram', CALPHAD, 1988, 12, 225-246.

80. T. Gladman: 'Microalloyed Steels', 1997, London, Inst. Mater.

81. T. Mori, M. Tokizane, K. Yamaguchi, E.Sumani andY.Nakazima: ' Thermodynamic Properties of Niobium Carbides and Nitrides in Steels', Tetsu To Hagane, 1968, 54, 763-776

82. S. Matsuda and N. Okumura: 'Effect of Distribution of TiN Precipitate Particles on Austenite Grain-Size of Low-Carbon Low-Alloy Steels', Trans Iron Steel Inst. Japan, 1978, 18, 198 205.

83. H. Wada and R. D. Pehlke: 'Nitrogen Solubility and Nitride Formation in Austenitic Fe-Ti Alloys', Metall. Trans., 1985, 16B, 815-822.

84. J. Kunze, B. Beyer, S.Oswald and W. Gruner: 'Thermodynamic data of the formation of titanium nitride in iron', Steel Res.Int.,1995, 66,161-166.

85. E. T. Turkdogan: 'Causes and Effects of Nitride and Carbonitride Precipitation during Continuous Casting', Iron Steelmaking, 1989, 16, 61-75.

86. N.R.Frage,V.G.Gurvich and V.I Tomilov: 'Solubility of nitrogen in Fe-Ti system',Steel in the USSR, 1974,4,462-463..

87. Z. Morita and K. Kunisada: 'Solubility of nitrogen and equilibrium of titanium nitride forming reaction in liquid Fe-Ti alloys', Trans. ISIJ 1978, 18, 648-654.

88. D.B. Evans and R.D. Pehlke : 'Equilibria of nitrogen with refractory metals titanium zirconium columbium vanadium and tantalum in liquid iron' Trans. Metall.

Soc.AIME,1965,233,(8),1620-1624.

89. H. Ohtani and M. Hillert: 'A thermodynamic assessment of the Ti-N system', CALPHAD, 1990, 14, 289-306

90. W. Y. Kim, J. O. Jo, T. I. Chung, D. S. Kim and J. J. Pak: 'Thermodynamics of Titanium, Nitrogen and TiN Formation in Liquid Iron', ISIJ Int., 2007, 47, 1082-1089. 
91. Steelmaking Data Sourcebook, The Japan Society for Promotion of Science, The 19th Committee in Steelmaking, Gordon and Breach.

92. J.M. Jang, S.H. Seo, J.S. Han, D.S Kim, Y.B. Kang and J.J. Pak: 'Reassessment of TiN $(s)=\mathrm{Ti}+\mathrm{N}$ Equilibration in Liquid Iron', ISIJ Int., 2015, 55, 2318-2324.

93. J. O. Jo, W. Y. Kim, C. O. Lee and J. J. Pak: “ Thermodynamic Interaction between Chromium and Titanium in Liquid Fe-Cr Alloys Containing 30 mass\% Cr', ISIJ Int., 2010, 50, 1373-1379

94. F. Ishii and T. Fuwa: 'Effect of Alloying Element on the Solubility of Nitrogen in Liquid Iron,' Tetsu-to-Hagané, 1982, 68 1560-1568.

95. J. Kunze: 'Solubility of titanium nitride in delta ferrite', Steel Res.Int.,1991,62,(10),430-432.

96. J. Kunze: 'Solubility Product of Titanium Nitride in $\gamma$-Iron', Metal Sci., 1982, 16, 217-218.

97. I. I. Gorbachev, and V. V. Popov: 'Analysis of the solubility of carbides, nitrides, and carbonitrides in steels using methods of computer thermodynamics: III. Solubility of carbides, nitrides, and carbonitrides in the Fe-Ti-C, Fe-Ti-N, and Fe-Ti-C-N systems', Phys. Met. Metall., 2009, 108, 484-495.

98. R. Kieffer, H. Nowotny, A. Neckel, P. Ettmayer and 1.Usner: 'Occurrence of miscibility gaps in cubic multicomponent carbides',Monatsh.Chem.1968,99,1020-1027.

99. H.L. Zhou and J.S. Kirkaldy: ' Carbonitride precipitate growth in titanium-niobium microalloyed steels', Metall Trans.A.,1991,22,1511-1524.

100. H.L. Zhou and J.S. Kirkaldy: 'Thermodynamic and experimental verificationof the carbonitride -austenite equilibrium in Ti-Nb microalloyed steels', Metall. Trans.A.,1992,23,651-657.

101. E. Rudy: 'Boundary phase stability and critical phenomena in higher- order solid solution systems',J.Less Comm.Met.1973,33,43-70.

102. K. Inoue, N. Ishikawa, I. Ohnuma, H. Ohtani and K. Ishida., 'Calculation of phase equilibria between austenite and (Nb, Ti, V) (C, N) in microalloyed steels', ISIJ Int., 2001, 41, 175182.

103. B.J. Lee, Thermodynamic assessment of the Fe-Nb-Ti-C-N system,' Metall. Mater. Trans.A, 2001, 32A, 2423-2439.

104. I. I. Gorbachev, V.V. Popov and A.Yu.Pasynkov: ' Thermodynamic simulation of the formation of carbonitrides in steels with $\mathrm{Nb}$ and Ti.', Phys.Met.Metall.,2012,113,687-695.

105. I.I. Gorbachev, V.V. Popov and A.Yu.Pasynkov: ' Thermodynamic simulation of the formation of carbonitrides in steels with V and Ti.', Phys.Met.Metall.,2012,113, 974-981.

106. Z.K. Liu: 'Thermodynamic calculations of carbonitrides in microalloyed steels,' Scripta Mat.,2004,50,601-606.

107. A.J. Craven, K. He, L.A.J. Garvie and T.N. Baker: ' Complex heterogeneous precipitation in titanium-niobium microalloyed Al-killed HSLA steels - I. (Ti,Nb)(C,N) particles', Acta Mater.2000,48, 3857-3868.

108. K. Frisk: 'Thermodynamic modeling of multicomponent cubic Nb, Ti and V carbides/carbonitrides,' CALPHAD, 2008, 32, 326-337.

109. K. Frisk and U. Borggren: 'Precipitation in Microalloyed Steel by Model Alloy Experiments and Thermodynamic Calculations', Metall. Mater. Trans. A., 2016, 47, 4806-4817.

110. K. Xu, B. G. Thomas and R. J. O'Malley: 'Equilibrium Model of Precipitation in Microalloyed Steels', Metall.Mater.Trans .A,2011,42, 524-539.

111. Y. Xu, D. Tang and Y. Song : 'Equilibrium Modeling of $(\mathrm{Nb}, \mathrm{Ti}, \mathrm{V})(\mathrm{C}, \mathrm{N})$ Precipitation in Austenite of Microalloyed Steels', Steel Res. Int., 2013,84,560-564.

112. S. Roy, S. Patra, S. Neogy, A. Laik, S.K.Choudharey and D.Chakrabarti:'Prediction of inhomogeneous distribution of microalloy precipitates in continuously cast high strength low alloy steel slab',Met.Mater.Trans.A,2012,43A,1845-1860. 
113.Y.L. Wang, L.C. Zhuo, M.W. Chen, Zi.D. Wan: 'Thermodynamic model for precipitation of carbonitrides in microalloyed steels and its application in Ti-V-C-N system', Rare Met. 2016, 35,735-741.

114. V. Raghavan: 'C-Fe-N-Nb-Ti (Carbon-Iron-Nitrogen-Niobium-Titanium)', J. Phase Equil.Diff.,2013, 34,140-142.

115. C. E. Sims: 'The non-metallic inclusions in steels', Trans. Met. Soc. AIME, 1959, 215,367393.

116. T. J. Baker and J.A. Charles: 'Morphology of manganese sulphides in steel', J. Iron Steel Inst.,1972, 210, 702-706.

117. J. H. Swisher: 'Sulfur solubility and internal sulfidation of iron-titanium alloys', Trans. TMSAIME, 1968,242, 2422-2439.

118. E.T. Turkdogan, S. Ignatowicz and J. Pearson: 'Solubility of sulphur in iron and iron manganese alloys', J. Iron Steel Inst., 1955, 180, 349-354.

119. W. J. Lui and J. J. Jonas: Proc. Conf. on 'Processing, microstructure and properties of HSLA steels', (ed. A. J. De Ardo et al.),39; 1988, Warrendale, PA, Metallurgical Society of AIME

120. A.J.Ardell: ' Precipitation hardening', Metall.Trans.A,1985,16,2131-2165.

121. Y. Ll, Y.Q. Ll and R. J. Fruehan: 'Formation of titanium carbonitride from hot metal', ISIJ Internal,2001, 41, 1417-1422.

122. Y-X Liu, J-L Zhang, G-H Zang, K-X Jiao and K-C Chou: 'Influence of $\mathrm{Ti}\left(\mathrm{C}_{0.3} \mathrm{~N}_{0.7}\right)$ on viscosity of blast furnace slags', Ironmaking Steelmaking,2017,44,609-616.

123. Y. Li, D. N. Crowther, P. S. Mitchell and T. N. Baker: 'The evolution of microstructure during thin slab direct rolling processing in vanadium microalloyed steels', ISIJ Int., 2002, 42,636-644.

124. D. N. Crowther and W. B. Morrison: 'Influence of hypostoichiometric additions of titanium on the properties of microalloyed structural steels', in 'Titanium technology in microalloyed steels', (ed. T. N. Baker), 44-64; 1997, London, Institute of Materials.

125. Z. Chen, M.H. Lorretto and R.C. Cochrane: 'Nature of large precipitates in titanium containing HSLA steels',Mater.Sci.Technol.,1987,3,836-844.

126. K. He and T. N. Baker: 'The effects of small titanium additions on the mechanical properties and the microstructures of controlled rolled niobium-bearing HSLA plate steels', Mater. Sci. Eng. A, 1993, A169, 53-65.

127. P.H. Li, A.K. Ibraheem and R. Priestner: 'Eutectic precipitation of (TiNbV)(CN) in cast, microalloyed low C austenite and effects of refining', Mater. Sci.Forum,1998,284-286,517524

128. T. N. Baker, Y. Li, J. A. Wilson, A. J. Craven and D. N. Crowther: 'Evolution of precipitates, in particular cruciform and cuboidal particles, during simulated direct charging of thin slab cast vanadium microalloyed steels', Mater. Sci. Technol., 2004, 20, 720-730.

129. S. Q. Yuan and G. L. Laing: ' Dissolving behaviour of second phase particles in Nb-Ti microalloyed steel',Mater.Lett.,2009,63,2324-2326.

130. D. V. Edmonds and R. W. K. Honeycombe: 'Precipitation in iron-based alloys', (ed. K. C. Russell and H. I. Aaronson), 121-160; 1978, Warrendale, PA,

131. K.H. Jack: 'The effects of substitutional alloying elements on the behaviour of interstitial solotes in iron. A review of current work at Newcastle', Scan. J.Metall.1972, 1, 195-202.

132. D.H. Kirkwood, O.E. Atasoy and S.R. Keown: 'The structure of nitrided and annealed irontitanium alloys', Metal Sci.,1974,8,49-55.

133. D.H.Jack : 'Structure of nitrided iron-titanium alloys', Acta.Metall.1976,24,137-147.

134. L.J. Cuddy, H.E. Knechtel and W.C. Leslie: 'Elevated temperature strengthening of iron alloys by titanium', Metall. Trans.,1974, 5, 1999-2003. 
135. G.L. Dunlop and P.J. Turner: 'Atom probe field- ion microscopy of mixed vanadiumtitanium carbides in a low alloy steel', Metal.Sci., 1975,9, 370-374.

136. G.L. Dunlop and R.W.K. Honeycombe: 'Ageing characteristics of VC, TiC, and (V, Ti ) C dispersions in ferrite', Met.Sci.1978, 12,367-371.

137. N.G.Chechenin, A.R. Chezan,C.B. Craus, D.G.Boerma,P.M.Bronsveld,J.Th,M,De Hosson and L.Niesen: 'Precipitate formation in low-temperature nitrided cold-rolled $\mathrm{Fe}_{94} \mathrm{Ni}_{4} \mathrm{Ti}_{2}$ and $\mathrm{Fe}_{93} \mathrm{Ni}_{4} \mathrm{Cr}_{3}$ films',Metall.Mater.Trans. A, 2002,33A, 3075-3087.

138. I.B. Timokhina, P.D. Hodgson, S.P. Ringer, R.K. Zheng and E.V. Pereloma: 'Application of advanced analytical techniques to study structure-property relationships of hot rolled high strength low alloy steel',Mater.Sci.Technol., 2011,27,305-309.

139. J. Angseryd, F. Liu, H.O. Andren, S.S. Gerstl, and M. Thuvander: 'Quantitative APT analysis of Ti (C, N)', Ultramicroscopy, 2011, 111, 609-614.

140. A. Hirata, T. Fujita, Y. R. Wen, J. H. Schneibel, C. T. Liu and M. W. Chen: 'Atomic structure of nanoclusters in oxide-dispersion-strengthened steels', Nature Materials,2011, 10,922-926.

141. D.J. Larson, P.J. Maziasz1, I-S. Kim and K. Miyahara: 'Three-dimensional atom probe observation of nanoscale titanium-oxygen clustering in an oxide-dispersion-strengthened $\mathrm{Fe}$ $12 \mathrm{Cr}-3 \mathrm{~W}-0.4 \mathrm{Ti}+\mathrm{Y}_{2} \mathrm{O}_{3}$ ferritic alloy', Scripta Mater., 2001, 44, 359-364.

142. S. Mukherjee, I.B. Timokhina, C. Zhu, S.P. Ringer and P.D.Hodgson: 'Three-dimensional atom probe microscopy study of interphase precipitation and nanoclusters in thermomechanically treated titanium-molybdenum', Acta Mater. 2013, 61, 2521-2530.

143. S. Mukherjee, I.B. Timokhina, C. Zhu, S. P. Ringer and P. D. Hodgson: 'Clustering and precipitation processes in a ferritic titanium-molybdenum microalloyed steel', J. Alloys Compds., 2017,690, 621-632.

144. S. Shanmugam, M. Tanniru, R. D. K. Misra, D. Panda and S. Jansto: 'Microalloyed V-NbTi and V steels Part 2 - Precipitation behaviour during processing of structural beams', Mater. Sci.Technol.2005, 21, 165-177.

145. X.Li, Z.Wang,X.Deng,G.Wang and R.D.K.Misra: 'The Determining Role of Finish Cooling Temperature on the Microstructural Evolution and Precipitation Behavior in an $\mathrm{Nb}-\mathrm{V}-\mathrm{Ti}$ Microalloyed Steel in the Context of Newly Developed Ultrafast Cooling',Metall.Mater.Trans.A,2016,47A,1929-1938.

146. J. McCann and K. A. Ridal: 'High Temperature decomposition of austenite in alloy steels', J. Iron Steel Inst.,1964, 202, 441-447.

147 J H Jang, Y-U Heo, C-H Lee, H K D H Bhadeshia and D-W Suh:' Interphase precipitation in Ti-Nb and Ti-Nb-Mo bearing steel', Mater. Sci. Technol., 2013, 29, 309-313.

148. H.I.Aaronson,M.R.Plichta, G.W.Franti and K.C.Russell:'Precipitation at interphase boundaries', Metall.Mater.Trans.,1978,9,393-371.

149. J.M. Gray and R.B.G. Yeo: 'Columbium carbonitride precipitation in low alloy steels with particular emphasis on "precipitate row" formation', Trans. Am. Soc. Met. 1968, 61, 255269.

150. A.T. Davenport and R. W. K. Honeycombe: 'Precipitation of carbides at gamma-alpha boundaries in alloy steels', Proc.Roy.Soc.,1971, 322,191-205.

151. S. Freeman: 'Interphase precipitation in a titanium steel' 'Effects of second-phase particles on the mechanical properties of steel', 152-156; 1971, London, The Iron and Steel Institute.

152. S. Freeman and R. W. K. Honeycombe: 'Strengthening of titanium steels by carbide precipitation', Met. Sci., 1977, 11, 59-64.

153. H.W.Yen, C.Y.Chen, T.Y.Wang, C.Y.Huang and J.R.Wang: 'Orientation relationship transition of nanometre sized interphase precipitated $\mathrm{TiC}$ carbides in Ti bearing steel',Mater.Sci.Technol.,2010,26,421-430.

154. D. P. Dunne: 'Interaction of precipitation and phase transformation in low alloy steels', Mater. Sci. Technol., 2010, 26, 410-420. 
155. S.G. Hong, K.B. Kang and C.G Park: 'Strain induced precipitation of $\mathrm{NbC}$ in $\mathrm{Nb}$ and $\mathrm{Nb}-\mathrm{Ti}$ microalloyed HSLA steels', Scripta Mater.,2002,46,163-168.

156. X. Ma, C. Miao, B. Langelier and S. Subramanian: ' Suppression of strain-induced precipitation of $\mathrm{NbC}$ by epitaxial growth of $\mathrm{NbC}$ on pre-existing $\mathrm{TiN}$ in $\mathrm{Nb}$-Ti microalloyed steel', Mater. Design, 2017, 132, 244-249.

157. J. Irvine and T. N. Baker: 'The influence of rolling variables on the strengthening of niobium steels', Mater. Sci. Eng., 1984, 64, 123-134.

158. A. H. Cottrell: 'Dislocations and plastic flow in crystals'; 1964, Oxford, Clarendon Press.

159. T. N. Baker: 'Determination of the friction stress from microstructural measurements', in 'Yield, flow and fracture of polycrystals', (ed. T. N. Baker), 235-273; 1983, London, Applied Science Publishers.

160. Y. Li, A. J. Bushby and D. J. Dunstan: 'The Hall-Petch effect as a manifestation of the general size effect', Proc. R. Soc., 2016, A 472,issue 1290.

161. K. Seto, Y. Funakawa and S. Kaneko: 'Hot rolled high strength steels for suspension and chassis parts"NANOHITEN" and "BHT ${ }^{\circledR}$ Steel”.' JFE Tech Rep 10:19-25, 2007.

162. U. F. Kocks: 'Alloy superposition of alloy hardening, strain hardening and dynamic recovery' Proc. 5th Int. Conf.'Strength of metals and alloys', (ed. P. Haasen, V. Gerold and, G. Kostorz), 1661-1680; 1980, Oxford, Pergamon Press.

163. J. Li, F. Y. Sun and W. C. Xu: 'On the evaluation of yield strength for microalloyed steels', Scr. Metall. Mater., 1990, 24, 1393-1398.

164. N. J. Petch: 'The influence of grain-boundary carbide and grain ize on the cleavage strength and impact transition temperature of steel', Acta Metall., 1986, 34, 1387-1393.

165. J. W. Martin: 'Micromechanisms in particle-hardened alloys', 150;1980, Cambridge, Cambridge University Press

166. R. D. Doherty and J. W. Martin: 'Effect of a dispersed second phase on recrystallization of aluminium-copper alloys', J. Inst. Met., 1962-1963, 91, 332-338.

167. C. Zener and C. S. Smith: 'Grains, phases and interfaces-an interpretation of microstructure',Trans AIME, 1948, 175, 1551.

168. F. J. Humphreys and M. Hatherly: 'Recrystallization and related annealing phenomena', 2nd edn; 2004, Oxford, Elsevier Ltd.

169. T. Gladman: 'On the theory of effect of precipitate particles on grain growth in metals', Proc.Roy. Soc. A, 1966,294, 298-309

170. L. J. Cuddy and J. C. Raley: Austenite grain coarsening in microalloyed steels', Metall. Trans. A, 1983, 14A, 1989-1995.

171. P. A. Manohar, M. Ferry and T. Chandra: 'Five decades of the Zener equation', ISIJ Int., 1998, 38, 913-924.

172. T. Gladman, I. D. McIvor and F. B. Pickering:'Effect of carbide and nitride particles on recrystallization of ferrite', J. Iron Steel Inst., 1971, 209, 380-390.

173. D.T. Gawne and G.T. Higgins: 'Secondary recrystallization in a steel containing coarse carbides and its relation to primary recrystallization structure', J Iron Steel Inst., 1971, 209,562-566.

174. D.T. Gawne and G.T. Higgins:'Associations between spherical particles of two dissimilar phases', J Mat.Sci., 1971, 6,403-412.

175. M.I.Vega, S.F. Medina, A. Quispe, M.Gómez and P.P.Gómez:'Recrystallisation driving forces against pinning forces in hot rolling of Ti-microalloyed ,'Mater.Sci.Eng.A,2006,423, 253-261.

176. M. Gómez, L. Rancel and S. F. Medina: 'Effects of Nb, V, Ti and Al on Recrystallisation/Precipitation Interaction in Microalloyed Steels', Mater. Sci. Forum, 2010, 638-642, 3388-3393. 
177. L. Erasmus: 'Effect of aluminium additions on forgeability austenite grain coarsening temperature + impact properties of steel,' J. Iron Steel Inst.,1964,202,(1),32-41.

178. L. Erasmus: Effect of small additions of vanadium on austenitic grain size forgeability + impact properties of steel', J. Iron Steel Inst., 1964, 202, 128-134.

179. T. Gladman and F.B. Pickering: 'Grain coarsening of austenite', J .Iron Steel Inst., 1967, 205, 653-664.

180. R. Phillips and J. A. Chapman: 'Methods of determining austenite grain size, and grain coarsening of mild steels containing niobium and titanium', in 'Metallurgical developments in carbon steels,' Special Report 81, 60-64;1963, London,Iron Steel Institute.

181 T.G. George and J.J. Irani: 'Control of austenite grain size by additions of titanium', J.Aust. Inst.Met.,1968, 13, 94-106.

182. J.W. Halley: 'Grain-growth inhibitors in steel', Trans. AIME, 1946,167, 224-236.

183. E. Houdremont, H.Bennek and H.Schrader: 'Hardening and tempering of steels containing carbides of low solubility, especially vanadium steels', Trans.AIMME, 1935,116,260-288.

184. E.J. Haynes and T.N. Baker: 'Tempered low-carbon titanium steels',Met. Technol.,1981, 8,413-419.

185. K. Kuo, 'Alloy Carbides Precipitated During the 4th Stage of Tempering', JISI, 1956,184, 258-268.

186. J.R. Cahoon, W.H. Broughton and A.R. Kutzak: 'The determination of yield strength from hardness measurements',Metall. Trans.,1971,2,1979-1983.

187. F.G Wei, T. Hara and K. Tsuzaki: 'High-resolution transmission electron microscopy study of crystallography and morphology of TiC precipitates in tempered steel', Philosp. Mag., 2004, 84:17, 1735-1751.

188.S. Roy, A. Karmakar, S. Mukherjee, S. Kundu, D. Srivastava \& D. Chakrabarti : 'Effect of starting microstructure on austenite grain sizes developed after reheating of HSLA steel', Mater.Sci. Technol., 2014, 30, 1142-1153.

189. A.J.Ardell: 'Effect of volume fraction on particle coarsening - theoretical considerations', Acta Metall.,1972,20,61-71 .

190. J.W. Martin and R.D. Doherty: 'Stability of microstructure in metallic systems,'173-209, 1976, Cambridge University Press, Cambridge, UK.

191. A. Baldin: 'Progress in Ostwald ripening theories and their applications to nickel-base superalloys Part I: Ostwald ripening theories',J Mater.Sci.,2002,37,2172-2202.

192. J.H. Jang, C.H. Lee, H.N. Han, H.K.D.H. Bhadeshia and D.W. Suh: 'Modelling the coarsening behaviour of TiC precipitates in high-strength, low-alloy steels', Mater. Sci. Technol., 2013, 29, 1074-1079.

193. Y. Funakawa, T. Shiozaki, K. Tomita, T. Yamamoto and E. Maeda: 'Development of High Strength Hot-rolled Sheet Steel Consisting of Ferrite and Nanometer-sized Carbides', ISIJ International, 2004, 44, 1945-1951.

194. Z Q. Wang, H. Zhang, C.H. Guo, Z. Leng Z.G. Yang, X.J. Sun, C. Yao, Z.G. Zhang and F.C. Jiang: 'Evolution of (Ti, Mo)C particles in austenite of a Ti-Mo-bearing steel'Mater. Des., 2016, 109, 361-366.

195. M. G. Akben, B. Bacroix and J.J. Jonas:' Effect of vanadium and molybdenum addition on high-temperature recovery, recrystallization and precipitation behavior of niobium-based microalloyed steels', Acta Metall.1983, 31,161-174.

196 R. Uemori, R. Chijiiwa, H.Tamehiro and H Morikawa: 'AP FIM study on the effect of Mo addition on microstructurein Ti-Nb steel',Appl.Surf.Sci.,1994,76,255-260.

197. Y. Funakawa, K. Seto: 'Coarsening behavior of nanometer-sized carbides in hot-rolled high strength sheet steel', Mater. Sci. Forum, 2007, 539, 4813-4818.183.

198. J.H. Jang, C.H. Lee, Y.U. Heo, D.W. Suh: 'Stability of (Ti, M) C (M = Nb, V, Mo and W) carbide in steels using first-principles calculations', Acta Mater., 2012, 60, 208-217. 
199. C.M. Enloe, K.O. Findley, C.M. Parish, M.K. Miller, B.C. De Coomanc and J.G. Speer: 'Compositional evolution of microalloy carbonitrides in a Mo-bearing microalloyed steel', Scripta Mater.,2013, 68, 55-58.

200. Z.Q. Wang, H. Zhang, C.H. Guo, W. B. Liu, Z.G. Yang, X.J. Sun, Z.G. Zhang and F.C. Jiang:" Effect of molybdenum addition on the precipitation of carbides in the austenite matrix of titanium micro-alloyed steels', J. Mater.Sci.,2016, 51, 4996-5007.

201. C.Y. Chen, H. W. Yen, F.H. Kao, W.C. Li, C.Y.Huang,J.R.Yang and S.H.Wang: 'Precipitation hardening of high-strength low-alloy steels by nanometer-sized carbides', Mater. Sci. Eng. A, 2009, 499, 162-166.

202. J. Strid and K. E. Easterling: On the chemistry and stability of complex carbides and nitrides in microalloyed steels',Acta Metall.,1985, 33, 2057-2074.

203. S.V. Subramanian and G. C. Weatherly: 'Precipitation behaviour of Ti-V and Ti-Nb microalloyed steels', in 'Titanium Technology in Microalloyed Steels', (ed. T.N. Baker), 133-149, 1997, London, Institute of Materials.

204. K. He and T.N. Baker: 'Zr-containing precipitates in a Ti-Nb microalloyed HSLA steel containing 0.016wt\% Zr addition', Mater. Sci. Eng., 1996, A215, 57-66.

205. K. He and T.N. Baker: 'Complex carbonitrides in multi-microalloyed Ti-containing HSLA steel and their influence on the mechanical properties', in 'Titanium Technology in Microalloyed Steels', (ed. T.N. Baker), 115-132, 1997, London, Institute of Materials.

206. K. He and T.N. Baker: 'Effect of zirconium additions on austenite grain coarsening of C-Mn and microalloyed steels', Mater. Sci.Eng., 1998, A256,111-119.

207. V. Carretero Olalla, V. Bliznuk, N. Sanchez, P.Thibaux,L.A.I.Kestens and R.H.Petrov: ‘ Analysis of the strengthening mechanisms in pipeline steels as a function of the hot rolling parameters', Mater. Sci. Eng. A, 2014, 60, 46-56.

208. A. Grajcar: 'Thermodynamic analysis of precipitatin processes in Nb-Ti microalloyed Si-Al TRIP steels', J. Therm.Anal. Calorim. 2014,118, 1011-1020.

209. M. Beres, T. E.Weich, K.Hulka and J.Meyer: 'TEM invesigations of fine niobium precipitates in HSLA steel', Steel Res.Internal. 2004, 75, 753-758.

210. T.N. Baker: 'The structure of controlled-rolled and continuously cooled low carbon vanadium steels'. J. Iron Steel Inst., 1973, 211,502-510.

211. C.Y Chen, C.C Chen, J.R Wang: 'Dualism of precipitation morphology in high strength low alloy steel', Mater. Sci. Eng.A, 2015, 626, 74-79.

212. J. Fu, G.Q. Li, X.P. Mao, and K.M. Fang: 'Nanoscale cementite precipitates and comprehensive strengthening mechanism of steel', Metall. Mater. Trans. A,2011, 42A, 37973812 .

213. X.P. Mao: 'Microalloyed technology on thin slab casting and rolling', 2008, 88-90, Metallurgical Industry Press, Beijing.

214. G.K. Tirumalasetty, C.M. Fang, Q. Xu, J.Jansen, , J. Sietsma, M.A. van Huis and, H.W. Zandbergen:Novel ultrafine $\mathrm{Fe}(\mathrm{C})$ precipitates strengthen transformation-induced-plasticity steel', Acta Mater. 2012, 60, 7160-7168.

215. X. Deng, T. Fu1, Z. Wang, G. Liu, G. Wang, and R. D. K. Misra: 'Extending the boundaries of mechanical properties of $\mathrm{Ti}-\mathrm{Nb}$ low-carbon steel via combination of ultrafast cooling and deformation during austenite-to-ferrite transformation', Met. Mater. Int., 2017, 23, 175 183.

216. H.K.D.H. Bhadeshia: 'Bainite in steels', 1992, London, The Institute of Materials.

217. D.V. Edmonds and R.C. Cochrane: 'Structure-property relationships in bainitic steels', Metall. Trans.A, 1990, 21, 1527-1540.

218.G.Tither and J.Kewell:'Properties of directly quenched and tempered structural steel plate', J.Iron Steel Inst.,1970,208,686-694.

219.G.Tither and J.Kewell: 'Microstructure and mechanical properties of some direct-quenched and tempered low- carbon steel', J.Iron Steel Inst.,1971,209,482-484. 
220.G.Tither J.Kewell and M.G.Frost: 'Improved properties of directly quenching', in 'Effects of second-phase particles on the mechanical properties of steel',157-165,1971,London,The Iron and Steel Institute.

221. Proc. 'Accelerated cooling of steel' (ed. P. D Southwick); 1986, Warrendale, PA, Metallurgical Society of AIME.

222. Proc. Int. Symp.on 'Accelerated Cooling of Rolled Steel,'( ed. G. E. Ruddle and A.F.Crawley), 1988, 1st edn. New York, Pergamon Press.

223. Y.E. Smith, A.P. Coldren, R.L. Cryderman: 'Manganese-molybdenum-niobium acicular ferrite steels with high strength and toughness, in 'Towards Improved Ductility and Toughness', 119-142 , 1971, Climax Molybdenum Development Company(Japan)Ltd.

224. J.K. Macdonald: 'Production of plate for high-test line pipe in Australia', in'Microalloying '75’359-373, 1977, New York, Union Carbide Corp.

225. D.A. Litvinenko: 'Development of vanadium-nitride strengthened low alloy steels for large diameter gas pipelines', in'Microalloying ‘75'470-473, 1977, New York, Union Carbide Corp.

226. F-R Xiao,B.Liao,Y-Y.Shan,G-Y Qiao,Y.Zhong,C.Zhang and K.Yang: 'Challenge of mechanical properties of an acicular ferrite pipeline steel',_Mater.Sci,Eng.A.,2006,431,4152.

227. X.L.Li, C.S.Lei, X.T.Deng, Z.D. Wang,Y.G.Yu,G.D.Wang and R.D.K.Misra: 'Precipitation strengthening in titanium microalloyed high-strength steel plates with new generationthermomechanical controlled processing (NG-TMCP)', J.Alloys Compds.,2016,689,542-55.

228. G.K.Tirumalasetty, M.A. van Huis, C.M. Fang, Q. Xu, F.D. Tichelaar, D.N. Hanlon, J.

Sietsma and, H.W. Zandbergen: 'Characterization of $\mathrm{NbC}$ and $(\mathrm{Nb}, \mathrm{Ti}) \mathrm{N}$ nanoprecipitates in TRIP assisted multiphase steels', Acta Mater. 2011, 59, 7406-7415.

229. R. D. K. Misra, H. Nathani, J. E. Hartmann and F. Siciliano: 'Microstructural evolution in a new 770MPa hot rolled Nb-Ti microalloyed steel', Mater. Sci. Eng. A, 2005, A394, 339352.

230. S. Shanmugam, N. K Ramisetti, R. D. K. Misra, J.Hartmann and S.G.Jansto: Microstructure and high strength-toughness combination of a new $700 \mathrm{MPa} \mathrm{Nb}-$ microalloyed pipeline steel', Mater.Sci.Eng.,2008, 478,26-37.

231. Z.J. Xie, Y.P. Fang, G. Han, H. Guo, R.D.K. Misra and C.J. Shang: 'Structureproperty relationship in a $960 \mathrm{MPa}$ grade ultrahigh strength low carbon niobium-vanadium microalloyed steel: The significance of high frequency induction tempering' Mater.Sci.Eng.,2014, A618,112-117.

232. H. Xie, L-X. Du, J. Hu and R. D.K. Misra: 'Microstructure and mechanical properties of a novel $1000 \mathrm{MPa}$ grade TMCP low carbon microalloyed steel with combination of high strength and excellent toughness', Mater. Sci. Eng., 2014, A612, 123-130.

233. M. Charleux, W. J. Poole, M. Militzer and A. Deschamps: 'Precipitation behavior and its effect on strengthening of an HSLA-Nb/Ti steel', Metall. Mater. Trans. A, 2001, 32A, 16351647.

234. H. L. Yi, L. X. Du, G. D. Wang and X. H. Liu: 'New Ti-bearing high strengthened steel', J. Mech. Eng., 2008, 44, 50-54.

235. H. L. Yi, L. X. Du, G. D. Wang and X. H. Liu: 'Development of Nb-V-Ti hot-rolled high strength steel with fine ferrite and precipitation strengthening', J. Iron Steel Res. Internl., 2009, 16, 72-77.

236. H. L. Yi, Y. Xu, Z. G. Xu, Z. Y. Liu and G. D. Wang:

'Microstructure and properties of low cost $780 \mathrm{MPa}$ hot-rolled high-strength steel', Mater. Mech. Eng., 2010, 34, 37-39.

237. H. L Yi, Z. Y. Liu, G. D. Wang and D I.Wu: 'Development of Ti-Microalloyed 600 MPa Hot Rolled High Strength Steel', J. Iron Steel Res. Internl., 2010, 17, 54-58. 
238. Z. Ning, Q. Cai, B. Xie and E. Dong: 'The effect of deformation-induced-ferritetransformation on nanometre-sized carbides in Ti-Mo ferritic steel', Mater. Sci. Technol., 2017,33, 1215-1223.

239. 'Overview of New Development for X80/X100 Grade Linepipe Steels,' nigc.ir/portal/File/ShowFile.aspx?ID=e18ab32c-d94d-4b11-a373-d106c8147f53 http:/www.shunitesteel.com/wp-content/uploads/2013/05/API-5L-2007-.

240. J. M. Gray and F. Siciliano: 'High Strength Microalloyed Linepipe: Half a Century of Evolution', Microalloyed Steel Institute, 2009 -

241. R. H. Petrov, J.J. Jonas, L. A.I. Kestens and J. M. Gray: 'Microstructure and texture and in pipeline steels', in Oil and Gas Pipelines: Integrity and Safety Handbook,1 ed.R.W.Revie 59185,2015 .

242. http://ir.exxonmobil.com/phoenix.zhtml? $\mathrm{c}=115024 \& \mathrm{p}=$ irol-newsArticle Print\&ID=524989

243. H.G. Hillenbrand, A.Liessen,K.Biermann,C.J.Heckmann and V.Schwinn: 'Development of grade 120 pipe material for high pressure gas transportation lines', $4^{\text {th }}$ International Conference on Pipeline Technology, May 9-12, 2004,Ostend, Belgium,pp110,Europipe, Ratingen,Germany.

244.H.Ashi,E.Tsuru,S.Ohita,N.Maruyama,K.KoyamaAkasaki,M.Murata,H.Miyazaki,T.Hara,H.M orimoto,M.Sugiyama,K.Shinda,Y.Terada,N.Ayyyyukawa,N.DoiandT.Yoshida:

Development of ultra-high-strength linepipe,X120',Nippon steel technical report,2004,no.90,82-87.

245. http://www.Ingworldnews.com/exxonmobil-grants-nippon-steel-first-license-for-x120welding-technology-usa

246. J.Moon, C.Park and S.J.Seong-Ju: 'Influence of Ti addition on the hydrogen induced cracking of API 5L X70 hot-rolled pipeline steel in acid sour media', Met.Mater.Internal., 2012,18,613-617.

247. C.F. Dong, Z.Y. Liu, X.G. Li and Y.F. Cheng: 'Effects of hydrogen-charging on the susceptibility of X100 pipeline steel to hydrogen-induced cracking', Internal J Hydrogen Energy,2009,34,9879-9884.

248. D. Hejazia, A.J. Haqa, N. Yazdipoura, D.P. Dunnea, A. Calkaa, F. Barbarob and E.V. Perelomaa: "Effect of manganese content and microstructure on the susceptibility of X70 pipeline steel to hydrogen cracking', Mater. Sci. Eng., 2012, A 551, 40- 49.

249. K T Jacob and S. Gupta: 'Phase diagram of the system Ca-Ti-O at $1200 \mathrm{~K}$ ', Bull. Mater. Sci., 2009, 32, 611-616.

250. S. Kimura and A. Muan: 'Phase relations in the system $\mathrm{CaO}$-iron oxide- $\mathrm{TiO}_{2}$ in air', $A m e r$. Miner., 1971, 56, 1332-1346.

251. B. Beidokhti, P. He, A.H. Kokabi and A. Dolati:' Control of hydrogen cracking in the welded steel using microstructural traps', Mater. Sci. Technol., 2017,33, 408-414.

252. N. Ilman, R. C. Cochrane and G. M. Evans: 'The development of acicular ferrite in reheated Ti-B-Al-N-type steel weld metals containing various levels of aluminium and nitrogen', Weld. World, 2015, 59, 565-575.

253. M.C Zhao, K. Yang and Y. Shan:'The effects of thermo-mechanical control process on microstructures and mechanical properties of a commercial pipeline steel', Mater.Sci.Eng. A., 2002, 335, 14-20.

254 J. Kong, LZhen, B. Guo, P. Li, A.Wang and C. Xie: 'Influence of Mo content on microstructure and mechanical properties of high strength pipeline steel', Mater. Des., 2004, 5,723-728

255. Z. Tang and W. Stumpf:'The role of molybdenum additions and prior deformation on acicular ferrite formation in microalloyed $\mathrm{Nb}$-Ti low-carbon line-pipe steels', Mater. Char., $2008, \mathbf{5 9}, 717-728$. 
256 F. Q. Ji, C. N. Li, S. Tang, Z. Y. Liu and G. D. Wang: 'Effects of carbon and niobium on microstructure and properties for Ti bearing Steels', Mater. Sci. Technol.2015, 69,695-702.

257. Z. Peng, L. Li, J.Gao and X.Huo:'Precipitation strengthening of titanium microalloyed highstrength steel plates with isothermal treatment',Mater.Sci.Eng.A,2016,657,413-421.

258. B. Guo, L. Fan, Q. Wang, Z. Fu, Q. Wang and F. Zhang: 'Effect of Finish Rolling Temperature on the Microstructure and Tensile Properties of Nb-Ti Microalloyed X90 Pipeline Steel,'Metals 2016, 6, 323-339.

259. J.G. Garland and P.R, Kirkwood: 'Towards improved submerged arc weld metal toughness', Metal Constr., 1975, 7, 275- 283.

260. R.A. Farrar and P.L. Harrison: 'Acicular ferrite in carbon-manganese weld metals: An Overview', Journal of Materials Science, 1987, 22, 3812-3820.

261. T. Koseki and G. Thewlis: 'Inclusion assisted microstructure control in C-Mn and low alloy steel welds', Mater. Sci. Technol., 2005, 21,869-879.

262. D. S. Sarma, A. V. Karasev and P. G. Jönsson: 'On the role of non-metallic inclusions in the nucleation of acicular ferrite in steels', ISIJ Internal., 2009, 49, 1063-1074.

263 G.M. Evans: 'The Effect of Titanium in Manganese-Containing SMA Weld Deposits', Weld.J., 1993, 72, 123s- 132s

264. C.S. Barritte: PhD thesis, University of Cambridge, 1982.

265. D. Loder, S.K. Michelic and C. Bernhard: 'Acicular Ferrite Formation and Its Influencing Factors - A Review', J. Mater. Sci. Res., 2017, 6, 2017 24-43.

266. Ø. Grong and D. K. Matlock:' Microstructural development in mild and low-alloy steel weld metals.' Int. Met. Rev., 1986, 31, 27-48.

267. D. J. Abson and R. J. Pargeter: 'Factors influencing as-deposited strength, microstructure, and toughness of manual metal arc welds suitable for C-Mn steel fabrications', Int . Met. Rev., 1986, 31, 141-196.

268. S.S. Babu: 'The mechanisms of acicular ferrite in weld deposits', Current Opinion Solid State Mater. Sci., 2004, 8, 267-278.

269. D.J. Abson, R.E. Dolby and P.H.M. Hart: 'The role of nonmetallic inclusions in ferrite nucleation in carbon steel weld metals', Proc. Int. Conf. Trends in Steels and Consumables, 75-101, 1978, The Welding Institute, Abington, England.

270. R.C. Cochrane and P.R. Kirkwood: 'The effect of oxygen on weld metal microstructure. Proc. Int. Conf. Trends in Steels and Consumables', 661-673, 1978, The Welding Institute, Abington, England.

271. R.A. Ricks, P.R. Howell and C. S. Barritte: 'The nature of acicular ferrite in HSLA steel weld metals', J. Mater.Sci., 1982, 17,732-740.

272. F.J. Barbaro, P. Krauklis and K.E. Easterling: 'Formation of acicular ferrite at oxide particles in steels', Mater. Sci. Technol., 1989, 5, 1057-1068.

273 J.M. Gregg and H. K. D. H. Bhadeshia: 'Solid-state nucleation of acicular ferrite on minerals added to molten steel', Acta mater., 1997,45,739-74

274. C. Blais, G. L'Esperance and G.M. Evans: 'Characterization of inclusions found in C-Mn steel welds containing titanium,' Sci. Tech.Weld. Join., 1999, 4,143-150.

275. J. H. Shim, Y. W. Cho, S. H. Chung, J.-D. Shim and D. N. Lee: 'Nucleation of intragranular ferrite at $\mathrm{Ti}_{2} \mathrm{O}_{3}$ particle in low carbon steel', Acta mater., 1999, 47,2751-2760.

276. S. Byun. J.H. Shim. Y.W. Cho and D.N. Lee: 'Non-metallic inclusion and intragranular nucleation of ferrite in Ti-killed C-Mn steel', Acta mater.,2003,51,1593-1606.

277. D. Loder, S. K. Michelic, A. Mayerhofer and C. Bernhard: 'On the capability of nonmetallic inclusions to act as nuclei for acicular ferrite in different steel grades', Metall.Mater.Trans. $B, 2017$, 48B, 1992-2006

278. Z. Zhang and R. A. Farrar: 'Role of non-metallic inclusions in formation of acicular ferrite in low alloy weld metals', Mater. Sci. Technol., 1996, 12, 237-260. 
279. A. R. Mills, G. Thewlis and J. A. Whiteman: 'Nature of inclusions in steel weld metals and their influence on formation of acicular ferrite', Mater. Sci. Technol., 1987, 3, 1051-1061.

280. K. Seo, Y-M Kim, G. M. Evans H. J. Kim \& C. Lee: 'Formation of Mn-depleted zone in Ticontaining weld metals', Weld. World, 2015, 59, 373-380.

281. K.H. Kim, H. J. Kim, G. M. Evans and Y. Choa: 'Microstructure and Inclusion Characteristics of C-Mn Steel Welds at a Minimal Level of Titanium', Conference: IIW Annual Assembly, Shanghai IIW 2017, Doc. IX-2603-17.

282. K. Yammoto, H. Hasegawa and I. J. Takamura:'Effect of boron bearing steels on intragranular ferrite formation in Ti-oxide', ISIJ Internal., 1996, 36,80-86.

283. C. Bonnet and J.P.Charpentier:'Effect of deoxidation residues in wire and of some particular oxides in CS fused fluxes on the microstructure of submerged-arc weld metals', Proceedings of Conference on 'The Effects of residual, impurity, and microalloying elements on weldability and weld properties' 1983, (Paper 8), 1-31.

284. T. K. Lee, H.J. Kim, B.Y. Kang and S.K. Hwang: Effect of inclusion size on the nucleation of acicular ferrite in welds. ISIJ Internal, 2000, 40, 1260-1268.

285. J. Takamura and S. Mizoguchi: 'Metallurgy of oxides in steell.Role of oxides in steel performance', Proc. 6th Int. Iron and Steel Cong., Nagoya, 1990, 1, 591-597, ISIJ, Tokyo.

286. K. Hui, S. YunFu, Z. YaHui, Y. Qiang, T. Lianhai and C. Z.Yu: 'Effects of titanium oxide precipitates on the acicular ferrite nucleation in carbon structural steel', Mater. Test, 2014, 56, 131-135.

287. M.Wakoh, T. Sawai and S. Mizoguchi: 'Effect of S content on the MnS precipitation in steel with oxide nuclei',ISIJ Internal.,1996,36,1014-1021.

288. M.M. Song, B. Song, C.L. Hu, W.B. Xin and G.Y. Song: Formation of acicular ferrite in $\mathrm{Mg}$ treated Ti-bearing C-Mn steel. ISIJ International, 2015, 55, 1468-1473.

289. W. Mu, P.G. Jönsson and K. Nakajima: 'Effect of sulfur content on inclusion and microstructure characteristics in steels with $\mathrm{Ti}_{2} \mathrm{O}_{3}$ and $\mathrm{TiO}_{2}$ additions', ISIJ Internal, 2014 54, 2907-2916.

290. C. Xuan, W. Mu, Z.I. Olano, P.G. Jönsson and K. Nakajima: 'Effect of the Ti, Al Contents on the inclusion characteristics in steels with $\mathrm{TiO}_{2}$ and $\mathrm{TiN}$ particle additions', Steel Res. Int., 2016, 87, 911-920.

291. Ø. Grong, L. Kolbeinsen, C. van der Eijk and G. Tranell:'Microstructure control of steels through dispersoid metallurgy using novel grain refining alloys', ISIJ Internal, 2006,46,824831.

292. H.K.D.H.Bhadeshia: 'Alternatives to the ferrite-pearlite microstructures', Mater.Sci.Forum, 1998, 284-2, 39-50.

293. S. Ohkita and Y. Horii: 'Recent development in controlling the microstructure and properties of low alloy steel weld metals', ISIJ Internal, 1995, 35, 1170-1182.

294. N. Bailey, Welding Institute Report, 221/1983/M (1983).

295. A. C. Hunt, A. O. Kluken and G. R. Edwards: 'Heat input and dilution effects in microalloyed steel weld metals', Weld. J. 1994, 73, S9-S15.

296. T.H. North, H.B. Bell, A. Koukabi and I. Craig: Notch toughness of low oxygen content submerged arc deposits', Weld. J., 1979, 58, 343s - 354s.

297. P. H. M. Hart: 'The influence of vanadium-microalloying on the weldability of steels', Welding Cutting, 2003,55,204-210.

298. J. Dearden and H O' Neill: 'A guide to the selection and welding of low alloy structural steel',Trans. Inst. Weld. 1940, 3, 203-214.

299. http://www.twi-global.com/technical-knowledge/faqs/material.

300. R. Lagneborg, T. Siwecki, S. Zajac and B. Hutchinson: 'The role of vanadium in microalloyed steels', Scand. J. Metall., 1999, 28, 186-241. 
301. S. Kanazawa, A. Nakashima,K.Okamota and K.Kanaya: 'Improvement of weld fusion zone toughness by fine TiN', Trans. Iron Steel Inst. Japan, 1976, 16, 486-495.

302. S. Matsuda and N. Okumura: 'Effect of distribution of TiN precipitate particles on the austenite grain size of low carbon low alloy steels', Trans. Iron Steel Inst. Japan, 1978, 18, 198-205.

303. S.F. Medina, M.I. Vega, M. Gómez and P. P. Gómez: 'Influence of the size and volume fraction of TiN particles on hot strength and dynamic recrystallization in structural steels', ISIJ Internal.,2005, 45, 1307-1315.

304. J. Du, M. Strangewood and C. L. Davis: 'Effect of TiN particles and grain size on the Charpy impact transition temperature in steels', J. Mater. Sci. Technol, 2012, 28,878-888.

305. H. Adrian and F.B. Pickering: 'Effect of titanium additions on austenite grain growth kinetics of medium carbon V-Nb steels containing 0.008-0.018\%N', Mater. Sci. Technol., 1991, 7,176-182.

306. M. Hamada, Y. Fukada and Y-I Komizo: 'Microstructure and precipitation behaviour in heat affected zones of C-Mn microalloyed steel containing $\mathrm{Nb}$, V and Ti.', ISIJ Internal.1995, 35,1196-1202.

307. A.H.Koukabi, T.H. North and H.B. Bell: 'Properties of submerged arc deposits -effects of zirconium,vanadium and titanium-boron',_Met.Constr.1979,7,639-642.

308. F. Chai, C.F. Yang, H. Su, Y.Q.Zhang, Z.Xu and Y.H.Yang:'Effect of Zr addition to Tikilled steel on inclusion formation and microstructural evolution in welding induced coarse-grained heat affected zone', Acta Metall. Sin. (Eng. Lett.), 2008, 21, 220-226.

309. Y. Tomita, N. Saito, T. Tsuzuki,Y.Tokunaga and K.Ojkamoto:Improvement in HAZ toughness by TiN-MnS addition', ISIJ Internal., 1994, 34, 829-835.

310. Y. Zhang, X. Li and H. Ma: 'Enhancement of heat -affected zone toughness of a low carbon steel by TiN particle', Metall. Mater.Trans.B, 2016, 47B, 2148-2156.

311. Z X Zhu, L Kuzmikova, M Marimuthu, H J Li \& F. Barbaro: 'Role of Ti and $\mathrm{N}$ in line pipe steel welds', Sci. Technol. Weld. Join., 2013, 18, 1-10.

312. Z.X. Zhu, M. Marimuthu, L. Kuzmikova, H. J. Li, F. Barbaro, L. Zheng, M Z Bai and C Jones: 'Influence of $\mathrm{Ti} / \mathrm{N}$ ratio on simulated CGHAZ microstructure and toughness in $\mathrm{X} 70$ steels', Sci. Technol. Weld. Join., 2013,18,45-51.

313.Z. Zhu, J. Han and H. Li: 'Effect of alloy design on improving toughness for X70 steel during welding', Mater. Design,2015, 88, 1326-1333.

314. Z. X. Zhu, L. Kuzmikova, H. J. Li, and F. Barbaro:'The effect of chemical composition on microstructure and properties of intercritically reheated coarse-grained heat-affected zone in X70 steels', Metall. Mater. Trans. B,2014,45,229-235.

315. N. Huda, A.R.H. Midawi, J.Gianetto, R.Lazo and A. P. Gerlich:'Influence of martensiteaustenite (MA) on impact toughness of X80 line pipe steels', Mater. Sci. Eng.A,2016,662, 481-491.

316.. C. L. Davis and J. E. King: 'Cleavage Initiation in the Intercritically Reheated CoarseGrained Heat-Affected Zone: Part I. Fractographic Evidence', Metall. Mater.Trans., 1994, 25, 5663-5673.

317. Y. Li, D.N. Crowther, M.J.W. Green, P. S. Mitchell and T.N. Baker:

'The effect of vanadium and niobium on the properties and microstructure of the intercritically reheated coarse grained heat affected zone in low carbon microalloyed steels', ISIJ Internal, 2001,41,46-55.

318. Y. Li and T.N.Baker: Effect of morphology of martensite-austenite phase on fracture of weld heat affected zone in vanadium and niobium microalloyed steels', Mater. Sci.Tech., 2010, 26, 1029- 1040. 
319. K. S. Bang and H. S. Jeong: 'Effect of nitrogen content on simulated heat affected zone toughness of titanium containing thermomechanically controlled rolled steel', Mater. Sci. Technol., 2002, 18, 649-654.

320. S. Mukae, K. Nishio and M. Katoh: 'Solution of TiN during synthetic weld thermal cycling and heat affected zone toughness in low carbon steels', Trans. Jpn Weld. Soc., 1987, 18, $148-158$.

321. M. Okastu, K. Oi, K. Ihara and T. Hoshino: 'High strength linepipe with excellent HAZ toughness', Proc. 23rd Int. Conf. on 'Offshore mechanics and arctic engineering', Vancouver, Canada, June 2004, ASME, 1-6.

322.Y. Shen and S. Hansen: 'Effect of the Ti/ $\mathrm{N}$ ratio on the hardenability and mechanical properties of a quenched-and tempered C-Mn-B steel', Metall. Mater. Trans. A, 1997, 28A, 2027-2035.

323. J. G. Williams: 'Advances in steels for high strength ERW linepipe application in Australia', Mater. Forum, 2007, 31, 1-10.

324.. Y. Li, J. Wilson, D.N. Crowther, P.S. Mitchell, A.J. Craven and T.N. Baker: 'The effects of vanadium, niobium, titanium and zirconium on the microstructure and mechanical properties of thin slab cast steels', ISIJ Int., 2004, 44, 1093-1102.

325. W. Mu, P.G. Jonsson and K.Nakajima: 'Recent Aspects on the Effect of Inclusion Characteristics on the Intragranular Ferrite Formation in Low Alloy Steels: A Review', High Temp. Mater. Proc., 2017, 36, 309-325.

326.T. Funakoshi, T. Tanaka, T.Ueda,S.Ishikawa,M.Koshizuka and K.Kobayashi: 'Improvement in microstructure and toughness of large heat-input weld bond due to addition of rare earth metals and boron in high strength steel ',Tetsu-toHagané, 1977,63,303-312.

327.T. Sawai, M. Wakoh, Y. Ueshima and S. Mizoguchi: 'Analysis of oxide dispersion during solidification in Ti,Zr-deoxidized steels', ISIJ Internal., 1992, 32, 169-173.

328. H. Nako, Y. Okazaki and J.G. Speer: 'Acicular ferrite formation on Ti-rare earth metal-Zr complex oxides', ISIJ Internal., 2015, 55, 250-256.

329. B. Mintz, S. Yue, and J. J. Jonas: 'Hot ductility of steels and its relationship to the problem of transverse cracking during continuous casting', Internal. Mater.Revs. 1991, 36, $187-217$.

330. B. Mintz and D.N. Crowther: 'The influence of small additions of Ti on the hot ductility of steels', 'Titanium Technology in Microalloyed Steels', (ed. T.N. Baker), 98-114, 1997, London, Institute of Materials.

331. N. Ånmark, A. Karasev and P. G. Jönsson: 'The effect of different non-metallic inclusions on the machinability of steels', Materials, 2015, 8, 751-783.

332. T. M. Banks and T. Gladman: 'Sulphide shape control', Met. Technol., 1979, 6, 81-94.

333. T.J. Baker and J.A. Charles: 'Deformation of MnS inclusions in steel', J Iron Steel Inst., 1972, 210,680-690.

334. T.J. Baker and J.A. Charles: 'Morphology of manganese sulfide in steel', J Iron Steel Inst., 1972, 210,702-706.

335. E. J. Lichy, G. C. Duderstadt and N. L. Samways: ' Control of sulfide shape in low carbon Al-killed steel', J. Met., 1965, 17, 769-775.

336. C.E.Sims: 'The nonmetallic constituents of steel', Trans.AIMME, 1959,215, 367-393.

337. P. J. H. Maunder and J. A. Charles: ' Behaviour of non-metallic inclusions in a 0.2 percent carbon steel ingot during hot rolling', J. Iron Steel Inst., 1968, 206, 705-715.

338. A. Segal and J. A. Charles: 'Influence of particle size on deformation characteristics of manganese sulphide inclusions in steel', Mater. Technol., 1977, 4, 177-182.

339. J.M. Gray: Linepipe and structural steel produced by high speed continuous casting.US

Patent No5993570.1999. 
340. A. Dehghan-Manshadi and R.J. Dippenaar: 'The behavior of precipitates during hotdeformation of low-manganese, titanium-added pipeline steels',Metall.Mater.Trans.A, 2010,41A,3291-3296.

341. F.J. Barbara, C.A. Jones, P.D.Edwards, J.G.Williams and P.R.Wilson: 'Sulphide inclusions in low manganese steels', www.betametallurgy.co.uk/public/images/publications/lowmn/ Barbaro .

342. D.T. Llewellyn and R.C. Hudd: Steels-Metallurgy \& Applications, $3^{\text {rd }}$. edition, ButterworthHeinemann, London, 1998

343. K. Oikawa, K. Ishida and T. Nishizawa: 'Effect of titanium addition on the formation and distribution of MnS inclusions in steel during solidification', ISIJ Internal.1997,37,332-338.

344. S.Aminorroaya and R.Dippenaar:'TEM analysis of centreline sulphide precipitates modified by titanium additions to low carbon steel', J. Micro., 2008, 232,123-129.

345. H. Kejian and T. N. Baker: 'Copper containing sulphide phases present in controlled rolled niobium-titanium bearing high strength low alloy steels', Mater. Sci. Technol., 1992, 8, 1082-1089.

346 E.M. Moore: 'Factors influencing hydrogen cracking sensitivity of pipeline steels', Mater. Perform.'1976, 15,17-23.

347. Y. Ishiguro, T. Murayama, T. Fujita and K. Kuroda: 'Sulfide precipitation in titanium-added steel with residual level of copper (1)-precipitation in austenite region', Mater. Trans., 2009, 50, $1360-1369$.

348. D. P. Escobar, L .Duprez, A. Atrens and K.Verbeken:'Thermal desorption spectroscopy study of experimental Ti/S containing steel', Mater. Sci. Tchnol., 2013, 29,261-267

349.R.L. Robbins, O.C. Shepard, O.D. Sherby: 'Role of crystal structure on the ductility of pure viron at elevated temperature', J. Iron Steel Inst., 1961,199, 175-180.

350. C. Rossard and P. Blain: 'A method of simulation by torsion to determine the influence of hot rolling conditions on the structure of steel', Rev. Métall.1962, 59,223-236.

351. B. Mintz and J. M. Arrowsmith: 'Hot ductility behaviour of CMn-Mn-Al steel and its relationship to crack propagation during straightening of continuously cast strand', Met. Technol., 1979, 6, 24-32.

352. H. G. Suzuki, S. Nishimura and S. Yamaguchi: Characteristics of hot ductility in steels subject to the melting and solidification, Trans. Iron Steel Inst. Jpn., 1982, 22, 48-56.

353. J. R. Wilcox and R. W. K. Honeycombe: 'Influence of prior precipitation on hot ductility of C-Mn-Nb-Al steels', in 'Hot working and forming processes', (ed. C. M. Sellars and G. J. Davies), 108-112; 1990, London, Institute of Materials.

354. H. Luo, L.P. Karjalainen, D.A. Porter, H.M. Liimatainen and Y. Zhang: 'The influence of Ti on the hot ductility of $\mathrm{Nb}$ bearing steels in simulated continuous casting processes', ISIJ Int., 2002, 42, 273-282

355. K. M. Banks, A. Tuling, C. Klinkenberg and B. Mintz: 'Influence of Ti on hot ductility of Nb containing HSLA steels', Mater. Sci.Technol., 2011, 27, 737-545.

356. D.N. Crowther and B. Mintz: 'Influence of grain size on hot ductility of plain C-Mn steels', Mater.Sci.Technol.,1986,2,951-955.

357.B. Mintz: 'The influence of composition on the hot ductility of steels and the problem of transverse cracking', ISIJ International, 1999, 39,833-855.

358. R. Abushosha, R. Vipnd, B. Mintz: 'Influence of titanium on hot ductility of as cast steels', Mater. Sci. Technol.,1991, 7, 613-621.

359. G.I.S.L. Cardoso, B. Mintz, S. Yue: 'Hot ductility of aluminium and titanium containing steels with and without cyclic temperature oscillations', Ironmaking Steelmaking, 1995, 22, 365-377.

360. R. Abushosha, O. Comineli \& B. Mintz : 'Influence of Ti on hot ductility of C-Mn-Al steels', Mater. Sci. Technol., 1999, 15,278-286. 
361. C. Spanbury and B. Mintz 'Influence of undercooling thermal cycle on hot ductility of C$\mathrm{Mn}-\mathrm{Al}-\mathrm{Ti}$ and C-Mn-Al-Nb-Ti steels', Ironmaking Steelmaking, 2005,32,319-324.

362. A.M. El-Wazri, F. Hassani, S. Yue, E. Es-Sadiqui, L.E. Collins and K.Iqual: 'The effect of thermal history on the hot ductility of microalloyed steels', ISIJInt., 1999, 39,256-262.

363. B Mintz and D N Crowther:'Hot ductility of steels and its relationship to the problem of transverse cracking in continuous casting', Internal. Mater. Revs., 2010, 55, 168-196

364. K. Banks, A. Tuling, and B. Mintz: 'Influence of V and Ti on hot ductility of Nb containing steels of peritectic C contents', Mater. Sci.Technol.,2011,27,1309-1314.

365.N. A. McPherson and A. McLean: 'Continuous Casting Volume Six-Tundish to Mold Transfer Operations', ed. 6 eds, ISSWarrendale, PA,1992,1-29.

366. L. Zhang and B. G. Thomas: 'Inclusions in continuous cast steel', XXIV National

Steelmaking Symposium, Morelia, Mich., Mexico,26-28 Nov.2003, pp.138-183.

367.G. A. DeMasi and R. F. Hartman: in $64^{\text {th }}$ Steelmaking Conference Proc. 64 eds., ISS, Warrendale, PA, 1981,245-253.

368.S. R. Cameron: 75 Steelmaking Conference Proc. ISS, Warrendale, PA,1992, 327-332.

369. Private communication 2017 J. Madill, Tata Steel Europe.

370.J. A. Kromhout: 'Mould Powder Development for Continuous Casting of Steel', Trans. Indian Inst. Met., 2013, 66, 587-596.

371.K.C. Mills, A.B. Fox, Z. Li \& R.P. Thackray: 'Performance and properties of mould fluxes', Ironmaking Steelmaking, 2005, 32, 26-34.

372. Q. Wang, Y. Lu, S. He, K.C. Mills, Z.S. Li: 'Formation of TiN and Ti(C, N) in $\mathrm{TiO}_{2}$ containing, fluoride free, mould fluxes at high temperature', Ironmaking Steelmaking, 2011, 38, 297-301.

373. K. C. Mills and C.Å. Däcker: 'Different Types of Mould Powders',,The Casting Powders Book pp 177-222, 2017, Springer International Publishing AG.

374.N. A. McPherson and S.L. McIntosh: 'Mold powder related defects in some continuously cast steel products', Iron Steel Maker,1987, June,19-25.

375. R. J. Glodowski: 'Experience in producing vanadium microalloyed steels thin-slab-casting steel technology' in Int. Symp. 'Thin-slab casting and rolling', Guangzhou, China, December 3- 5, 2000, 329- 339, Chinese Society for Metals.

376.Q.Y. Sha and Z.Q Sun: 'Microstructure and precipitation in as cast low carbon Nb-V-Ti microalloyed medium thin slab', Ironmaking Steelmaking,2010,37,320-325.

377. J. S. Park, M. Ajmal and R. Priestner: 'Tensile Properties of Simulated Thin Slab Cast and Direct Rolled Low-carbon Steel Microalloyed with Nb, V and Ti', ISIJ Internal.2000, 40,380-385.

378. J. M. Rodriguez-Ibabe: 'Thin slab direct rolling of microalloyed steels', Mater. Sci. Forum, 2005, 500-501, 49-62.

379. H. Bruns and R. Kaspar: 'Direct charging of thin slabs of a cold formable HSLA steel', Steel Res., 1997, 68, 215-219.

380. R. Priestner and C. Zhou: 'Simulation of microstructural evolution in Nb-Ti microalloyed steel during hot direct rolling', Ironmaking Steelmaking, 1995, 22, 326-332.

381.Y. Li, J. A. Wilson, A. J. Craven and T. N. Baker: 'Dispersion strengthening in vanadium microalloyed steels processed by simulated thin slab casting and direct charging. Part 1:

processing parameters, mechanical properties and microstructure', Mater. Sci. Technol., 2007, 23, 509-518.

382. J. A. Wilson, A. J. Craven, Y. Li and T. N. Baker: 'Dispersion strengthening in vanadium microalloyed steels processed by simulated thin slab casting and direct charging. Part 2: chemical characterisation of dispersion strengthening precipitates', Mater.Sci. Technol., 2007, 23, 519-527. 
383. B.K.Show, R.Veerababu, R.Balamuralikrishnan and G.Malakondaiah:'Effect of vanadium and titanium modification on the microstructure and mechanical properties of a microalloyed HSLA steel', Mater. Sci.Eng. A,2010,527,1595-1604.

384.J-C Herman, P. Messien and T.Gréday: 'HSLATi-containng steels', in 'Thermomechanical Processing of microalloyed austenite',(ed A.J.Deardo et al.), 655-671, 1982,Warrendale,PA, Metallurgical Society- AIME.

385.A.M. Sage, R.C. Cochrane and D. S. Howse, Proceedings of the International Conference on Processing Microstructure and Properties of Microalloyed and Other Modern HSLA Steels, Pittsburgh, PA, USA, 1992, 443-460.

386. M.Arribas,B.López and J.M.Rodriguez-Ibabe:'Additional grain refinement in recrystallization controlled rolling of Ti-microalloyed steels processed by near-net-shape casting technology',Mater.Sci.Eng.A,2008,485,383-394.

387. M.T. Nagata, J.G. Speer and D.K. Matlock: 'Titanium nitride precipitation in thin-slab cas high-strength low-alloy steel', Metall.Mater. Trans., 2002, 33A, 3099-3110.

388. B. Lopez, J.M..Rodriguez-Ibabe: 'Some metallurgical issues concerning austenite conditioning in $\mathrm{Nb}-\mathrm{Ti}$ and $\mathrm{Nb}-\mathrm{Mo}$ microalloyed steels processed by near-net-shape casting and direct rolling technologies', Metall. Mater. Trans.A,2017,48A, 2801-2811.

389.W.J.Liu and J.J.Jonas: 'A stress-relaxation method for following carbonitride precipitation in austenite at hot-working temperatures', Metall.Trans. A,1988,19,1403-1413.

390. W.J.Liu and J.J.Jonas: 'TI(CN) precipitation in microalloyed austenite during stressrelaxation',Metall.Trans. A,1988,19,1415-1424.

391. A.I. Fernández, B. López and J.M. Rodrıguez-Ibabe: 'Relationship between the austenite recrystallized fraction and the softening measured from the interrupted torsion test technique', Scripta Mater., 1999,40, 543-549.

392. L.A. Leduc and C.M.Sellars: 'Hot rolling of C-Mn-Ti steels', in 'Thermomechanical

Processing of microalloyed austenite',(ed A.J.Deardo et al.), 641-652, 1982,Warrendale,PA, Metallurgical Society- AIME.

393. Z. Wang, X. Mao, Z Yang, X. Sun, Q. Yong, Z. Li and Y. Weng: 'Strain-induced precipitation in a Ti micro-alloyed HSLA steel', Mater.Sci. Eng.A,2011,525,459-45

394. M.G.Abken,T.Chandra,P.Plassiard and J.J.Jonas: 'Dynamic precipitation and solute hardening in a titanium microalloyed steel containing 3 levels of manganese', Acta Metall.,1984,32,591-601.

395. F.Dong,F.Xue,L.Du and X.Liu:'Promoting Ti4C2S2 strain induced precipitation during asymmetrical hot rolling to improve $r$ value and advantaged texture in Ti stabilized IF steel',J.Alloys Cpds.,2015,620,240-248.

396. Z. Wang, X.Sun, Z. Yang, Q.Yong, C.Zhang,Z.Li. and Y. Weng: 'Carbide precipitation in austenite of a Ti-Mo-containing low-carbon steel during stress relaxation', Mater.S.Eng.A.,2013,573,84-91.

397. W. Roberts, A. Sandberg, T. Siwecki and T. Weriefors: 'Prediction of microstructure development during hot rolling of Ti-V steels', HSLA Steels. Technology and Applications, 67-84,1984, ASM, Ohio.

398. A.I. Fernández, P. Uranga, B. López and J.M. Rodriguez-Ibabe, Static recrystallization behaviour of a wide range of austenite grain sizes in microalloyed steels, ISIJ Internal, 2000, 40,893-901.

399. P. Uranga, A.I. Fernández, B. López and J.M. Rodriguez-Ibabe: 'Study of the interaction between precipitation and recrystallization in Ti-microalloyed steels after reheating at very high temperature', Proc. Conf. Thermomechanical Processing of Steels, 204-213,2000, The Institute of Materials, London. 
400. J. Wadsworth, J. H. Woodhead and S. R. Keown: 'The influence of stoichiometry upon carbide precipitation',Met.Sci.,1976,10,342-348.

401.X.G. Mao, Q.G. Chen and X.G. Sun: 'Metallurgical interpretation on grain refinement and synergistic effect of Mn and Ti inTi-microalloyed strip produced by TSCR', J. Iron Steel Res.Internal, 2014,21,30-40.

402. C. Wang, Q. Yong, X. Sun, X. Mao,Z. Li and X.Yong: 'Effects of Ti and Mn contents on the precipitate characteristics and strengthening mechanism in Ti microalloyed steels produced by CSP',Acta Metall.Sin.,2011,47,1541-1549.

403. D. Bhattacharya and S. Misra: 'Development of Microalloyed Steels Through Thin Slab Casting and Rolling (TSCR) Route', Trans. Ind. Inst. Met., 2017,70, 1647-1659.

404. Q. Y. Sha, Z.Q. Sun and L.F.Li: 'Refinement of coarse grained austenite in Nb-V-Ti microalloyed steels during roughing rolling', Ironmaking Steelmaking,2015,42,74-80.

405. Q.Y. Sha and Z. Q Sun: 'Grain growth behaviour of coarse-grained austenite in a Nb-V-Ti microalloyed steel', Mater.Sci. Eng.,2009, A523,77-84.

406. Q. Y. Sha and Z.Q. Sun: 'Prediction of grain growth of coarse-grained austenite in Nb-VTi microalloyed steel', Mater. Sci. Technol.,2011,27,1408-1411.

407. P. Uranga, A.I. Fernández, B. López and J.M. Rodriguez-Ibabe: 'Modeling of austenite grain size distribution in $\mathrm{Nb}$ microalloyed steels processed by thin slab casting and direct rolling (TSDR) route', ISIJ International,2004,44,1416-1425.

408. C.P. Reip, S. Shanmugam and R.D.K. Misra: 'High strength microalloyed C Mn(V-Nb-Ti) and $\mathrm{C}$ Mn $(\mathrm{V}-\mathrm{Nb})$ pipeline steels processed through CPS thin -slab technology: microstructure, precipitation and mechanical properties,' Mater.Sci.Eng.,2006, A424,307317.

409. C. Lee, H.Bhadeshia and H.Lee:'Effect of plastic deformation on the formation of acicular ferrite',_Mater.Sci.Eng., 2003, A360, 249-257.

\section{Figure captions}

$1 \mathrm{Fe}$-rich portion of an isothermal section of the Fe-Ti-B ternary phase diagram at $1273 \mathrm{~K}$ from Tanaka and Saito. ${ }^{40}$

2 O-Ti equilibrium diagram based on Murray and Wreidt. ${ }^{47}$

3 Free energy oxides, $\Delta \mathrm{G}$ vs temperature $\mathrm{T} \mathrm{K}$.

4 Titanium-iron oxides at $1873 \mathrm{~K}$, after Cha et al. ${ }^{49}$

5 Ti-S equilibrium diagrams prior to 1986 collated by Murray ${ }^{52}$

6 Comparison of $\mathrm{Ti}$ and $\mathrm{S}$ with constant $\mathrm{C}$ level sections for IF $(0.005 \% \mathrm{C})$ and an MA $\operatorname{steel}(0.05 \% \mathrm{C})^{61}$

7 (a) $0.01 \% \mathrm{Ti}$ steel containing mixed MnFeS and FeTiS precipitates ${ }^{65}$ 
(b) EDX of Mn-Fe- S inclusion in Fig 8a 0.01\% Ti. ${ }^{65}$

8 Calculated solubility by Dumitrescu and Hillert ${ }^{77}$ for TiC in $\gamma$ when $\mathrm{M}_{\mathrm{Ti}}=\mathrm{X}_{\mathrm{c}}$ The dashed line represents bcc that is metastable at $\mathrm{M}_{\mathrm{Ti}}=\mathrm{X}_{\mathrm{c}}$.

9 Equilibrium [\%Ti] [\%N] relations in Fe-Ti-N melts saturated with TiN at (a) $1823 \mathrm{~K},(\mathrm{~b}) 1873 \mathrm{~K},(\mathrm{c}) 1923 \mathrm{~K}$ and (d)1973K. ${ }^{92}$

10 Solubility product $\log (\mathrm{wt} \% \mathrm{Ti})(\mathrm{wt} \% \mathrm{~N}) \mathrm{v}$ a function of $\mathrm{T} .{ }^{77}$

11 Results of measurements and calculations of the solubility product

$\mathrm{K}_{\mathrm{TiN}}=[\% \mathrm{Ti}][\% \mathrm{~N}]$ in austenite. ${ }^{84}(1-$ see ref.84,2-ref82,3-ref.96,4-ref.83,5- ref.89,6-ref.84 measurements at $1300^{\circ} \mathrm{C}, 7-$ ref. 84 calculated data)

12 (a) Four caps formed on the sides of a cuboid core with the probability that there are also ,caps on the top and bottom faces.

(b) Cruciform particle with four arms nucleating and growing from core. ${ }^{107}$

13 The solubility of manganese sulphide in austenite ${ }^{115}$

14 Comparison of temperature dependent solubility of TiC, TiS, $\mathrm{Ti}_{4} \mathrm{C}_{2} \mathrm{~S}_{2}, \mathrm{TiN}$ and $\mathrm{MnS}{ }^{60}$

15 TEM micrograph showing the dendritic particle in Steel V-Ti-N. Li et al ${ }^{123}$

16 TEM micrograph showing the Ti rich particles in Steel V-Ti-N. Li et al ${ }^{123}$

17 TEM micrograph showing the irregularly shaped particles on the prior austenite grain boundary in Steel V-Ti-N. Li et al ${ }^{123}$

18 Coarse rounded particles which probably nucleated in austenite, and a finer dispersion, nucleated in ferrite. Li et al ${ }^{123}$

19 Schematic of thermomechanical processing simulation ${ }^{143}$

20 Calculated volume fraction of $(\mathrm{Ti}, \mathrm{Nb} 0 \mathrm{C}$ and $(\mathrm{Ti}, \mathrm{Nb})(\mathrm{C}, \mathrm{N})$ as a function of temperature in(a)alloy1 and (b) alloy 2.(c) Composition of $(\mathrm{Ti}, \mathrm{Nb})(\mathrm{C}, \mathrm{N})$ in alloyl as a function of temperature with the schematic illustrating bin successive layers of varying composition forming as the alloy is cooled ${ }^{75}$.

21a An unusual image of interphase precipitation in a V steel, discreate interphase precipitation (DIP), fibrous interphase precipitation (FIP) and random precipitation (RP). The ringed particles show double-lobe contrast.

$21 \mathrm{~b}$ Fibrous precipitation in a vanadium microalloyed steel

22 Example of random precipitation.TEM micrograph of carbon replica, which has extracted, $\sim 2 \mathrm{~nm}$ particles ${ }^{157}$

23 The PTT diagrams of the $\mathrm{Nb}$ steel and the $\mathrm{Nb}-\mathrm{Ti}$ steel, where $P_{\mathrm{s}}$ and $P_{\mathrm{f}}$ are start and finish times of the strain-induced precipitation, respectively. ${ }^{155}$ 
24 Comparison of the predicts of dispersion strengthening by Orowan and by Ashby-Orowan equations shown as yield stress increase as a function of particle volume fraction ${ }^{80}$

25 Effect of size and amount of precipitates on dispersion strengthening, $\sigma_{\mathrm{p}}{ }^{161}$

26 Ratio of limiting grain radius to particle radius $\left(\mathrm{R}_{\mathrm{c}} / \mathrm{r}\right)$ as a function of the volume fraction of particles(f). After Manohar et al. ${ }^{171}$

27 Experimental data of ratio of limiting grain radius to particle $\operatorname{radius}\left(\mathrm{R}_{\mathrm{c}} / \mathrm{r}\right)$ as a function of the volume fraction of particles(f) for the alloy systems collated by Manohar et al. ${ }^{171}$

28 A comparison of solubility products of carbides and nitrides in microalloy steels. Top horizontal axis is ${ }^{\circ} \mathrm{C}$.

29 Mean of grain coarsening temperature versus \% titanium in steel ( after Halley. ${ }^{182}$ )

30 The distribution of precipitate particle sizes in a series of steels heated over a temperature range $1000^{\circ} \mathrm{C}-1350^{\circ} \mathrm{C} .^{18}$

$\downarrow$ indicates the grain coarsening temperature

$X$ indicates the predominant particle size after each heat treatment

31 Mean of grain coarsening temperature versus atomic \% microalloying element. ${ }^{170}$

32 Effect of transformation temperature on the $0.2 \% \mathrm{PS}$ of steels in Table 16 plus data for steel $\mathrm{B}$ in the $\mathrm{Q}+\mathrm{T}$ state. ${ }^{149}$

33 Carbide dispersions after isothermal transformation at $725^{\circ} \mathrm{C}$ for $15 \mathrm{~min}$.

Dark field electron micrographs (a)Alloy 1 (Fe-V-C);(b) Alloy 2 (Fe-V-Ti C); (c) Alloy3 (Fe-Ti-C).(d) Alloy 1 aged at $725^{\circ} \mathrm{C}$ for $50 \mathrm{~h} .{ }^{13}$

34 Particle size distribution after isothermal transformation at $725^{\circ} \mathrm{C}$ for $15 \mathrm{~min} .{ }^{136}$

35 Schematic diagram of thermomechanical treatment in dilatometric test. ${ }^{193}$

36 Schematic diagram for the morphology of a (Ti, Mo)C particle formed in austenite.

The symbol' $\rightarrow$ ' denotes the direction of atomic diffusion. ${ }^{200}$

37 Changes with time in $(\mathrm{Ti}, \mathrm{Mo}) \mathrm{C}$ particle size compared with TiC particle size ${ }^{194}$ The solid points and line represent data showing the change in particle size with holding time, collected for $(\mathrm{Ti}, \mathrm{Mo}) \mathrm{C}$ particles, while the dotted line is for $\mathrm{TiC}$ particles.

38(a) Two large Ti-Nb particles in 0.01\% Ti-Nb steel, with smaller Nb-rich spheroids (b) An EELS spectrum collected from the centre of a $\sim 20 \mathrm{~nm} \mathrm{Nb-rich} \mathrm{spheroid} \mathrm{showing} \mathrm{the}$ niobium, carbon, nitrogen and titanium edges. ${ }^{126}$

39 Relationship between yield strength and Ti content and strip thickness of the steel. ${ }^{212,213}$

40 Schematic diagram of processing route of experimental steel. ${ }^{215}$

41 Schematic diagram of processing route of experimental steel. ${ }^{238}$ 
42 Development of line pipe steels as an example of MA steel research

(TMCP: thermomechanical controlled processing; ACC: accelerated cooling; DQ: direct quench), after Vervynckt. ${ }^{5}$

43 Material savings due to the use of high strength steel for a given pipe diameter. ${ }^{243}$

44 Optical micrograph showing Widmanstatten ferrite (WF), acicular ferrite (AF) and bainite (B). (after Ilman et al. ${ }^{252}$ )

45 The influence of $\mathrm{Mn}$ and Ti on the volume fraction of AF in conjunction with other phases. ${ }^{263}$

46 TEM of replica of acicular ferrite plates nucleating from particles with spherical (S) or angular (C) morphologies. (After Barritte ${ }^{264}$ )

47 Thin foil showing several ferrite laths, $\alpha$, nucleated at a $\mathrm{Ti}_{2} \mathrm{O}_{3}$ particle (after Byun et al. ${ }^{276}$ )

48 Schematic illustration of heterogeneous nucleation of $\mathrm{AF}$ on a surface of $\mathrm{Ti}_{2} \mathrm{O}_{3}$ inclusion with a MDZ near a MnS inclusion. ${ }^{282}$

49 Nucleation probability $\%$ as a function of inclusion size for three levels of titanium additions. $^{252}$

50 Effect of Ti/ $\mathrm{N}$ and heat input on austenite grain size. ${ }^{311}$

51 The effect of soaking time at $1673 \mathrm{~K}\left(1400^{\circ} \mathrm{C}\right)$ on austenite grain size. ${ }^{310}$

52 Effect of total $\mathrm{N}$ content on austenite grain size of water quenched simulated HAZ. ${ }^{306}$

53 Effect of Ti content on the size and number density of $\mathrm{MnS}$ inclusions in Fe-0.1C$1.0 \mathrm{Mn}-0.02 \mathrm{~S}$ specimens. ${ }^{343}$

54 Hot ductility curve for $0.19 \% \mathrm{C}$ steel with various austenite grain sizes. ${ }^{356}$

55 Influence of grain size on the minimum $\mathrm{R}$ of A value for $1.4 \% \mathrm{Mn} \mathrm{C}-\mathrm{Mn}$ and C$\mathrm{Mn}-\mathrm{Al}$ steels in which no precipitation of Al has occurred. ${ }^{356}$

56 Influence of $\mathrm{Al}$ and $\mathrm{Ti}$ on the hot ductility of steels. ${ }^{356}$

57 Schematic drawing showing formation of agglomerates of $\operatorname{Ti}(\mathrm{C}, \mathrm{N})$ when casting steels contain titanium. ${ }^{373}$

58 (a) Schematic diagram showing process route to simulate thin slab direct-charging by ASP and TDSR routes. ${ }^{403}$

(b) Scheme showing the metallurgical mechanisms at the different stages of the TSDR process plus the potential problems related to microalloying. ${ }^{375}$

59 Relationship between the post solidification cooling rate and the mean size of the fine TiN particles. ${ }^{388}$ The dashed interval corresponds to industrial thin slab conditions where cooling rates have not been reported.

60 Stress-strain curve for two stage interrupted compression test used to determine the softening ratio $\mathrm{X}^{393}$

61 Effect of different initial microalloying conditions on the time for $50 \%$ static recrystallization with a strain of $30 \%$ and a strain rate of $1 \mathrm{~s}^{-1(385,388,397)}$ 
62 TiN solubility diagram with mean particle size for end product samples ${ }^{387}$

63 Mean TiN particle size and 95\% confidence interval for end product samples ${ }^{387}$

\section{Table captions}

1 Microalloyed additions, country, year and yield strength ${ }^{4,12}$

2 Recovery of the groups $1 \mathrm{Va}$ and $\mathrm{Va}$ and rare earth elements in carbon steels. ${ }^{29}$

3 Relationship between titanium and elements in Groups IV, V, VI and VII ${ }^{31}$

4 Atomic radii of refractory metals ${ }^{31}$

5 Compounds characterised and reported in the literature based on titanium additions to steels

6 Orientation relationships (OR) found between phases in MA steels

7 Solubility constants for $\mathrm{TiC}$ in $\gamma^{77}$

8 Solubility constants for TiN in $\gamma^{77}$

9 The steel compositions investigated by Craven et al. ${ }^{107}$

10 Calculated core compositions of the $\left(\mathrm{Ti}_{\mathrm{x}} \mathrm{Nb}_{1-\mathrm{x}}\right) \mathrm{N}_{\mathrm{y}} \mathrm{C}_{\mathrm{z}}$ carbonitride in three steel compositions,${ }^{108}$ and those of Liu, ${ }^{106}$ compared with the measurements of Craven et al ${ }^{107}$

11 Calculated cap compositions of the $\left(\mathrm{Ti}_{\mathrm{x}} \mathrm{Nb}_{1-\mathrm{x}}\right) \mathrm{N}_{\mathrm{y}} \mathrm{C}_{\mathrm{z}}$ carbonitride in three steel compositions ${ }^{108}$, and those of Liu ${ }^{106}$, compared with the measurements of Craven et al. 107

12 Composition of experimental steels and quench temperatures ${ }^{127}$

13 Atomic $\%$ analysis of particles after isothermal transformation for $10 \mathrm{~min}$ at $800^{\circ} \mathrm{C}{ }^{135}$.

14 Chemical Compositions of the Experimental Alloys ${ }^{75}$

15 Compositions of Ti steels wt.- $\%{ }^{151,152}$

16 Compositions of experimental steels ${ }^{136}$ 
17 Mechanical properties for pipeline steels

18 Chemical compositions of experimental hot rolled steels (wt. \%) ${ }^{246}$

19 Composition in wt-\% of steels considered in Fig. $56^{330}$

20 Chemical compositions and longitudinal mechanical properties of two treated steels ${ }^{402}$

\section{Nomenclature}

\section{Symbols}

A pre-exponential factor

A austenite

AF acicular ferrite

AGG abnormal grain growth

AP atom probe

APT atom probe tomography

B bainite

B-M bainite-martensite

BNOR Baker -Nutting orientation relationship

$\mathrm{C}_{\alpha} \quad$ solubility of the particle material

CB conventional bainite

$\mathrm{CE} \quad$ carbon equivalent

CTOD crack tip opening displacement

D diffusion coefficient of the particle material

DIFT deformation-induced-ferrite transformation

DP dual phase 
$\Delta \mathrm{G} \quad$ Gibbs free energy

$E_{a} \quad$ activation energy

EDX energy-dispersive X-ray spectroscopy

f $\quad$ volume fraction

F ferrite

FEG field emission gun

FFC Fray Farthing Chen

FIM field ion microscope

FRT finish rolling temperature

CGHAZ coarse grain heat affected zone

GP Guinier-Preston

HAZ heat affected zone

HE hydrogen embrittlement

HIC hydrogen induced cracking

HRTEM high resolution transmission electron microscopy

HSLA high strength low alloy

ICCGHAZ intercritical coarse grained heat affected zone

IGF inter granular ferrite

IHT isothermal heat treatment

JCPDS Joint Committee Powder Diffraction - International Center for powder diffraction data

K solubility product

KSOR Kurdjumov-Sachs orientation relationship

L interaction parameter

LWS Lifshitz Wagner Slyozov

M metal

MA micro alloyed

M-A martensite-austenite

$\mathrm{M}_{\mathrm{s}} \quad$ martensite start temperature

MDZ manganese depleted zone

NWOR Nishiyama-Wassermann orientation relationship 
pearlite

PEELS parallel electron energy loss spectroscopy

PSOR Pitsch-Schrader orientation relationship

Q heat of dissolution

Q\&T quenched and tempered

$R \quad$ Universal or ideal gas constant

RA retained austenite

$R_{c} \quad$ critical maximum grain radius

$2 \overline{\mathrm{r}} \quad$ average particle diameter

REM rare earth metal

RT room temperature

SAED selected area electron diffraction

SEM scanning electron microscopy

SIP strain induced precipitate

SSC sulphide stress cracking

SSS solid solution strengthening

STEM scanning transmission electron microscopy

$\mathrm{T} \quad$ absolute temperature in degrees Kelvin

$T_{c} \quad$ impact transition temperature

TRZ oxide REM-rich and Zr-rich oxide phases

t time

$\mathrm{t}_{8 / 5} \quad$ time to cool between $800^{\circ} \mathrm{C}$ and $500^{\circ} \mathrm{C}$

TEM transmission electron microscopy

TRIP transformation-induced-plasticity-assisted (steels)

TMP thermomechanical processing

TSDR thin slab direct rolled

$\mathrm{V}_{\mathrm{m}} \quad$ molar volume of the particle material

$\mathrm{X} \quad$ interstitial element

Greek letters

$\alpha \quad$ ferrite 
austenite

$\sigma_{\mathrm{c}} \quad$ cleavage strength

$\sigma_{y}$

lower yield stress

$\sigma_{o}$

experimental constant

$\sigma_{\mathrm{p}}$

contribution to yield strength from precipitates giving dispersion strengthening

$\sigma_{\mathrm{s}}$ contribution to yield strength from solid solution strengthening

$k_{y}$ experimental constant

$\rho$ particle surface tension or energy solubility of the particle material

vE-20 impact absorption energy at $-20^{\circ} \mathrm{C}$

words 43,294 
Table 1 Microalloyed additions, country, year and yield strength ${ }^{4,20}$

$\begin{array}{ccccc}\text { Element } & \text { wt } \% & \text { Country } & \text { Date } & \text { Yield Strength } \mathrm{Nmm}^{-2} \\ \mathrm{~V} & 0.10-0.20 & \text { USA } & 1916 & 275-342 \\ \mathrm{~V} & 0.10 & \text { Germany } & 1945 & >390 \\ \mathrm{Nb} & 0.02-0.03 & \text { USA } & \text { pre1959 } & 325-445 \\ \mathrm{Nb} & 0.005-0.05 & \text { UK } & 1959 & 350-425 \\ \mathrm{Ti} & 0.10-0.20 & \text { Germany } & 1921 & 260-550 \\ \mathrm{Zr} & 0.10-0.20 & \text { Germany } & 1914 & 250-400 \\ \mathrm{Zr} & 0.05-0.10 & \text { USA } & 1918 & 260-450\end{array}$

Table 2 Recovery of the groups $1 \mathrm{Va}$ and Va and rare earth elements in carbon steels. ${ }^{29}$
V: $90-1005$
Ti: $50-80 \%$
$Y: 35-60 \%$
$\mathrm{Nb}: 80-100 \%$
Zr: $50-80 \%$
La: $20-50 \%$
Ta: $70-90 \%$
Hf: $\quad 40-80 \%$
U $20-50 \%$ 
Table 3 Relationship between titanium and elements in Groups IV, V, VI and VII ${ }^{31}$

\begin{tabular}{|c|c|c|c|c|}
\hline Group & Element & Metal structure & Carbide (metal atom structure & Composition range \\
\hline \multirow[t]{5}{*}{ IV } & $\mathrm{Ti}$ & bcc, hcp & fcc & $\mathrm{TiC}$ \\
\hline & $\mathrm{Zr}$ & bcc, hcp & fCC & $\mathrm{ZrC}$ \\
\hline & $\mathrm{Hf}$ & bcc, hcp & fcc & $\mathrm{HFC}$ \\
\hline & V & bcc & fcc & $\mathrm{VC}-\mathrm{V}_{4} \mathrm{C}_{3}$ \\
\hline & & & hсp & $\mathrm{V}_{2} \mathrm{C}-\mathrm{V}_{8} \mathrm{C}_{3}$ \\
\hline \multirow[t]{5}{*}{ V } & $\mathrm{Nb}$ & bcc & fcc & $\mathrm{NbC}-\mathrm{Nb}_{4} \mathrm{C}_{3}$ \\
\hline & & & hсp & $\mathrm{Nb}_{2} \mathrm{C}-\mathrm{Nb}_{3} \mathrm{C}$ \\
\hline & $\mathrm{Ta}$ & bcc & fcc & $\mathrm{TaC}$ \\
\hline & & & hcp & $\mathrm{Ta}_{2} \mathrm{C}-\mathrm{Ta}_{8} \mathrm{C}_{3}$ \\
\hline & $\mathrm{Cr}$ & bcc & Complex structures & $\mathrm{Cr}_{23} \mathrm{C}_{6}, \mathrm{Cr}_{7} \mathrm{C}_{3}, \mathrm{Cr}_{3} \mathrm{C}_{2}$ \\
\hline \multirow[t]{4}{*}{ VI } & Mo & $\mathrm{bcc}$ & hcp & $\mathrm{Mo}_{2} \mathrm{C}-\mathrm{Mo}_{3} \mathrm{C}$ \\
\hline & & & hex. & MoC \\
\hline & W & $\mathrm{bcc}$ & hcp & $\mathrm{W}_{2} \mathrm{C}$ \\
\hline & & & hex & WC \\
\hline VII & $\mathrm{Mn}$ & bcc, fcc and complex structures & Complex structures & $\mathrm{Mn}_{4} \mathrm{C}, \mathrm{Mn}_{23} \mathrm{C}_{6}, \mathrm{Mn}_{3} \mathrm{C}, \mathrm{Mn}_{5} \mathrm{C}_{2}, \mathrm{Mn}_{7} \mathrm{C}_{3}$ \\
\hline
\end{tabular}

Table 4 Atomic radii of refractory metals ${ }^{31}$

\begin{tabular}{lll}
\hline Element & Atomic radius/nm & Difference in atomic radium relative to iron/\% \\
\hline $\mathrm{Ti}$ & 0.147 & +14.8 \\
$\mathrm{~V}$ & 0.136 & $+6 \cdot 2$ \\
$\mathrm{Cr}$ & 0.128 & $\gg 0$ \\
$\mathrm{Zr}$ & 0.160 & $+25 \cdot 0$ \\
$\mathrm{Nb}$ & 0.148 & $+15 \cdot 6$ \\
$\mathrm{Mo}$ & 0.140 & +9.4 \\
$\mathrm{Hf}$ & 0.205 & +31.3 \\
$\mathrm{Ta}$ & 0.148 & $+15 \cdot 6$ \\
$\mathrm{~W}$ & 0.141 & +1 \\
\hline
\end{tabular}


Table 5 Compounds Characterized in Titanium MA Steels

\begin{tabular}{|c|c|c|c|c|c|}
\hline \multirow{2}{*}{ COMPOUND } & \multirow{2}{*}{ STRUCTURE } & \multicolumn{3}{|c|}{ LATTICE PARAMETERS nm } & \multirow{2}{*}{$\begin{array}{c}\text { JCPDS } \\
\text { Card No }\end{array}$} \\
\hline & & $\mathrm{a}$ & $\mathrm{b}$ & $\mathrm{c}$ & \\
\hline $\mathrm{TiB}_{2}$ & Hexagonal & 0.3028 & & 0.3228 & $8-0121$ \\
\hline $\mathrm{Ti}_{3} \mathrm{~B}_{4}$ & Orthorhombic & 0.3259 & 1.373 & 0.3042 & $9-1368$ \\
\hline $\mathrm{TiC}$ & Cubic & 0.4329 & & & $6-0614$ \\
\hline (Ti,Mo)C & Cubic & 0.430 & & & \\
\hline $\mathrm{TiN}$ & Cubic & 0.4240 & & & $6-0642$ \\
\hline $\begin{array}{c}\mathrm{TiO}_{2} \\
\text { (Anatase) }\end{array}$ & Tetragonal & 0.37805 & & 0.95143 & $21-1272$ \\
\hline $\begin{array}{c}\mathrm{TiO}_{2} \\
\text { (Brookite) }\end{array}$ & Orthorhombic & 0.5456 & 0.91819 & 0.51429 & $16-617$ \\
\hline $\begin{array}{c}\mathrm{TiO}_{2} \\
\text { (Rutile) }\end{array}$ & $\begin{array}{c}\text { Tetragonal } \\
\text { (P42/mmm) }\end{array}$ & 0.45933 & & 0.29592 & $21-1276$ \\
\hline $\mathrm{Ti}_{4} \mathrm{O}_{7}$ & $\begin{array}{c}\text { Triclinic } \\
\text { Magneli phase }\end{array}$ & $\begin{array}{c}0.5594 \\
\alpha \\
95.05^{\circ}\end{array}$ & $\begin{array}{c}0.71216 \\
\beta \\
95.19^{\circ}\end{array}$ & $\begin{array}{c}1.24600 \\
\gamma \\
108.76^{\circ}\end{array}$ & $77-1391$ \\
\hline $\mathrm{Ti}_{3} \mathrm{O}_{5}$ & Monoclinic & & & & $40-0806$ \\
\hline $\mathrm{Ti}_{2} \mathrm{O}_{3}$ & Hexagonal & 0.5139 & & 1.3659 & $10-0063$ \\
\hline $\mathrm{MnTiO}_{4}$ & Tetragonal & 0.8726 & & 0.8567 & $20-0728$ \\
\hline $\mathrm{MnTiO}_{3}$ & Rhombohedral & 0.51316 & & 1.429 & $29-0902$ \\
\hline $\mathrm{MnTi}_{2} \mathrm{O}_{4}$ & Cubic & 0.8627 & & & $41-0064$ \\
\hline
\end{tabular}




\begin{tabular}{|c|c|c|c|c|c|}
\hline TiS & Hexagonal & 0.3229 & & 0.6380 & $12-534$ \\
\hline TiS & Hexagonal & 0.3416 & & 2.64 & $9-289$ \\
\hline TiS & $\begin{array}{l}\text { Trigonal with } \\
\text { Rhombohedral } \\
\text { sub lattice }\end{array}$ & 0.317 & & 2.650 & Ref.[59] \\
\hline $\mathrm{Fe}_{0.5} \mathrm{Ti}_{1.0} \mathrm{~S}_{2}$ & Hexagonal & 0.3423 & & 0.5710 & $10-64$ \\
\hline $\mathrm{FeTi}_{2} \mathrm{~S}_{4}$ & Monoclinic & 0.5929 & $\begin{array}{l}0.3426 \\
\beta=90.10^{\circ}\end{array}$ & 1.731 & $20-1303$ \\
\hline $\mathrm{Fe}_{1.2} \mathrm{Ti}_{0.8} \mathrm{~S}_{2}$ & Hexagonal & 0.3473 & & 0.5777 & $10-48$ \\
\hline $\mathrm{FeTiS}_{2}$ & $\begin{array}{l}\text { Trigonal } \\
\left(\mathrm{CdI}_{2} \text { type }\right) \\
(\mathrm{P} \overline{3} \mathrm{~m} 1)\end{array}$ & 0.341 & & 0.569 & Ref[67] \\
\hline $\mathrm{Ti}_{4} \mathrm{C}_{2} \mathrm{~S}_{2}$ & Hexagonal & 0.321 & & 1.120 & $16-849$ \\
\hline$\alpha-\mathrm{MnS}$ & Cubic & 0.52236 & & & $6-518$ \\
\hline $\mathrm{MnS}+\mathrm{Fe}$ & $\begin{array}{l}\text { Hexagonal } \\
\mathrm{P}_{3} \mathrm{mc}\end{array}$ & 0.399 & & 0.644 & Ref[67] \\
\hline
\end{tabular}


Table 6. Orientation relationships (OR) found between phases in MA steels

\begin{tabular}{|c|c|c|}
\hline OR & Plane & Direction \\
\hline Bain & $\{010\}_{Y} \|\{010\}_{\alpha}$ & $<001>_{\gamma} \|<101>_{\alpha}$ \\
\hline Kurdjumov-Sachs & $\{111\}_{Y} \|\{110\}_{\alpha}$ & $\left.<110\rangle_{\gamma} \|<111\right\rangle_{\alpha}$ \\
\hline Nishiyama-Wassermann (N-W) & $\{111\}_{Y} \|\{110\}_{\alpha}$ & $<011>_{\gamma} \|<001>_{\alpha}$ \\
\hline Baker-Nutting & $\{110\}_{\alpha} \|\{110\}_{\mathrm{MCN}}$ & $\left.<011\rangle_{\alpha} \|<010\right\rangle_{\mathrm{MCN}}$ \\
\hline Pitsch-Schrader & $(110)_{b c c} \|(0001)_{h c p}$ & {$[1 \overline{10}]_{\mathrm{bcc}} \|[1 \overline{1} 00]_{\mathrm{hcp}}$} \\
\hline
\end{tabular}


Table 7 Solubility constants for $\mathrm{TiC}$ in $\gamma$

$\begin{array}{ccc}C & \text { Q } & \text { Ref } \\ 2.750 & 7000 & 78 \\ 5.330 & 10475 & 79 \\ 5.540 & 11300 & 79 \\ 4.370 & 10580 & 76 \\ 2.970 & 6780 & 29\end{array}$

Table 8 Solubility constants for TiN in $\gamma^{77}$

$\begin{array}{crr}C & \text { Q } & \text { Ref } \\ 3.820 & 15020 & 76 \\ 0.322 & 8000 & 82 \\ 5.190 & 15490 & 84 \\ 4.940 & 14400 & 83 \\ 5.400 & 15790 & 85\end{array}$


Table 9 The steel compositions investigated by Craven et al ${ }^{107}$

\begin{tabular}{lllll}
\hline Steel & $\mathrm{C}$ & $\mathrm{N}$ & $\mathrm{Nb}$ & $\mathrm{Ti}$ \\
\hline $\mathrm{A}$ & 0.07 & 0.0079 & 0.025 & 0.009 \\
$\mathrm{~B}$ & 0.097 & 0.0049 & 0.017 & 0.010 \\
$\mathrm{C}$ & 0.081 & 0.0050 & 0.016 & 0.022 \\
\hline
\end{tabular}

All values are given in wt $\%$.

Table 10 Calculated core compositions of the $\left(\mathrm{Ti}_{\mathrm{x}} \mathrm{Nb}_{1-\mathrm{x}}\right) \mathrm{N}_{\mathrm{y}} \mathrm{C}_{\mathrm{z}}$ carbonitride in three steel compositions, compared with the measurements of Craven et al ${ }^{107}$ ( $\mathbf{x}, \mathbf{y}$ and $\mathrm{z}$ are integers)

\begin{tabular}{|c|c|c|c|c|c|c|}
\hline \multirow[t]{2}{*}{ Steel } & \multicolumn{2}{|l|}{ Steel A } & \multicolumn{2}{|l|}{ Steel B } & \multicolumn{2}{|l|}{ Steel C } \\
\hline & $\bar{x}$ & $y$ & $\bar{x}$ & $y$ & $x$ & $y$ \\
\hline Experiment & $\begin{array}{l}0.86 \pm \\
0.04\end{array}$ & $\approx 1$ & $\begin{array}{l}0.91 \pm \\
0.03\end{array}$ & $\begin{array}{l}0.84 \pm \\
0.05\end{array}$ & $\begin{array}{l}0.91 \pm \\
0.03\end{array}$ & $\begin{array}{l}0.6 \pm \\
0.2\end{array}$ \\
\hline $\begin{array}{l}\text { Calculation } \\
\text { This work }\end{array}$ & 0.95 & 0.92 & 0.98 & 0.87 & 0.99 & 0.78 \\
\hline Calculation & 0.78 & 0.99 & 0.82 & 0.99 & 0.89 & 0.95 \\
\hline
\end{tabular}

The Calculation is from $\mathrm{Liu}^{106}$ 
Table 11 Calculated cap compositions of the $\left(T i_{x} N b_{1-x}\right) N_{y} C_{z}$ carbonitride in three steel compositions, compared with the measurements of Craven et al 107 ( $\mathbf{x}, \mathbf{y}$ and $\mathrm{z}$ are integers)

\begin{tabular}{|c|c|c|c|c|c|c|}
\hline \multirow[t]{2}{*}{ Steel } & \multicolumn{2}{|c|}{ Steel A } & \multicolumn{2}{|l|}{ Steel B } & \multicolumn{2}{|l|}{ Steel C } \\
\hline & $t$ & $u$ & $t$ & $u$ & $t$ & u \\
\hline Experiment & 1 & $\approx 0.7$ & 1 or $\approx 0.8$ & $\approx 1$ & $0.76 \pm 0.07$ & $* * *$ \\
\hline $\begin{array}{l}\text { Calculation } \\
\text { This work }\end{array}$ & 0.96 & 0.90 & 0.92 & 0.93 & 0.80 & 0.99 \\
\hline Calculation & 0.78 & 0.99 & 0.82 & 0.99 & 0.89 & 0.95 \\
\hline
\end{tabular}

Table 12 Composition of experimental steels and quench temperatures ${ }^{127}$

\begin{tabular}{|c|c|c|c|c|c|c|c|c|}
\hline & $\mathrm{C}$ & $\mathrm{N}$ & $\mathrm{Ti}$ & $\mathrm{Nb}$ & $\mathrm{V}$ & $\mathrm{Mn}$ & $\mathrm{Si}$ & $\begin{array}{c}\text { Quench } \\
\text { Temperature }\end{array}$ \\
\hline Cast 1 & 0.22 & 0.0024 & 0.006 & 0.04 & 0.011 & 1.27 & 0.25 & 1401 \\
\hline Cast 2 & 0.075 & 0.0032 & 0.007 & 0.04 & 0.011 & 1.23 & 0.23 & 1421 \\
\hline Cast 3 & 0.218 & 0.0117 & 0.005 & 0.04 & 0.011 & 1.27 & 0.25 & 1347 \\
\hline Cast 4 & 0.074 & 0.0145 & 0.006 & 0.04 & 0.011 & 1.27 & 0.25 & 1396 \\
\hline
\end{tabular}

$\mathrm{P}$ and $\mathrm{S}$ were $0.006-0.008 \mathrm{wt} \%, \mathrm{Cu}$ was $0.007-0.008 \mathrm{wt} \%, \mathrm{Al}$ was $<0.002 \mathrm{wt} \%$. 
Table 13 Atomic \% analysis of particles after isothermal transformation for $10 \mathrm{~min}$ at $800^{\circ} \mathrm{C} .{ }^{115}$

\begin{tabular}{lccrr}
\hline & $\mathrm{Fe}$ & $\mathrm{V}$ & $\mathrm{Ti}$ & $\mathrm{C}$ \\
\hline Particle I & 2 & 7 & 9 & 20 \\
Particle II & 1 & 6 & 7 & 9 \\
Particle III & 2 & 9 & 13 & 17 \\
\hline
\end{tabular}

Table 14 Chemical Compositions of the Experimental Alloys ${ }^{75}$

$$
\begin{array}{lllllllll}
\mathrm{C} & \mathrm{Si} & \mathrm{Mn} & \mathrm{Ti} & \mathrm{Nb} & \mathrm{V} & \mathrm{N} & \mathrm{Fe}
\end{array}
$$

\begin{tabular}{llllllll}
\multicolumn{7}{c}{ Alloy 1 } \\
(wt pct) 0.050 & 0.3001 .280 & 0.116 & 0.034 & 0.014 & 0.009 & Bal. \\
(at. pct) 0.231 & 0.593 & 1.294 & 0.135 & 0.020 & 0.015 & 0.036 & Bal. \\
& \multicolumn{7}{c}{ Alloy 2 } \\
(wt pct) 0.040 & 0.2201 .030 & 0.060 & 0.060 & 0.004 & 0.008 & Bal. \\
(at. pct) 0.185 & 0.436 & 1.043 & 0.069 & 0.034 & 0.004 & 0.032 & Bal
\end{tabular}

Table 15 Compositions of Ti steels wt.-\% ${ }^{151,152}$

$\begin{array}{ccccc}\text { Alloy } & \mathrm{Ti} & \mathrm{C} & \mathrm{Mn} & \text { Vol. fraction of carbide (approx.) } \\ \text { B } & 0 \cdot 55 & 0 \cdot 11 & 0 \cdot 18 & 0 \cdot 45 \% \\ \mathrm{D} & 0 \cdot 25 & 0 \cdot 05 & - & 0 \cdot 43 \% \\ \text { C } & 0 \cdot 13 & 0.02 & - & 0 \cdot 16 \%\end{array}$

Nitrogen content was between 10 and $45 \mathrm{ppm}$. 
Table 16 Compositions of experimental steels ${ }^{136}$

$\begin{array}{llcccc} & \text { Alloy } & \mathrm{C} & \mathrm{V} & \mathrm{Ti} & \begin{array}{c}\text { Mean particle } \\ \text { size,nm }\end{array} \\ 1 & \text { (Fe-V-C) } & 0.08 & 0.40 & - & 2.9 \\ 2 & \text { (Fe-V-Ti-C) } & 0.08 & 0.18 & 0.13 & 2.1 \\ 3 & \text { (Fe-Ti-C) } & 0.09 & - & 0.33 & 6.2\end{array}$

Table 17 Mechanical properties for pipeline steels

Grade YS (MPa) TS (MPa) YR (\%) El\%
$X 65 \geq 448 \geq 530 \quad \leq 90 \quad \geq 24$
$X 70 \geq 482 \geq 565 \quad \leq 90 \quad \geq 23$
$X 80 \geq 551 \quad 620-827 \leq 93 \quad \geq 22$
$X 100 \geq 690 \quad \geq 760 \quad 90$
$X 120 \geq 883 \geq 1023$
$(X 140 \geq 965)$

Table 18 Chemical compositions of experimental hot rolled steels (wt. \%) ${ }^{246}$

\begin{tabular}{cccccccccccc}
\hline & $\mathrm{C}$ & $\mathrm{Si}$ & $\mathrm{Mn}$ & $\mathrm{P}$ & $\mathrm{S}$ & $\mathrm{Al}$ & $\mathrm{Ti}$ & $\mathrm{Nb}$ & $\mathrm{V}$ & $\mathrm{N}, \mathrm{ppm}$ & $\mathrm{Ca}$ \\
\hline Steel A & 0.058 & 0.2 & 1.6 & 0.013 & 0.0010 & 0.034 & 0.015 & 0.070 & 0.040 & 34 & added \\
Steel B & $0 . .054$ & 0.2 & 1.2 & 0.008 & 0.0007 & 0.029 & - & 0.045 & 0.035 & 50 & added \\
\hline
\end{tabular}


Table 19 Composition in wt-\% of steels considered in Fig. $56^{322}$

\begin{tabular}{llcccccccc}
\hline & Steel & $\mathbf{C}$ & Si & Mn & P & S & sol.Al & N & Ti \\
\hline 1 & C-Mn & 0.14 & 0.15 & 1.28 & 0.004 & 0.017 & 0.002 & 0.0035 & - \\
2 & C-Mn-Al & 0.16 & 0.23 & 1.40 & 0.002 & 0.014 & 0.028 & 0.004 & - \\
3 & C-Mn-Al & 0.16 & 0.22 & 1.40 & 0.002 & 0.015 & 0.068 & 0.004 & - \\
4 & C-Mn-Al-N & 0.17 & 0.24 & 1.50 & 0.002 & 0.015 & 0.030 & 0.007 & - \\
5 & C-Mn-Al-N & 0.16 & 0.23 & 1.40 & 0.002 & 0.016 & 0.078 & 0.007 & - \\
6 & C-Mn-Ti-Al & 0.15 & 0.20 & 1.25 & 0.003 & 0.018 & 0.03 & 0.004 & 0.02 \\
7 & C-Mn-Ti-Al & 0.16 & 0.23 & 1.50 & 0.002 & 0.013 & 0.03 & 0.004 & 0.03 \\
8 & C-Mn-Ti-Al & 0.17 & 0.20 & 1.40 & 0.002 & 0.015 & 0.072 & 0.004 & 0.03 \\
\hline
\end{tabular}

Table 20 Chemical composition and longitudinal mechanical properties of two tested steels ${ }^{400}$

$\begin{array}{llllllllllllllll}\text { Steel } & \mathrm{C} & \mathrm{Si} & \mathrm{Mn} & \mathrm{S} & \mathrm{P} & \mathrm{Cr} & \mathrm{Ni} & \mathrm{Cu} & \mathrm{Ti} & \mathrm{N} & \sigma_{0.2} & \sigma_{\mathrm{b}} & \text { Agt } & \delta & \mathrm{Ti} / \mathrm{N}\end{array}$ $\mathrm{MPa} \mathrm{MPa} \% \quad \%$

No.1 0.0470 .0840 .430 .0030 .0110 .4160 .2430 .2550 .1090 .008362569512 .52613 .1 No.2 0.0460 .0911 .380 .0030 .0150 .6050 .0350 .1020 .1310 .012072577511 .52310 .9 Note: $\sigma_{0.2}$-proof stress, $\sigma_{b}$-tensile strength, Agt—uniform elongation, $\delta$-elongation 


\section{Figures for Role of Ti in MA steels}

(a)

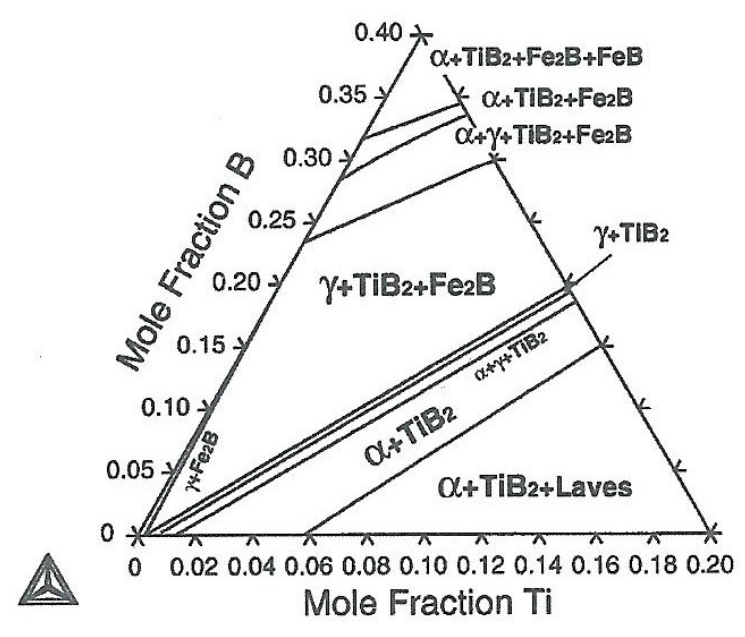

(b)

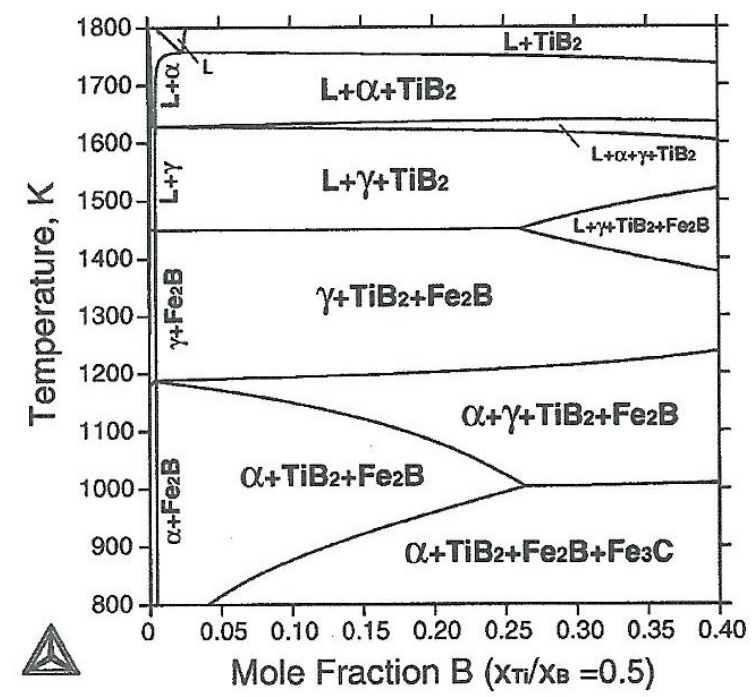

1 


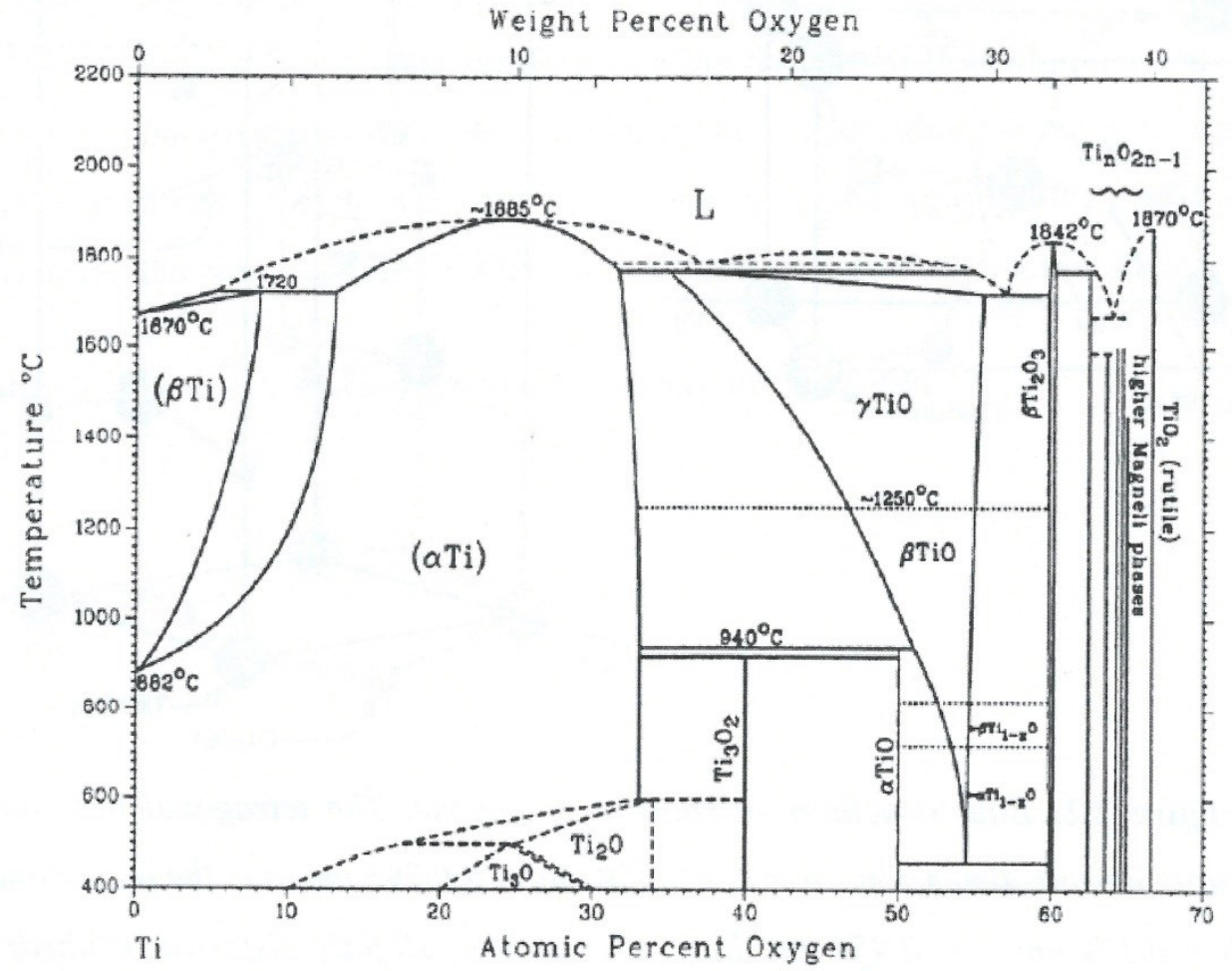

2 


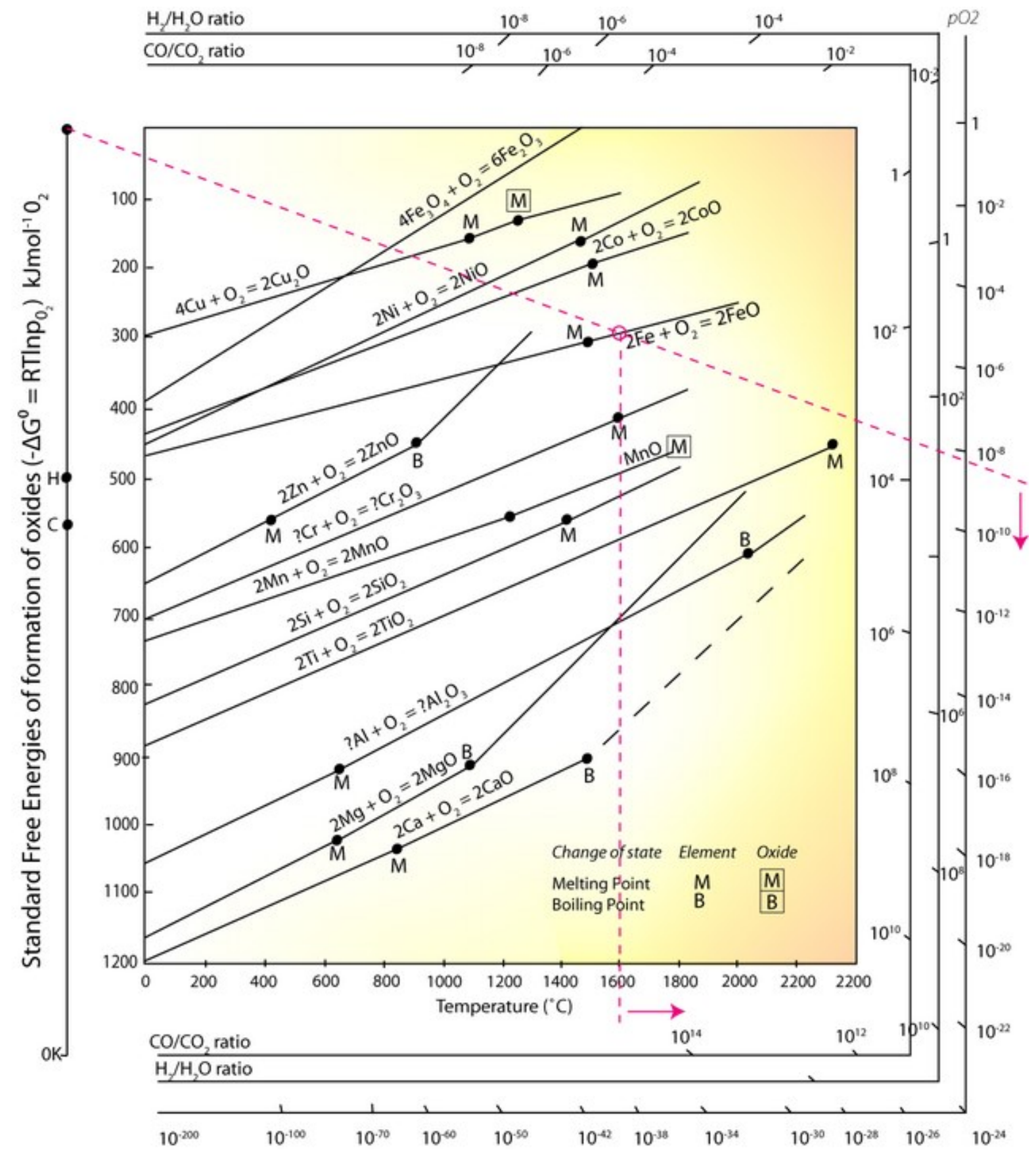




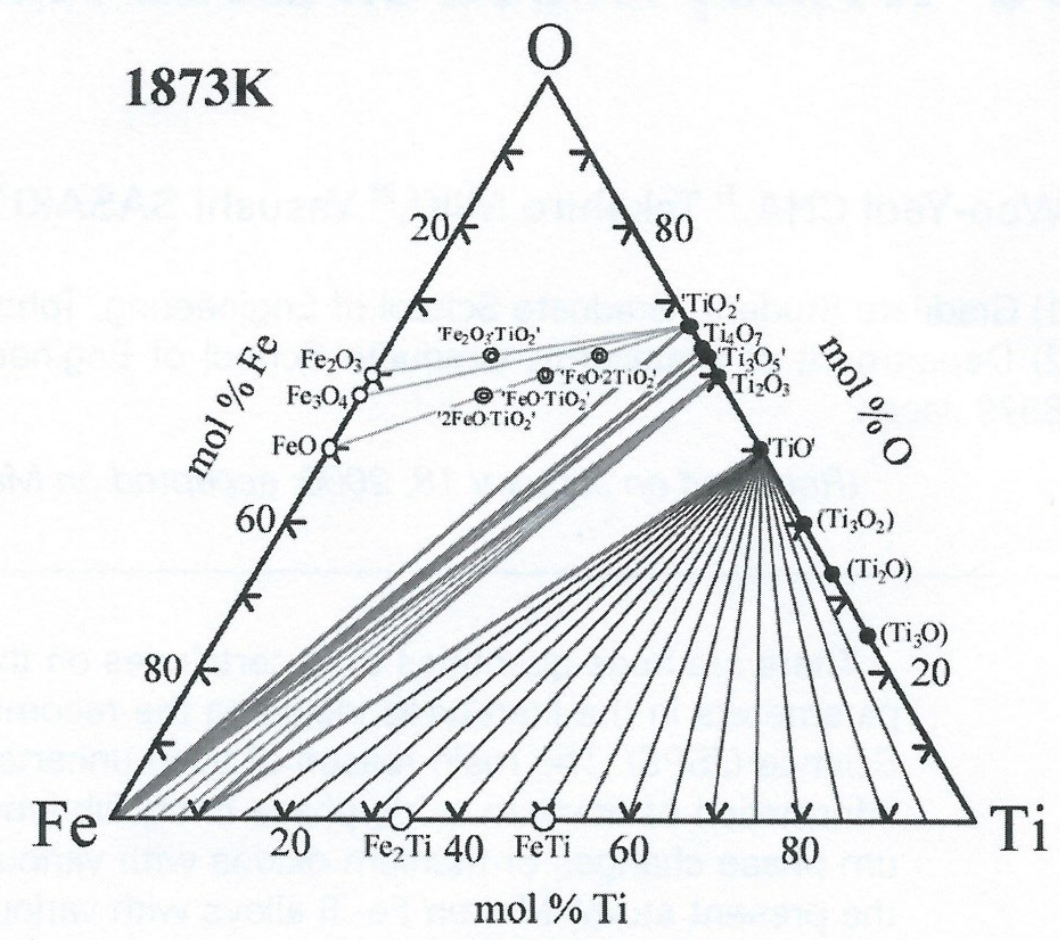

4 


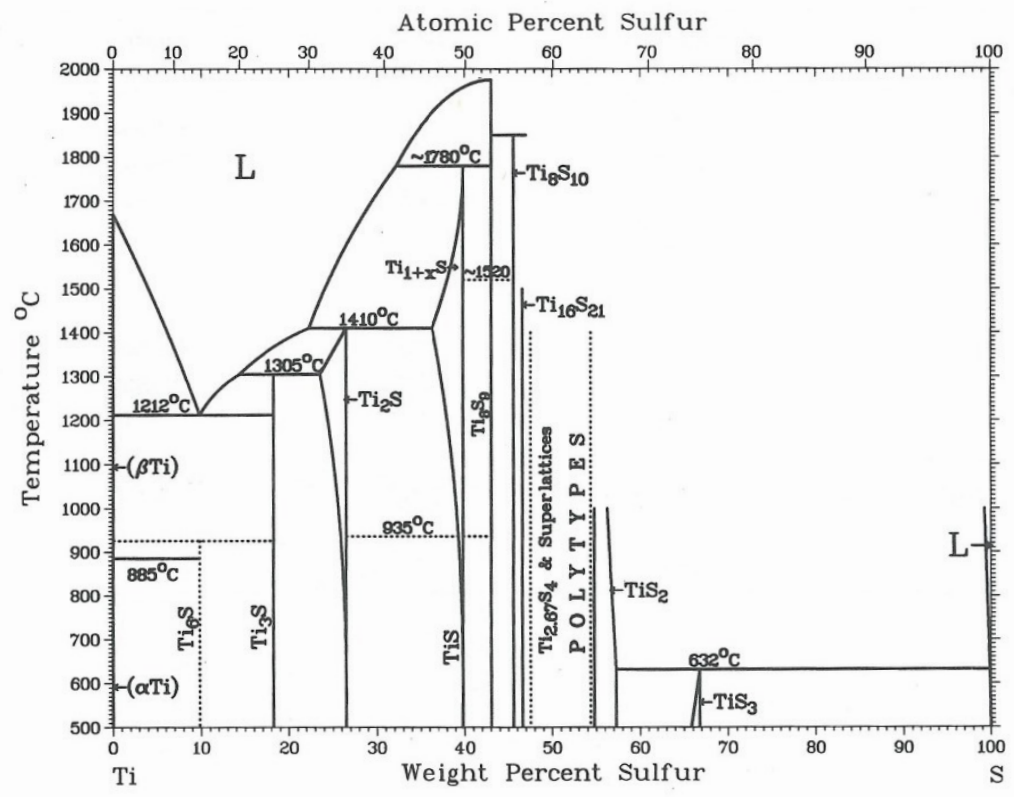

5 


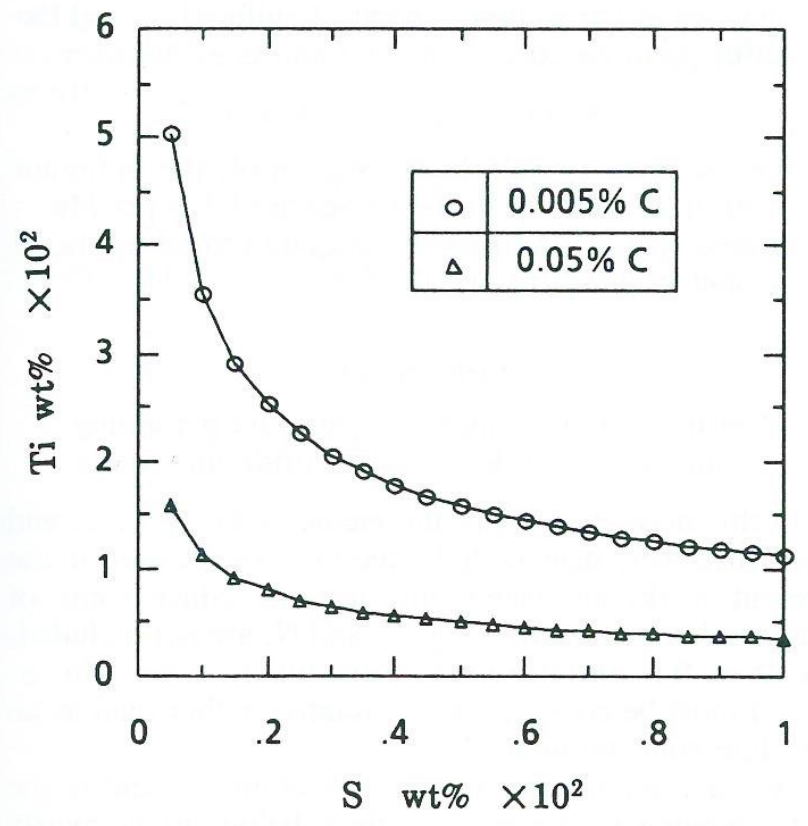

6 


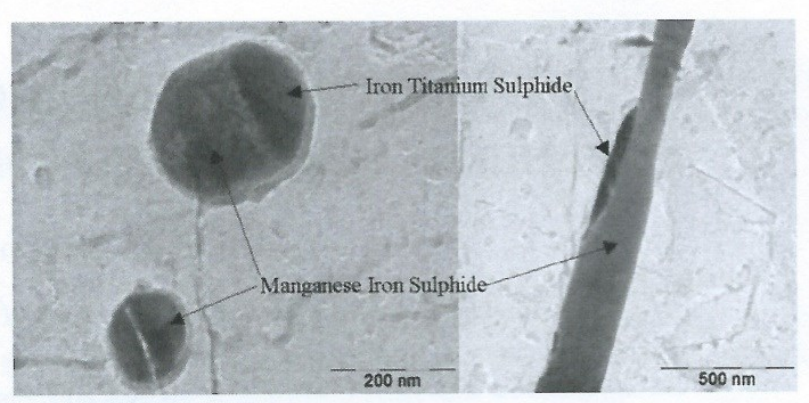

$7 a$

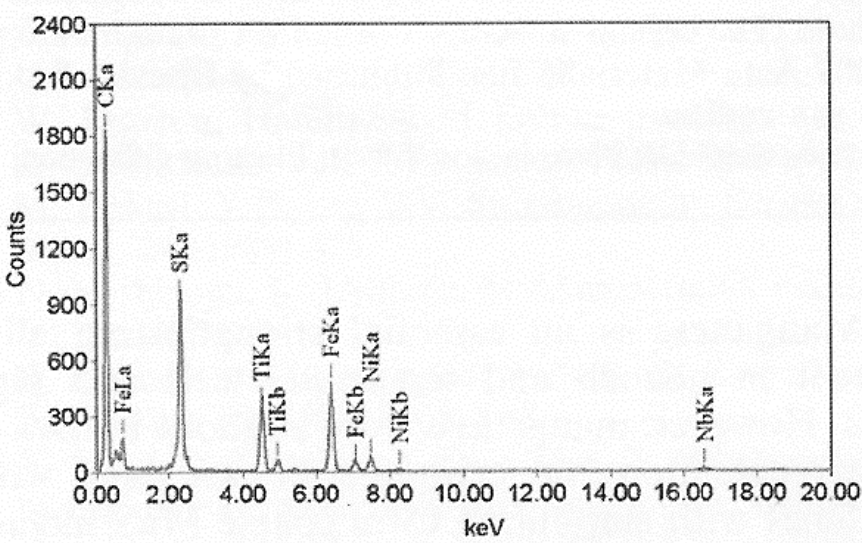

$7 b$ 


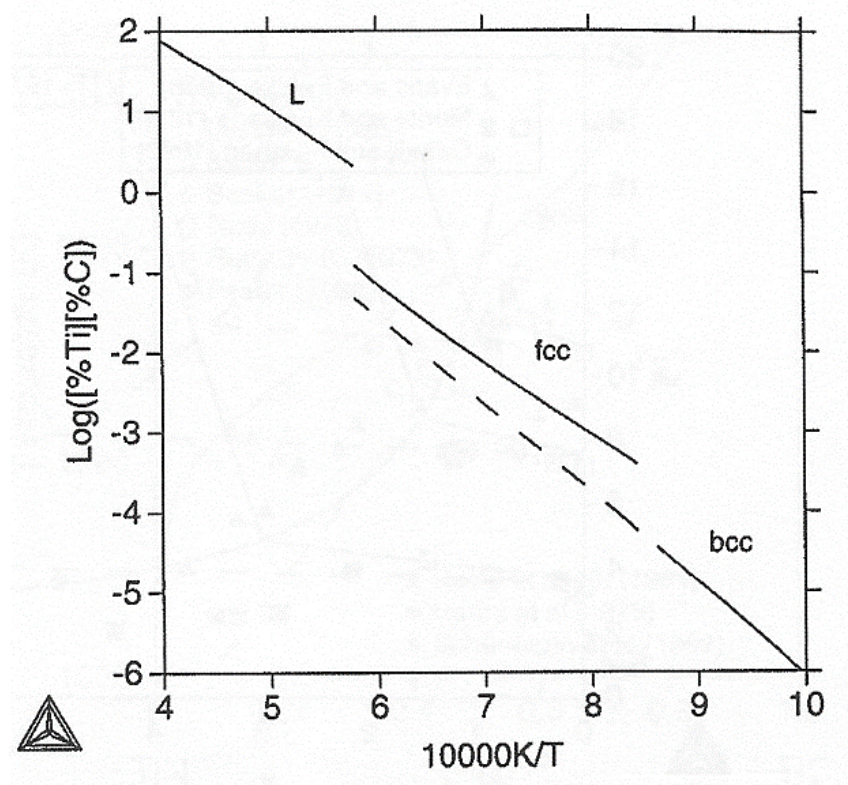

8 


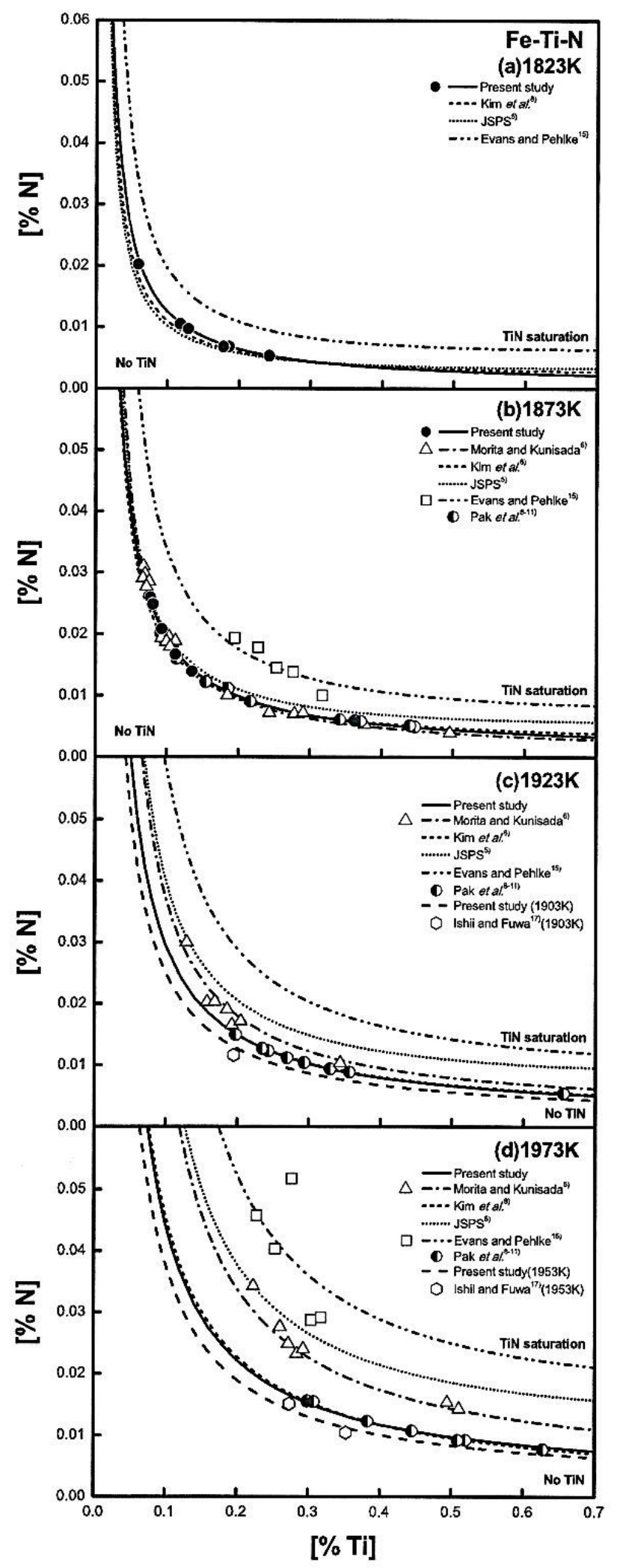

9 


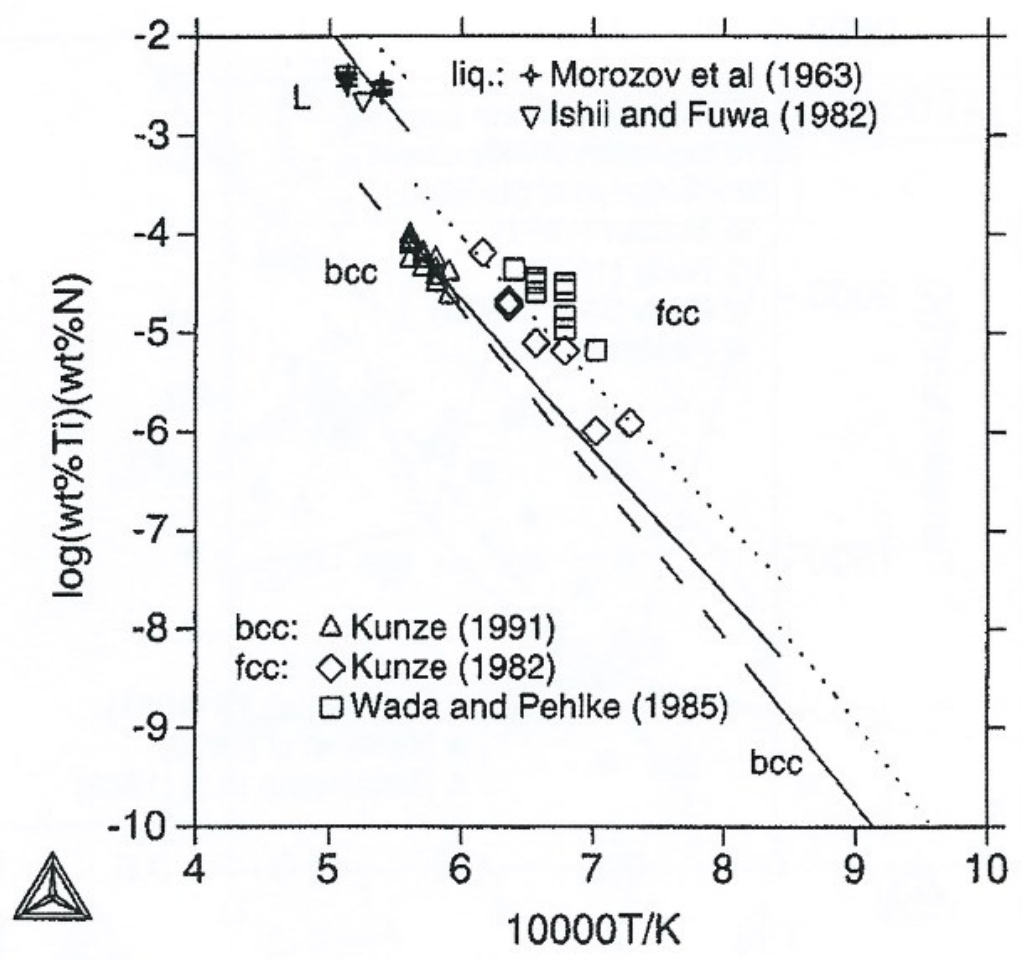

10 
Temperature $\mathrm{T},{ }^{\circ} \mathrm{C}$

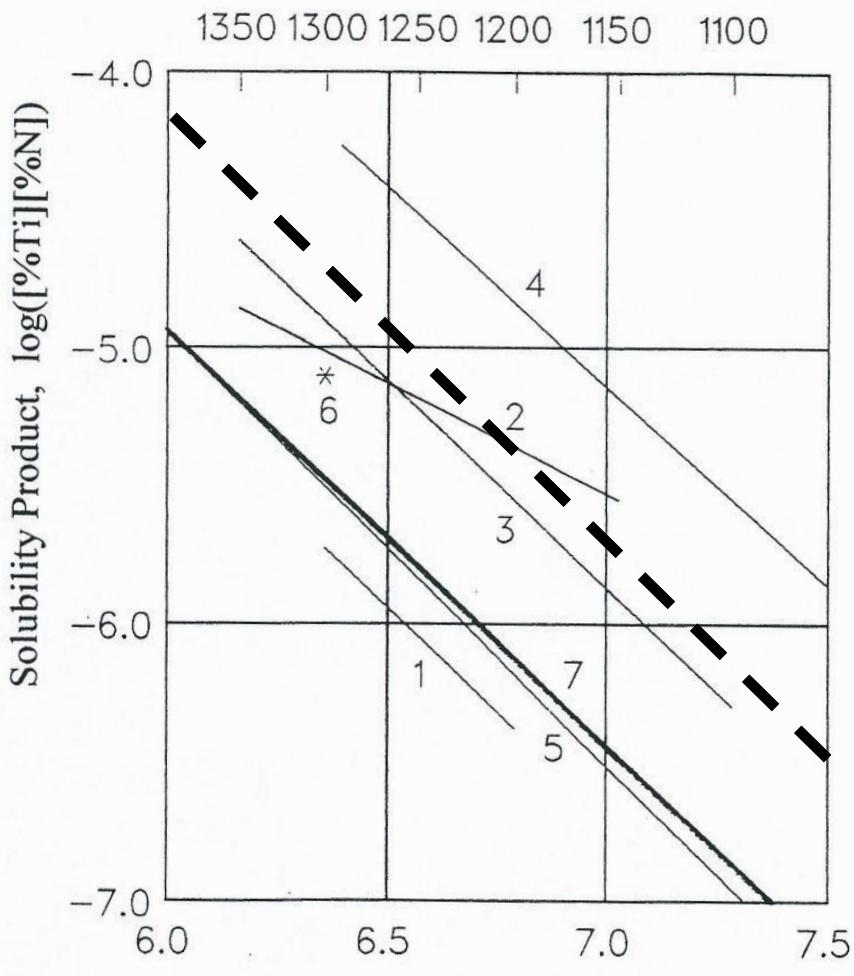

Reciprocal Temperature $104 / \mathrm{T}, \mathrm{K}^{-1}$ 

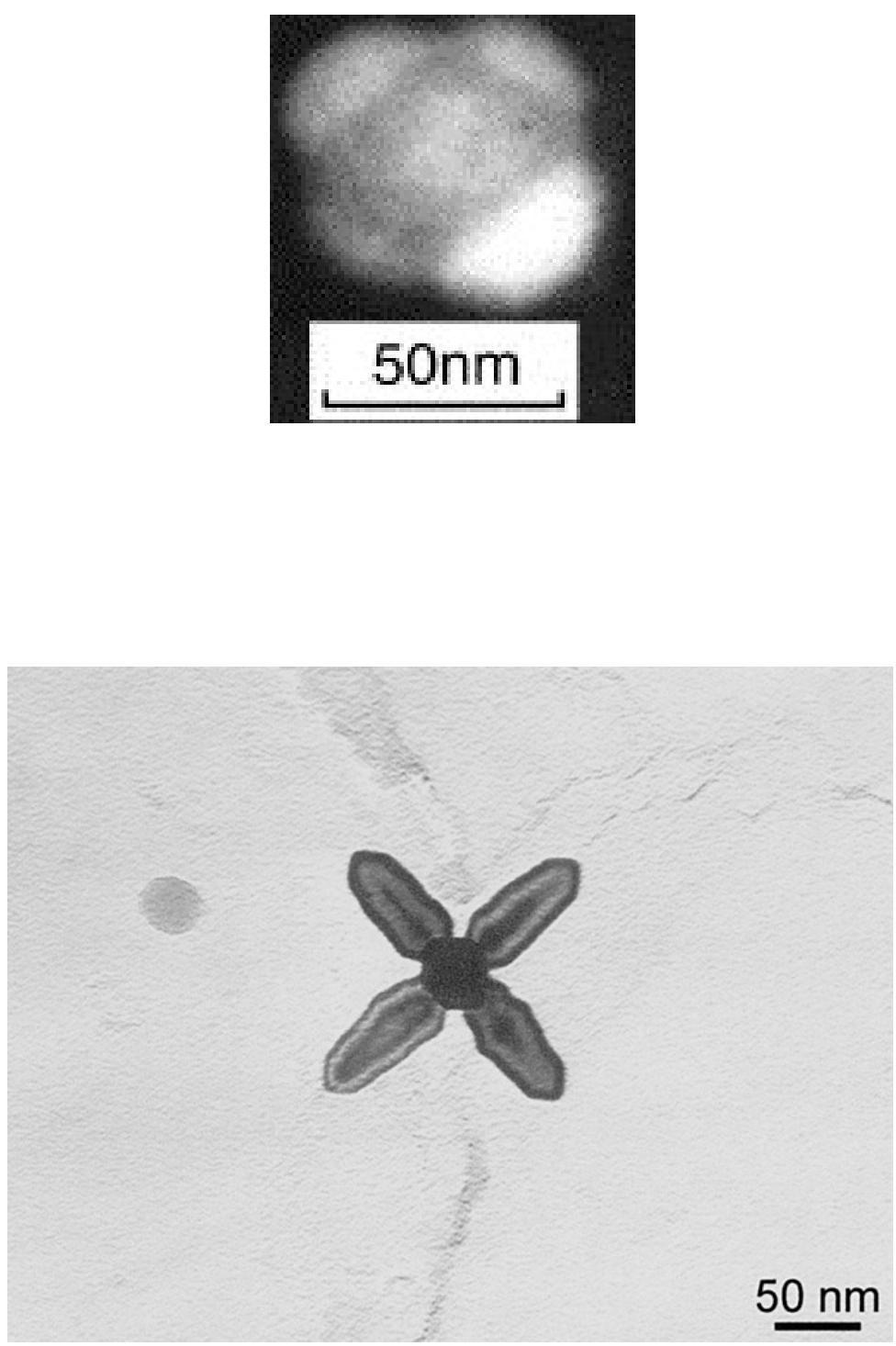

12 


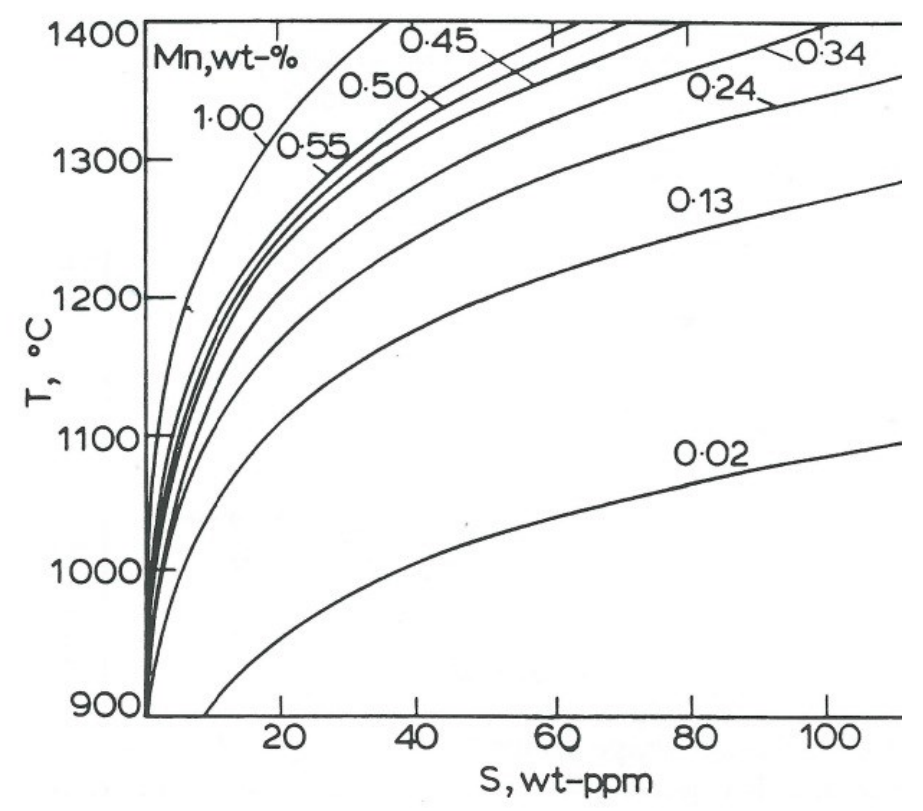

13 


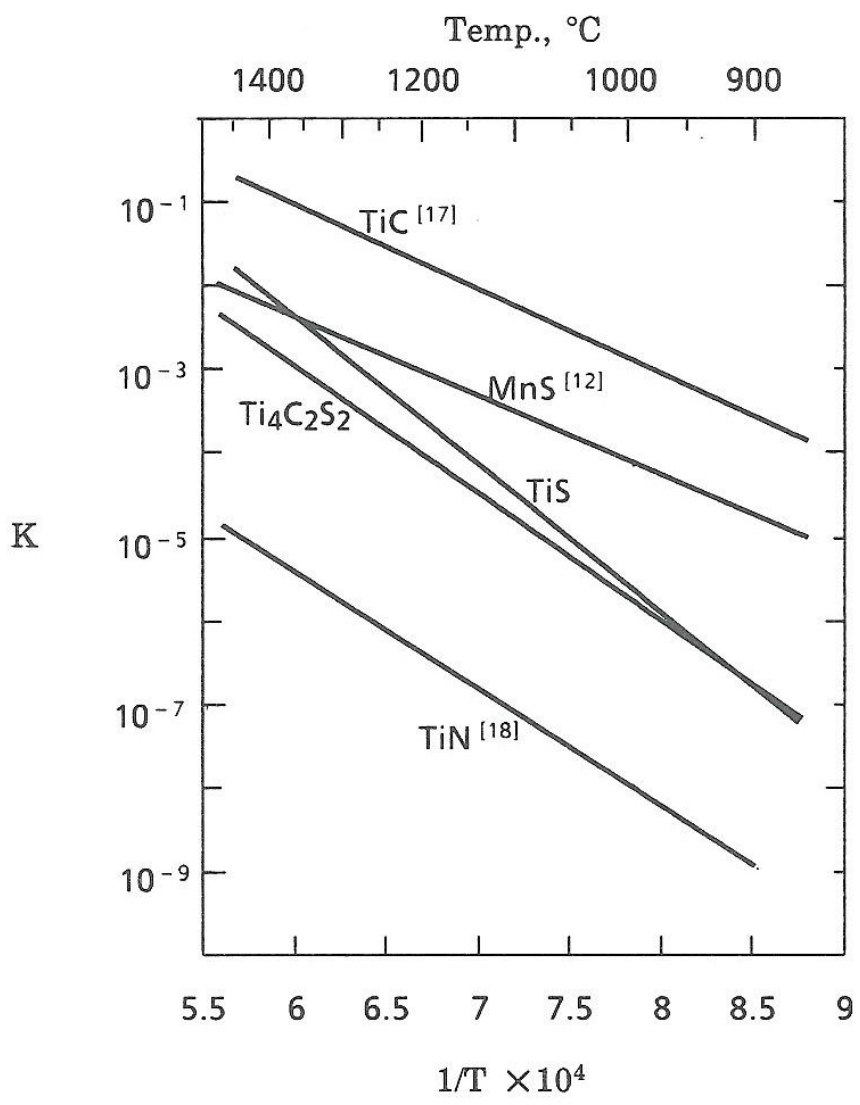

14 


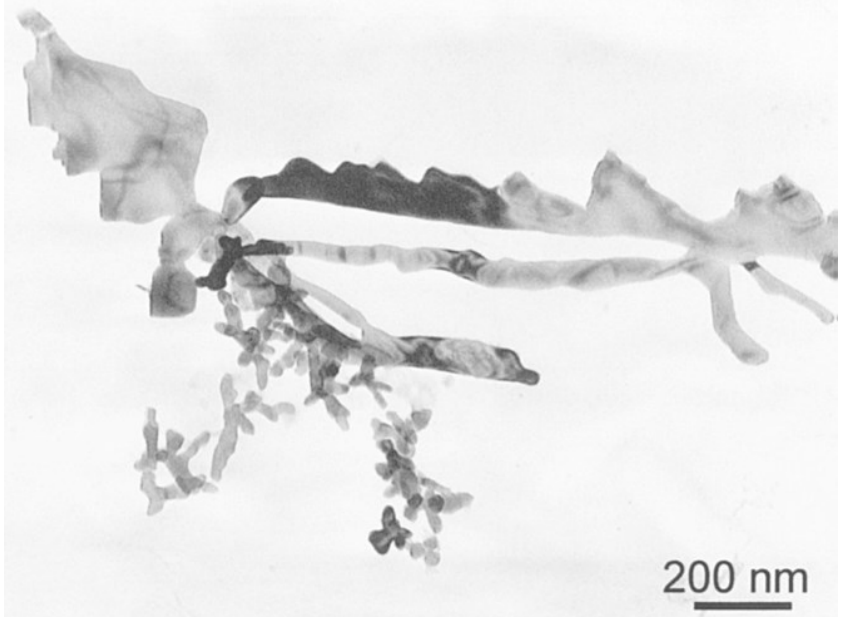

15 


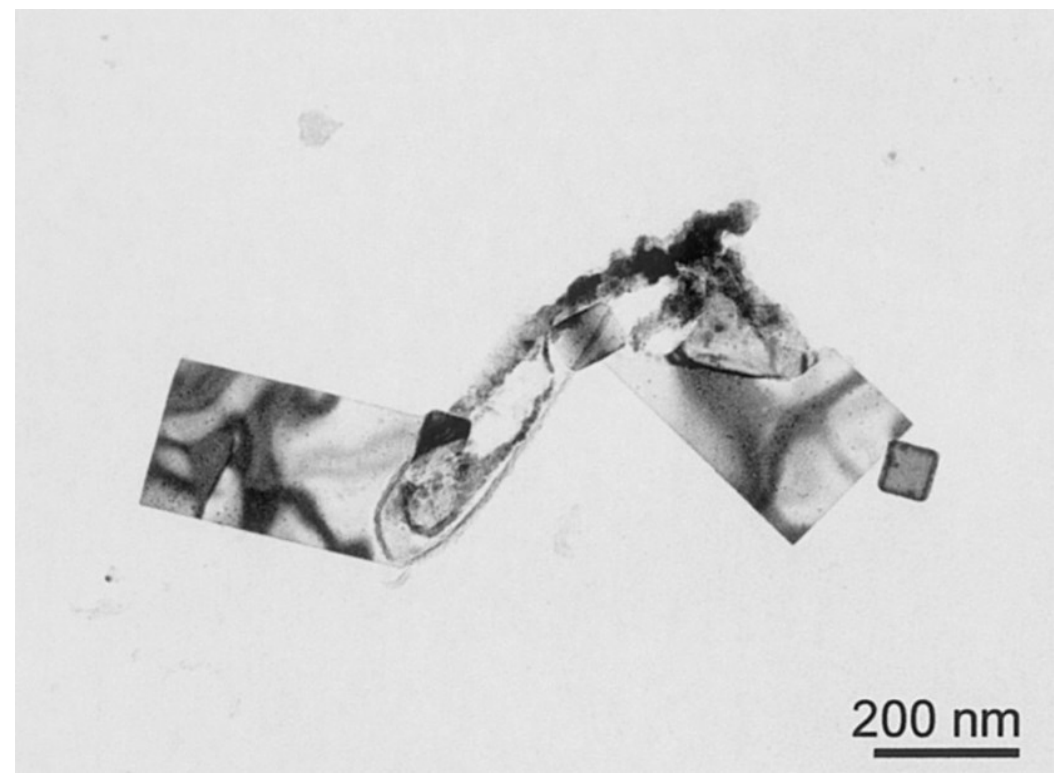

16 


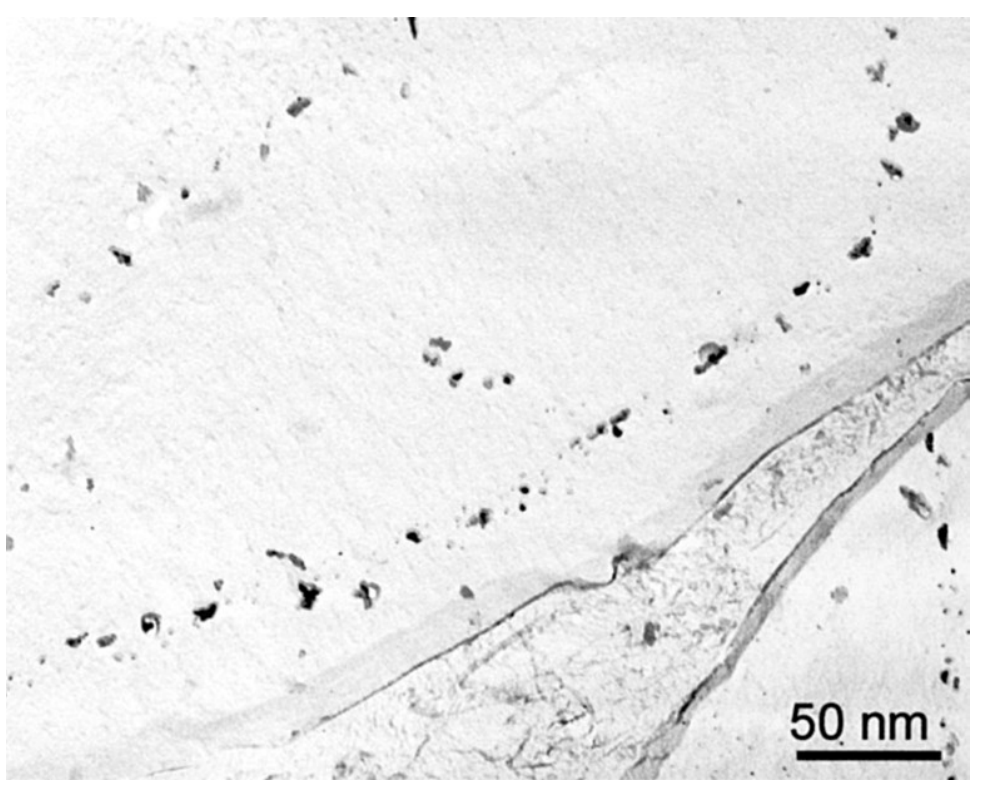

17 


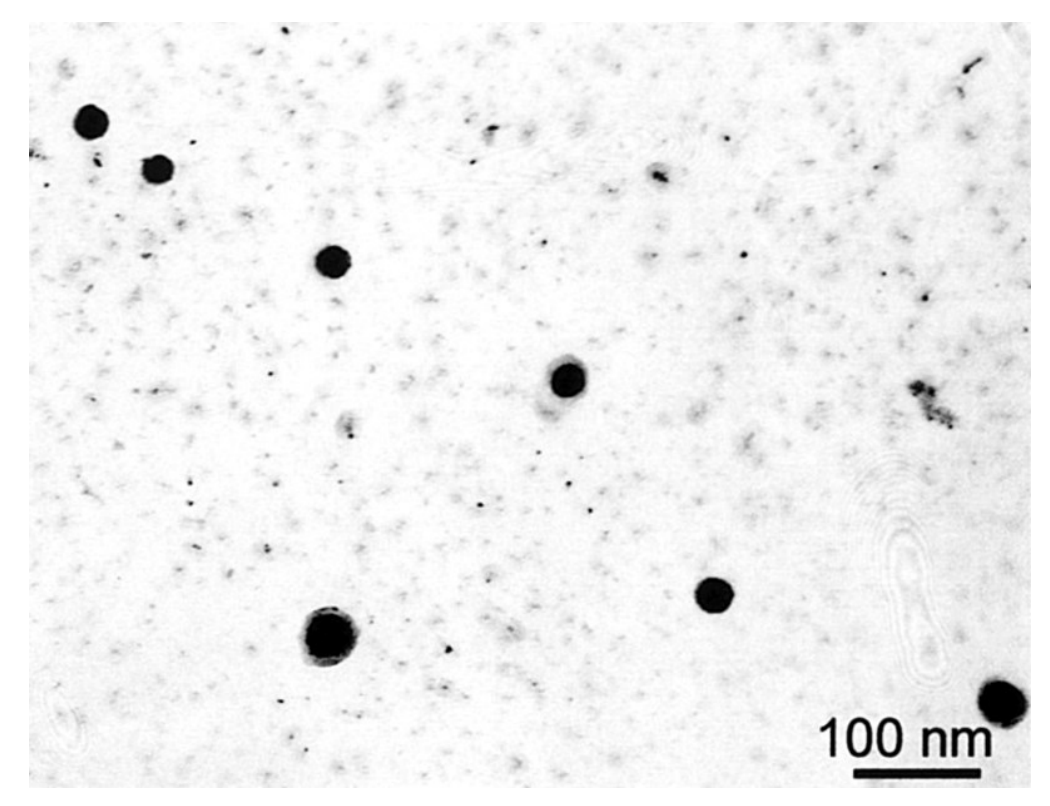

18 


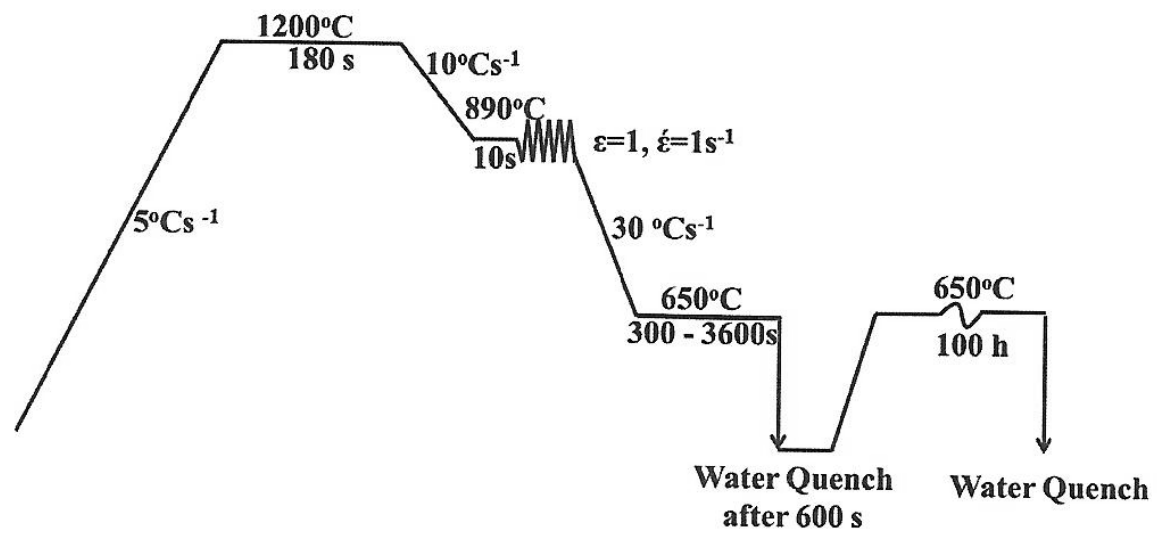

19 


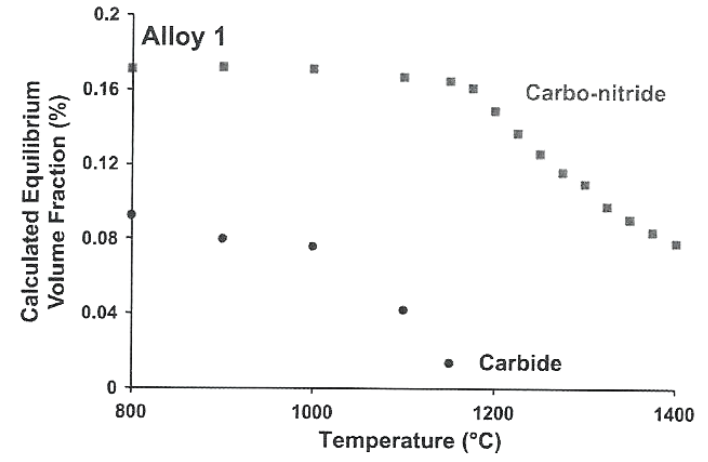

(a)

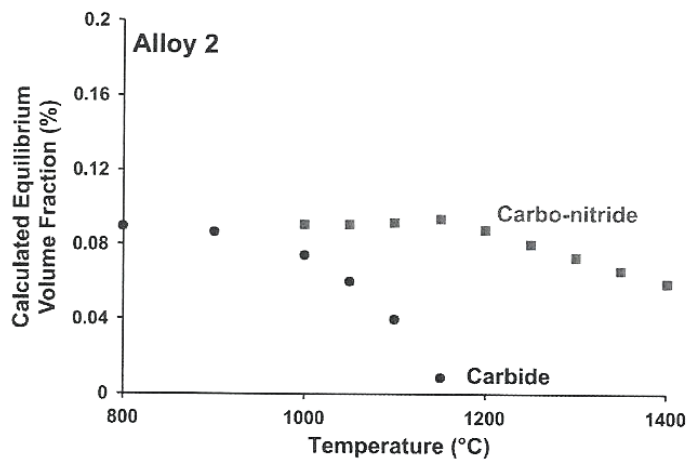

(b)

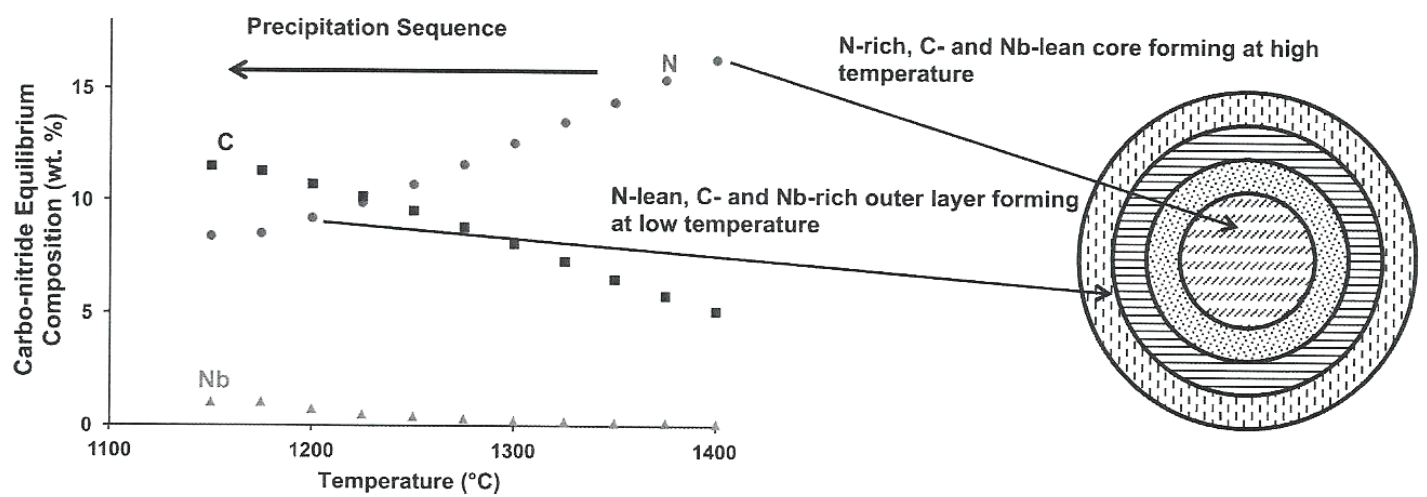

(c)

20 


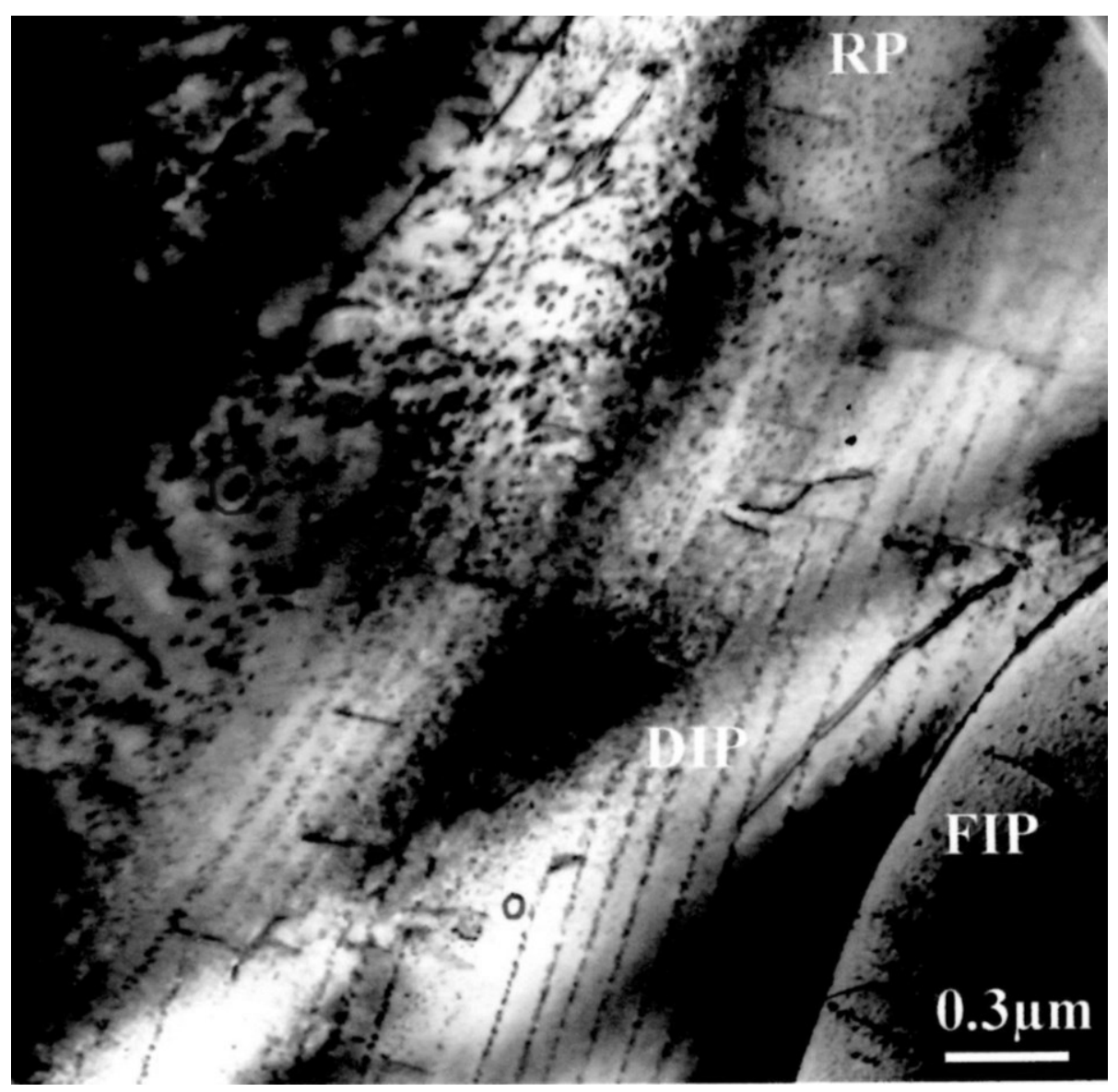

21a 


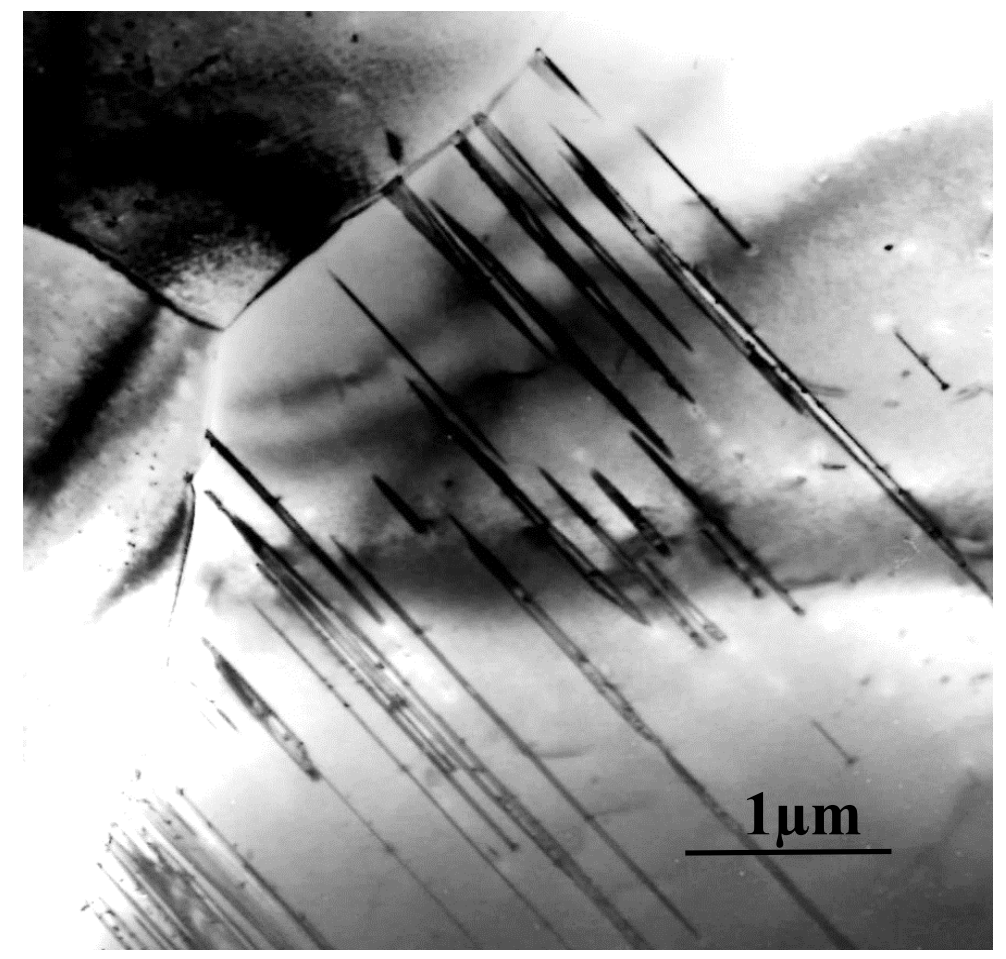

21b 


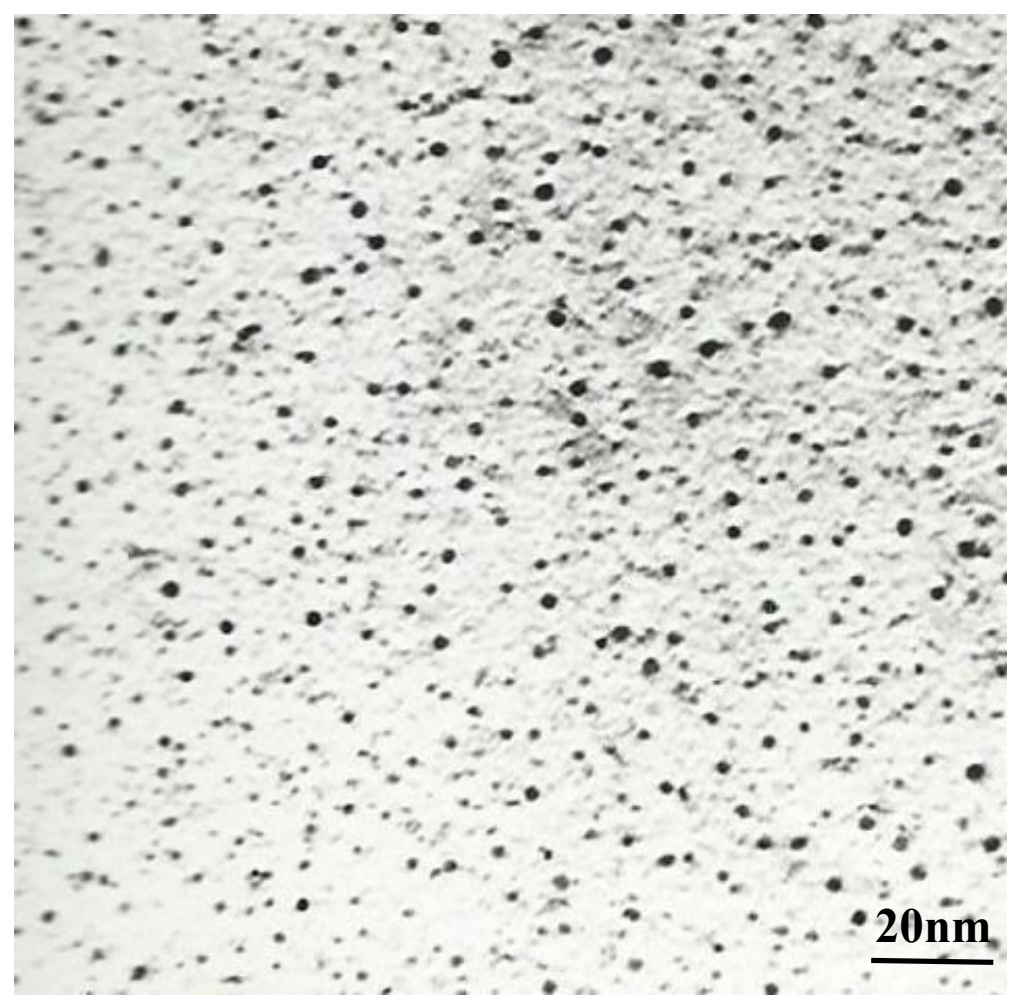

22 


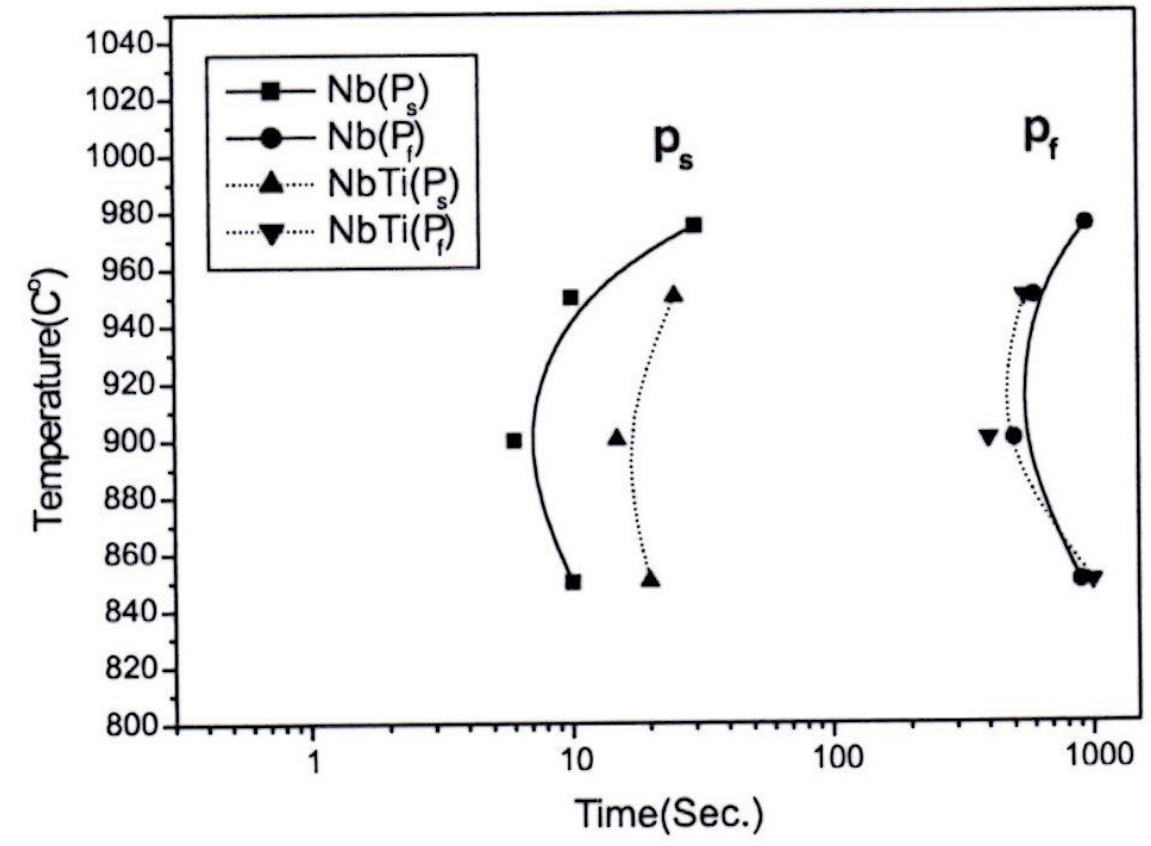

23 


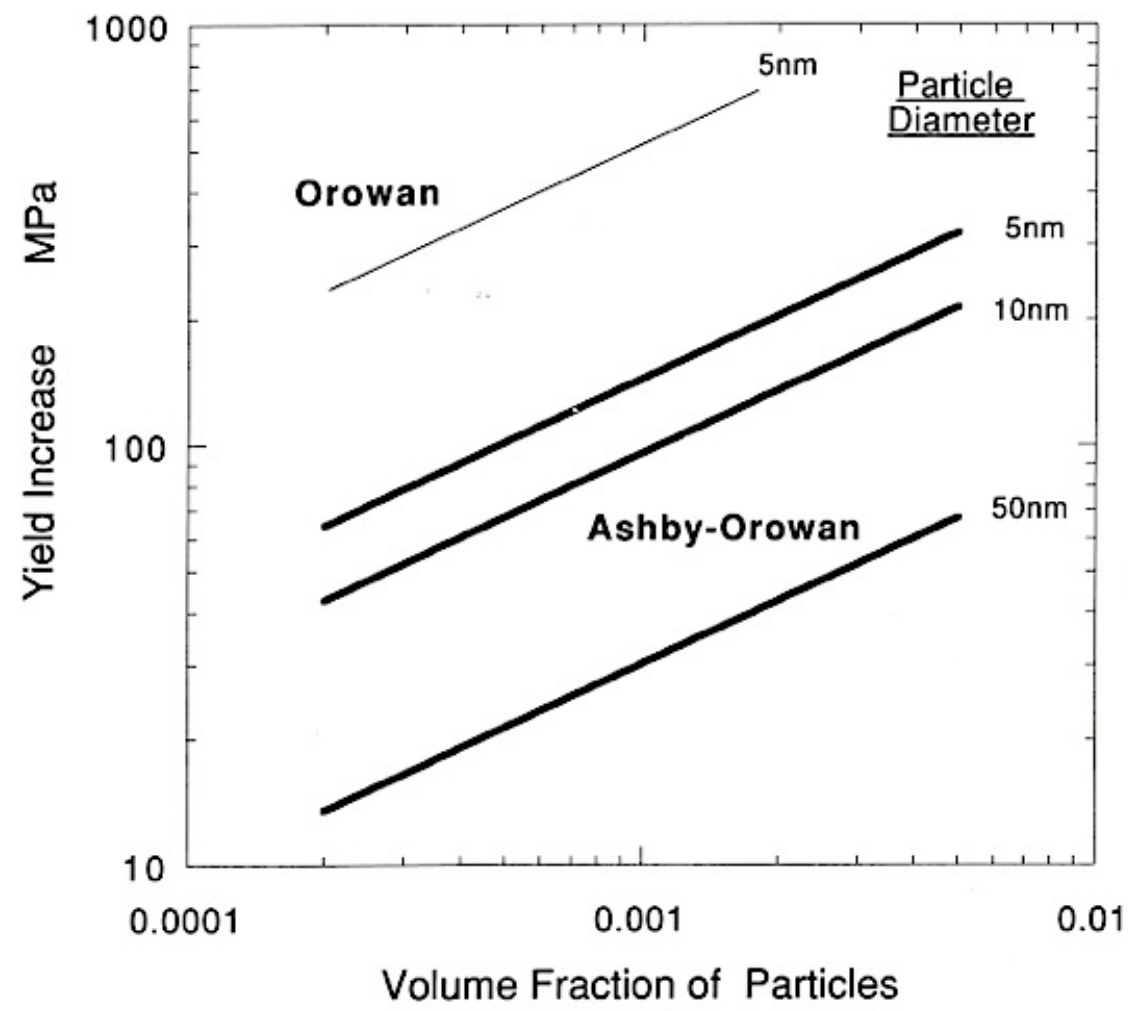

24 


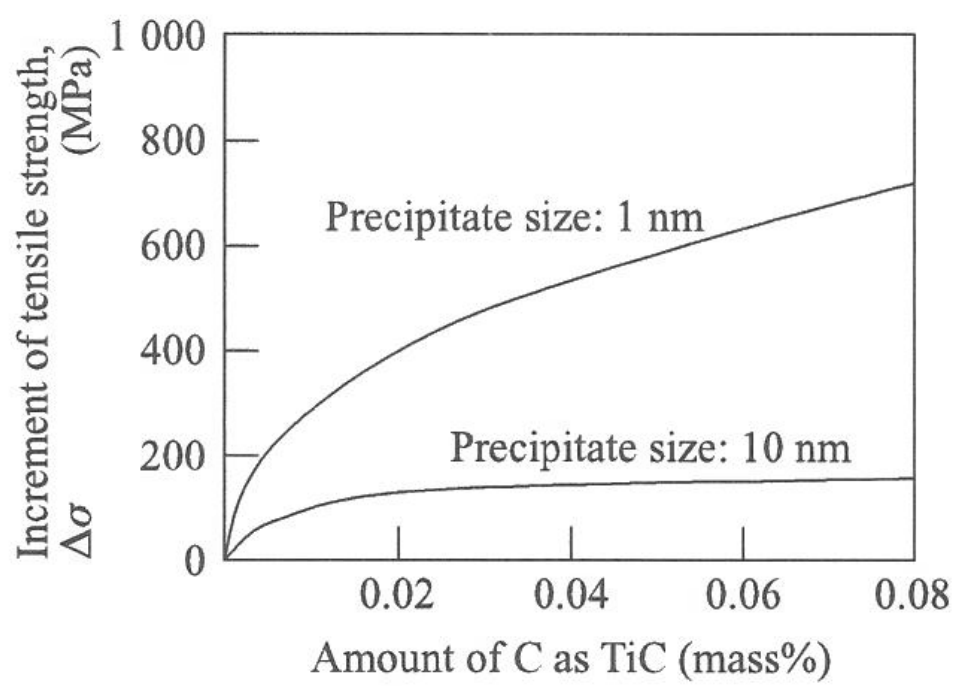

25 


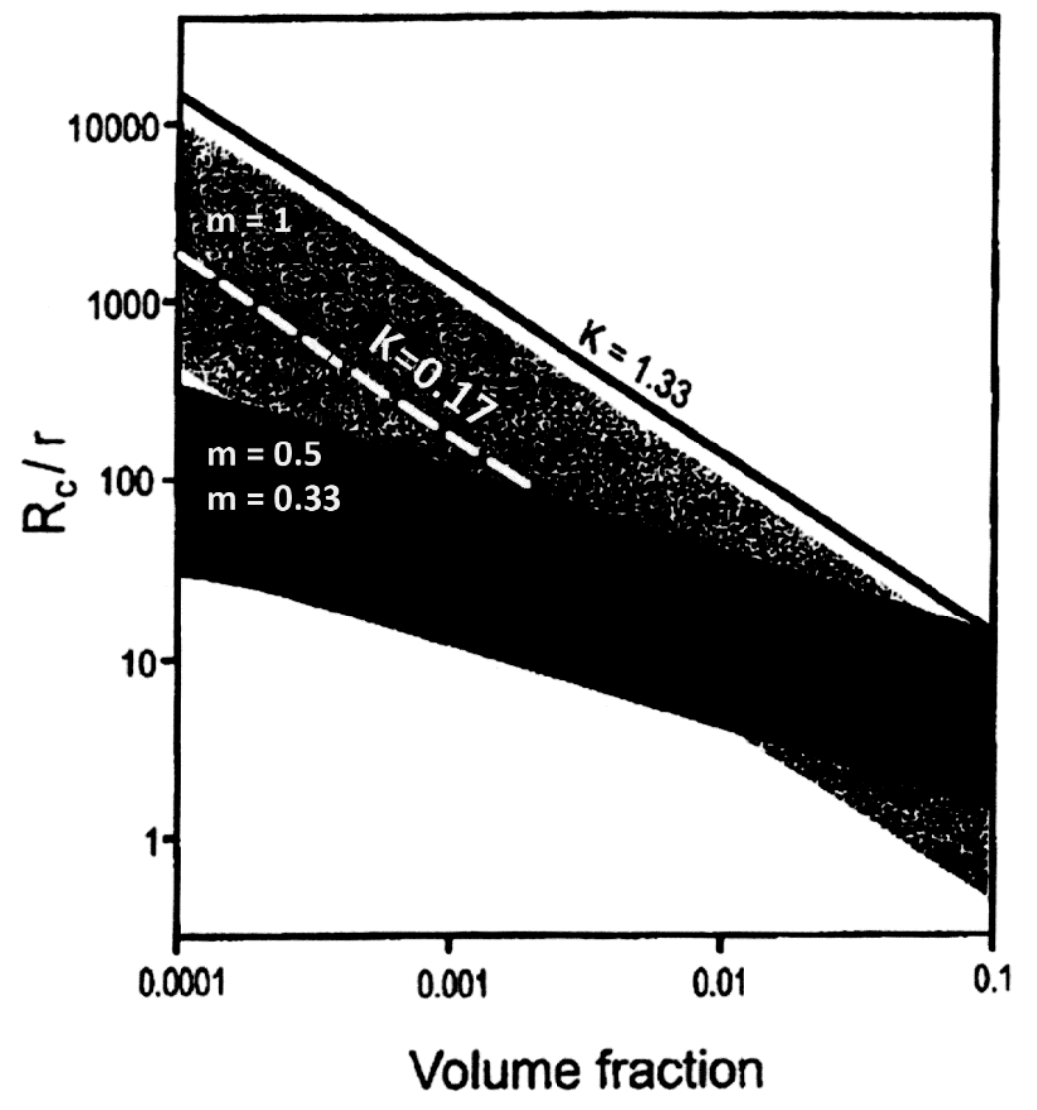

26 


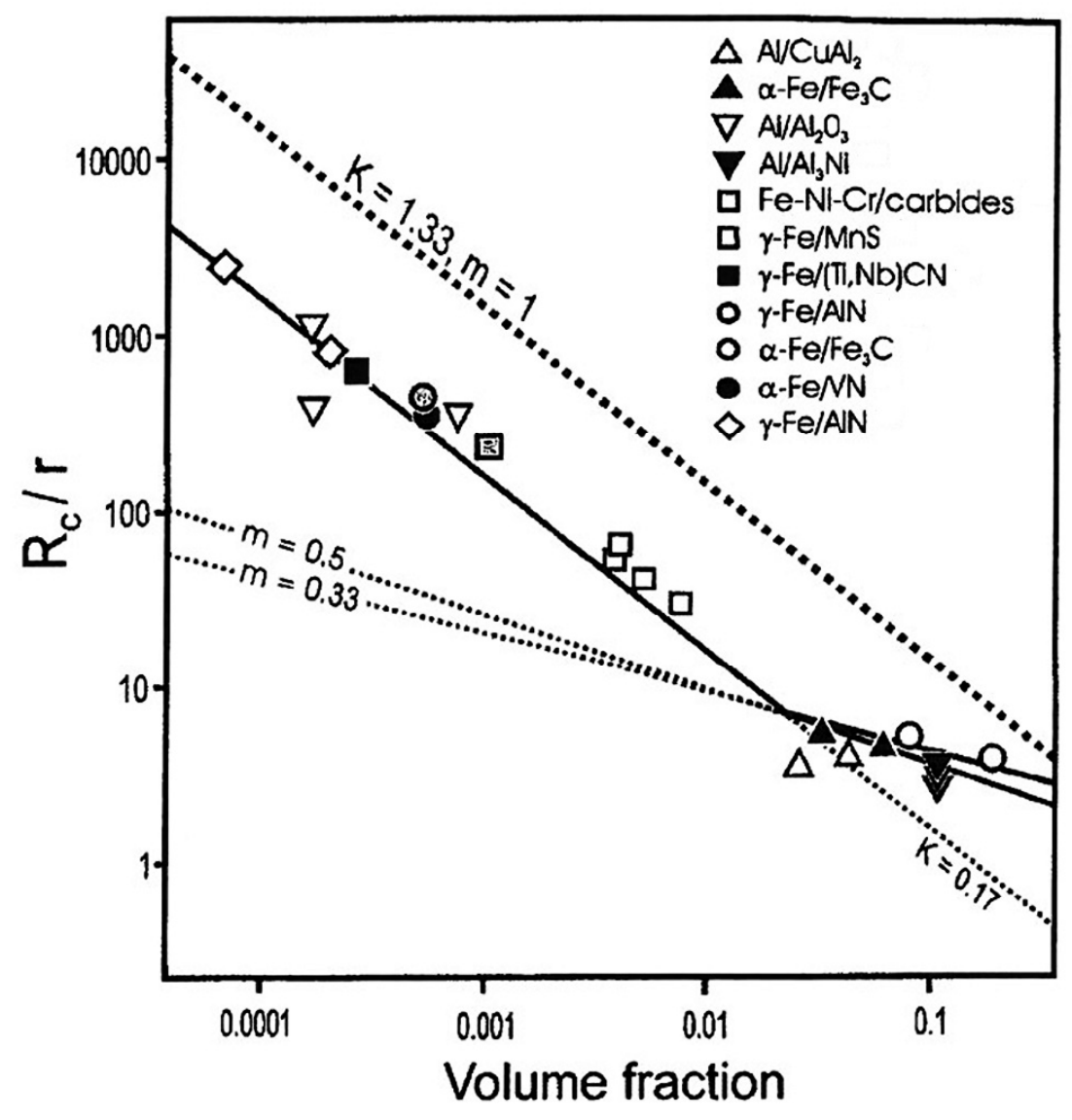




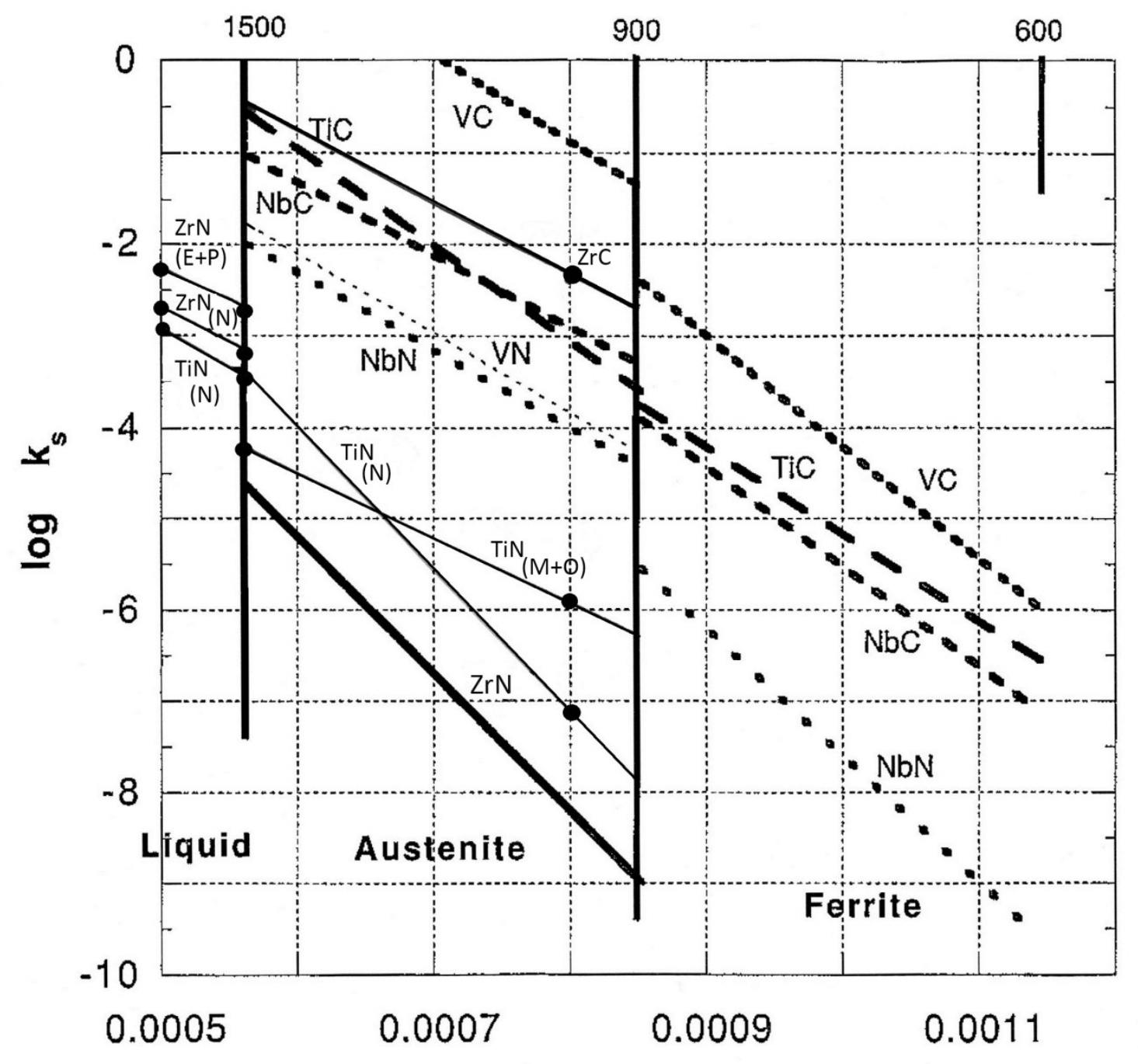

$1 / \mathrm{T} \quad K^{-1}$

28 


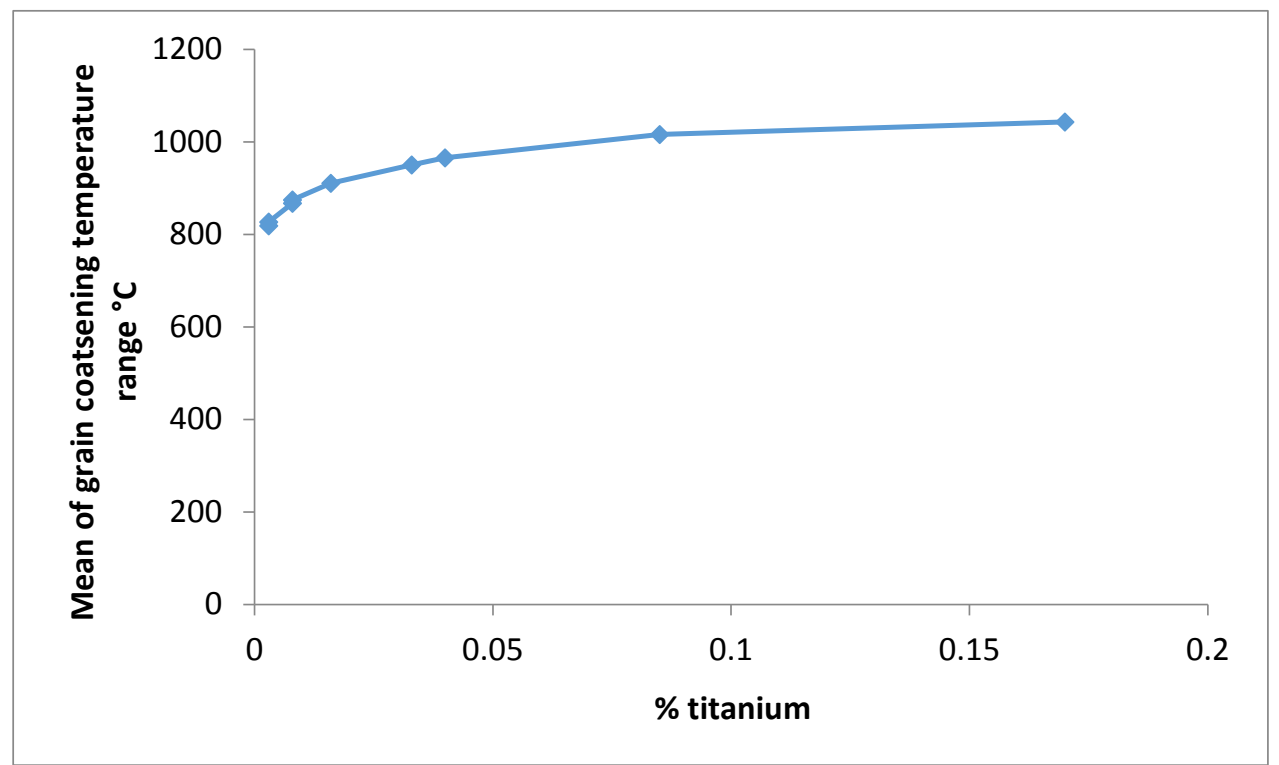

29 


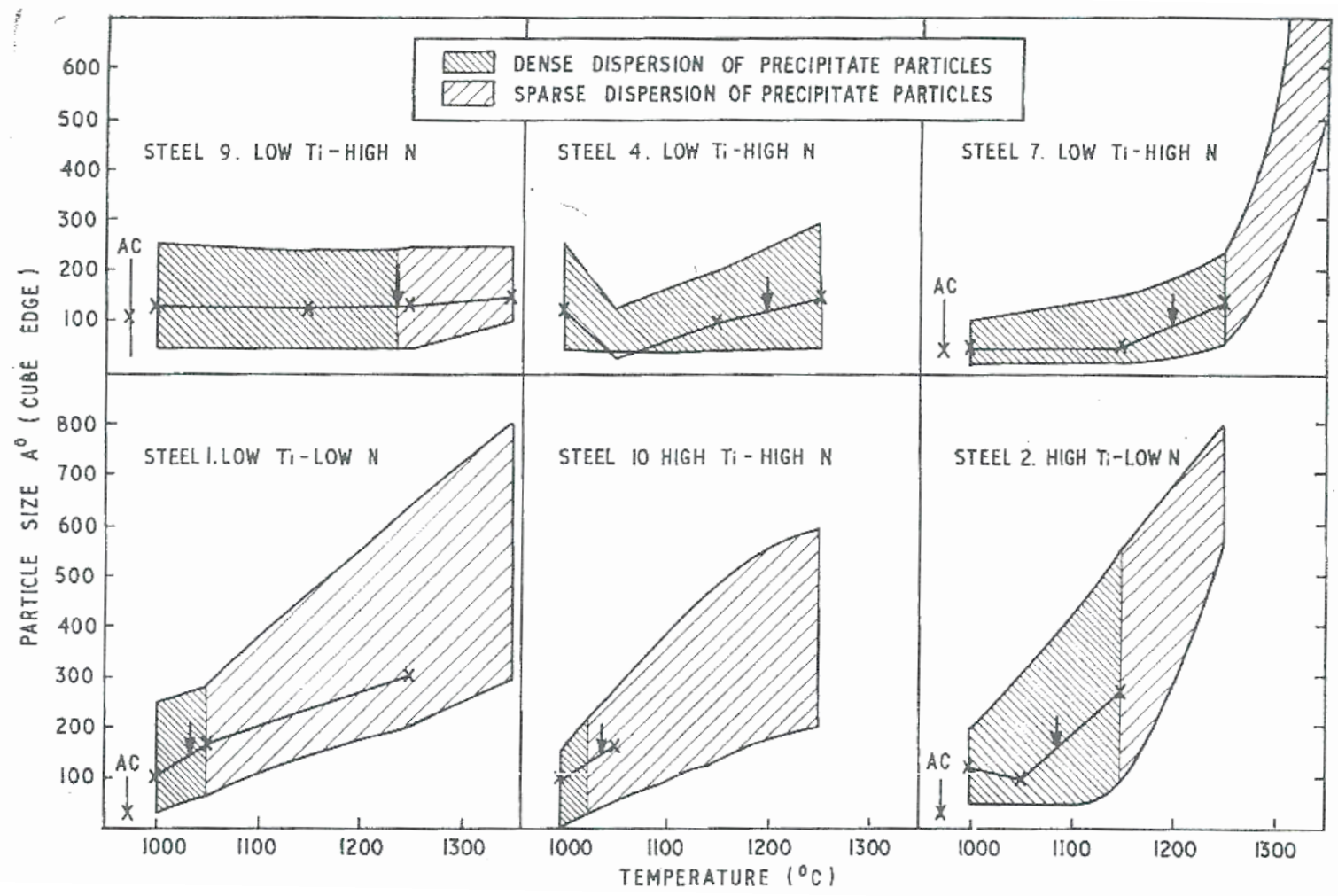

30 


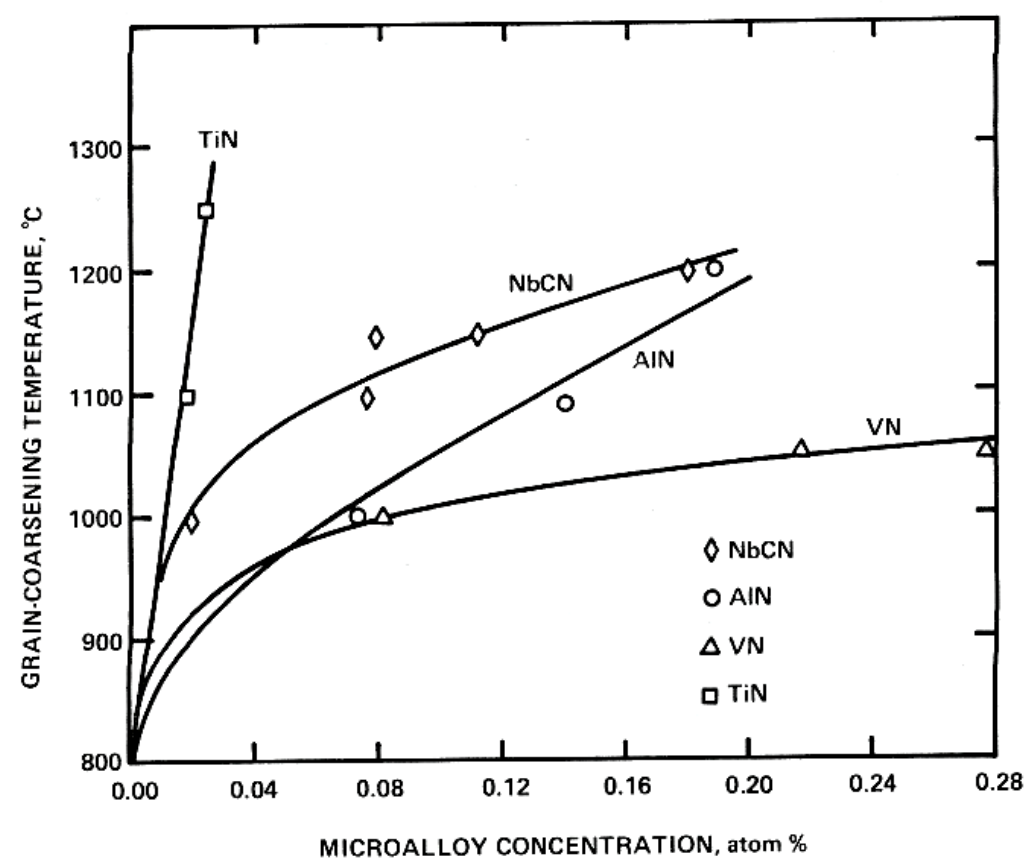

31 


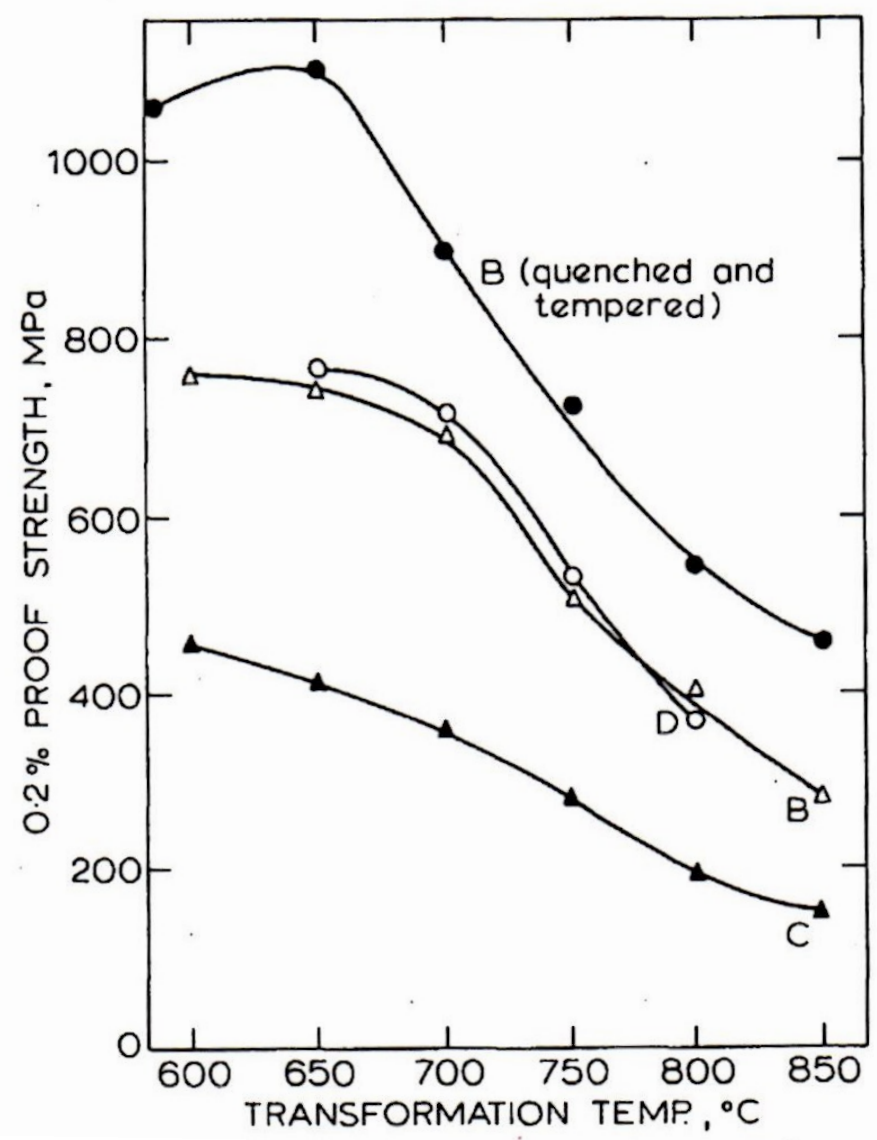

32 


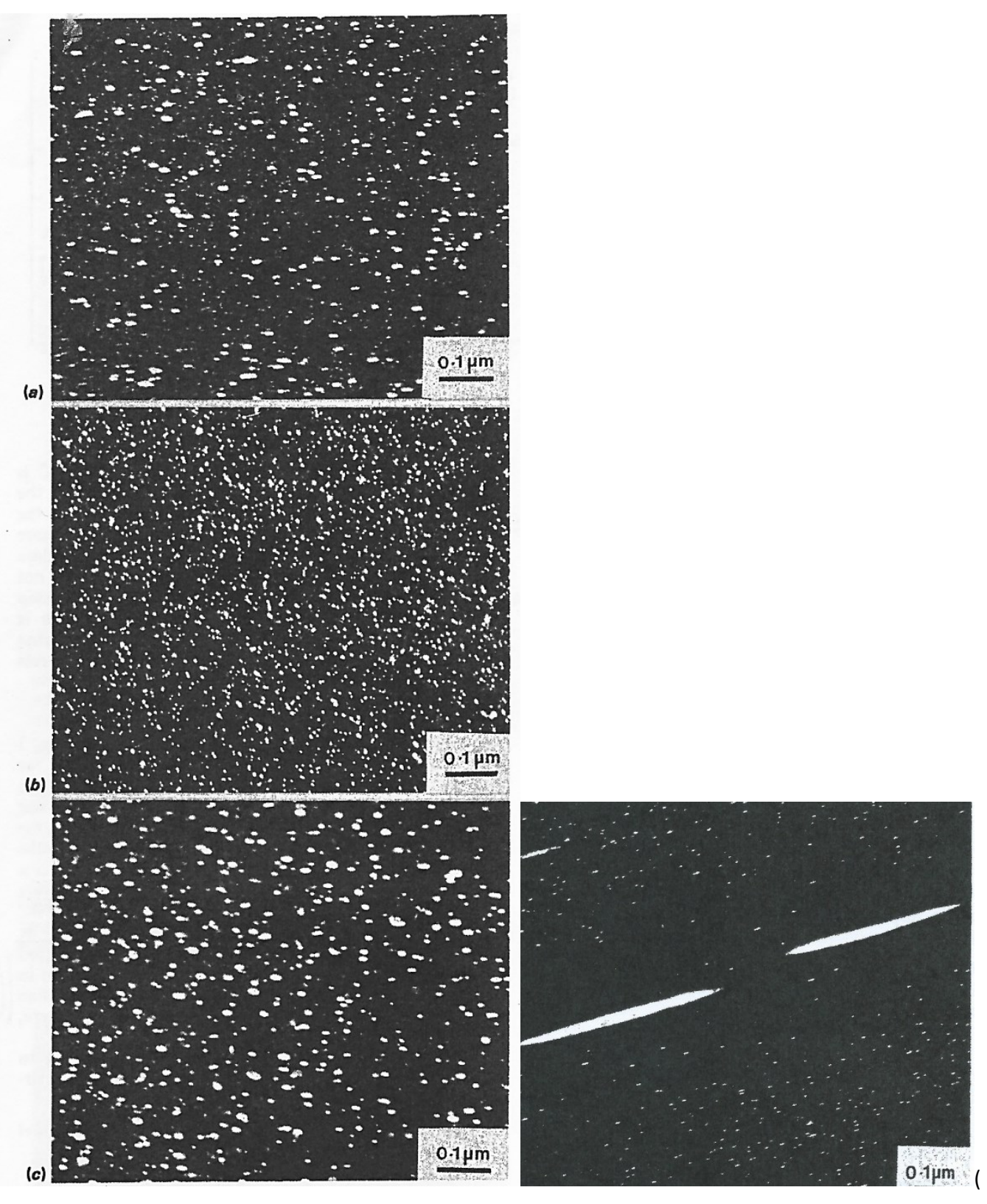




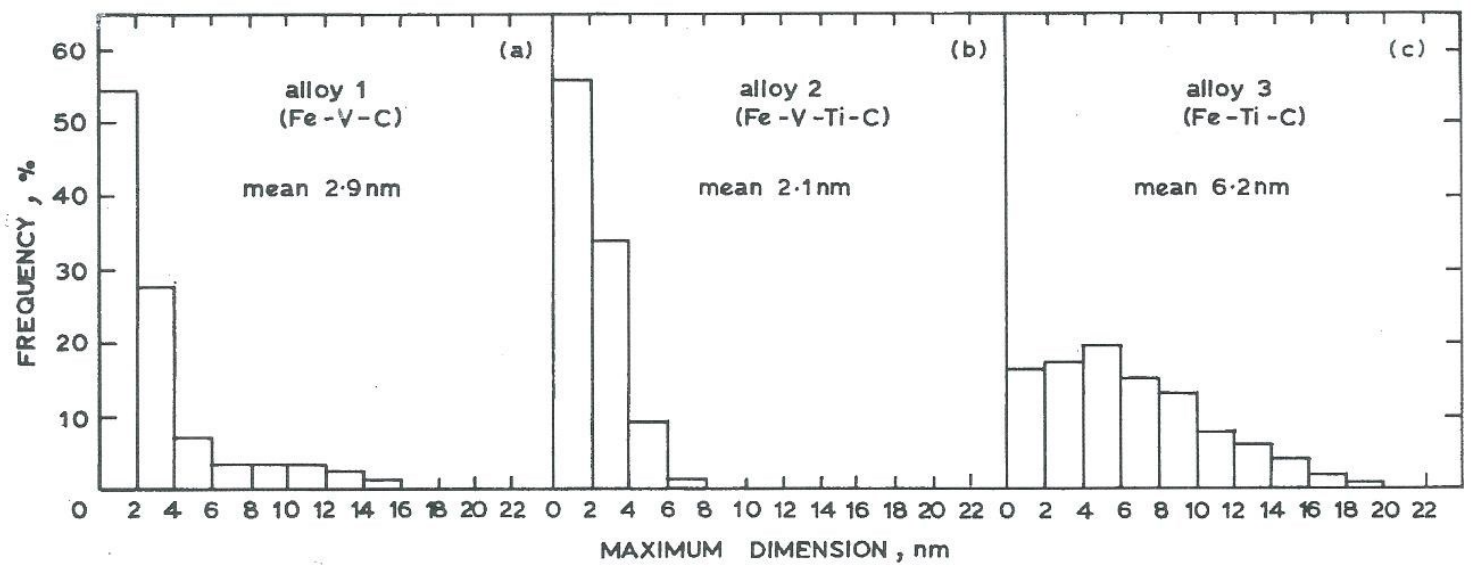

34 


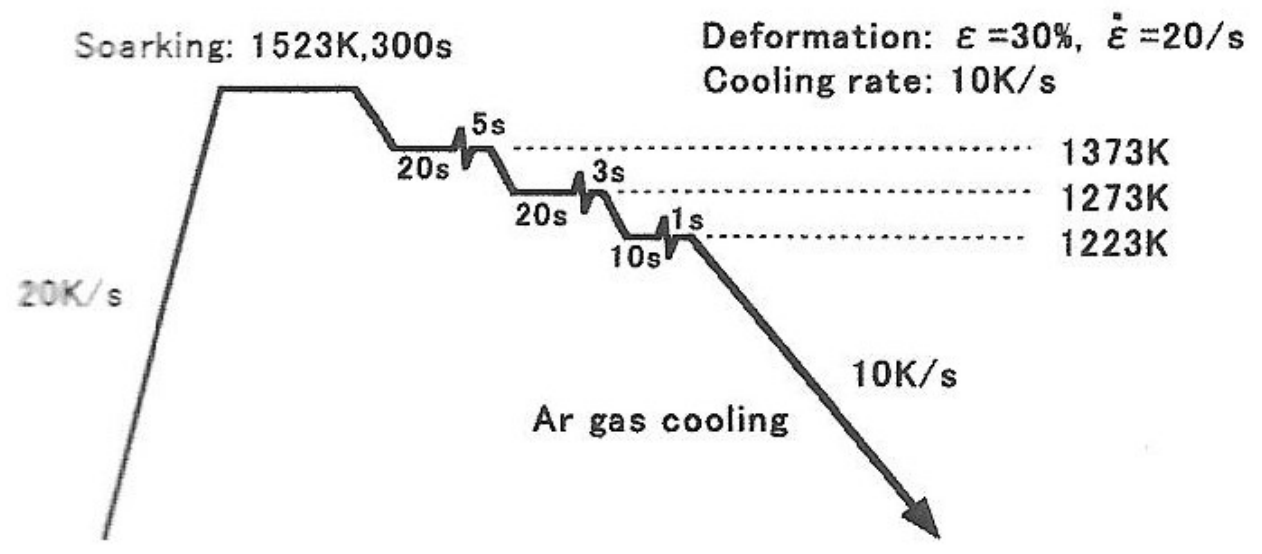

35 

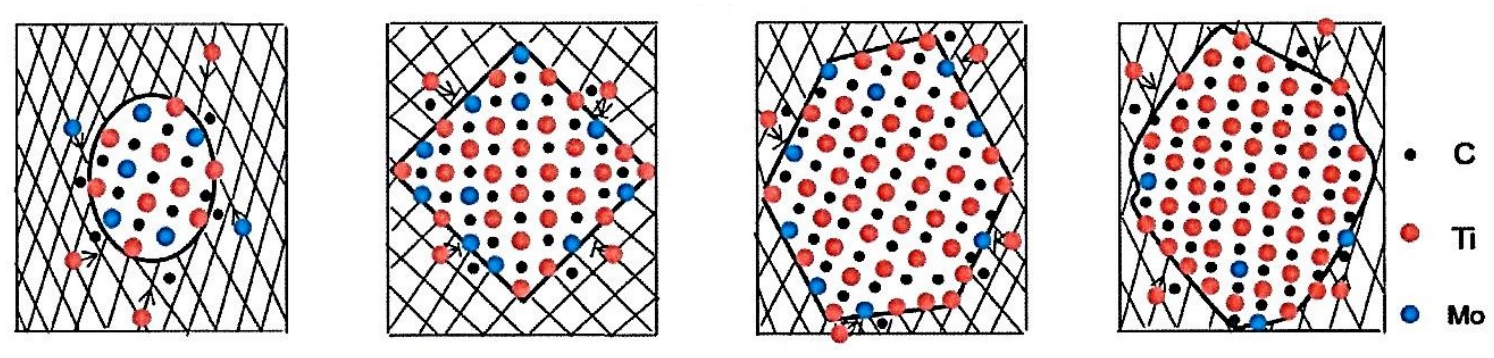

growth stage

slow coarsening stage

fast coarsening stage

36 


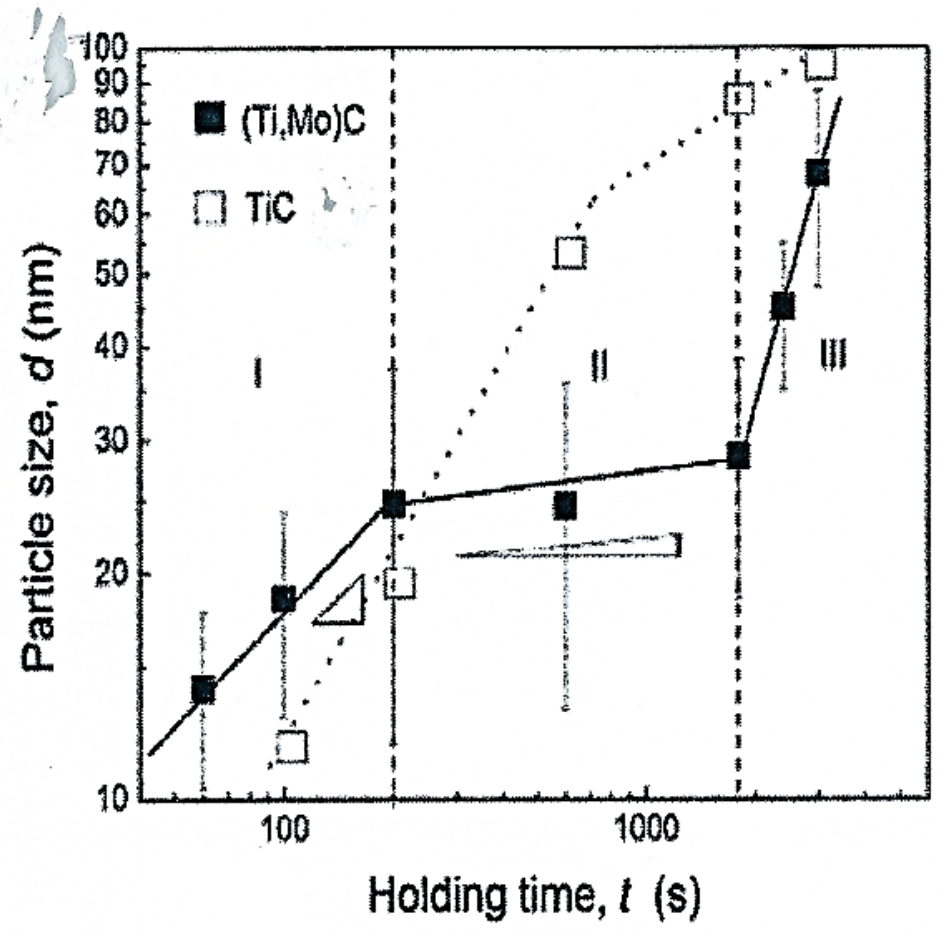

37 


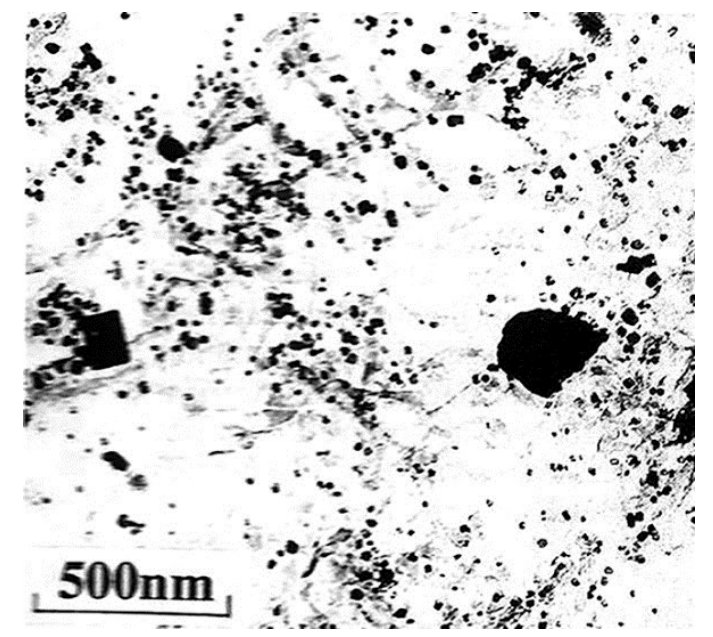

(a)

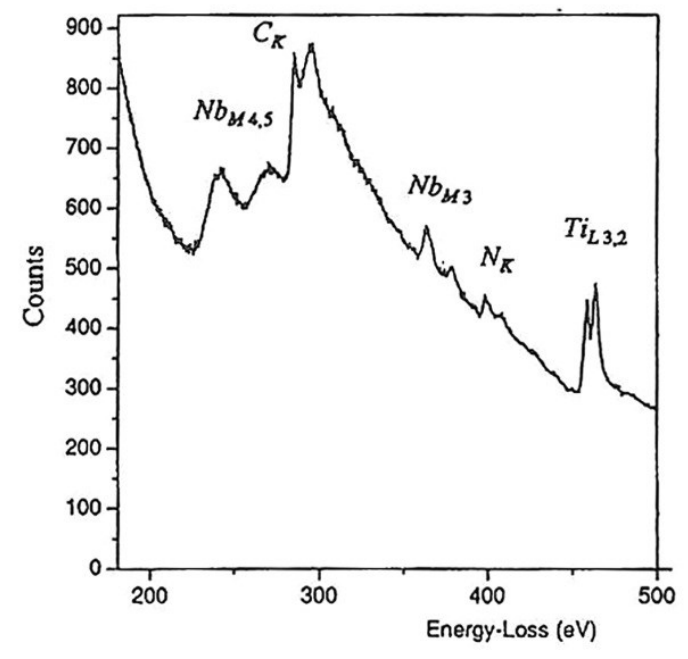

(b)

38 


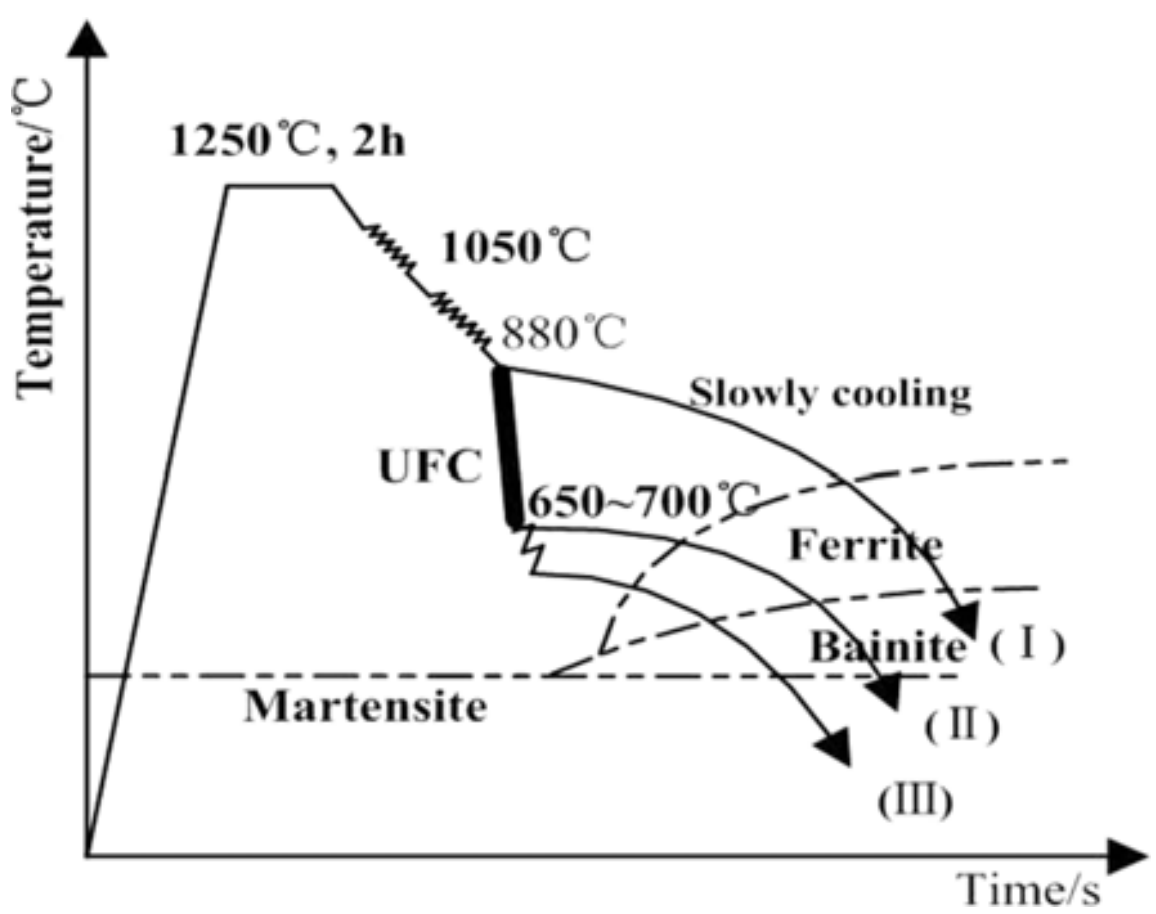

40 


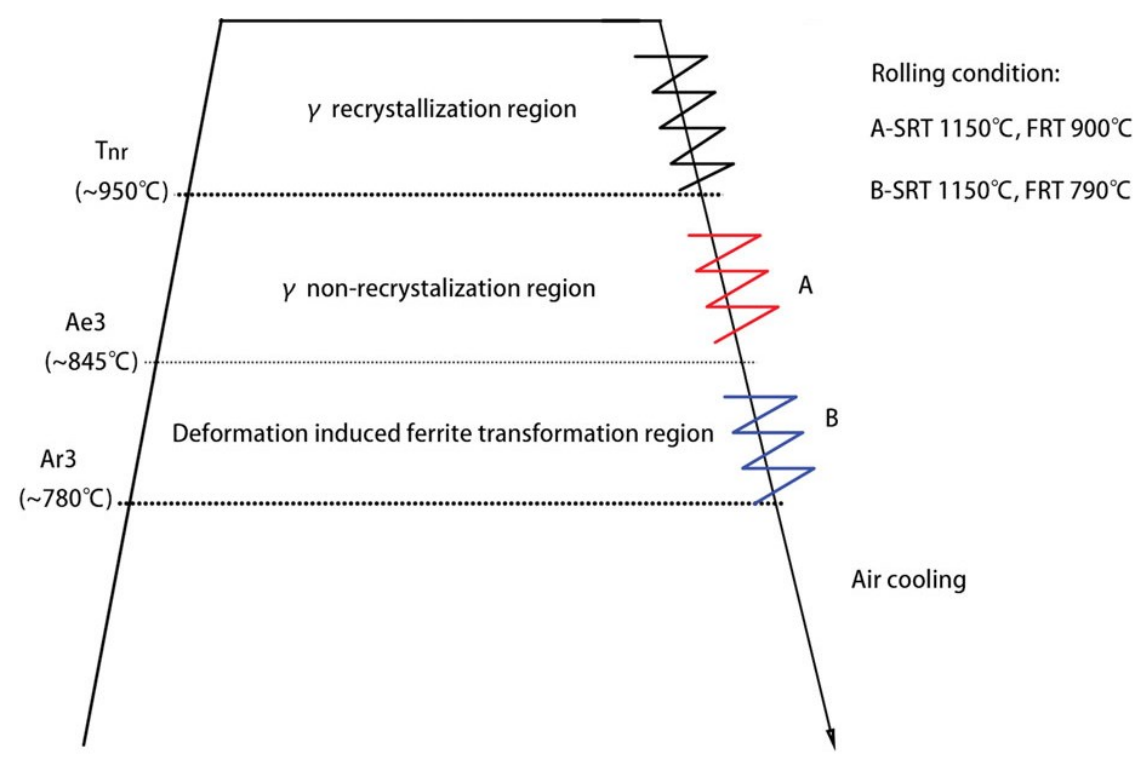

41 


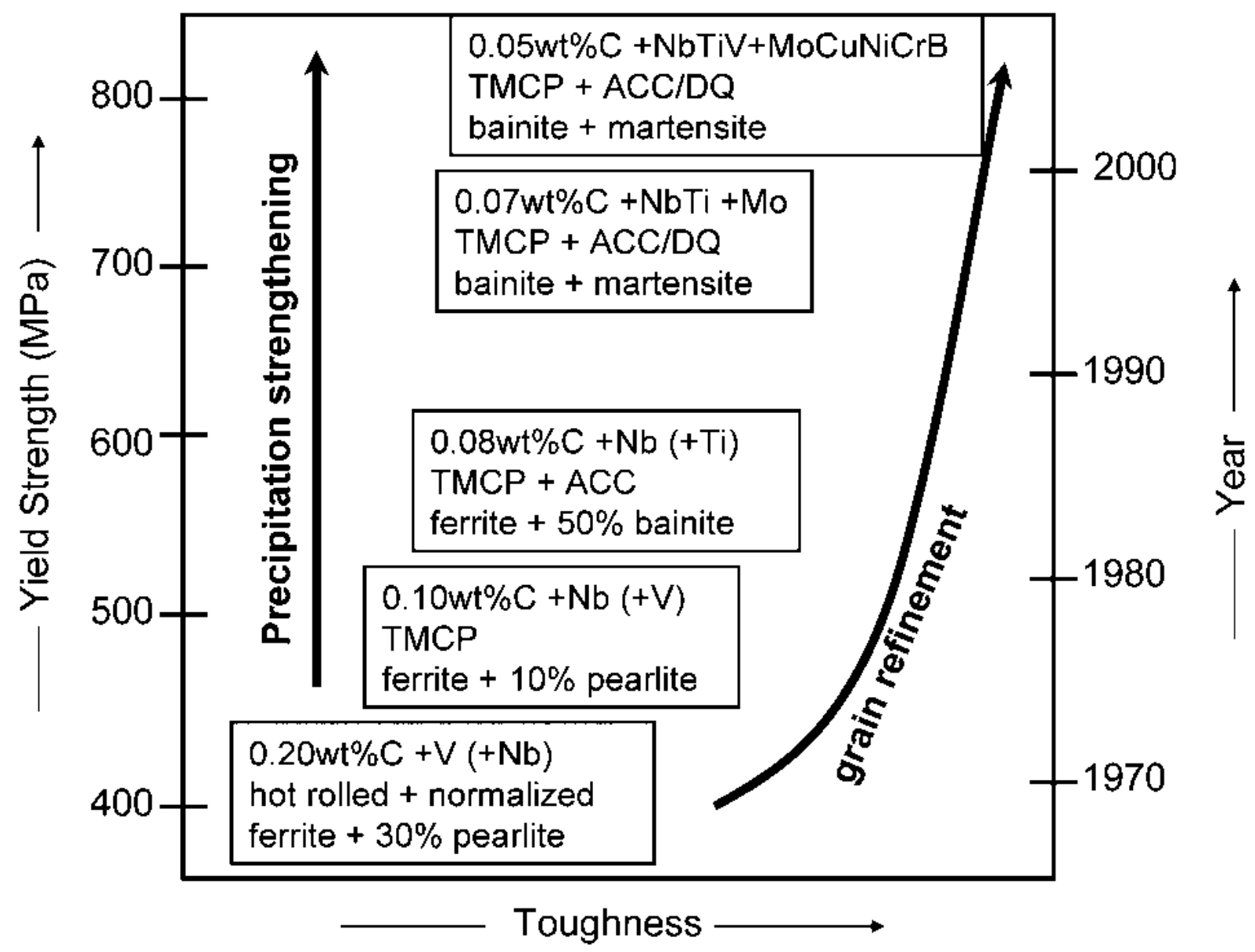




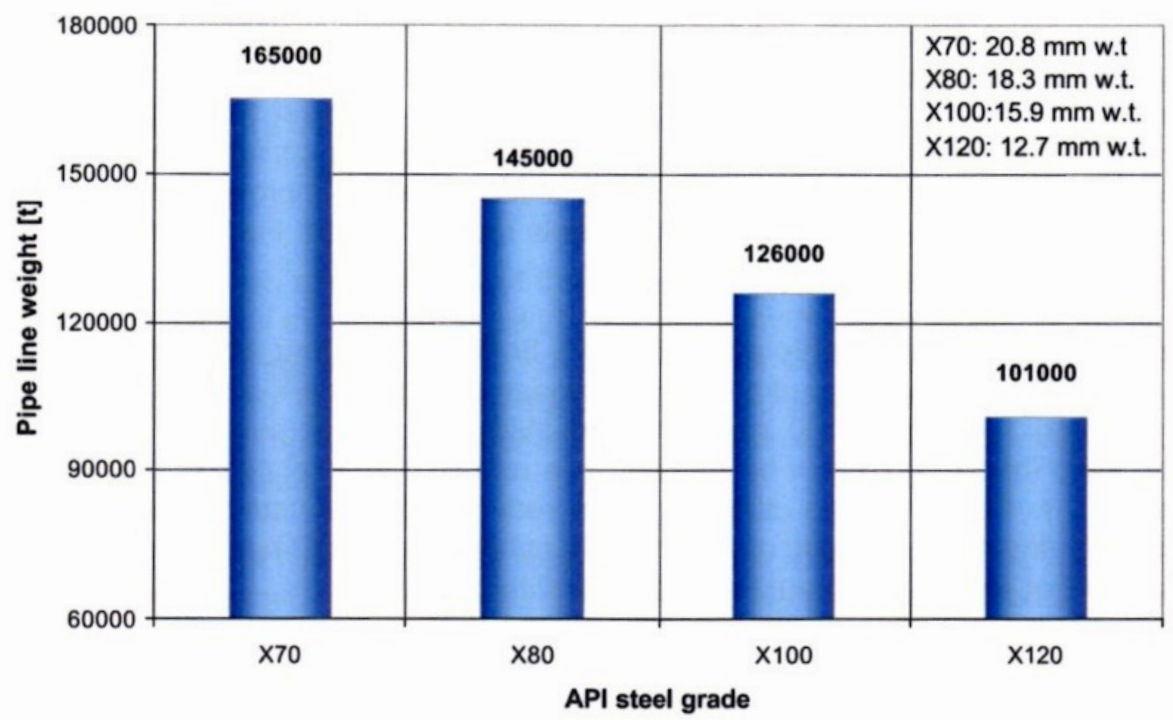

43 


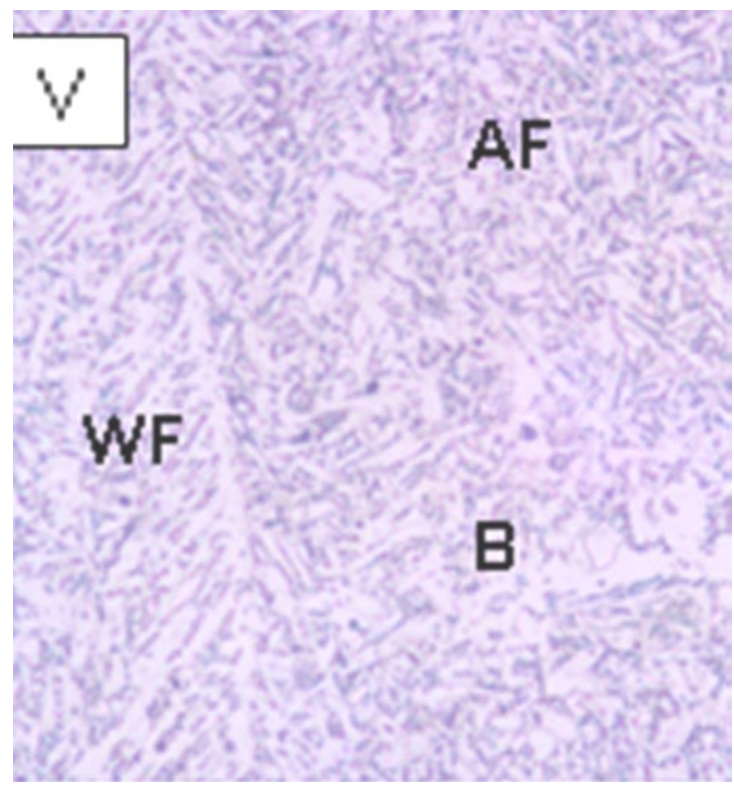

44 


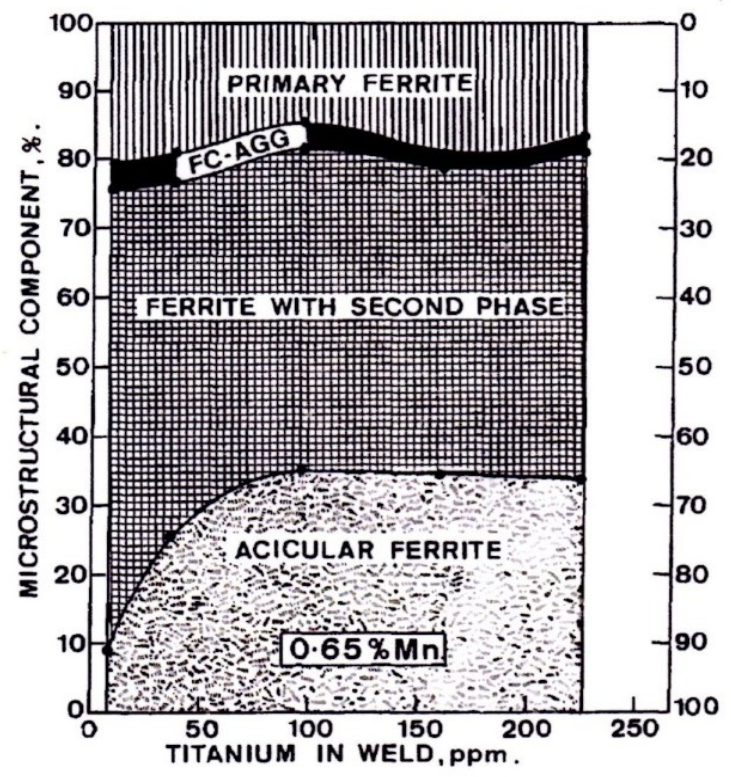

(a)

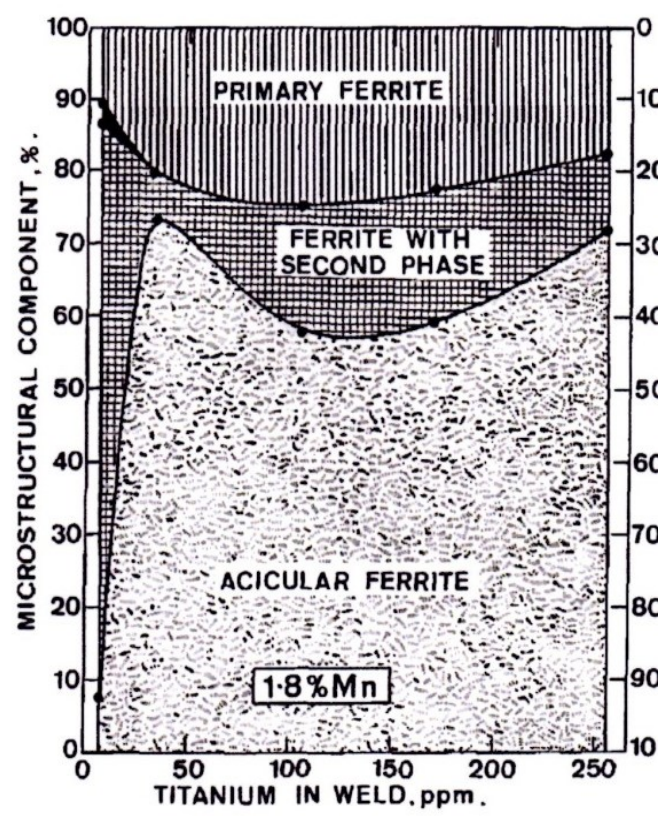

(b)

45 


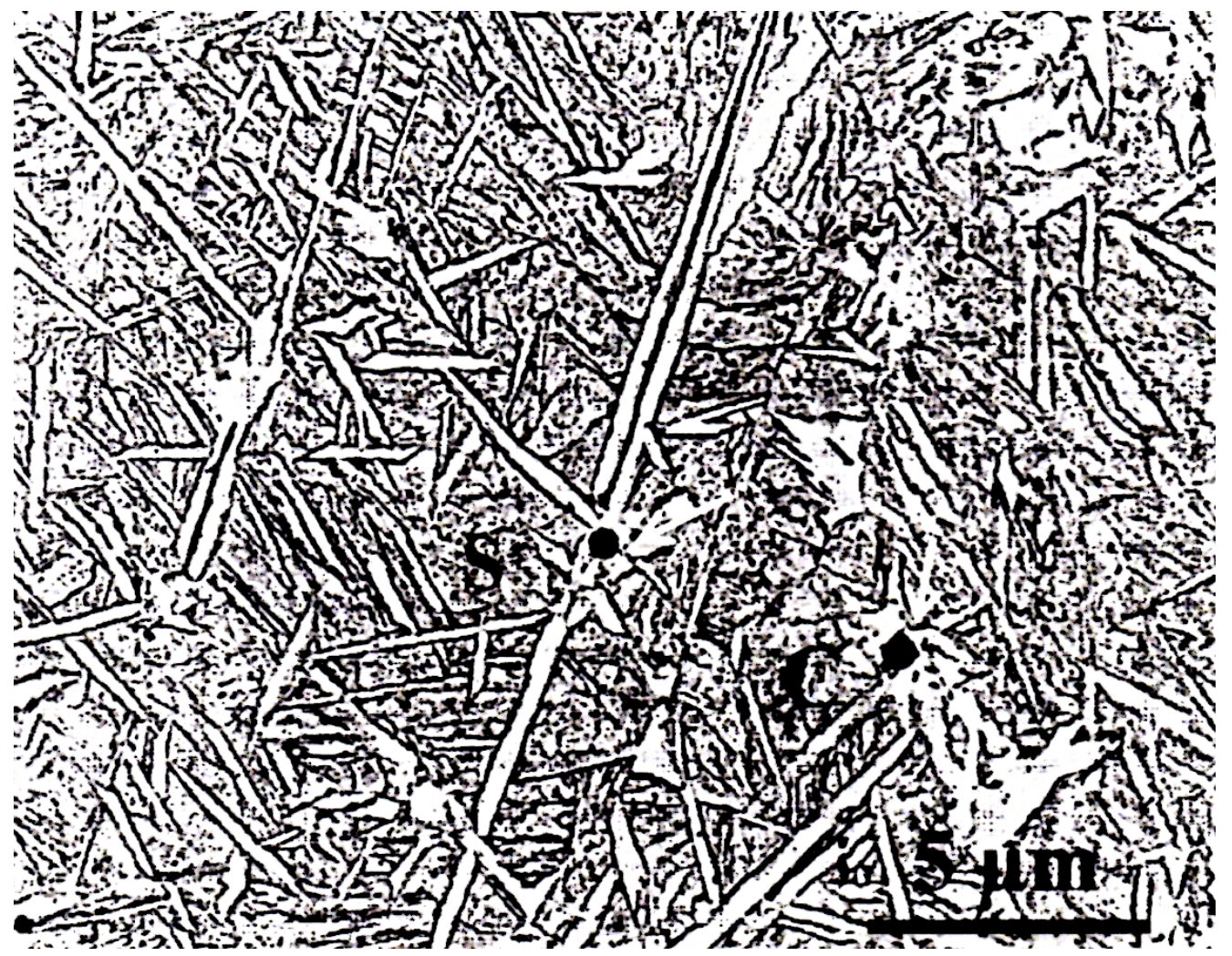




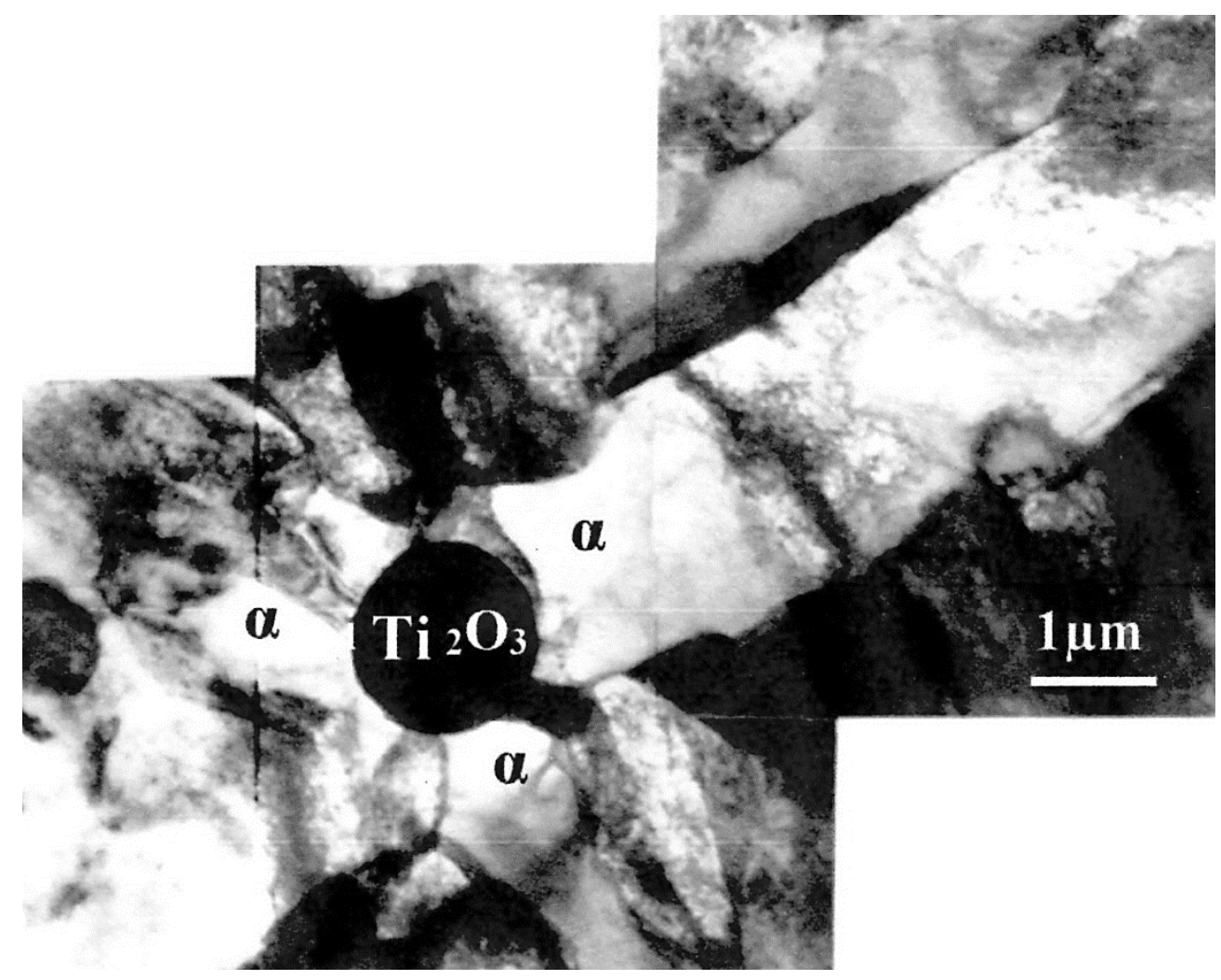

47 


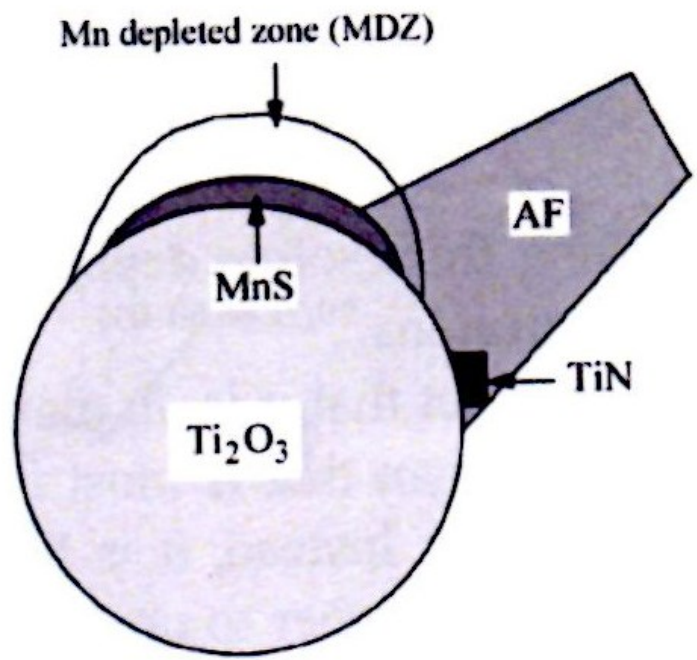

48 


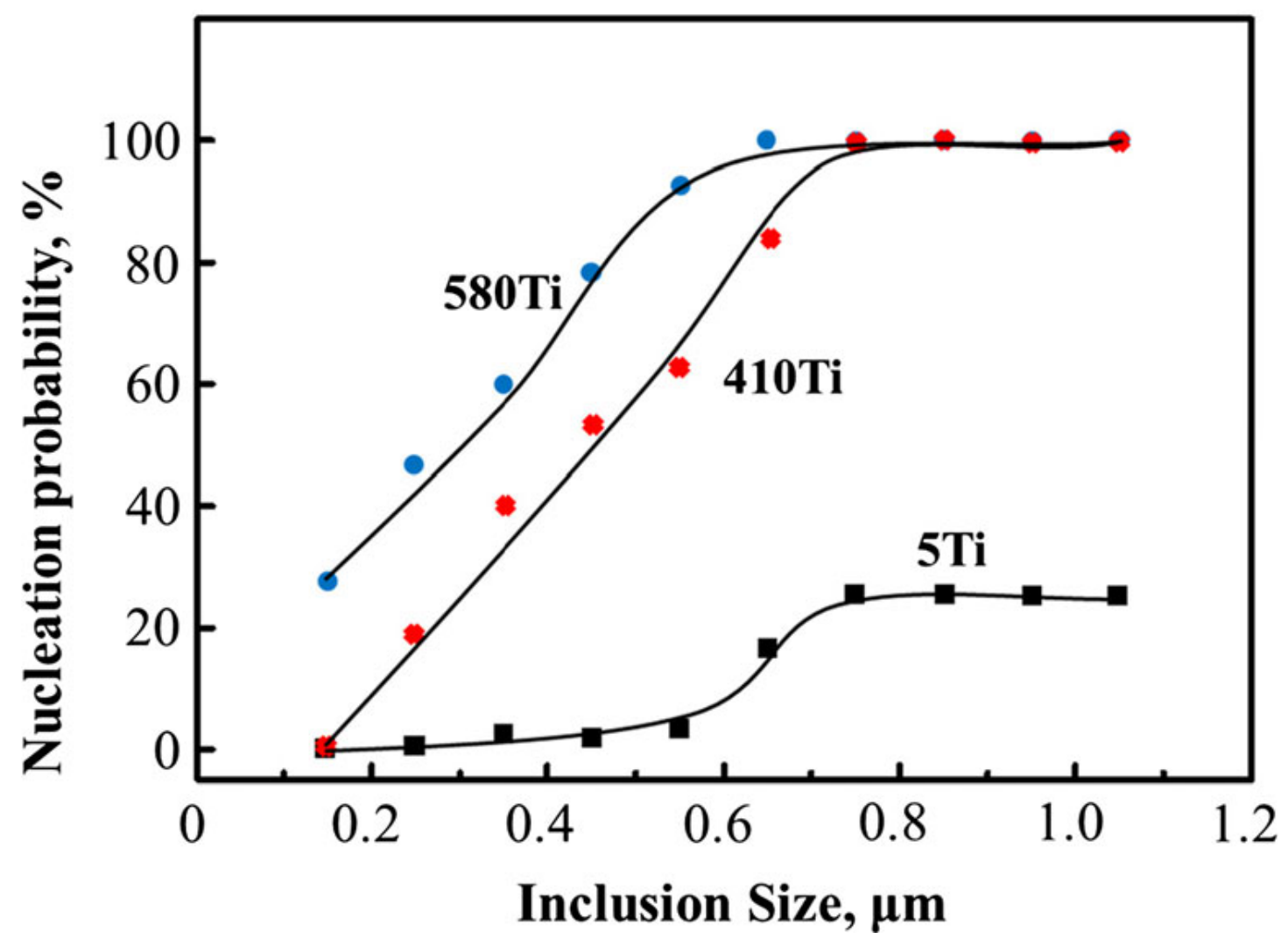

49 


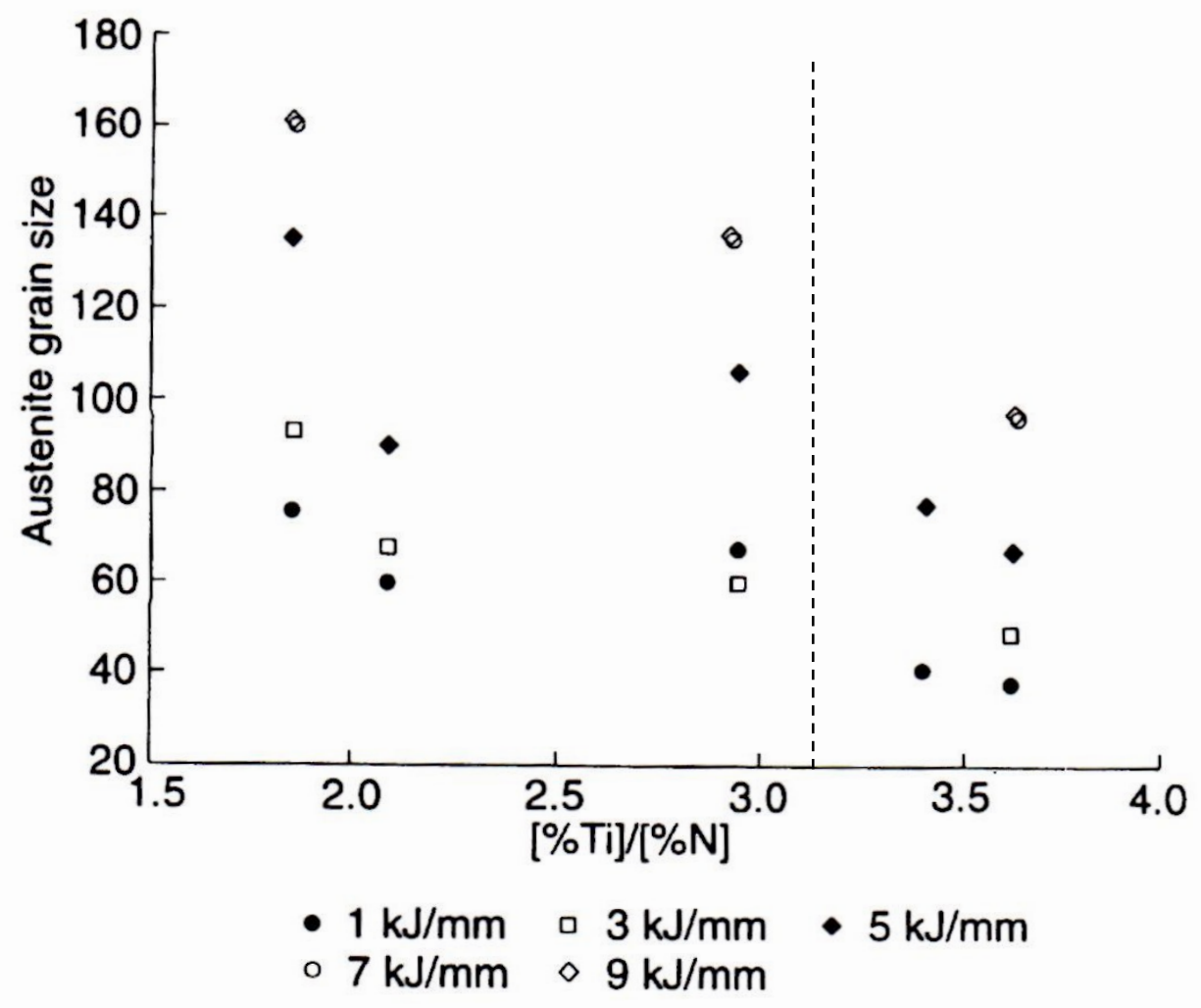

50 


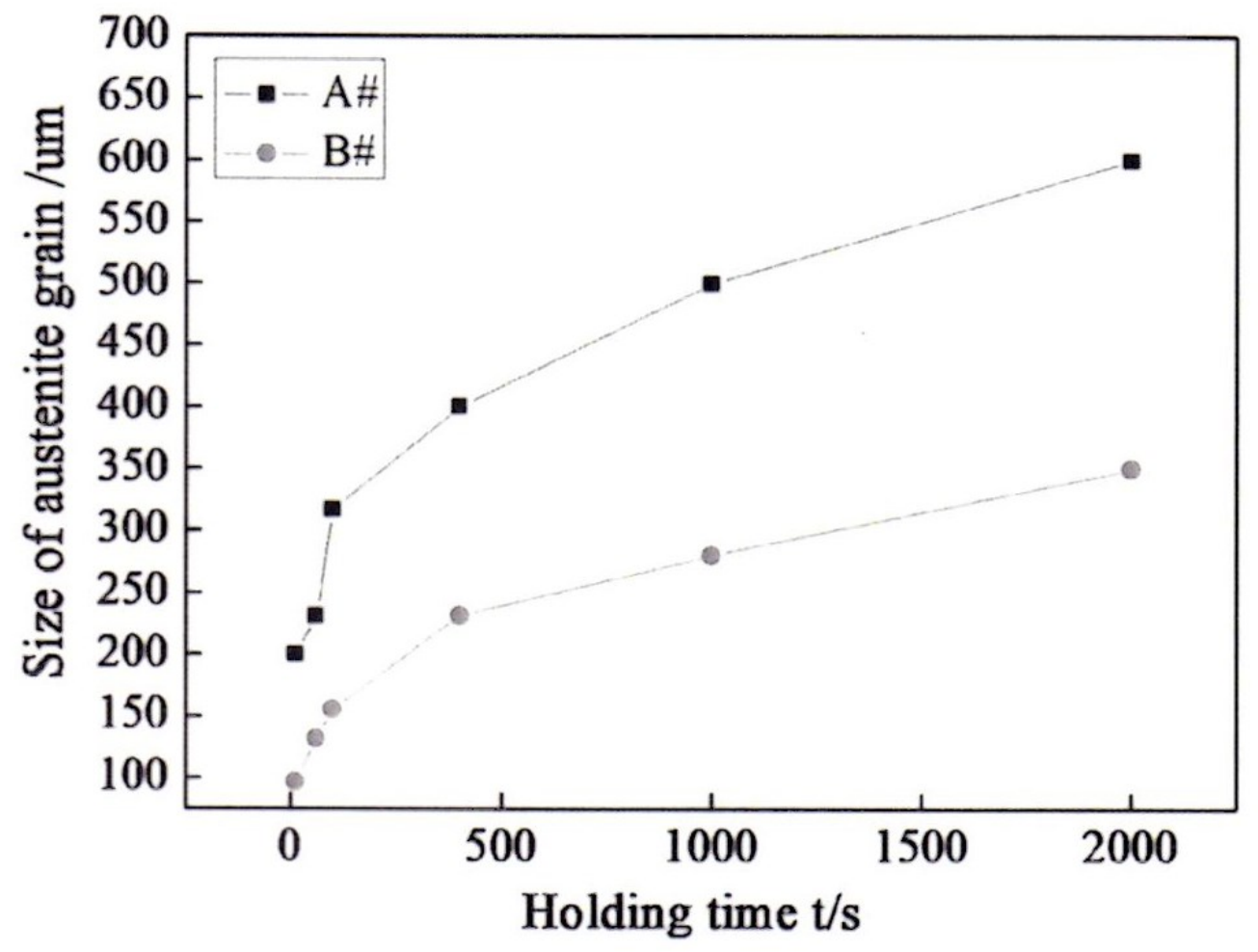

51 


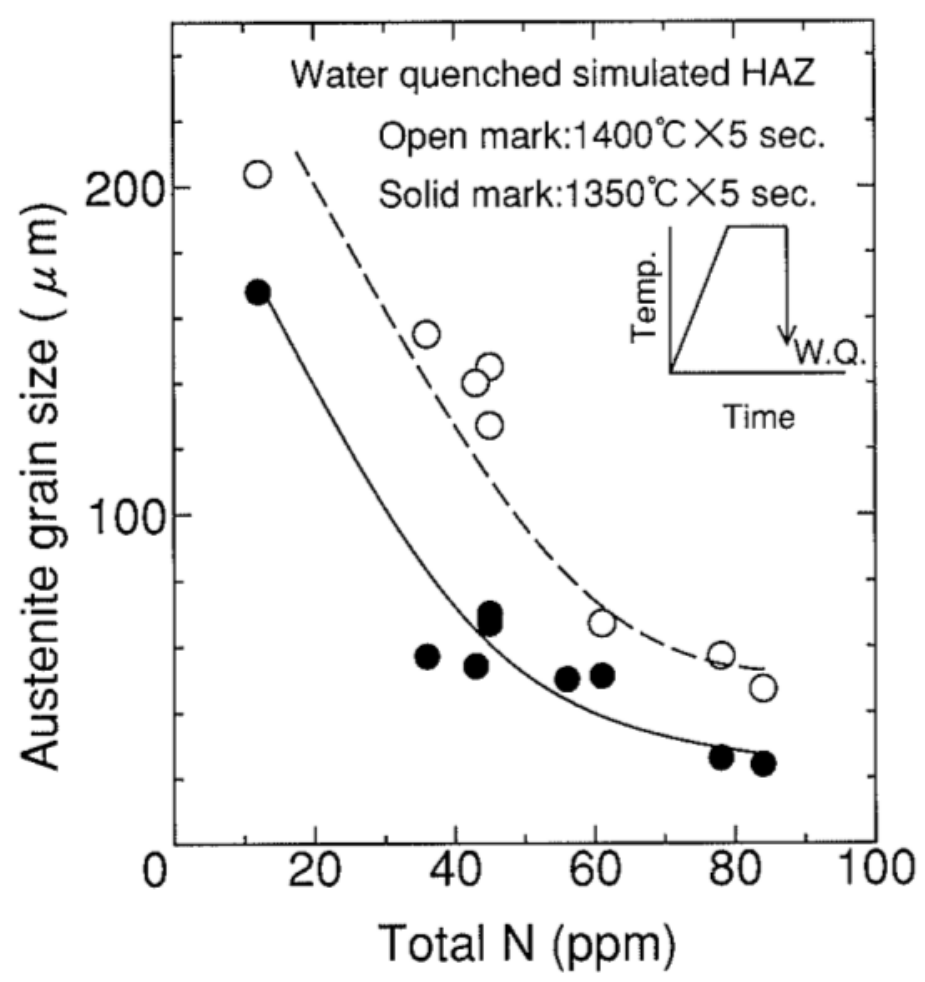

52 


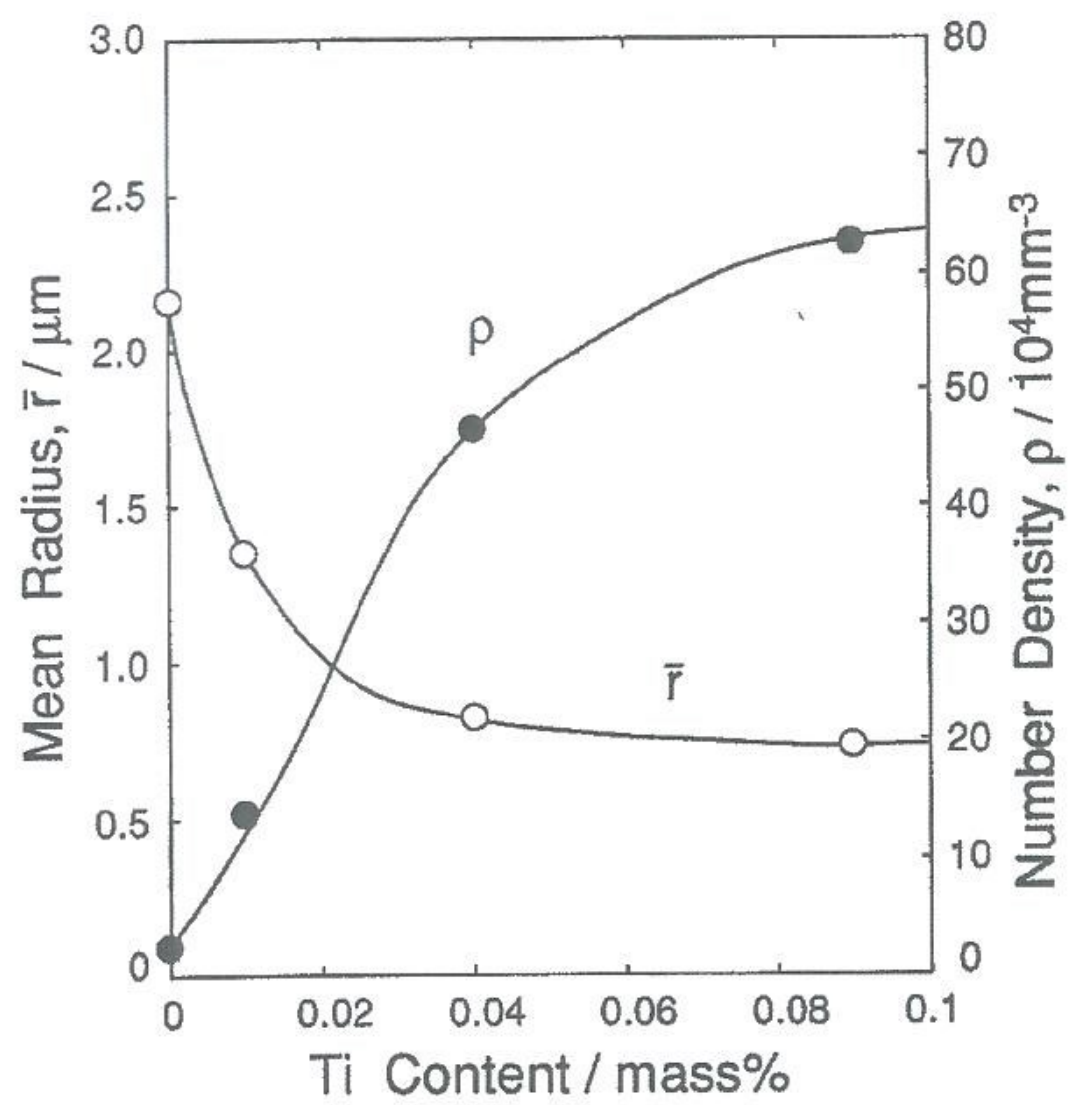

53 


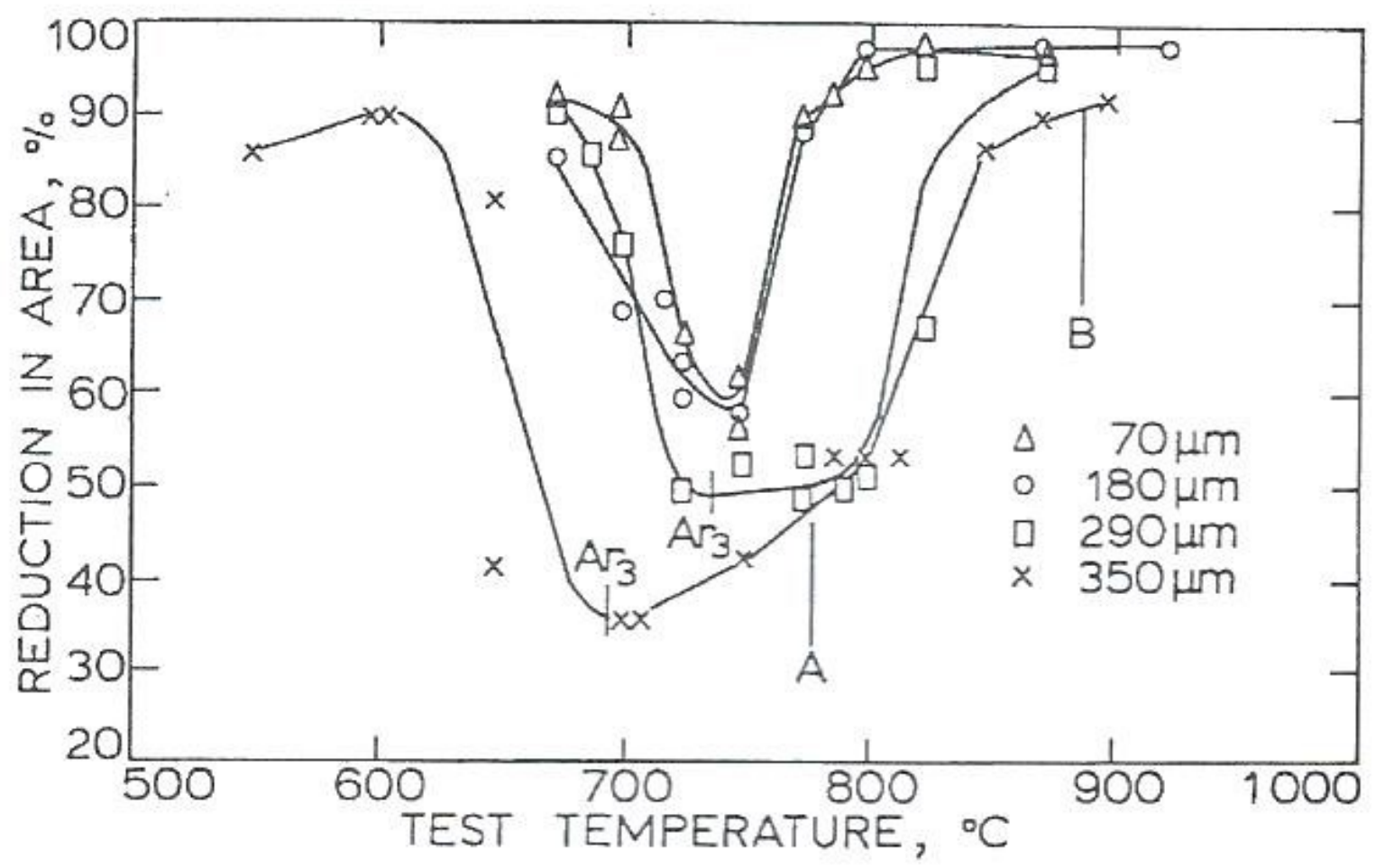

54 


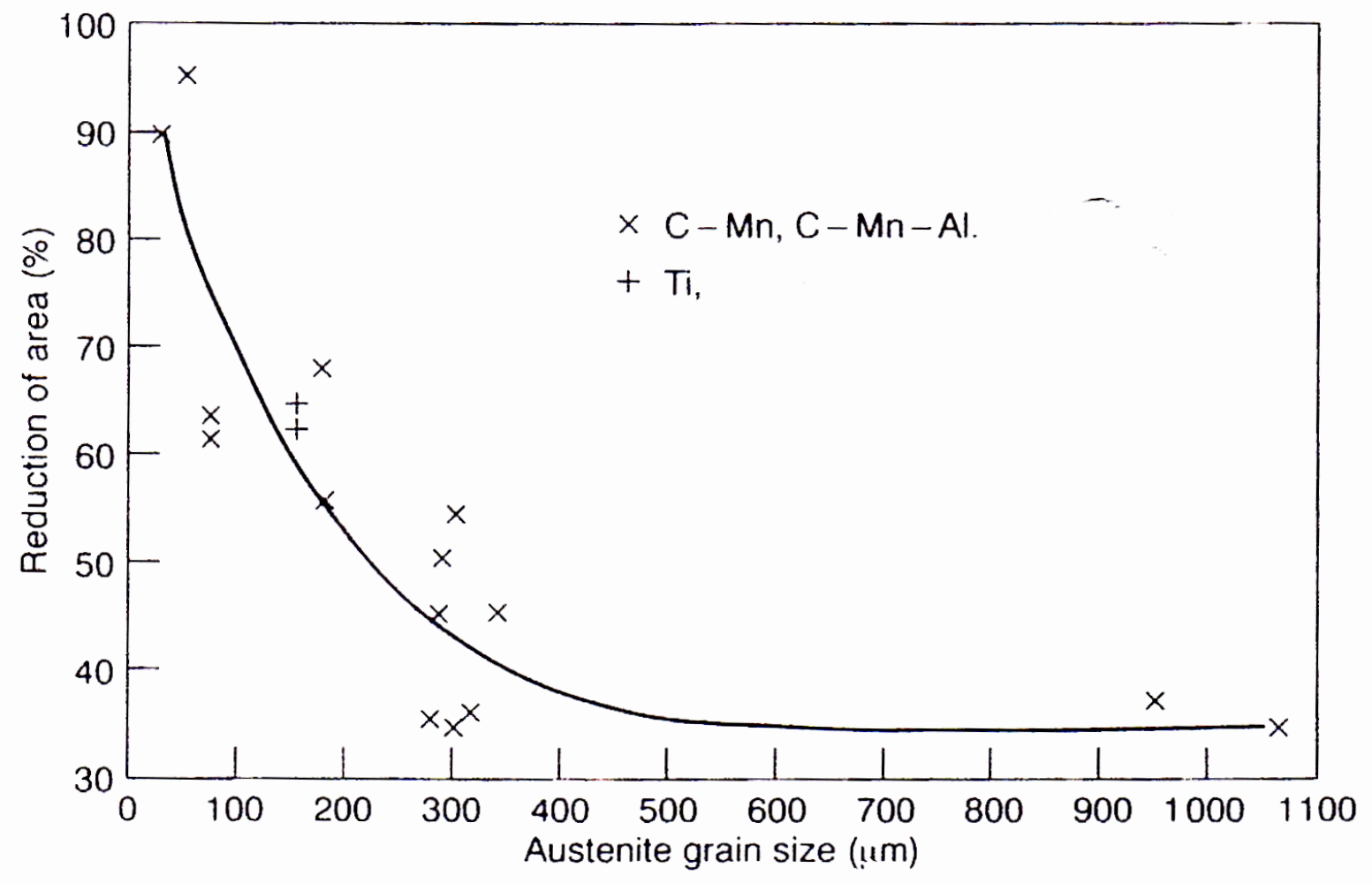

55 


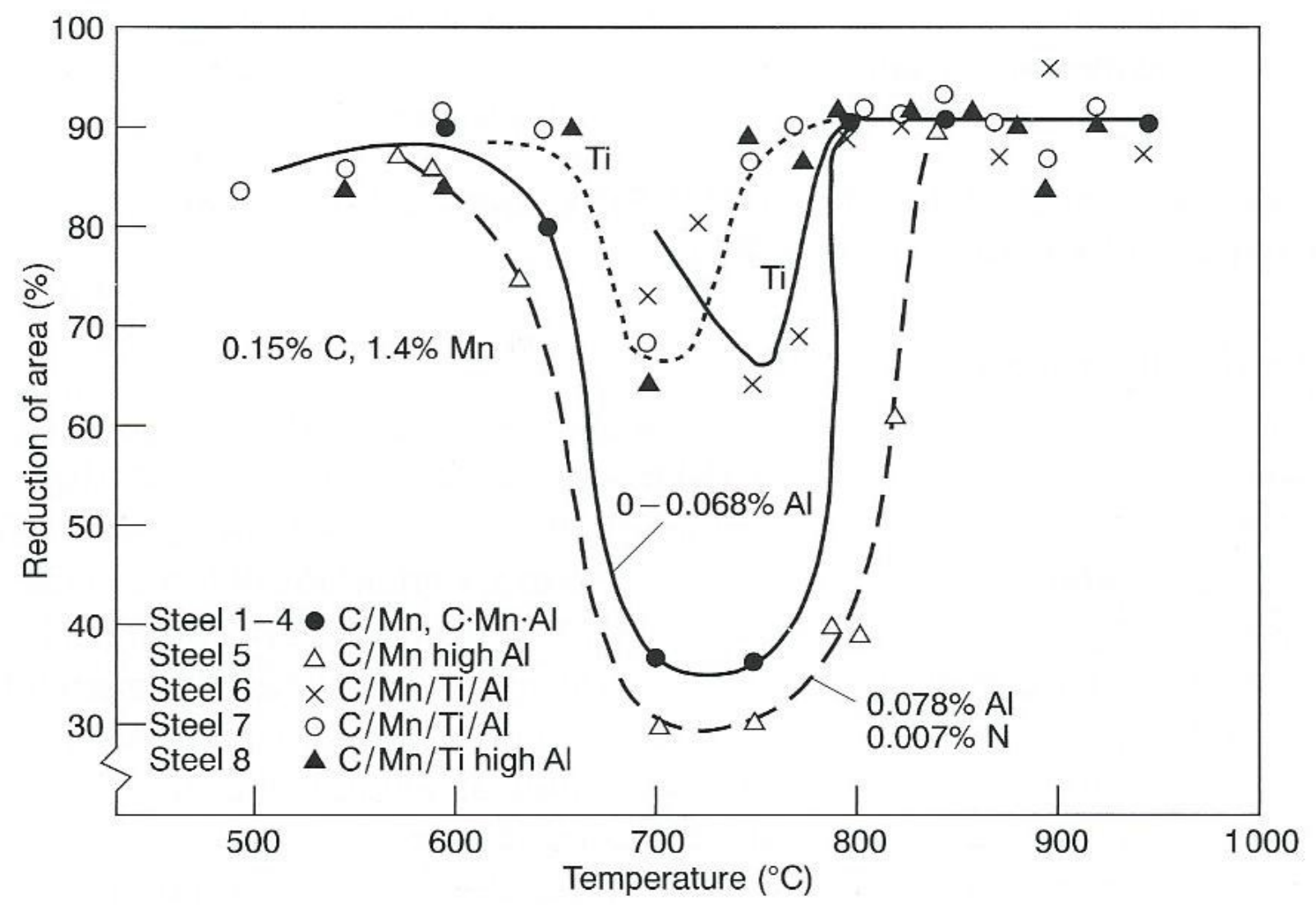

56 


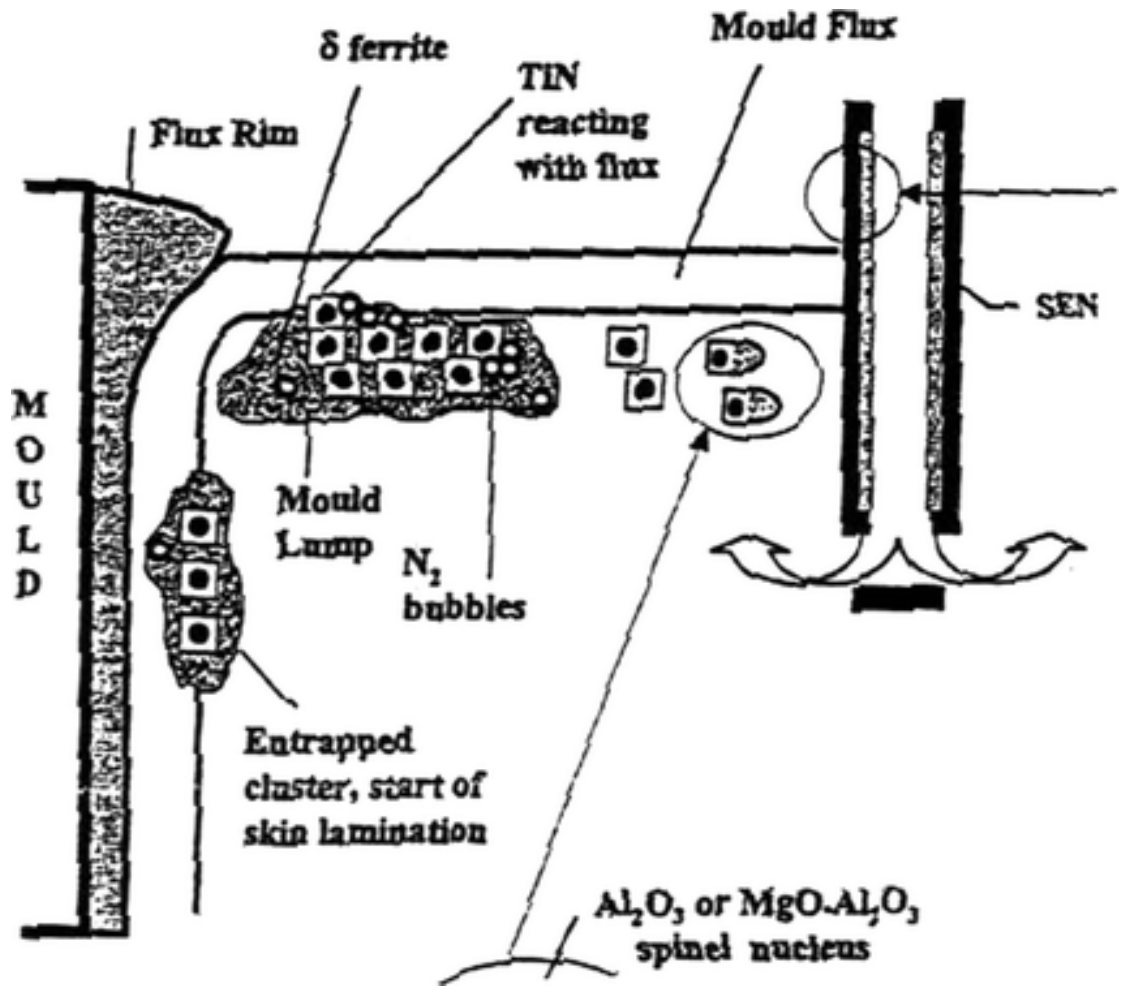


(a)

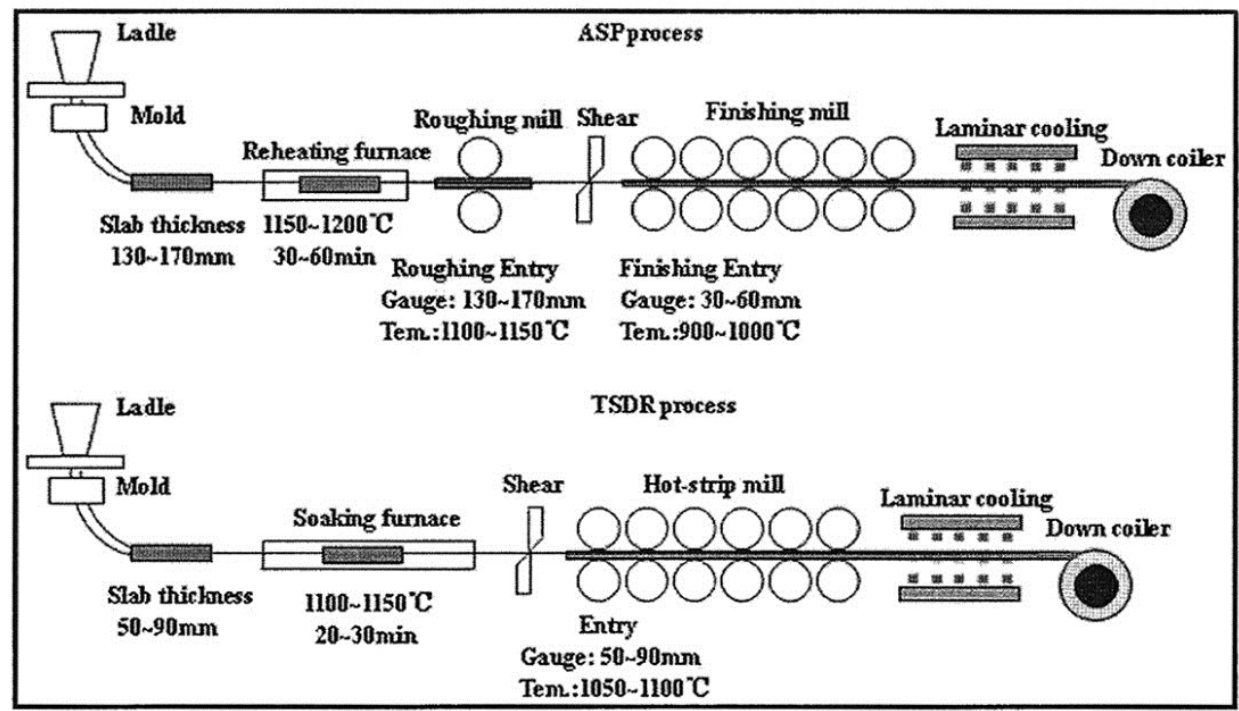

1 Schematic diagram of ASP [medium thin slab and direct rolling (TSDR)] and TSDR process

(b)

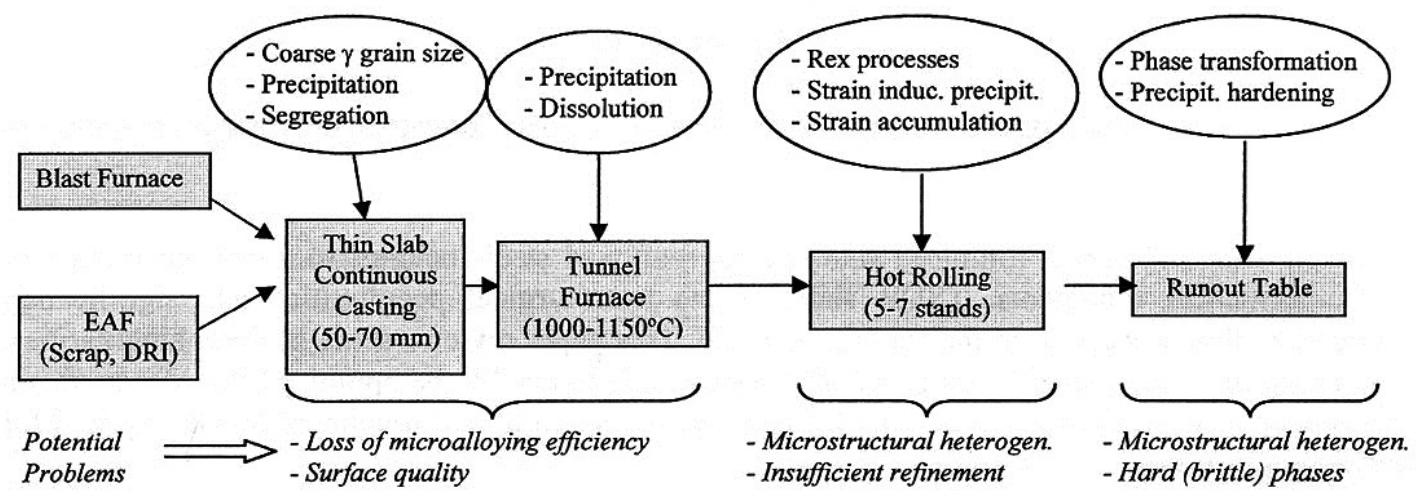




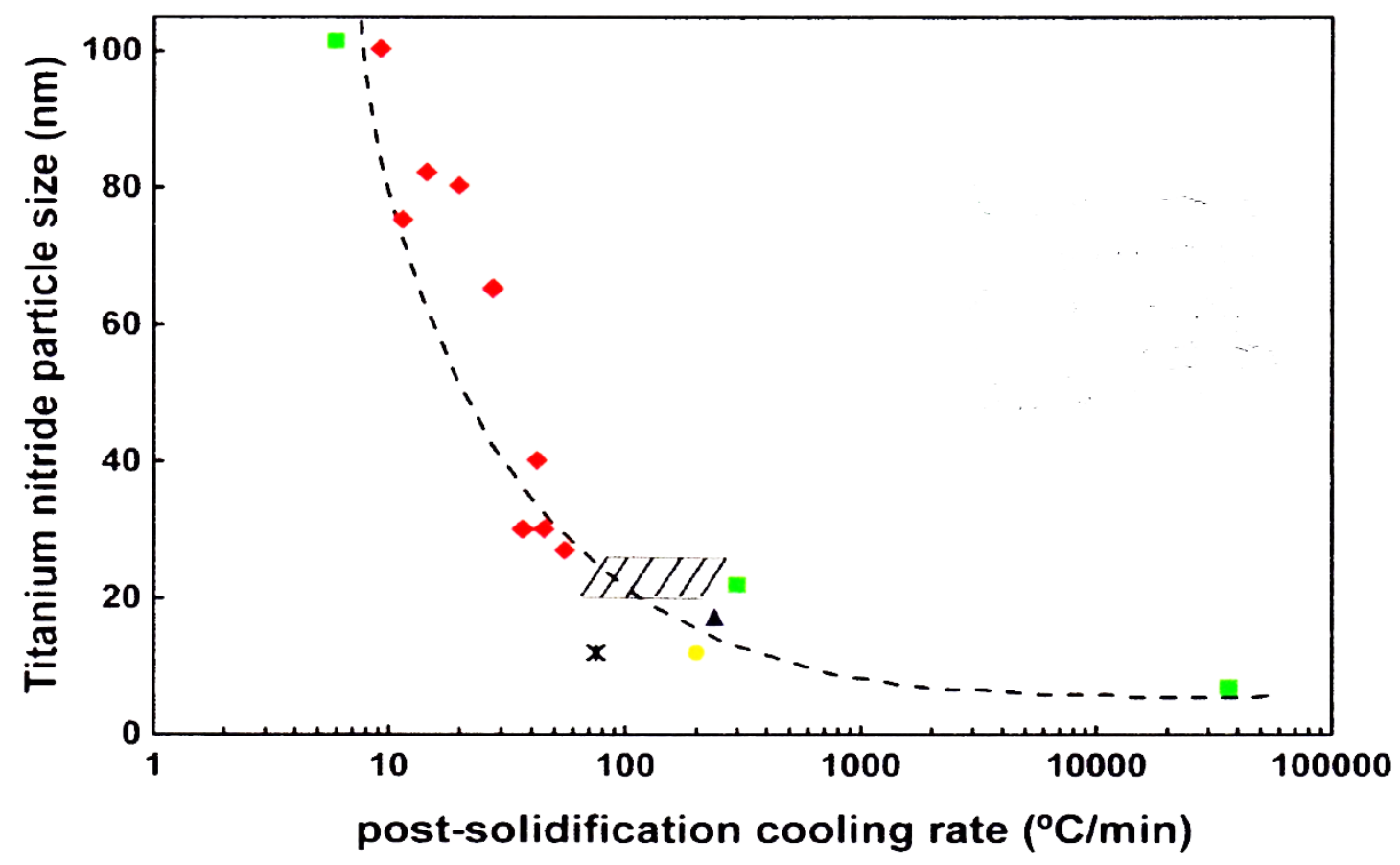

59 


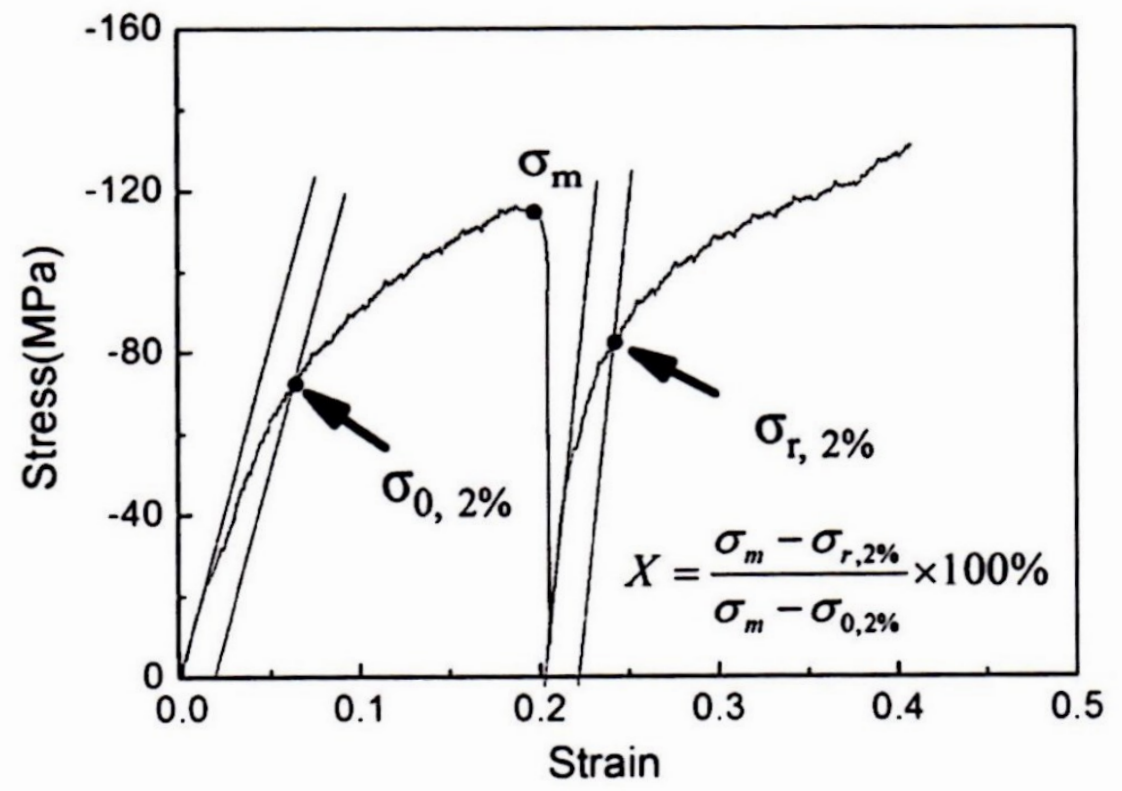

60 


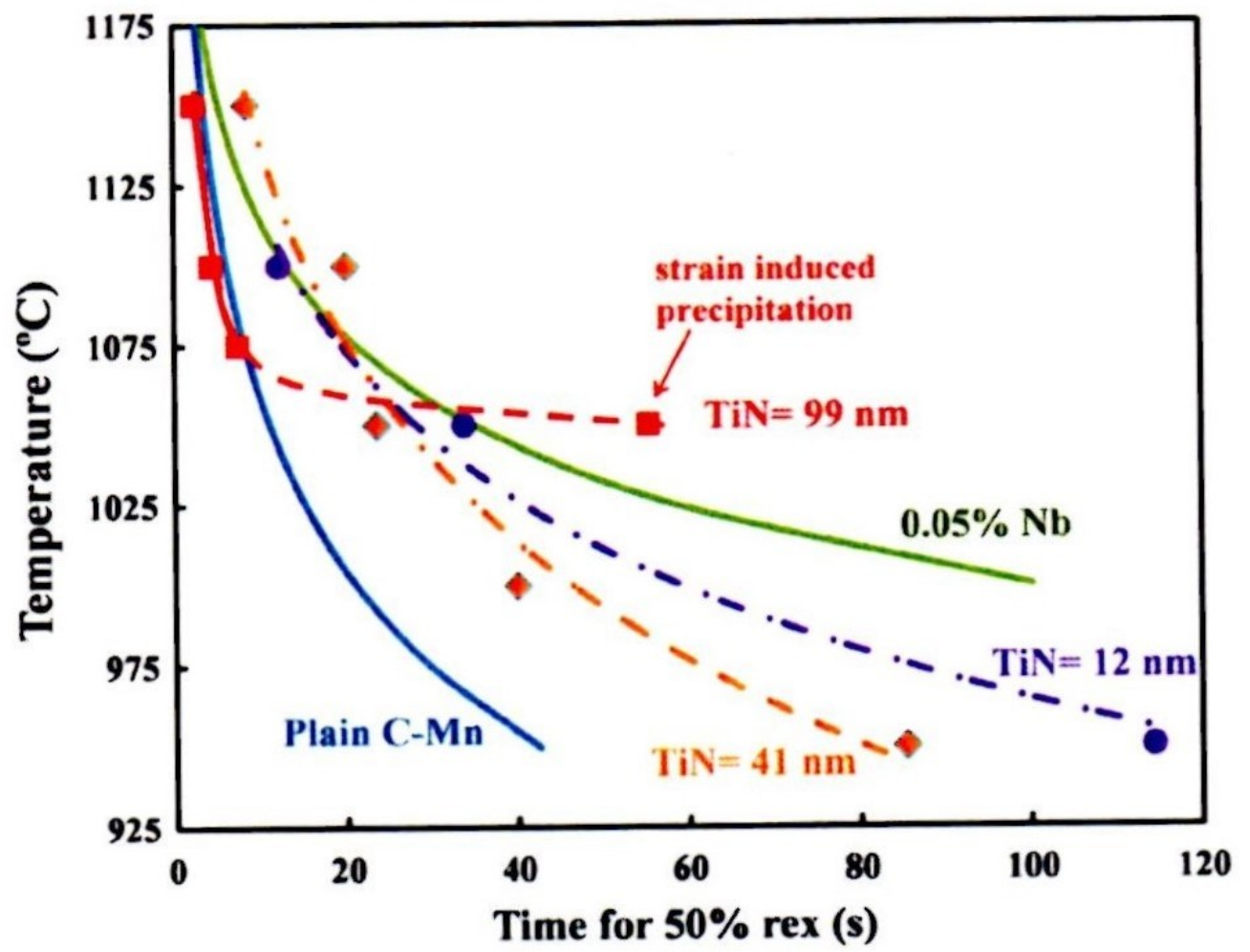

61 


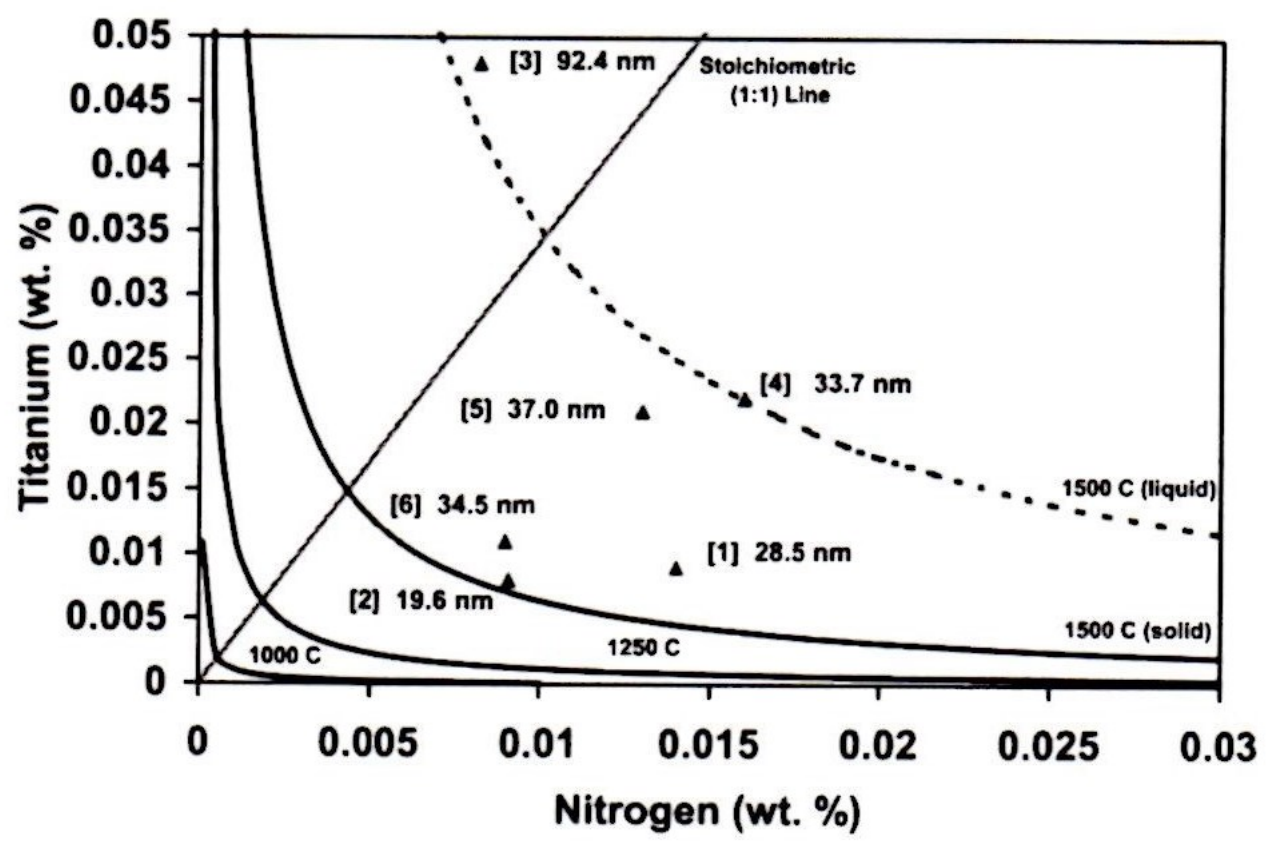

62 


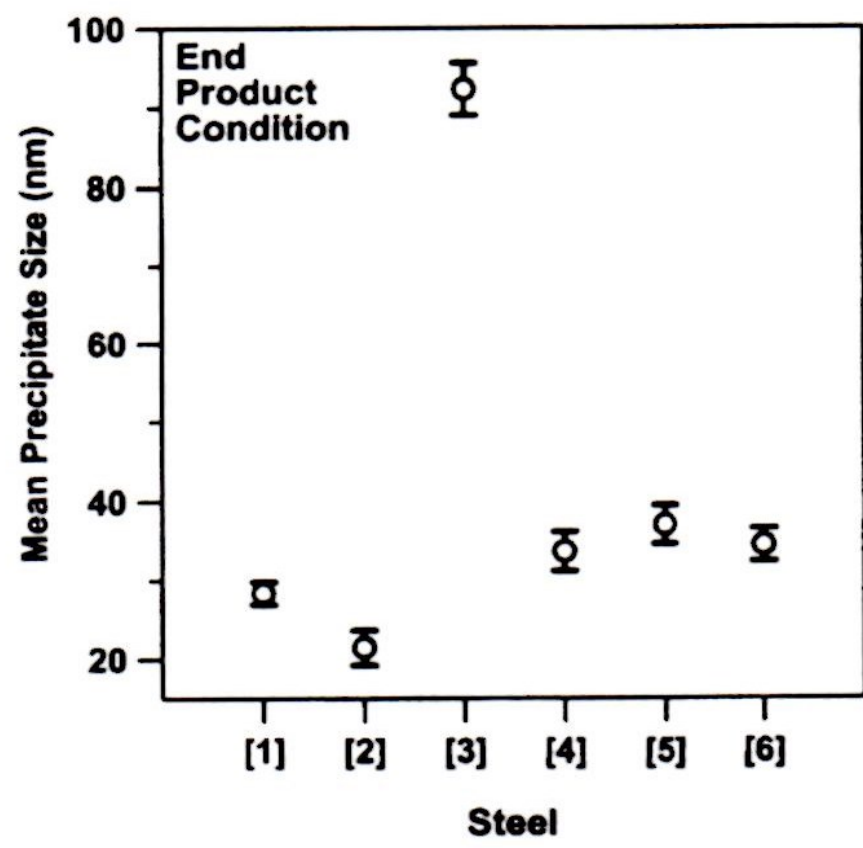

[1] $0.009 \mathrm{TI}, 0.014 \mathrm{~N}$

(2) $0.0087 \mathrm{~T}$

[3] $0.048 \mathrm{TI}, 0.008 \mathrm{~N} \quad 6.00$

[4] $0.022 \mathrm{Ti}, 0.016 \mathrm{~N}$

1.38

[5] $0.021 \mathrm{TI}, 0.013 \mathrm{~N}$

1.62

[6] $0.011 \mathrm{TI}, 0.009 \mathrm{~N}$

1.22

63 
